EVALUATION OF DESIGN TOOLS FOR THE MICRO-RAM AIR TURBINE

\author{
A Thesis \\ presented to \\ the Faculty of California Polytechnic State University, \\ San Luis Obispo \\ In Partial Fulfillment \\ of the Requirements for the Degree \\ Master of Science in Mechanical Engineering
}

by

Victor Fidel Villa

April 2015 
(C) 2015

Victor Fidel Villa

ALL RIGHTS RESERVED 


\section{COMMITTEE MEMBERSHIP}

TITLE:

AUTHOR:

DATE SUBMITTED:

COMMITTEE CHAIR:

COMMITTEE MEMBER:

COMMITTEE MEMBER:
Evaluation of Design Tools for the Micro-Ram Air Turbine

Victor Fidel Villa

April 2015

Dr. Russell Westphal, Professor

Mechanical Engineering Department

Dr. William R. Murray, Professor

Mechanical Engineering Department

Dr. Rob McDonald, Associate Professor

Aerospace Engineering Department 


\title{
ABSTRACT \\ Evaluation of Design Tools for the Micro-Ram Air Turbine
}

\author{
Victor Fidel Villa
}

The development and evaluation of the design of a Micro-Ram Air Turbine ( $\mu$ RAT), a device being developed to provide power for an autonomous boundary layer measurement system, has been undertaken. The design tools consist of a rotor model and a generator model. The primary focus was on developing and evaluating the generator model for the prediction of generator brake power and output electrical power with and without rectification as a function of shaft speed and electrical load, with only basic manufacturer specifications given as inputs. A series of motored generator evaluation test were conducted at speeds ranging from 9,000 to $25,000 \mathrm{rpm}$ for loads varying between 1 and $3.02 \mathrm{Ohms}$ with output power of up to $80 \mathrm{Watts}$. Results demonstrated that predicted generated power was at or below 3\% error when compared to measured results with about $1 \%$ uncertainty. A rotor model was also developed using basic blade element theory. This model neglected induced flow effects and was therefore expected to over predict rotor torque and power. A second rotor model that includes induced flow effects, the open source program X-Rotor, was also used to predict rotor power and for comparison to the blade element rotor model results. Both rotor models were evaluated through wind tunnel validation tests conducted on a turbine generator with two different 3.25 in diameter rotors, rotor- 1 (untwisted blades) and rotor-2 (twisted blades). Wind tunnel validation test airspeeds varied between 71-110 mph with electrical loads ranging from 1-20 ohms. Results indicated power predictions to be 50-75\% higher for the blade element model and 20-30\% for X-Rotor results. The blade element rotor model was modified by applying the Prandtl tip-loss factor to approximately account for the induced flow effects; this addition brought predictions much closer to X-Rotor results. Based on the motor-driven generator test results, it is believed that most of the discrepancy in baseline rotor/generator validation test between predicted and observed power generated is due to inaccuracy in the rotor performance modeling with likely contributors to error being induced flow effects, crude section lift/drag modeling, and aero-elastic deformation. It is concluded that the proposed generator model is sufficient although direct torque measurements may be desired and further development of the $\mu$ RAT design tools should focus on an improved rotor performance model.

Keywords: Micro-RAT, Blade Element Model, Generator Model 


\section{ACKNOWLEDGMENTS}

A special thanks to the Northrop Grumman Corporation for their support of the BLDS.

I would like to extend a sincere thank you to Dr. Russell Westphal for his unfaltering energy and enthusiasm that inspires excellence and the desire to pursue and overcome new challenges. Your exemplary leadership, motivation, and work ethic are things that I will carry with me in everything I do.

A big thanks to the BLDS team! You all have amazing talents! It has been a pleasure working with you all and hope to work with you all in the future.

Thanks to my family for their continued love and support. Specifically my parents, Fidel and Rosa Villa; everything I have achieved and will achieve is a result of your loving support, sacrifice and hard work.

I would like to add a special thanks to my high school instructor and mentor, Mr. John Vogt who steered me towards pursuing engineering. In my pursuit for a career in aviation, he convinced me to look into engineering when he told me, "If you want to learn how to fly a plane you first have to learn why they fall out of the sky". Thank you! 


\section{TABLE OF CONTENTS}

LIST OF TABLES viii

LIST OF FIGURES $\quad$ X

NOMENCLATURE $\quad$ XV

1. Introduction 1

2. Generator Model 20

2.1 Generator Performance Parameters ....................................................................21

2.1.1 Internal Resistance and Impedance .................................................... 21

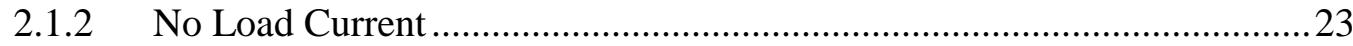

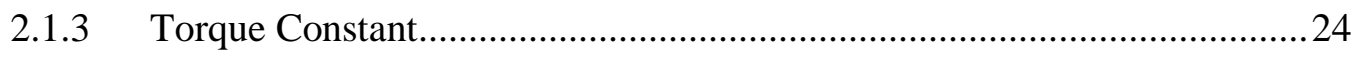

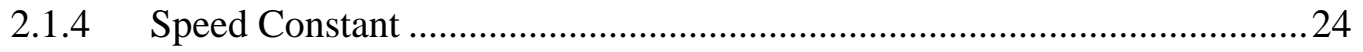

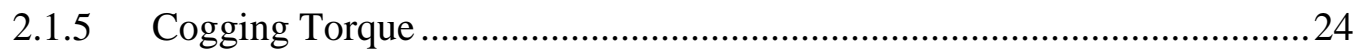

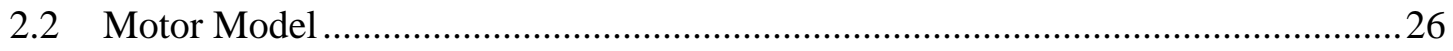

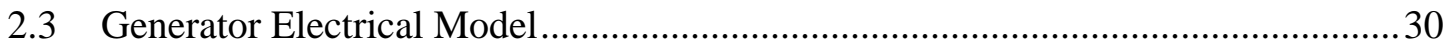

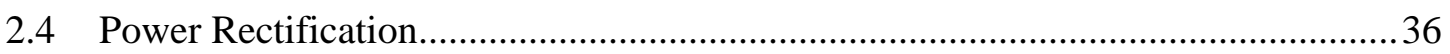

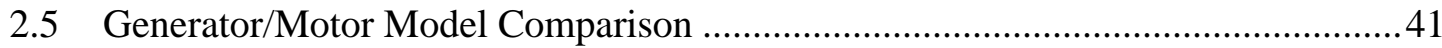

2.6 Generator Model Evaluation (Validation) Testing ..............................................43

3. Rotor Model $\quad 57$

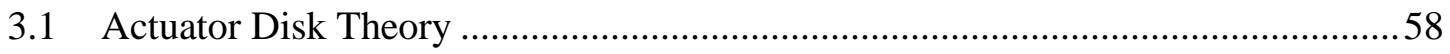

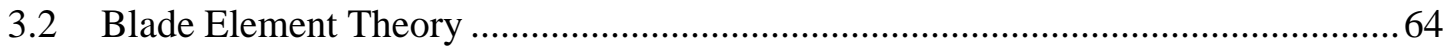

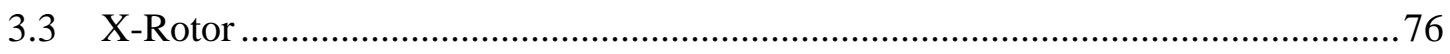

4. Rotor/Generator Matching $\quad 83$

5. Baseline Rotor/Generator Validation Test 96

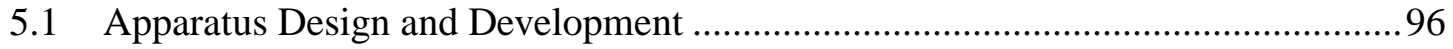

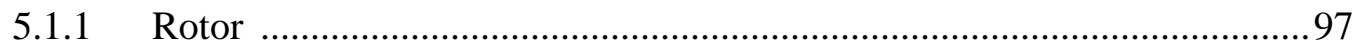

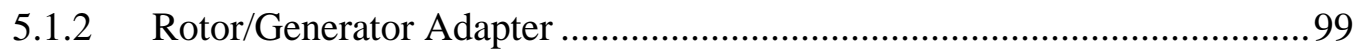

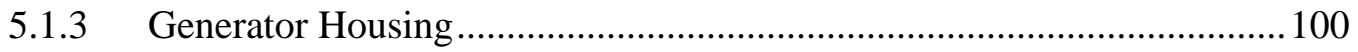




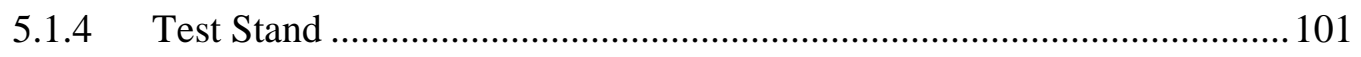

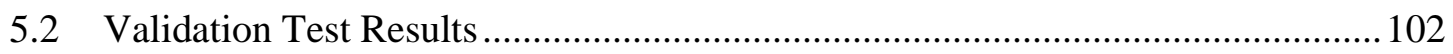

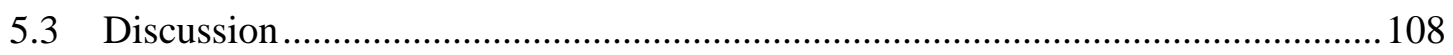

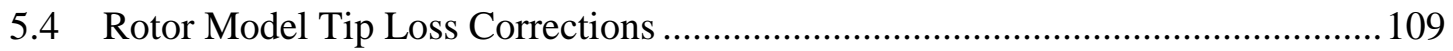

6. Conclusion and Recommendations 116

$\begin{array}{ll}\text { References } & 121\end{array}$

Appendices

$\begin{array}{lll}\text { Appendix A. } & \text { Rotor Model Matlab } & 125\end{array}$

$\begin{array}{lll}\text { Appendix B. Generator Model Matlab } & 130\end{array}$

B.1 Generator Model Efficiency Contour Charts..................................................... 132

$\begin{array}{lll}\text { Appendix C. Motor Model Matlab } & 135\end{array}$

C. 1 Motor Model Efficiency Contour Charts Matlab .................................................. 136

Appendix D. Generator Model Evalutaion Test Results 138

Appendix E. $\quad$ Blade Element Rotor Model Peak Power Sectional Results 146 


\section{LIST OF TABLES}

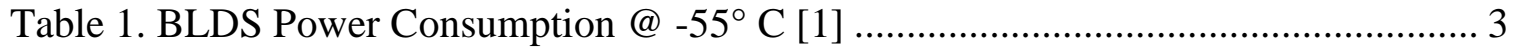

Table 2. Selection of Generator Type Decision Matrix [7] .......................................... 7

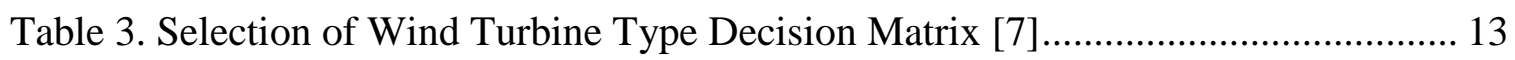

Table 4. Motor/Generator Equation Comparison ..................................................... 42

Table 5. Generator Kv Verification Results ............................................................... 45

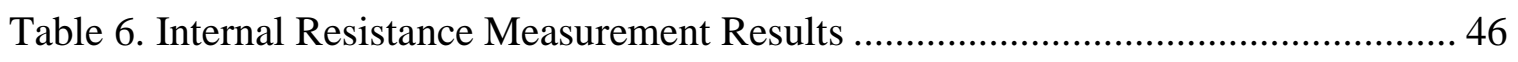

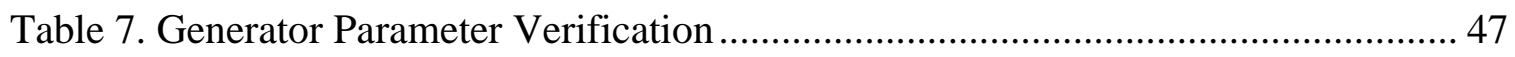

Table 8. Generator Model Test Results at 3.02 Ohms ............................................... 49

Table 9. Motor Parameter Verification [Ammo BLDC (part\# 35-56-1800kv)] ............... 51

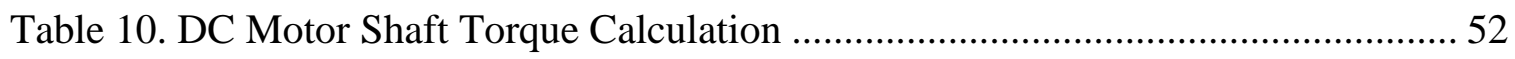

Table 11. Generator Shaft Torque Calculation ............................................................ 53

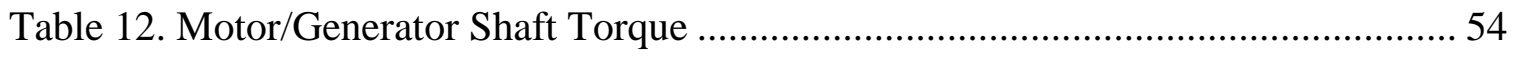

Table 13. Motor to Generator Terminal Power Calculation .......................................... 55

Table 14. Motor to Generator Model Calculated Terminal Power Compared

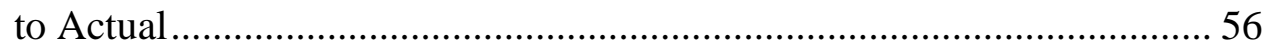

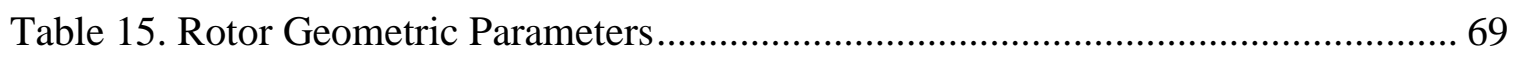

Table 16. Rotor-Generator Performance at Maximum Rotor Power Operating Point for Rotor 1 ................................................................... 88

Table 17. Rotor-Generator Performance at Max Rotor Power Operating Point

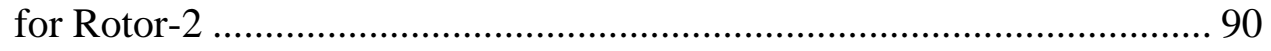

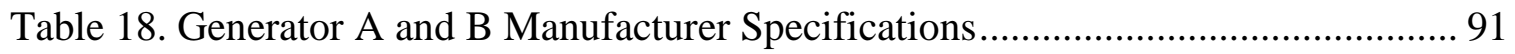

Table 19. Generator-B Efficiency at Maximum Rotor-1 Power Operating

$$
\text { Point. }
$$

Table 20. Differential Pressures and Pressure Coefficients across the Wind Tunnel Nozzle. 103

Table 21. Airspeed Calculation for Rotor-1 and Rotor-2 Test ................................... 104

Table 22. Generator Evaluation Test Results (RL=1.04) (Maxon \#386677) ................. 138

Table 23. Generator Evaluation Test Results (RL=1.39) (Maxon \#386677) ................ 139 
Table 24. Generator Evaluation Test Results (RL=1.53) (Maxon \#386677) ................ 140

Table 25. Generator Evaluation Test Results (RL=1.74) (Maxon \#386677) ................ 141

Table 26. Generator Evaluation Test Results (RL=2.07) (Maxon \#386677) ................ 142

Table 27. Generator Evaluation Test Results ( $\mathrm{RL}=2.33$ ) (Maxon \#386677) ................ 143

Table 28. Generator Evaluation Test Results ( $\mathrm{RL}=2.89)$ (Maxon \#386677) ................. 144

Table 29. Generator Evaluation Test Results (RL=3.02) (Maxon \#386677) ................ 145

Table 30. Rotor-1 Blade Element Rotor Model Sectional Results at Peak

Power@ Sea Level, 110 mph and 21,000 RPM ................................. 146

Table 31. Rotor-2 Blade Element Rotor Model Sectional Results at Peak

Power @ Sea Level, 110 mph and 21,000 RPM ............................... 147 


\section{LIST OF FIGURES}

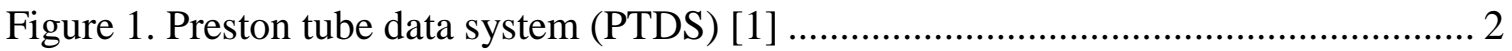

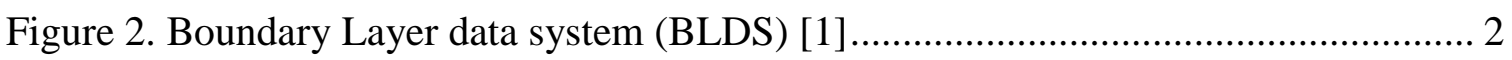

Figure 3. Basic Electric Machines [3] ................................................................... 4

Figure 4. Brushed Motor/Generator Commutator and Brushes [5] [6] ........................... 5

Figure 5. Team AeroRAT Generator Test Schematic [7] ............................................ 8

Figure 6. Team AeroRAT Generator Test Setup [7] ..................................................... 8

Figure 7. Team AeroRAT Proof-of-Concept Test Results [7] ....................................... 9

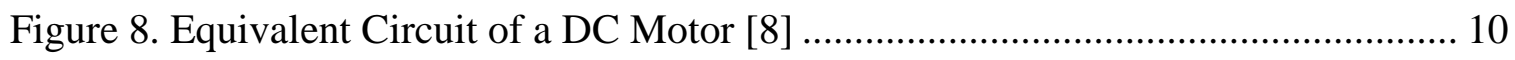

Figure 9. Motor and Propeller Parameters at Specific Flight Speed and Motor

Voltage [8] ........................................................................... 11

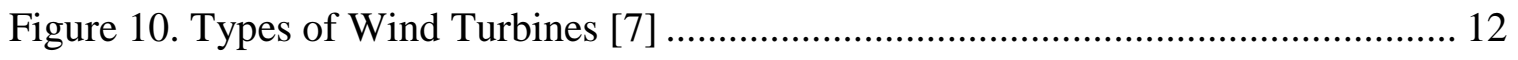

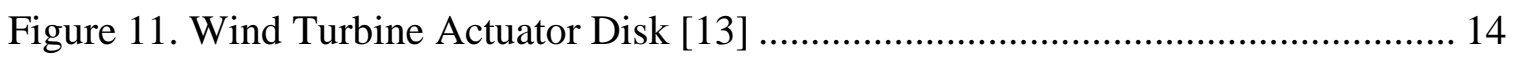

Figure 12. Betz Limit at Different Altitudes for Varying Airspeed .............................. 15

Figure 13. Team AeroRAT Proof-of-Concept Wind Tunnel Test Results [7] ................. 17

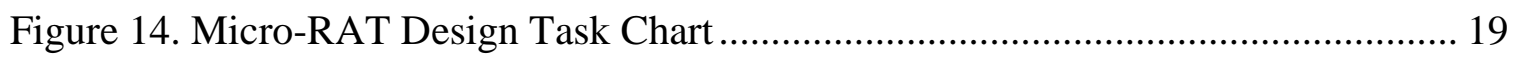

Figure 15. BLDC Motor/Generator Stator and Rotor [17] ......................................... 25

Figure 16. Cogging Torque at Different Rotor Positions [16] ...................................... 25

Figure 17. Prime Mover DC Motor Model Electrical schematic [8] ............................. 27

Figure 18. Maxon Motor Manufacturer Performance Parameters for BLDC Motor \#386677 [14] [18] ................................................................. 28

Figure 19. Motor Model Predicted Torque and Brake Power ..................................... 29

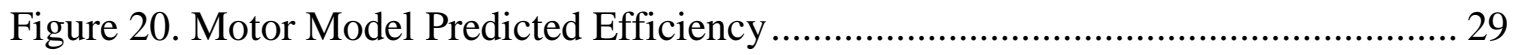

Figure 21. Motor Model Efficiency Contour Chart ....................................................... 30

Figure 22. Generator Model Electrical schematic [8] ............................................. 31

Figure 23. Generator Model Predicted Torque and Shaft Power at 5 Ohms ................... 33

Figure 24.Generator Model Predicted Efficiency at 5 Ohms ...................................... 34

Figure 25. Brake Torque and Power for different Electrical Loads ............................. 35

Figure 26. Generator Model Efficiency Contour Chart ............................................... 35 
Figure 27. Diode Current - Voltage relationship [19]................................................. 36

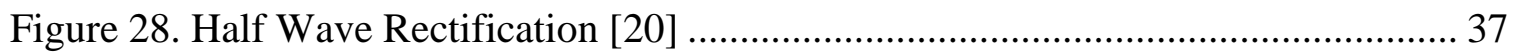

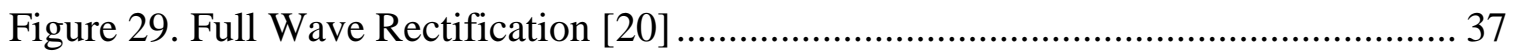

Figure 30. Voltage rectification using 3-phase bridge rectifier [21] ............................. 38

Figure 31. Current - Voltage per Diode in IXYS FUO 22 Three Phase Rectifier Bridge [21] ...................................................................... 38

Figure 32. Generator Model Electrical schematic [8] [9] ................................................ 39

Figure 33. Generator Model Predicted Torque and Shaft Power [5 Ohms (Rectified)] ...................................................................................... 41

Figure 34. Generator Model Predicted Efficiency at 5 Ohms (Rectified) ........................ 41

Figure 35. Generator Kv Test Schematic......................................................................... 43

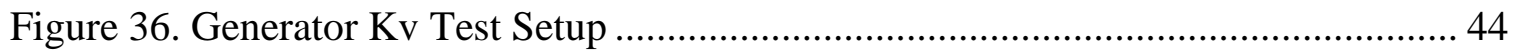

Figure 37. Electrical Schematic of Generator Internal Resistance

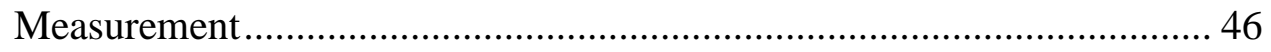

Figure 38. Generator Test Schematic............................................................................. 48

Figure 39. Generator Test Setup ............................................................................... 48

Figure 40. Generator Model Test Results at 3.02 Ohms............................................... 49

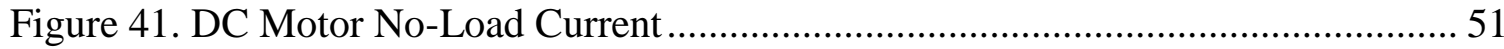

Figure 42. Torque Verification diagram ..................................................................... 53

Figure 43. Motor and Generator Model Predicted Shaft Torque ....................................... 54

Figure 44. Motor to Generator Model Validation Test Diagram....................................... 55

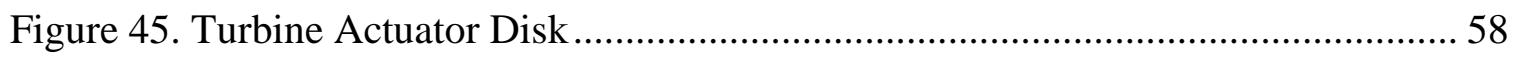

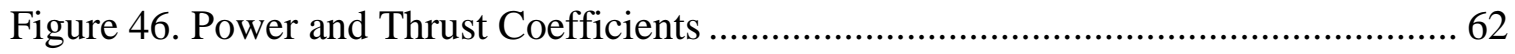

Figure 47. Power Curve for a 3.25 in. Diameter Rotor.................................................... 62

Figure 48. Actuator Disk Power Extracted for Different Axial Velocities at Varying Axial Induction Factors. (Dotted Line Represents

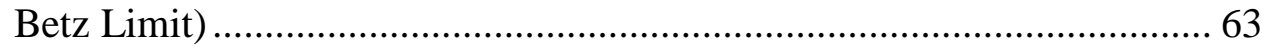

Figure 49. Schematic of Rotor Blade Partitioned into Blade Elements [13] .................... 64

Figure 50. Blade Velocity and Force Breakdown [12] ................................................... 65

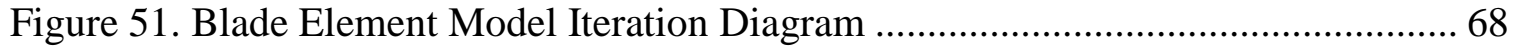

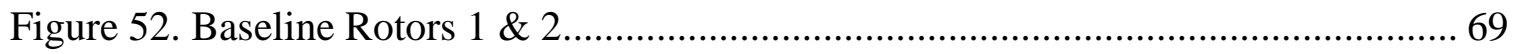


Figure 53. Selected Rotor Blade Airfoil (NACA 2412) .............................................. 70

Figure 54. QBlade GUI for Analyzing Airfoil CL and CD [23] [22] ........................... 71

Figure 55. Montgomery Extrapolated NACA 2412 Lift and Drag curves at

Re:80,000;Using QBlade Extrapolation Module [23] [22].................... 72

Figure 56. Blending Function for Combining Potential and Thin Plate Flow

for Montgomery Extrapolation Method [25] ...................................... 73

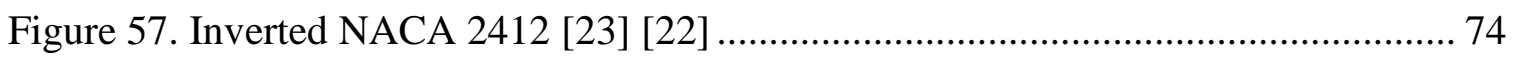

Figure 58. Blade Element Model Power and Torque Predictions for Rotor-1

Model for Airspeed of $110 \mathrm{mph....................................................} 75$

Figure 59. Blade Element Model Power and Torque Predictions for Rotor-2

Model for Airspeed of 110 mph........................................................ 76

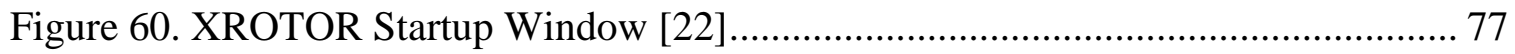

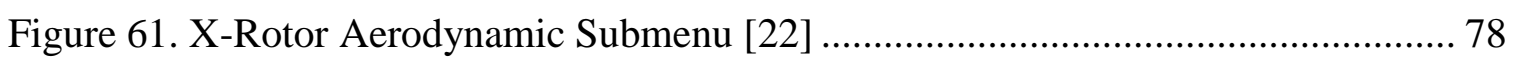

Figure 62. XROTOR Aerodynamic Section Editting Submenu [22] ............................. 78

Figure 63. Straight and Twisted Blade Geometry Created in XROTOR [22] ................ 79

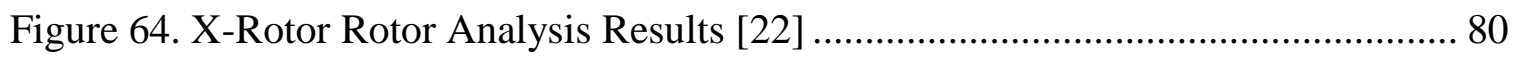

Figure 65. Rotor 1 (straight blades) Predicted Power @ 110 mph (sea level) ................ 81

Figure 66. Rotor 1 (straight blades) Predicted Torque @ 110 mph (sea level)............... 81

Figure 67. Rotor 2 (twisted blades) Predicted Power @ $110 \mathrm{mph}$ (sea level) ................. 82

Figure 68. Rotor 2 (twisted blades) Predicted Torque @ $110 \mathrm{mph}$ (sea level)................ 82

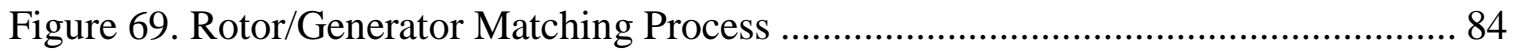

Figure 70. Maxon (\#386677) Generator Efficiency Contour Map ................................ 85

Figure 71. Maxon (\#386677) Generator Brake Torque and Power for

Terminal Loads 1-20 Ohms ........................................................ 85

Figure 72. Rotor-1 Brake Power Plotted onto Generator Efficiency Contour

[Generator: Maxon \#386677]; [ @ sealevel, 110 mph, Betz

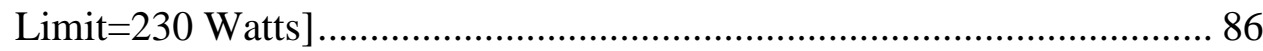

Figure 73. Rotor 1 Brake Torque and Power Curves Overlaid Generator

Brake Torque and Power plots fort varying Electrical Loads of

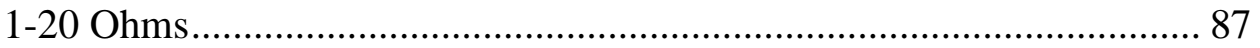

Figure 74. Rotor-2 Generator Efficiency Contour Plot ............................................ 88 
Figure 75. Rotor Brake Torque and Power Curves Overlaid Generator Brake Torque and Power plots fort varying Electrical Loads of 1-20

Ohms 89

Figure 76. Generator-B Manufacturer Specifications [Maxon \#386678] [18] ............... 91

Figure 77. Rotor-1 \& Generator B Efficiency Contour 92

Figure 78. Rotor-1 Brake Torque and Power Curves Overlaid Generator-B

Brake Torque and Power plots fort varying Electrical Loads of 1-20 Ohms. 93

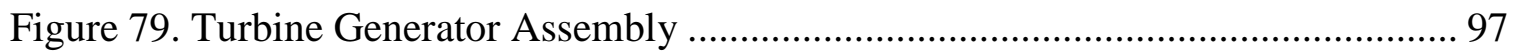

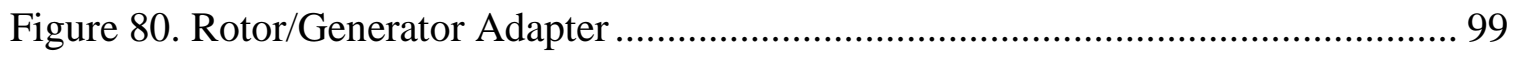

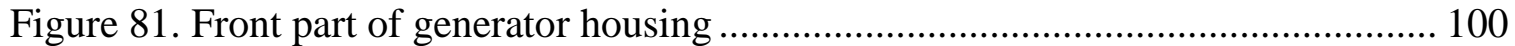

Figure 82. Aft part of generator housing [26] ........................................................ 100

Figure 83. Test Stand Attached to Bottom Wind Tunnel Plate [26]............................ 101

Figure 84. Turbine Generator Mounted on Test Stand [26] ..................................... 101

Figure 85. Turbine Generator Validation Test Schematic [26] .................................. 102

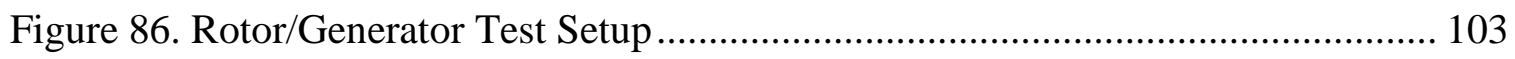

Figure 87. Rotor-1 Power @ 49.05m/s compared to model predictions ........................ 105

Figure 88. Rotor 2 Power @ 49.05m/s compared to model predictions......................... 105

Figure 89. Rotor-1 Power @ 41.04m/s compared to model predictions ...................... 106

Figure 90. Rotor 2 Power @ 41.04m/s compared to model predictions......................... 106

Figure 91. Rotor-1 Power @ 32.79 m/s compared to model predictions ....................... 107

Figure 92. Rotor 2 Power @ 32.79m/s compared to model predictions........................ 107

Figure 93. Prandtl Tip Loss Factor (Fp) as a Function of Normalized Radius ............... 110

Figure 94. Sectional Torque without Tip Loss Factor ............................................... 111

Figure 95. Sectional Torque with Tip Loss Factor .................................................. 111

Figure 96. Rotor-1 Power @ 49.05m/s compared to model predictions ........................ 113

Figure 97. Rotor-2 Power @ 49.05m/s Compared to Model Predictions....................... 113

Figure 98. Rotor-1 Power @ 41.04m/s Compared to Model Predictions...................... 114

Figure 99. Rotor-2 Power @ 41.04m/s Compared to Model Predictions....................... 114

Figure 100. Rotor-1 Power @ 32.79 m/s Compared to Model Predictions.................... 115

Figure 101. Rotor-2 Power @ 32.79m/s Compared to Model Predictions..................... 115 
Figure 102. Generator Evaluation Test Results (RL=1.04) (Maxon \#386677) .............. 138

Figure 103. Generator Evaluation Test Results (RL=1.39) (Maxon \#386677) .............. 139

Figure 104. Generator Evaluation Test Results (RL=1.53) (Maxon \#386677) .............. 140

Figure 105. Generator Evaluation Test Results (RL=1.74) (Maxon \#386677) .............. 141

Figure 106. Generator Evaluation Test Results (RL=2.07) (Maxon \#386677) .............. 142

Figure 107. Generator Evaluation Test Results (RL=2.07) (Maxon \#386677) ............. 143

Figure 108. Generator Evaluation Test Results (RL=2.89) (Maxon \#386677) .............. 144

Figure 109. Generator Evaluation Test Results (RL=3.02) (Maxon \#386677) .............. 145 


$$
\begin{aligned}
\mathrm{I}_{\mathrm{O}} & =\text { No-load current, amps } \\
\mathrm{R}_{\mathrm{i}} & =\text { Internal resistance, ohms } \\
\mathrm{R}_{\mathrm{L}} & =\text { Terminal electrical load, ohms } \\
\mathrm{L} & =\text { Inductance, henry } \\
\mathrm{K}_{\mathrm{V}} & =\text { Speed constant, rpm/volt } \\
\mathrm{K}_{\mathrm{T}} & =\text { Torque constant, } \mathrm{N}-\mathrm{m} / \mathrm{amp} \\
\mathrm{P} & =\text { Power, watts } \\
\mathrm{V}_{\mathrm{a}} & =\text { Armature Voltage, volts } \\
\mathrm{V}_{\mathrm{r}} & =\text { Rectified terminal voltage, volts } \\
\mathrm{V}_{\mathrm{DO}} & =\text { Rectifier forward voltage drop, volts } \\
\mathrm{P}_{\mathrm{brake}} & =\text { Power at the shaft, watts } \\
\mathrm{Q} & =\text { Torque, lbf-ft } \\
\eta & =\text { Efficiency } \\
\mathrm{RPM}_{\mathrm{f}} & =\text { Revolutions per minute } \\
\mathrm{V}_{\infty} & =\text { Freestream airspeed, ft/s } \\
\mathrm{V}_{\mathrm{O}} & =\text { Axial airspeed at rotor face, } \mathrm{ft} / \mathrm{s} \\
\mathrm{V}_{1} & =\text { Relative airspeed, ft/s } \\
\varphi & =\text { Relative velocity angle, }{ }^{\circ} \\
\alpha & =\text { Angle of attack, }{ }^{\circ} \\
\Delta \mathrm{T} & =\text { Sectional Thrust, lbf } \\
\Delta \mathrm{Q} & =\text { Sectional Torque, lbf-ft } \\
\mathrm{l} & =\text { Sectional Lift, lbf } \\
\mathrm{d} & =\text { Sectional Drag, lbf } \\
& \\
& =1
\end{aligned}
$$




\section{INTRODUCTION}

The development of a Micro Ram Air Turbine ( $\mu$ RAT) system is being investigated to provide power to a heating element that will eliminate sensor drop out due to cold temperatures on the Boundary Layer Data System (BLDS) during high altitude flights. In addition, a $\mu$ RAT could be used to augment or replace the BLDS battery for extended operation. This thesis project builds on previous proof-of-concept work with the aim of developing a set of design tools to intelligently design the $\mu$ RAT turbine/generator for specific operating conditions and particularly to match a turbine rotor to an appropriate generator. The $\mu$ RAT design tools consist of turbine rotor and generator models; the latter is the primary focus of the current work. The generator will undergo a series of motored generator tests followed by wind tunnel tests for the fully assembled turbine generator. Results are then used to evaluate the design tools, and particularly to improve and validate the generator model.

The Boundary Layer Data System (BLDS) along with the Preston Tube Data System (PTDS) are Northrop Grumman Corp. sponsored devices developed by Dr. Russell Westphal and the BLDS team for the purpose of measuring in-flight boundary layer and airflow properties. These devices are standalone, battery powered, flight rated devices that can be non-intrusively attached to any aircraft or surface and operate autonomously without having to task an operator for data collection. Both of these systems are capable of measuring absolute static pressure, temperature and average skin friction. The BLDS can additionally measure mean boundary layer velocity profile with a Pitot tube that is mounted onto a motorized stage. The PTDS measures three pressures 
simultaneously, these include free-stream dynamic pressure using a Pitot tube, local surface static pressure using the Sproston-Goskel probe, and skin friction using the Preston tube [1].

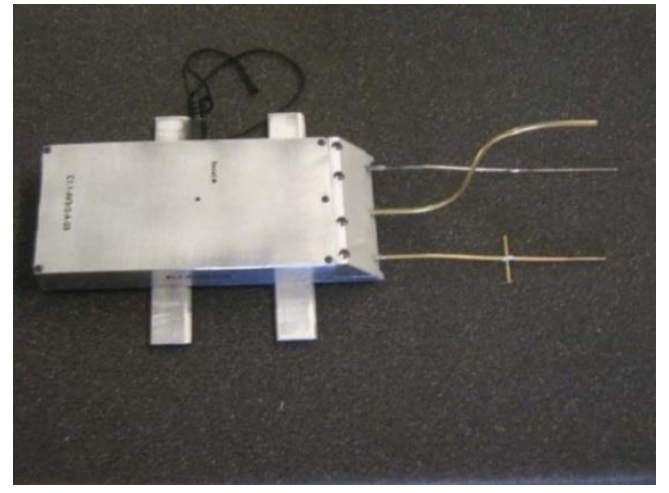

Figure 1. Preston Tube Data System (PTDS) [1]

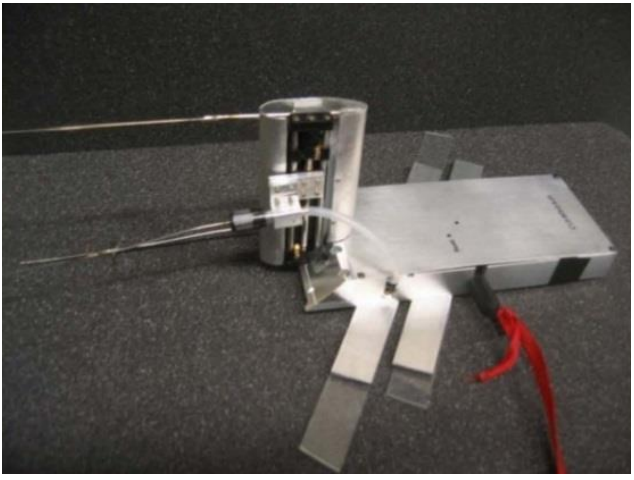

Figure 2. Boundary Layer Data System (BLDS) [1]

Both systems share similar basic components such as: the microcontroller, data storage, battery, pressure sensors and pressure probes. The battery pack consist of 4 AA sized Lithium Sulfur Dioxide (LiSO2) batteries that provide up to $1000 \mathrm{mAhr}$ and $12 \mathrm{~V}$ at $20^{\circ} \mathrm{C}$. Components such as the microcontroller and sensors are not rated to operate at temperatures below $-20^{\circ} \mathrm{C}$, however, test results have shown continued operation down to and below $-55^{\circ} \mathrm{C}$. Battery and sensor performance have been observed to rapidly diminish at temperatures below $-55^{\circ} \mathrm{C}$. Typically at theses temperatures the battery output diminishes to $250 \mathrm{mAHr}$ and $10 \mathrm{~V}$ and sensors are more likely to fail [1]. To approximate the maximum power required to power the BLDS, Table 1 reflects the power requirements at temperatures of $-55^{\circ} \mathrm{C}$, which impose higher power requirements than at higher temperatures. The higher power requirements are mainly due to the higher current draw from the stage, which is dependent on temperature and is higher at lower temperatures - all other parts draw a fixed current, independent of temperature. Our 
approximation concludes that no more than a couple of watts are required to power all components of the BLDS at its coldest operating temperature. It should also be noted that the BLDS conserves power consumption by going to sleep mode, which turns off all components with exception of the micro controller when data is not being collected.

Table 1. BLDS Power Consumption @ -55 ${ }^{\circ} \mathrm{C}$ [1]

\begin{tabular}{|c|c|c|c|}
\hline & Current Draw (mA) & $\begin{array}{c}\mathbf{4} \text { x LiSO2 } \\
\text { Voltage @ -55 C }\end{array}$ & $\begin{array}{c}\text { Approx. Power } \\
\text { Required (Watts) }\end{array}$ \\
\hline Pressure Sensor & $24(3$ @ 8 each) & 10 & 0.24 \\
\hline Temp. Sensor (x1) & 1 & 10 & 0.01 \\
\hline Stage Motor & $25-100+$ & 10 & 1 \\
\hline Micro Controller & 4 (sleep), 14 (operation) & 10 & 0.14 \\
\hline & & Total: & $\mathbf{1 . 3 9}$ max \\
\cline { 2 - 4 }
\end{tabular}

Previous work investigated the possibility of eliminating sensor dropout through insulation and self-heating. A study conducted by Htet htet Oo [2] investigated the possibility of maintaining a 1-degree temperature difference between ambient air and internal temperatures. In this study, a BLDS satellite was modeled with a prototype circuit board within a "sandwich" of insulation. Within the insulation, a heating element simulated the generated heat, typical of a BLDS satellite circuit board [2]. Estimates based on this study indicate an average heat dissipation per Kelvin of $46 \mathrm{~mW} / \mathrm{K}$.. Based on this estimate it is feasible to gain a few degrees of temperature through the use of selfheating and insulation, however a more substantial increase in internal temperatures can be achieved through providing additional heat. These results further demonstrate how an insulated BLDS would require modest power for heating. For an insulated BLDS satellite a $10^{\circ}$ internal temperature rise would require an estimated 0.5 watts in addition to what is required to power the BLDS, as outlined in Table 1. A total of less than 2 watts, 
maximum, would be required to power the BLDS and provide sufficient heat for an internal temperature rise of $10^{\circ}$. In the development of the $\mu$ RAT for the purpose of heating the BLDS, it is the generator that directly supplies this power to the heating element. A thorough understanding of the generator will enable the optimization and proper matching of rotor performance and overall system efficiency for a required heating element.

Electric generators along with motors are electric machines that convert mechanical power to electrical energy or conversely convert electrical energy to mechanical power. Basic laws such as Faraday's law of electromagnetic induction and Lorentz's force law explain the fundamental working principles of typical electrical motors and generators; this is illustrated below in Figure 3. The motoring application can be understood from the Lorentz Force Law, which explains how a current passing through a conductor that is freely suspended within a fixed magnetic field will create a force, resulting in the motion of the conductor through the magnetic field [3] [4].

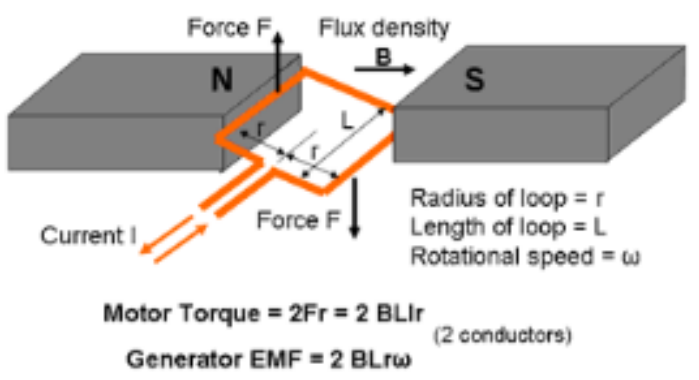

\section{Figure 3. Basic Electric Machines [3]}

The generator application is understood through Faraday's explanation of how a moving conductor through a magnetic field or moving a magnetic field relative to a conductor will induce a current through the conductor. Brushed generators and motors 
rely on Faraday's law and Lorentz's force law. These type of electric machines, shown in Figure 4, run current to the rotating shaft or "coil" through carbon brushes that make contact with a commutator that rotates with the shaft.
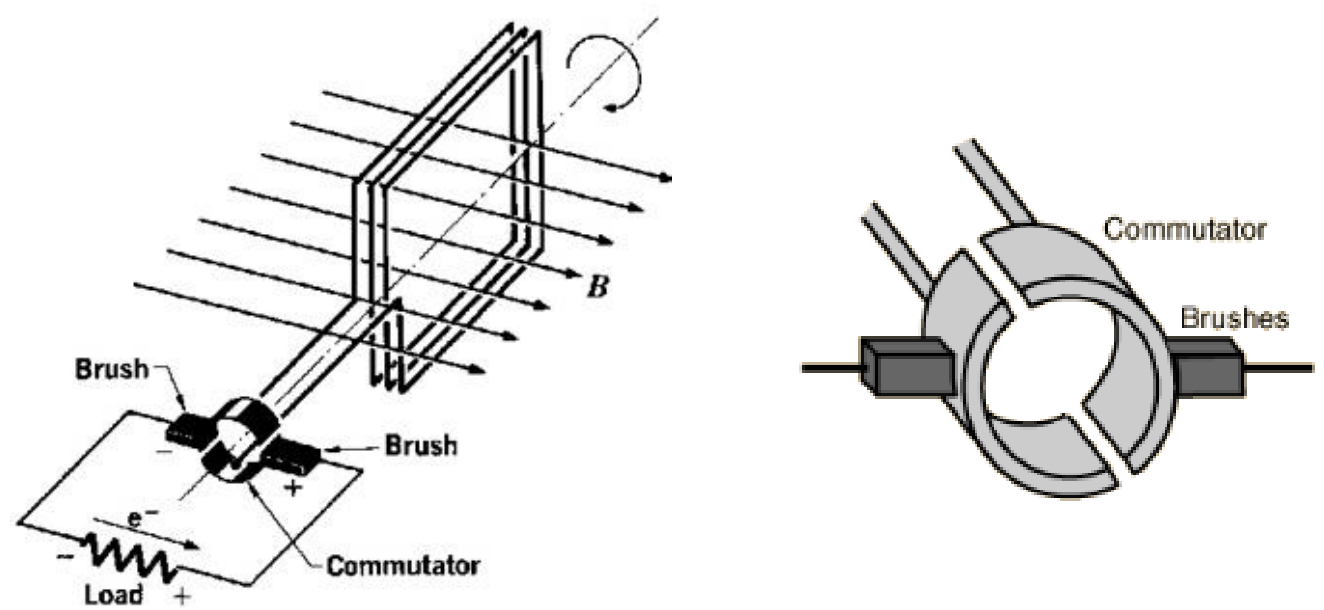

\section{Figure 4. Brushed Motor/Generator Commutator and Brushes [5] [6]}

DC brushed machines have advantages that include low cost, high reliability, and simplicity that is, they do not require a controller to operate. Some disadvantages include high maintenance, low life span, and low efficiencies. Many of the disadvantages are due to the carbon brushes and rotating commutator required to make moving electrical contact with the shaft. These components are responsible for additional frictional losses and tend to wear rapidly under continued operation.

While DC brushless electrical machines depend on the Lorentz force, it also takes advantage of an additional method of motor power. This motoring power comes from the reluctance torque; reluctance torque takes advantage of the repulsive and attractive force that is exerted on a magnet or any magnetic material when it is placed in the field of another magnet. The motoring motion is established through the pulsing and switching of stator poles in order to rotate the magnetic field; the magnetic field then brings the 
magnet along with it as it rotates. For this phenomenon to be practical, one of the magnets must be an electro-magnet. This will ensure control of the magnetic field necessary for continued motion. BLDC motors rely on a speed controller to manage the pulsing a switching of stator poles in order to drive the motor. Running these machines backwards as generators produces $\mathrm{AC}$ voltages and currents requiring a rectifier if it is desired to convert AC power to DC. Although BLDC machines can alternatively be run as an $\mathrm{AC}$ generator, it is most common to find these machines sold as motors with manufacturers providing performance charts for the motoring application only. This prompts the need to develop a generator model that can characterize the performance of a generator using performance parameters that are typically provided for the motoring application.

In previous generator proof-of concept work conducted by the AeroRAT senior design group [7], the type of generator was determined and the need to develop a method to predict and match rotor performance with an off-the-shelf generator was identified. Initial selection of the type of candidate generator was based on efficiency, cost, size and weight. Rotational speed ranges and maintenance requirements were also taken into account. Table 2 shows the decision matrix used in the selection of the brushless DC motor as the candidate generator type [7]. 


\section{Table 2. Selection of Generator Type Decision Matrix [7]}

\begin{tabular}{|c|c|c|c|c|}
\hline Evaluation Criteria & Weight & $\begin{array}{l}\text { U } \\
\tilde{n} \\
\frac{\varrho}{\frac{n}{n}} \\
\frac{n}{n}\end{array}$ & પ & $\ddot{4}$ \\
\hline Cost & 0.10 & $S$ & +1 & +1 \\
\hline Size & 0.25 & $S$ & $S$ & $S$ \\
\hline Weight & 0.25 & $\mathrm{~S}$ & $\mathrm{~s}$ & $\mathrm{~s}$ \\
\hline Efficiency & 0.40 & $\mathrm{~S}$ & -1 & -1 \\
\hline Normalized $\Sigma$ of +1 & & 0.00 & 0.20 & 0.20 \\
\hline Normalized $\Sigma$ of -1 & & 0.00 & -0.40 & -0.40 \\
\hline Normalized $\Sigma$ of $S$ & & 1.00 & 0.50 & 0.50 \\
\hline$\Sigma$ & & 1.00 & 0.70 & 0.70 \\
\hline
\end{tabular}

Brushless DC motors proved to be more practical for the application of a turbine generator in that they have reduced maintenance, higher power per unit volume, higher efficiencies due to not having the wear and mechanical power losses imposed by the contact of the brushes with the commutator. Additionally, previous experience using BLDC motors to drive the BLDS stage in flight has proven their successful operability at low temperatures. Referencing Table 2 it can be seen that team AeroRAT placed most of the decision weight on the efficiency parameter, which is based off motoring data. Although these efficiencies were based on motoring efficiencies, these values do provide a rough estimate of the generator efficiencies.

Upon selecting the BLDC motor as the type of generator, Team AeroRat conducted generator proof-of-concept test. The test schematic in Figure 5 shows the test setup with generator lead wires going to a rectifier, where the generated AC current is converted to DC current. Current then flows through a resistor load bank where terminal current and voltage are measured. 


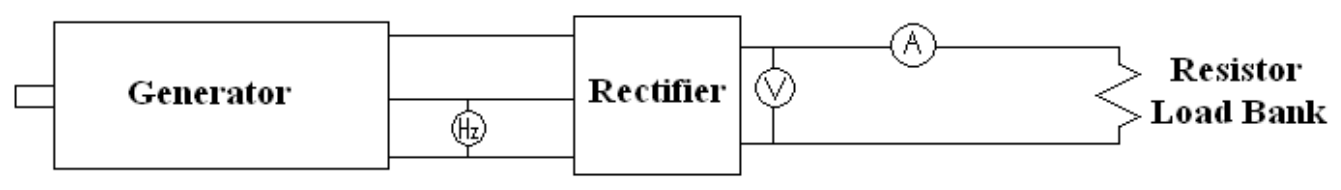

Figure 5. Team AeroRAT Generator Test Schematic [7]

The physical test set up is shown in Figure 6; here we can see that an air powered die grinder is used as the prime mover to the generator. The die grinder rotates the generator through a shaft coupler. The three generator lead wires are connected to the rectifier, which connects to the electrical load as shown. Two multimeters are shown: one is connected in parallel to measure voltage, and the other in series with the load to measure current.

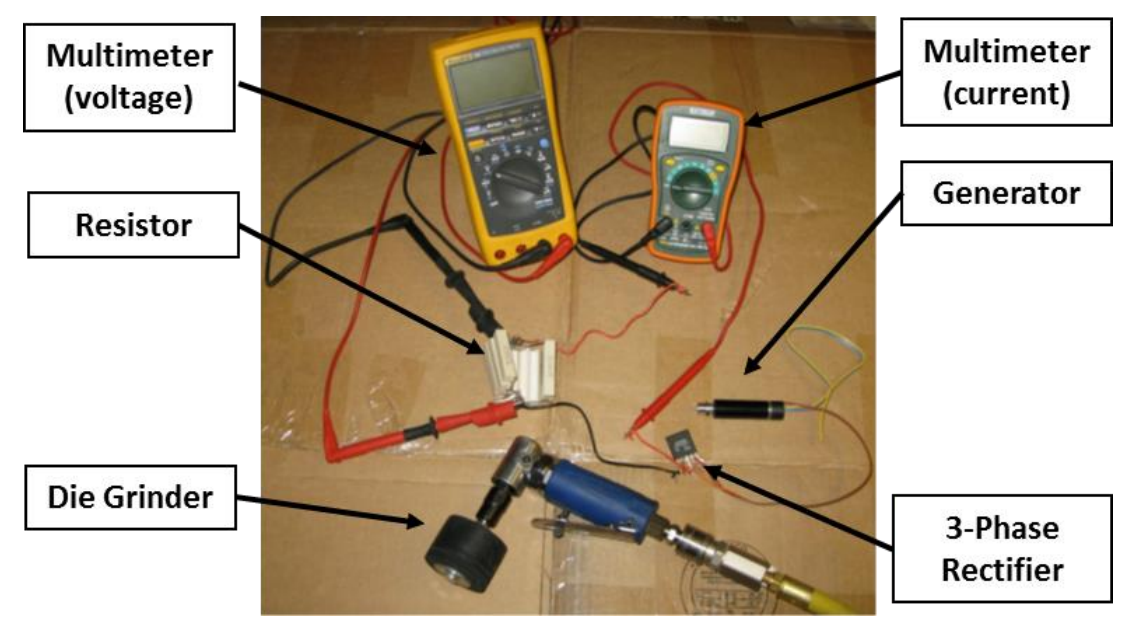

Figure 6. Team AeroRAT Generator Test Setup [7]

For the test, terminal power was measured as the die grinder drove the generator through various rotational speeds with two different loads at the terminal; $12.7 \mathrm{ohms}$ and 10.1 ohms. These results are shown below in Figure 7. 


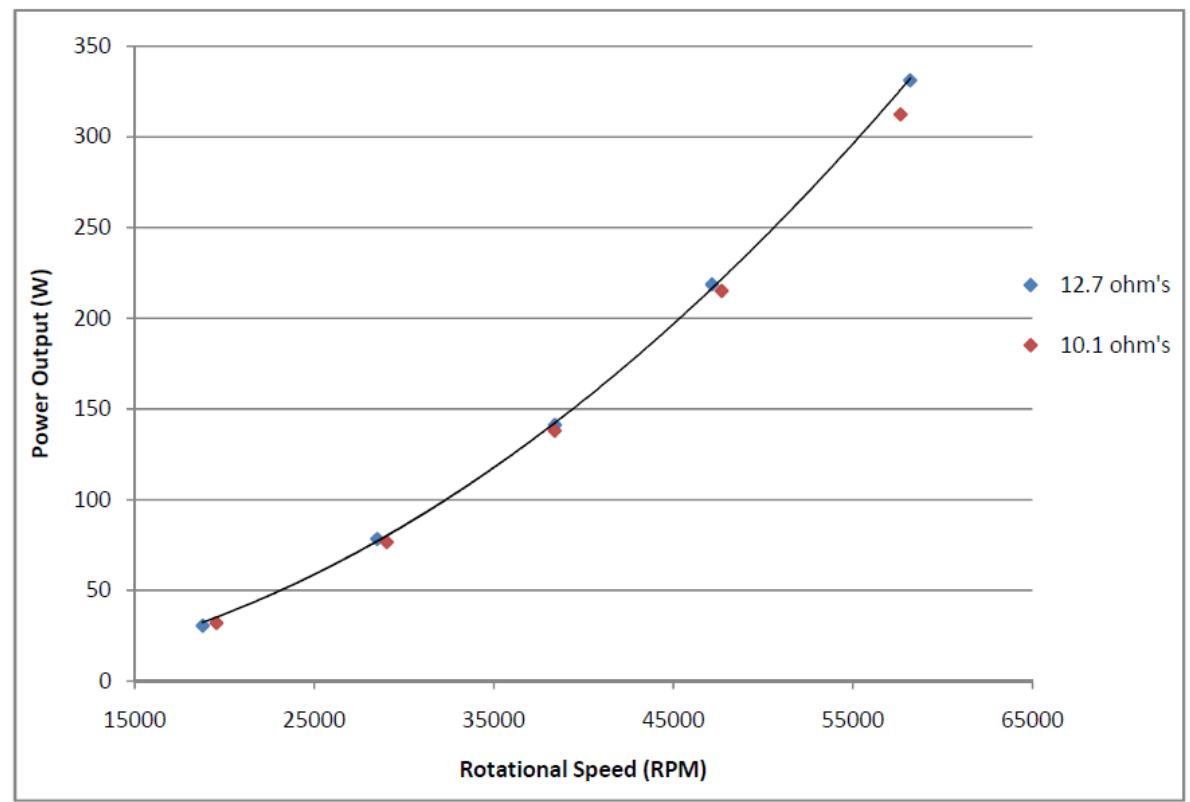

Figure 7. Team AeroRAT Proof-of-Concept Test Results [7]

While the feasibility of producing power by rotating the generator was proved, an optimum operating point for the generator was not determined. Questions such as: What is the minimum shaft torque required of the blades to turn the generator shaft?, or How much torque for a given load do the blades need to produce in order to drive the generator to a speed of optimum efficiency?, were still left unanswered. Although motor data provides a crude approximation to generator performance, it is important to understand that power losses are applied differently in a generator and if converting generated AC power to DC power, rectifier losses also need to be accounted for. In order to efficiently generate power, a method for predicting generator performance and matching a generator to the performance of a rotor is necessary [7].

As mentioned before, typically DC brushless machines are sold as motors with specifications only detailing the motoring applications. In search for a published generator model suitable for our application, an exact match was not found however, 
Drela's explanation of a 3-constant DC motor model [8] along with turbine generator work done by Wood, D. [9] was of particular interest. The 3-constant DC motor model explained by Drela implements established electro-mechanics to match a basic DC Brushless motor to a rotor blade. Wood gives details on different generator electrical schematics that can be modified for our particular application. Below in Figure 8, a basic electro-mechanical schematic from Drela's model details how the DC current induces torque at the rotor shaft.

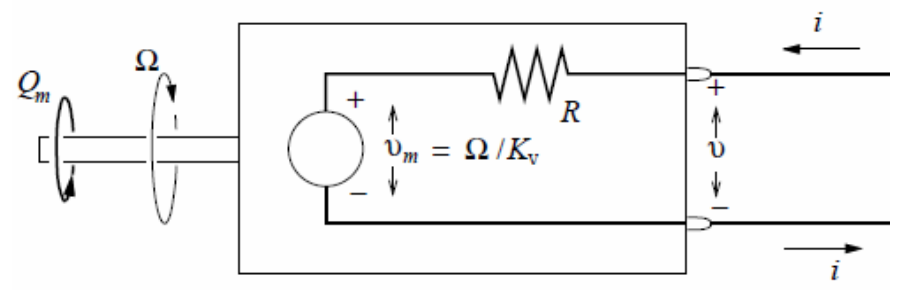

Figure 8. Equivalent Circuit of a DC Motor [8]

Although this models the motoring application of an electric machine as it is matched to a propeller, it is useful in understanding and establishing an approach to modeling a generator that is to be matched to a turbine. Figure 9 displays the method in which a propeller is matched to a motor using Drela's model. Here the schematic of Figure 8 is used to establish equations to model the motors torque and efficiency as it varies with RPM. Motor torque and efficiency are then plotted along with propeller torque and thrust parameters. One can then match the propeller operating points with the motor performance as seen with the vertical dotted line in Figure 9 [8]. 


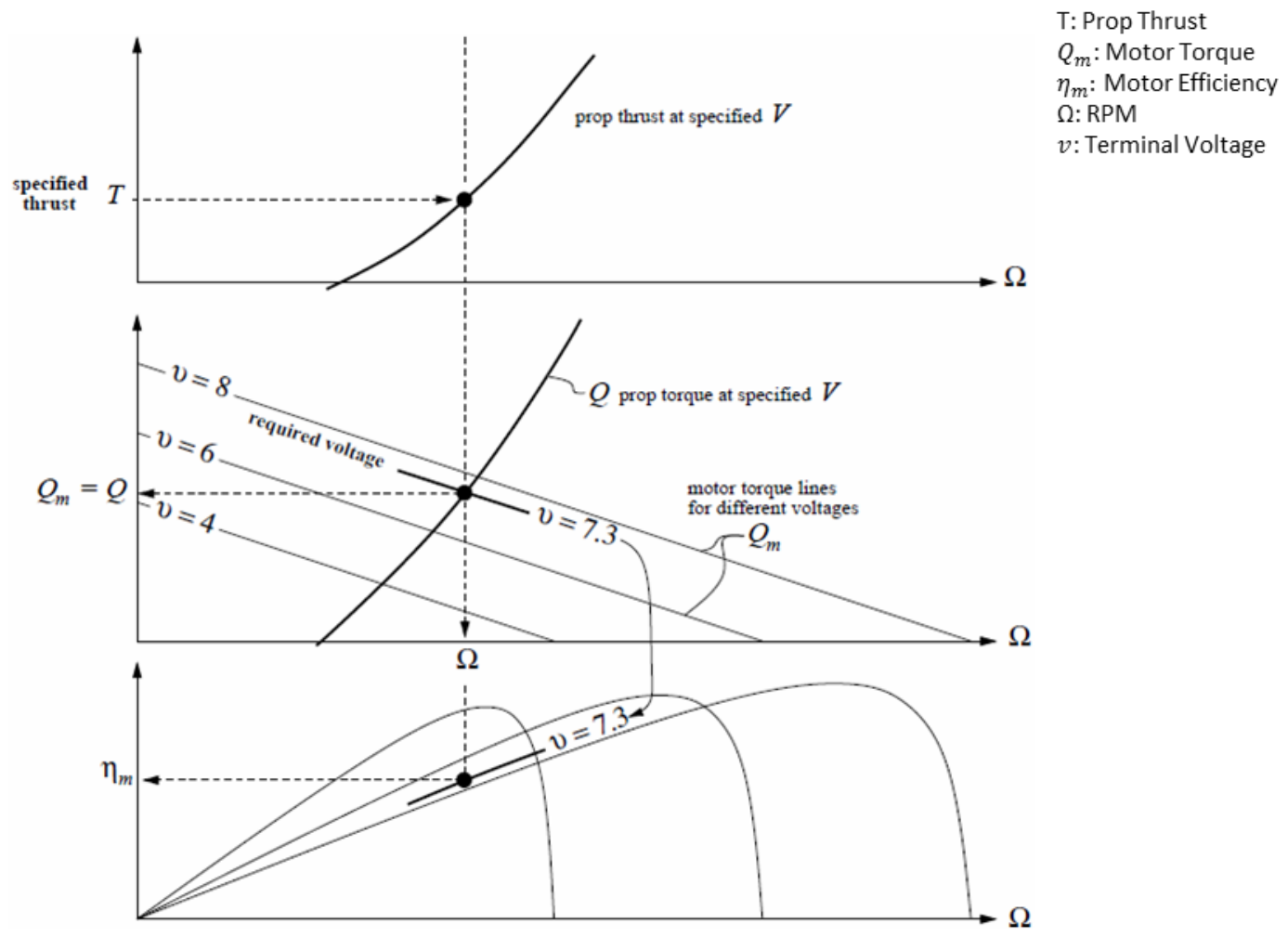

\section{Figure 9. Motor and Propeller Parameters at Specific Flight Speed and Motor Voltage [8]}

The motor/propeller matching approach used in Drela's motor model is used in establishing a method to optimally match a rotor to a generator and in effectively predicting performance. For the generator model, an electrical schematic similar to that of Figure 8 is developed. The electrical model of the generator differs from that of the motor in that current will flow in the opposite direction and will reflect additional losses incurred by the generator and rectifier. To match the generator with a rotor, rotor performance predictions are calculated and matched with generator torque and efficiency plots. One possible criteria for matching is when rotor peak power is at the same operating point as generator max-efficiency. Rotor performance predictions will be developed using methods similar to those previously employed by team AeroRAT [7] [8]. 
Previous rotor blade design work entailed selecting the blade type, conducting $1^{\text {st }}$ order calculations to determine rotor sizing, manufacturing, and performing proof of concept test. In selecting the blade type, different blade concepts such as the ones shown in Figure 10 were considered by team AeroRAT. These concepts included Axial, Vertical, Screw, and Paddle Wheel.

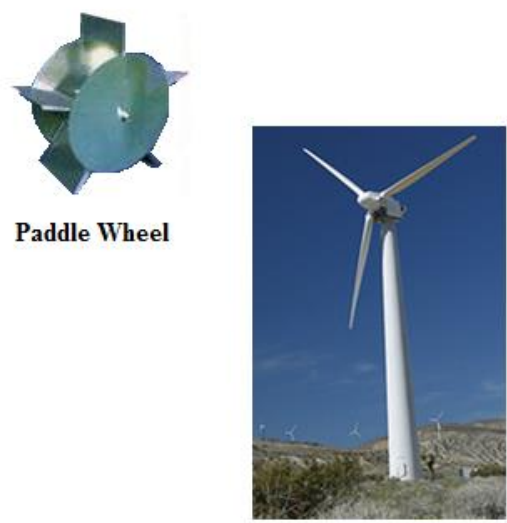

Axial Flow

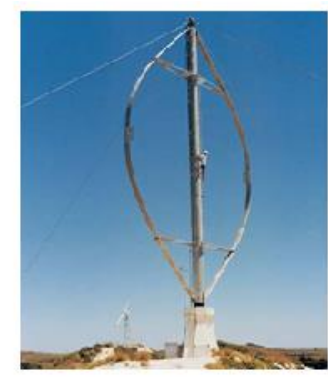

Verticle Axis

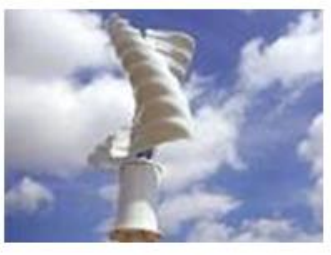

Screw

Figure 10. Types of Wind Turbines [7]

Vertical axis type of turbines tend to produce cyclical stress and torque ripples resulting in low reliability and high maintenance. Some variations of vertical axis turbines and paddle wheel type are also considered drag type turbines and generally are less efficient then axial turbines. Unlike vertical axis and drag type turbines, axial turbines produce power throughout the entire rotation from each blade. Vertical axis turbines require the blade to backtrack against the direction of airflow resulting in lower efficiencies. For the reasons mentioned above and for the reasons outlined in Table 3, team AeroRAT selected the axial turbine as the best fit for the application of providing power to a heating element for the BLDS. To be consistent with previous work, the horizontal axis wind turbine was selected for this work [10] [7]. 


\section{Table 3. Selection of Wind Turbine Type Decision Matrix [7]}

\begin{tabular}{|c|c|c|c|c|c|c|}
\hline Evaluation Criteria & Weight & $\frac{\frac{n}{x}}{\frac{\pi}{d}}$ & $\frac{\bar{\pi}}{x}$ & 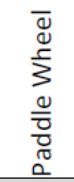 & ఏँ & 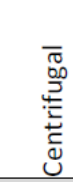 \\
\hline Power Requirement & 0.30 & $S$ & $S$ & $S$ & -1 & $S$ \\
\hline Durability & 0.10 & $S$ & +1 & +1 & +1 & +1 \\
\hline Manufacturability & 0.15 & $\mathrm{~S}$ & +1 & $\mathrm{~S}$ & +1 & -1 \\
\hline Ease of Design & 0.05 & $S$ & +1 & +1 & $S$ & -1 \\
\hline Size & 0.15 & $S$ & +1 & $S$ & -1 & $S$ \\
\hline Weight & 0.10 & $S$ & $S$ & $\mathrm{~S}$ & -1 & -1 \\
\hline $\begin{array}{l}\text { Compatibility with a } \\
\text { Generator }\end{array}$ & 0.05 & $\mathrm{~S}$ & +1 & +1 & $\mathrm{~S}$ & +1 \\
\hline Operating Wind Speed & 0.10 & $\mathrm{~S}$ & $\mathrm{~S}$ & $\mathrm{~S}$ & -1 & -1 \\
\hline Normalized $\Sigma$ of +1 & & 0.00 & 1.00 & 0.40 & 0.50 & 0.30 \\
\hline Normalized $\Sigma$ of - 1 & & 0.00 & 0.00 & 0.00 & -0.65 & -0.40 \\
\hline Normalized $\Sigma$ of $S$ & & 1.00 & 0.50 & 0.80 & 0.10 & 0.45 \\
\hline$\Sigma$ & & 1.00 & 1.50 & 1.20 & 0.60 & 0.75 \\
\hline
\end{tabular}

Team AeroRAT [7] additionally conducted first order calculations to size and determine blade geometry of the rotor. Actuator disk theory was applied in determining the rotor sizing. This analysis is based on 1-D momentum theory and represents the turbine as a disc that is infinitely thin uniformly loaded throughout the rotor area. It assumes a homogenous, inviscid, incompressible, steady flow. Static pressures far upstream and downstream of the rotor are assumed to be equal to the static ambient pressure. Figure 11 below illustrates the actuator disc model for a turbine. In the analysis, Bernoulli's equation and Newton's $2^{\text {nd }}$ Law (momentum) are applied to 3 different control volumes, from station 1-4, 1-2, and 3-4. The velocities represented by $U$ are assumed uniform across each station [11] [12] [13]. 


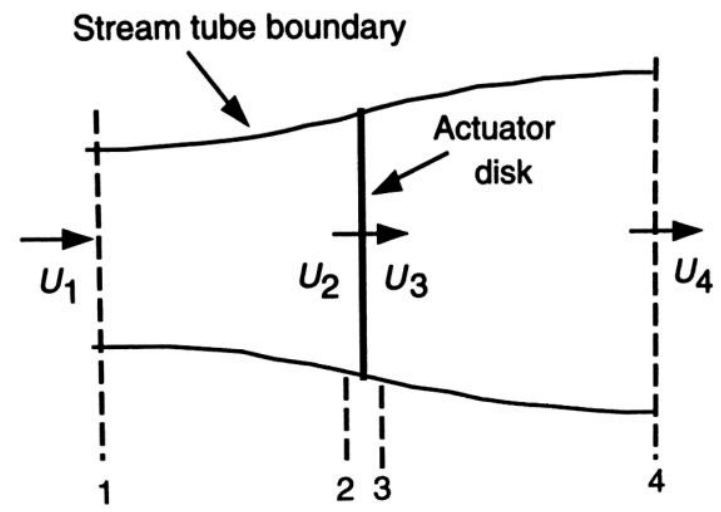

Figure 11. Wind Turbine Actuator Disk [13]

Through actuator disk analysis, maximum theoretical power extracted known as the Betz limit is determined. The Betz Limit states that no bare rotor turbine can extract more than $16 / 27(59.26 \%)$ of the kinetic energy in the free-stream air flowing through the rotor swept area [13] [11]. This model is highly idealized, typically commercial turbines only achieve up to $50 \%-75 \%$ of the Betz Limit. Figure 12 below displays the calculated Betz limit values in watts per swept area for varying airspeeds at different altitudes. At sea level, Figure 12 shows the Betz limit ranging from 6.63 watts/in^2 at $100 \mathrm{ft} / \mathrm{s}$ to 828.9 watts/in^2 at $500 \mathrm{ft} / \mathrm{s}[13][11][12]$.

$$
C_{P}=\frac{P_{\text {extracted }}}{P_{\text {available }}}=\frac{16}{27}
$$




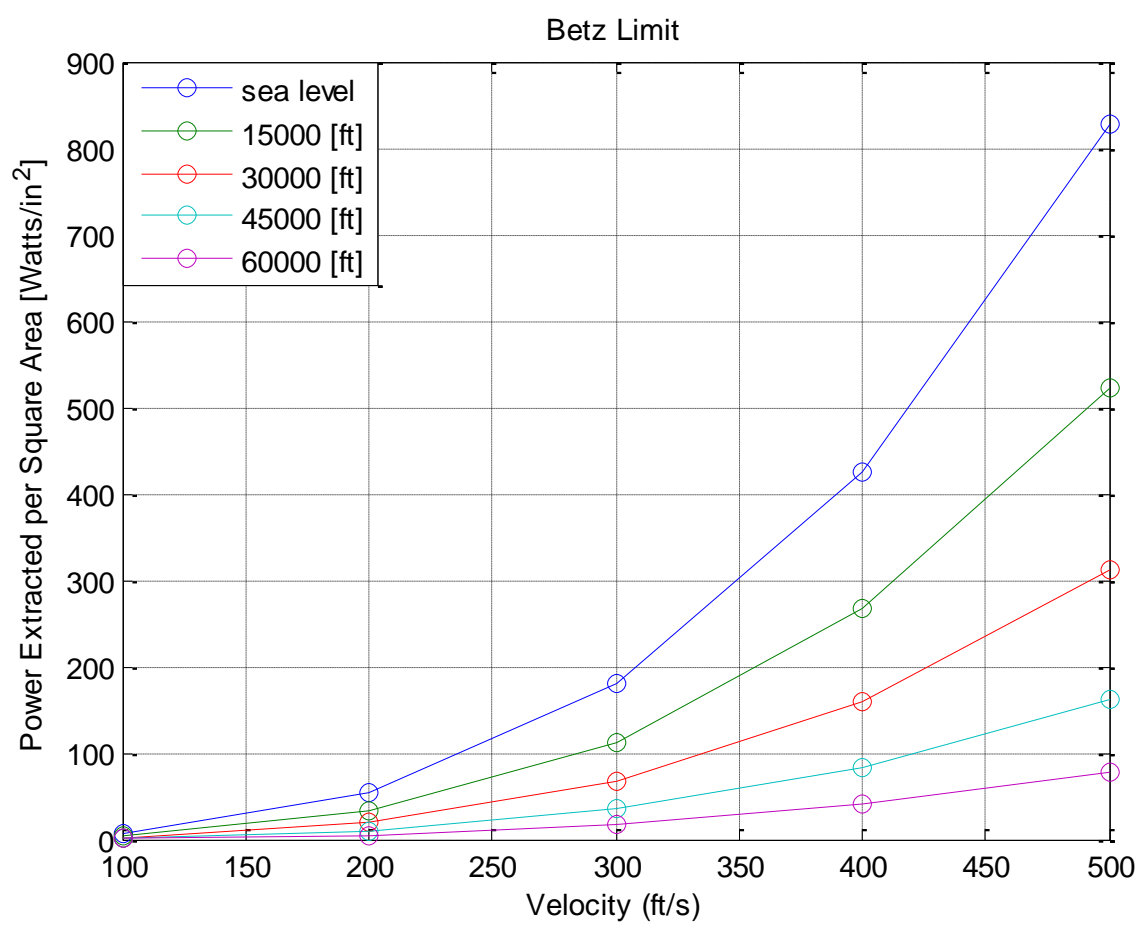

Figure 12. Betz Limit at Different Altitudes for Varying Airspeed

A blade element analysis was also conducted in order to get a better idea of what type of blade geometry would be required to produce 50 Watts at a target design point of 30,000 ft and airspeed of $400 \mathrm{ft} / \mathrm{s}$. Classic Glauert Blade Element Analysis [11] is a simple, 2-D, iterative method of predicting performance of a rotor and optimizing geometric parameters such as blade angle, chord, and twist distribution. It involves the partitioning of rotor blades into independent sections along the length of the blade. At each section, thrust and torque are calculated through a force balance that is conducted using 2-D airfoil lift and drag coefficient data. Sectional thrust and torque values can then be summed up in order to predict the performance of the entire rotor. This analysis is limited to 2-D, incompressible flow and does not take into account induced flow effects. As such, it can only provide a rough approximation of rotor performance [13] [11] [12]. 
Through this analysis, team AeroRat determined that for the design point mentioned, an off-the-shelf rotor such as a model airplane propeller would not be a viable option and that a higher solidity rotor would be required to produce a target power of 50 Watts. Although blade element theory loses accuracy for high solidity rotors, it was used to estimate the performance of an initial rotor design from which a variety of additional designs were developed with varying parameters such as number of blades, chord, and airfoil profiles. Between rotors, blade number varied between 3 and 12; chord varied from $11 \mathrm{~mm}$ to $13 \mathrm{~mm}$; and both NACA 2412 and 6512 airfoil profiles were used. Based on Betz Limit and the max allowable load, all rotors were sized $30 \mathrm{~mm}$ in diameter. Proof of concept tests were then conducted in the $2 \times 2 \mathrm{ft}$ Cal Poly Wind Tunnel for several rotors. Figure 13, below displays results from these proof of concept tests showing power output in watts for a varying electrical load at an airspeed of $165 \mathrm{ft} / \mathrm{s}$. Blade performance varied from peak power at approximately 8.5 Watts to a peak of 11.3 Watts [7]. The highest performing rotor with a peak of 11.3 Watts, achieved $38 \%$ of the Bets limit and the lowest rotor achieving $29 \%$ 


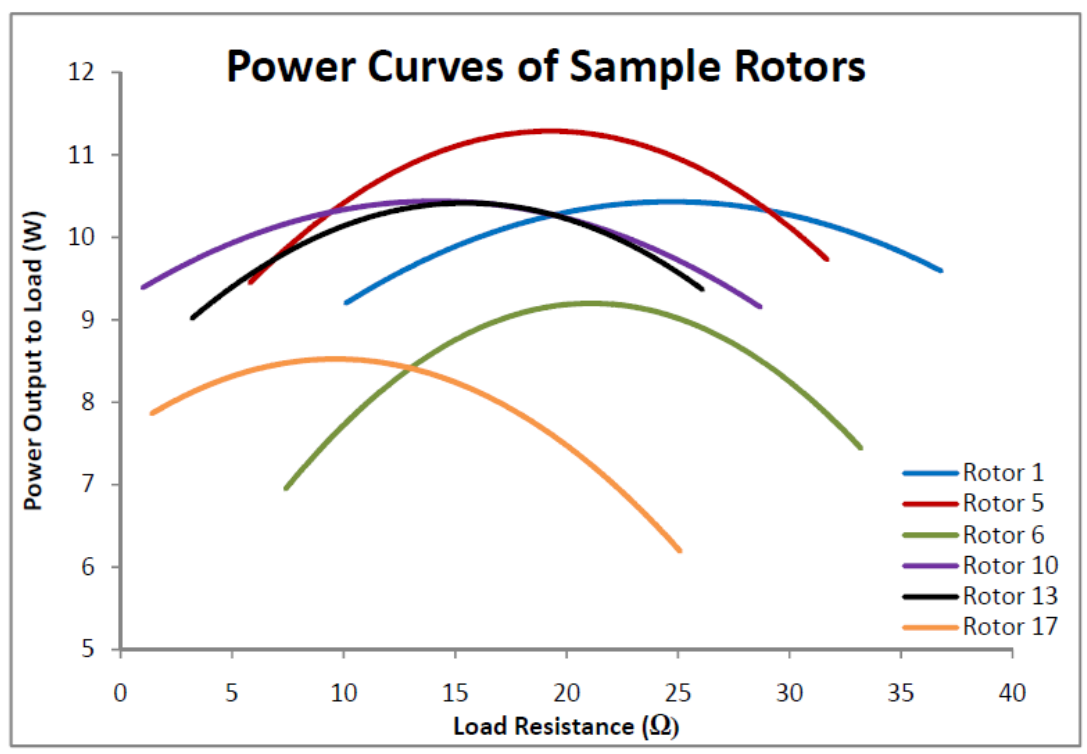

\section{Figure 13. Team AeroRAT Proof-of-Concept Wind Tunnel Test Results [7]}

The proof of concept test by Team AeroRAT showed that a small ram-air turbine could be expected to provide sufficient power to power and heat (more than a few Watts) the BLDS. However, it did not offer a method to design a rotor for specific flight operating conditions or to effectively match it to a generator. Looking at benchmark test results, it is not clear how rotor and generator parameters effect the overall performance of the rotor generator combination. This is due to the combination of not fully understanding generator performance coupled with the various limitations of Blade Element Analysis. This thesis will build on the proof of concept work done by team AeroRAT to establish a method of designing a $\mu$ RAT for specific operating conditions.

The approach taken in this thesis will build on this previous work and develop an improved set of tools for $\mu$ RAT design. The main focus will be on developing and validating a generator model that will be able to take known rotor performance predictions and effectively match them to the performance of a generator. With only manufacturer specifications provided, the generator model will be able to predict 
performance at varying speeds for given input torque and terminal loads. An iterative process will then take place as peak rotor performance is compared to the generator's maximum efficiency operating point. An example of a good match will be when the peak rotor performance is at or nearest to a generators max efficiency point. This model will then be validated through motored generator test where a prime mover will drive the generator and terminal power values measured will be compared to those predicted by the model.

An outline of the development and validation process for the $\mu$ RAT design tools is presented in Figure 14. Here it can be seen that along with the generator model, a rotor model is developed to provide baseline rotor performance data. Rotor model results will then be compared to an open source rotor analysis software. Leading up to testing both rotor and generator models will come together to match a generator to a rotor. The baseline rotor/generator will then be manufactured and assembled; and undergo testing in the 2x2 Cal Poly Wind Tunnel. As shown in the flow chart, Results will then be assessed to make improvements on both design tools and to make recommendations for future work. The following chapters will go into detail on the development of generator and blade models, the rotor/generator matching process, and validation test setup and results. 


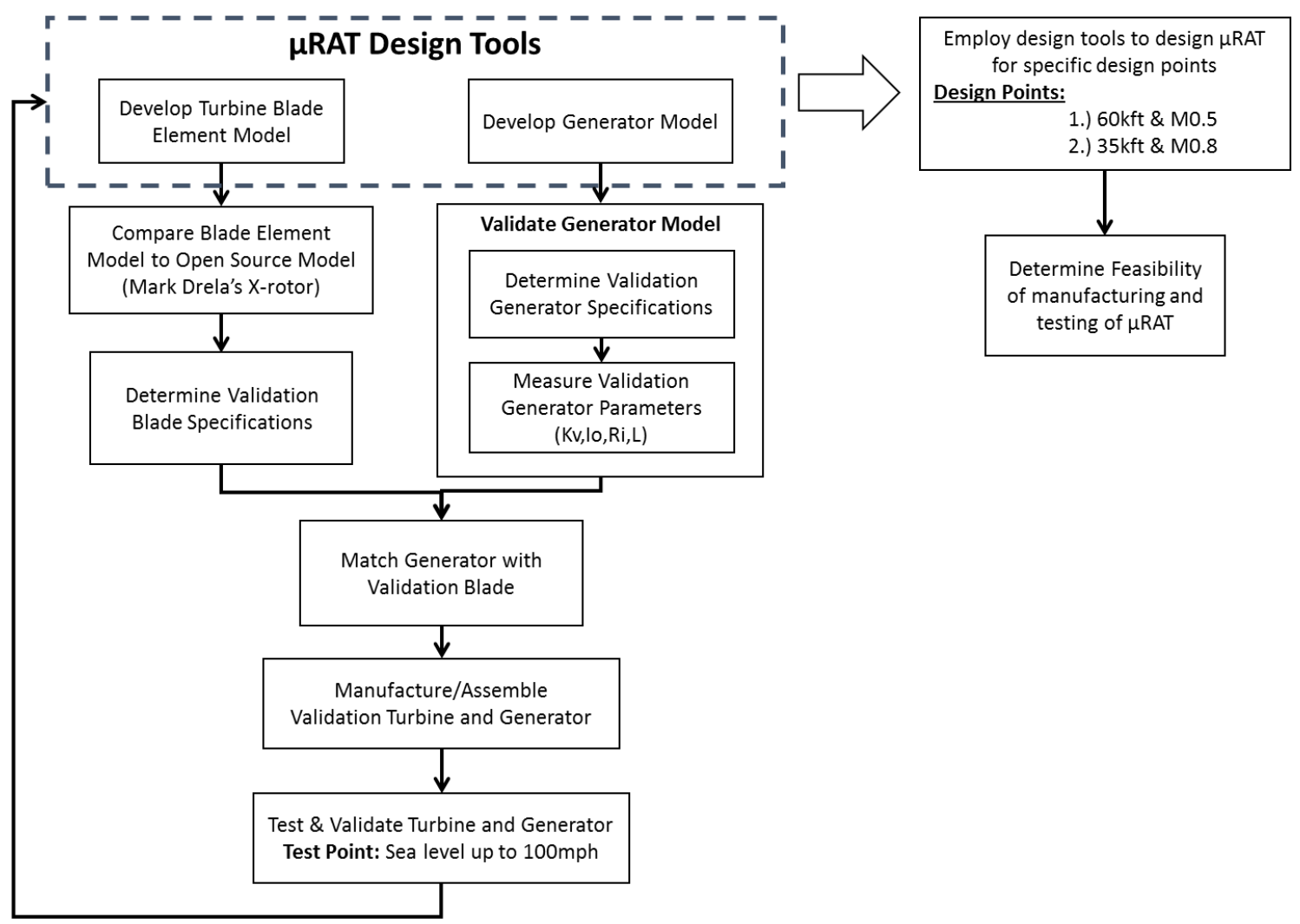

Figure 14. Micro-RAT Design Task Chart 


\section{GENERATOR MODEL}

A generator model was developed to predict generator shaft ("brake") power and electrical power as a function of electrical load and shaft speed. In this thesis "shaft" and "brake" are used interchangeably. The model was to be applicable to small BLDC machines operated as a generator, optionally including rectification of the generator's 3phase output. A highly detailed electrical model was not desired-rather, generator performance was to be modeled, if possible, using only a few specifications that are typically provided by the manufacturer. Those specifications, generally aimed at motor applications, include the machine's Internal Resistance $\left(R_{i}\right)$, No-Load Current $\left(I_{o}\right)$, Torque Constant $\left(K_{T}\right)$, Speed Constant $\left(K_{V}\right)$, Inductance $(\mathrm{L})$ and Cogging torque $\left(C_{T}\right)$. The following subsections expand on these parameters and first apply them to a motoring application before detailing the generator model. Although a generator is our main focus, a motor model is first introduced so that once the generator model is detailed, differences in how BLDC machine parameters are applied in motoring performance predictions can be distinguished in how they are applied in the generating application. Additionally, a motor model is required during motored generator model evaluation test to predict generator input torque as the motor applies it. From the established motor model, modifications are made to accommodate generator operation, as well as AC to DC power rectification, if desired. The established generator model is then evaluated through motored generator testing. 


\subsection{Generator Performance Parameters}

\subsubsection{Internal Resistance and Impedance}

The Internal Resistance $\left(R_{i}\right)$, also known as the terminal resistance represents the opposition to the flow of current through a conductor and directly contributes to power losses in an electrical machine. Lower resistance electrical machines have thicker wire with fewer turns and are rated at lower voltages and higher current [14]. Low resistance machines are favorable when operating at higher speeds and low torque. Higher resistance machines have thinner wire with many turns and are rated at higher voltages and lower currents. These machines are more applicable when higher torque at lower

speeds are needed. For DC machines resistance is governed by Ohm's Law $\left(R=\frac{V}{I}\right)$, which states that the current between two points in a conductor is directly proportional to the voltage across those two points, and inversely proportional to the resistance between those same two points. However, for an AC circuit the concept of resistance must be extended to include both magnitude and phase. Impedance $(Z)$ extends the concept of resistance as it is expressed in complex form below (Equation (2) [15] [14].

$$
Z=R+j X
$$

The imaginary portion of impedance is known as the reactance $(j X)$. Reactance opposes the change of electric voltage or current due to the electric and magnetic fields of the inductor. In a DC circuit, resistance is considered equal to impedance with a zero phase angle. Resistance in an AC circuit changes with respect to time and is derived by first solving for voltage and current with respect to time. Below we see equations for induced voltage and current (Equations 3-4). 


$$
\begin{gathered}
V_{\text {ind }}=L \frac{d(I)}{d t} \\
I_{\text {ind }}=I_{\text {max }} \cos (\omega t)
\end{gathered}
$$

Applying the time derivative to current, we are able to solve for induced voltage through Equations $5-6$.

$$
\begin{gathered}
V_{\text {ind }}=L \frac{d}{d t}\left(I_{\text {max }} \cos (\omega t)\right) \longrightarrow V_{\text {ind }}=-\omega L I_{\text {max }} \sin (\omega t) \\
V_{\text {ind }}=\omega L I_{\text {max }} \cos (\omega t+90)
\end{gathered}
$$

Now peak voltage can be solved for by setting $\cos (\omega t+90)$ equal to one, this gives:

$$
\begin{gathered}
V_{\max }=\omega L I_{\max } \\
\frac{V_{\max }}{I_{\max }}=\omega L
\end{gathered}
$$

Similar to resistance in a DC circuit, reactance is the ratio of voltage to current and is also measured in ohms.

$$
X_{\text {ind }}=\frac{V_{\text {max }}}{I_{\max }} \longrightarrow X_{\text {ind }}=\omega L
$$

Equation 9 can be alternatively written as:

$$
X_{\text {ind }}=(2 \pi f) L
$$

Reactance as shown in Equation 10 varies linearly with frequency and is applied in the generator circuit analysis [15]. 


\subsubsection{No Load Current}

No-load current corresponds to the friction and windage losses in an electric machine. The frictional losses associated with no-load current come from the friction between the shaft and bearings, and windage loss that is generated by friction between air and the rotor. This friction torque is composed of two components: a constant and a speed dependent component. However due to the frictional torque being fairly low compared to the machines rated torque, the speed dependent component is often neglected for practical purposes [14]. In applying this parameter to a performance model for a BLDC machine it is important to understand that no-load current is not an actual current instead it represents the amount of current that would be required to turn the un-loaded shaft of the machine. This means that for a BLDC motor no-load current will be equivalent to the current required at the input in order for the shaft to rotate when it is experiencing no resistive torque. For a BLDC motor operated as a generator, the no-load parameter is equivalent to how much current would be generated with the input torque necessary to rotate the shaft with no electrical load. However it is understood that current cannot be generated with no load at the generator terminals. Because of this, no-load current can only be measured in the motoring application at the input. For the generator this value is

still applied by subtracting the no-load current from the gross generated current in order to account for friction and windage losses at the shaft. 


\subsubsection{Torque Constant}

The torque constant is in units of Nm/amp and defines the proportional relationship between current and torque. The torque produced in a motor is defined by the arrangement and density of the windings, distance from the rotational axis, magnetic field strength, and amount of current. Because all of these parameters with the exception of current are locked into the design once the motor/generator has been manufactured, all of their effects are summed up in one value known as the torque constant [14].

\subsubsection{Speed Constant}

The speed constant is in units of rpm per volt and describes how much voltage is induced in the winding that is rotating in the magnetic field. The speed constant is inversely related to the torque constant as it also depends on the same design factors [14].

\subsubsection{Cogging Torque}

In addition to current induced torque, permanent magnet electrical machines are also known for developing cogging torque, which is due to the interaction between permanent magnets and teeth in the rotor or stator. Cogging torque is evident by the tendency of the rotor to line itself to the stator slots. Speed ripples and pulsating torque are a result of cogging torque and does not contribute to the net effective torque. This torque is influenced by various design parameters such as pole/stator combinations, the geometry of the stator slots, the magnet arc, and the skew angle of the slots. Cogging torque varies with angular position and is instantaneously zero when the interpole axes lines up with the center of the stator teeth and slots. Cogging torque peaks occur when the 
interpole axes is in line with any slot edge. This behavior is captured in the plot of Figure 16, where cogging torque with varying angular position is plotted [16].

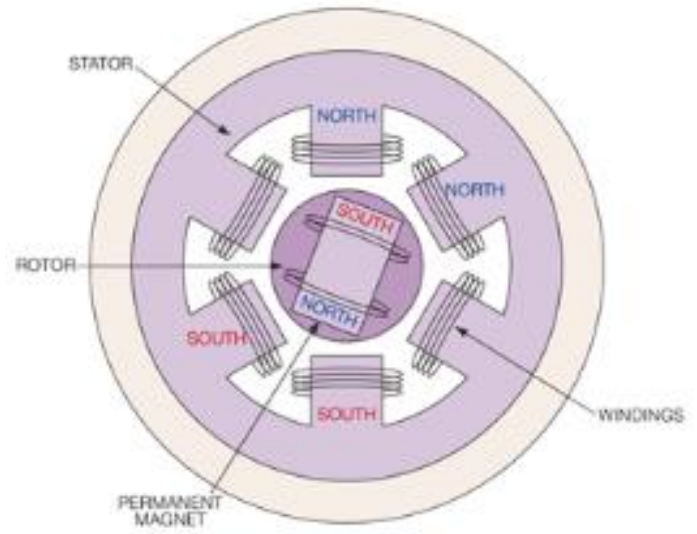

Figure 15. BLDC Motor/Generator Stator and Rotor [17]

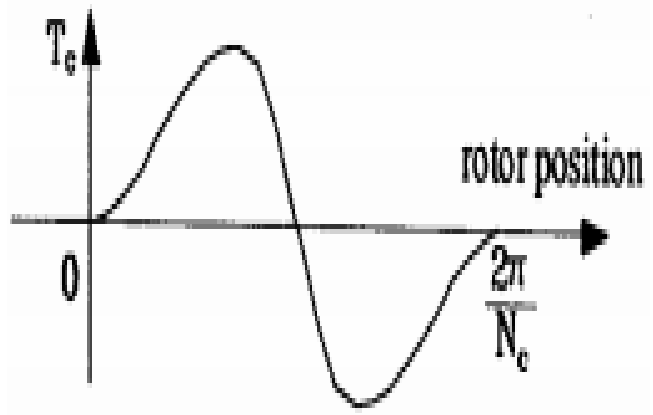

Figure 16. Cogging Torque at Different Rotor Positions [16]

Zhu and Howe [16] offer an analytical approach to predicting cogging torque. However, their approach involves knowing many geometrical design parameters that are not typically provided by the manufacturer. Because the goal in the motor/generator model is to use basic parameters provided by the manufacturer, the analytical approach was not implemented. Zhu and Howe's work [16] did suggest a factor $\mathrm{C}_{\mathrm{T}}$ that would aid in the selection of an electrical machine with less cogging torque. The "Goodness Factor" $\mathrm{C}_{\mathrm{T}}$ only takes into account the number of pole and stator combinations [16].

$$
C_{T}=\frac{2 p Q_{S}}{N_{C}}
$$

In Equation 11, p, is the number of pole pairs, $Q_{S}$, is the slot number and $N_{C}$, is the lowest common multiple between slot number and number of poles. It has been found that a larger factor corresponds to higher cogging torque values [16]. 
In selecting a motor/generator for the $\mu \mathrm{RAT}$ it is highly desirable to have no cogging. This is mainly due to higher cut-in torque requirements and torque ripples that also cause distortion in the output power wave. Although distortion is not of major concern for heating or for battery charging, a distorted output power waveform would result in higher inaccuracies between observed and calculated terminal power during model evaluation test. This is because a sine wave is used to approximate the output power wave, any distortion in the actual power wave would increase error; this is undesirable for generator model evaluation. In acquiring a generator with very low cogging, not only was the "goodness" factor [16] of Equation 11 considered but also the off-the-shelf motor was purchased from a high quality motor manufacturer that takes advantage of the various parameters that can be manipulated to affect cogging torque to achieve very low cogging torque.

\subsection{Motor Model}

A motor model for BLDC machines was established in order to accurately predict motor performance at specific operating points using only basic manufacturer provided specifications [8]. This model is used in predicting brake power and torque as a function of input power and speed for the prime mover during motored generator evaluation test. Similar to the generator model, input parameters such as Internal Resistance $\left(\mathrm{R}_{\mathrm{i}}\right)$, NoLoad Current $\left(\mathrm{I}_{\mathrm{o}}\right)$, and the Speed Constant $\left(\mathrm{K}_{\mathrm{V}}\right)$ are considered. Figure 17 illustrates the DC motor electro-mechanical schematic from which equations characterizing performance are developed. Note that the BLDC machines that are being considered all have 3 phases; the schematic shown in Figure 3 represents phase-to-phase which is 
essentially two phases or two out of the three motor lead wires. Starting from the input power on the right side of the diagram, DC power is provided at the motor terminals.

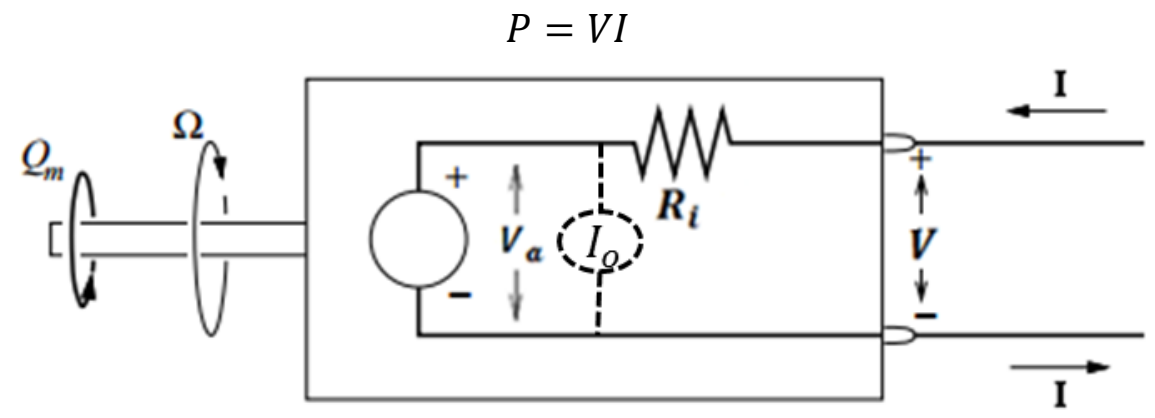

Figure 17. Prime Mover DC Motor Model Electrical schematic [8]

Armature voltage $\left(V_{a}\right)$ and current $(I)$ can be solved by applying no-load current $\left(I_{o}\right)$ and motor internal resistance losses to the input power. Note that the no-load current is unconventionally shown as bypassing the armature.

$$
\begin{gathered}
I=I_{a}+I_{o} \\
V=V_{a}+I R_{i}
\end{gathered}
$$

Armature voltage can alternatively be calculated with the velocity constant where the motor RPM is known

$$
V_{a}=\frac{R P M}{K_{v}}
$$

Output shaft torque is then calculated by first solving for the armature power and dividing by the angular velocity $(\omega)$ in units of $\mathrm{rad} / \mathrm{s}$.

$$
\begin{gathered}
\mathrm{P}=I \mathrm{~V} \text { and } P_{\text {brake }}=I_{a} V_{a} \\
Q_{m}=\frac{P_{\text {brake }}}{\omega}
\end{gathered}
$$

Output brake power over input power at the motor terminals gives the motor efficiency. 


$$
\eta_{m}=\frac{P_{\text {brake }}}{P}
$$

Now the motor model equations can be used to develop torque, power, and efficiency curves. Note that this model is a function of input voltage and speed - a different performance curve is generated for different voltages. Inputs to the model include input voltage, speed, and motor performance parameters. The model will output brake torque, power, and efficiency at varying speeds. Motor specifications for the Maxon brushless DC motor [14] are displayed in Figure 18, along with performance parameters, the manufacturer also provides motor performance at a nominal voltage. To evaluate the motor model; motor no-load current, speed constant and internal resistance values at a nominal voltage of $24 \mathrm{~V}$, as specified was applied to the model.

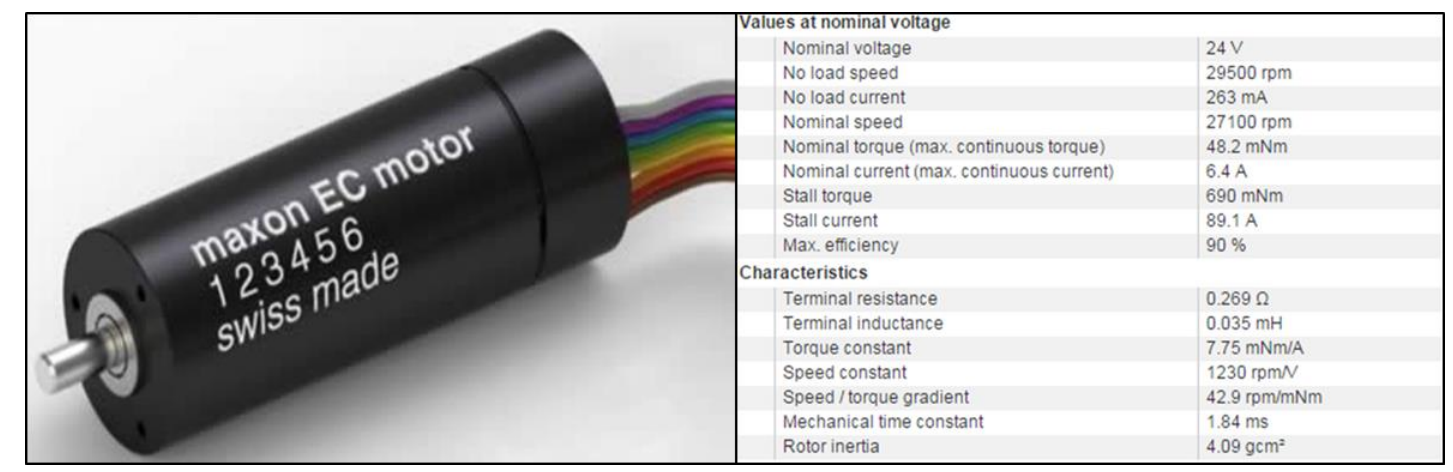

Figure 18. Maxon Motor Manufacturer Performance Parameters for BLDC Motor \#386677 [14] [18]

Predicted brake torque and power curves shown in Figure 19 accurately predict no-load speed to be approximately $29,500 \mathrm{rpm}$ for nominal voltage of $24 \mathrm{~V}$, as specified in motor performance data in Figure 18. 


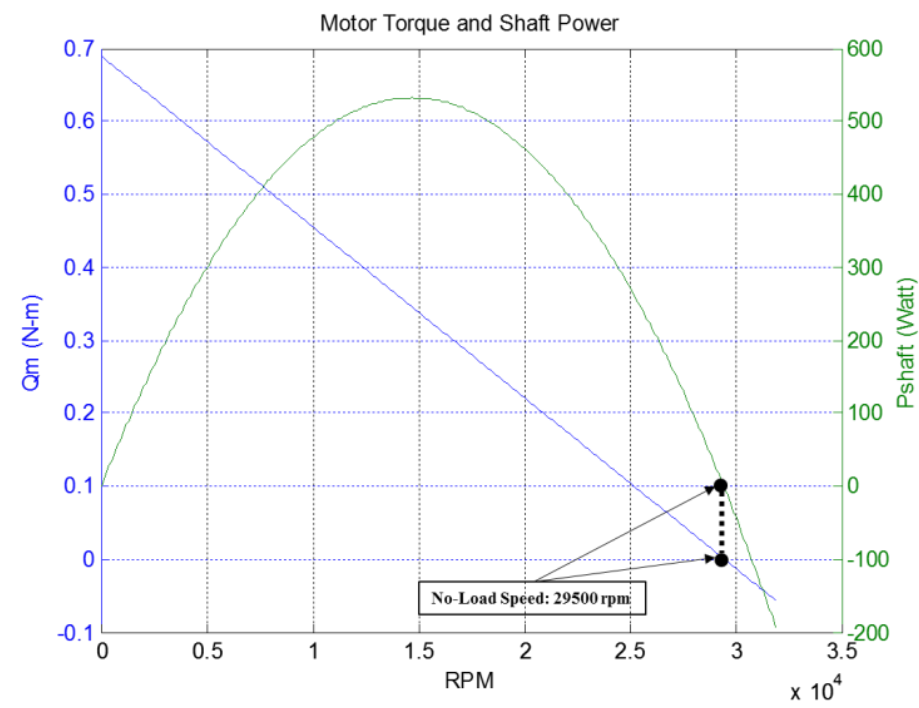

\section{Figure 19. Motor Model Predicted Torque and Brake Power}

The predicted motor efficiency curve shown in Figure 20 is also able to accurately predict maximum efficiency to be approximately $90 \%(89.44 \%)$ for the published nominal voltage of $24 \mathrm{~V}$.

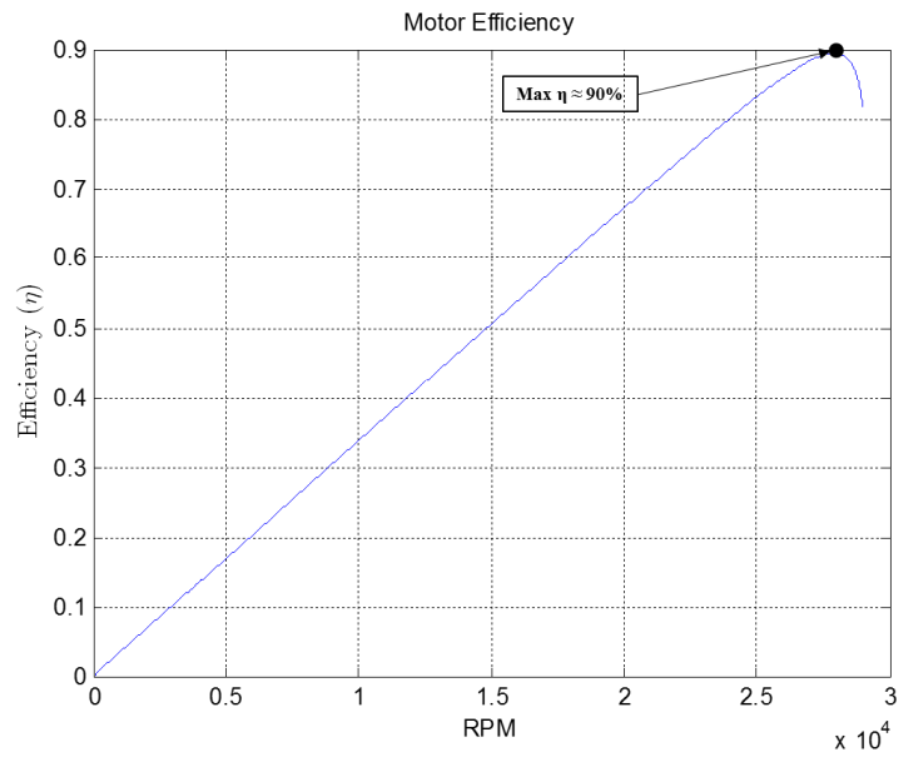

Figure 20. Motor Model Predicted Efficiency 
An efficiency contour chart was also created for different input power values at varying speeds as seen below in Figure 21. This is useful as a quick look-up chart to estimate efficiency at a specific power input and speed.

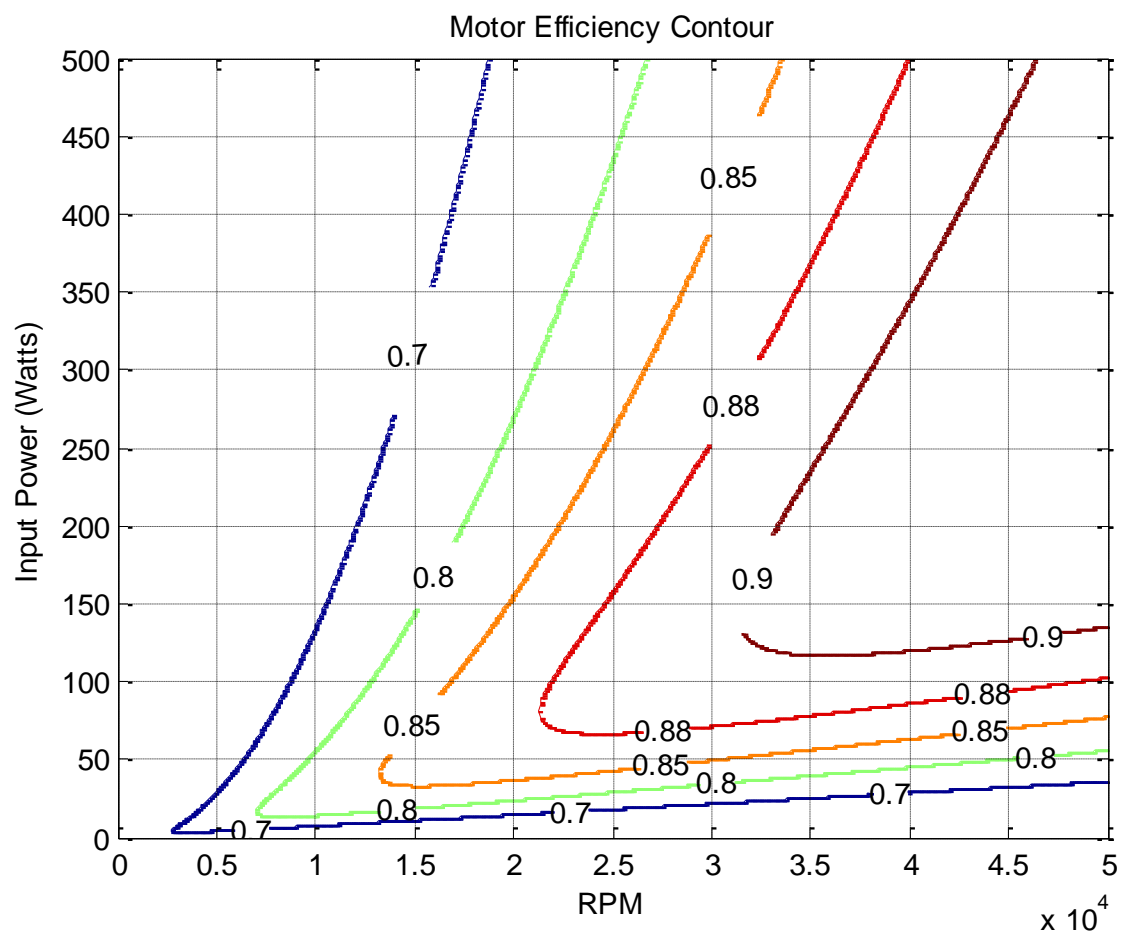

Figure 21. Motor Model Efficiency Contour Chart

\subsection{Generator Electrical Model}

The electrical diagram of the generator model is illustrated in Figure 22. Note that the BLDC generators that are being considered, all generate 3 phase power; the schematic shown in Figure 22 only represents phase-to-phase or two of the three phases. Starting from the shaft power as the input on the left side of the diagram, the gross or "ideal" power delivered at the shaft experiences several losses throughout the generator. The power losses in the generator consist of the following: windage and friction losses which are accounted for in the no-load current $\left(\mathrm{I}_{\mathrm{O}}\right)$ parameter, motor winding resistance, also 
known as the internal resistance, $\left(\mathrm{R}_{\mathrm{i}}\right)$, and inductance reactance losses which are approximated by multiplying inductance (L) by $2 \pi$ times the frequency (f) of the generator. Additionally we have a load $\left(\mathrm{R}_{\mathrm{L}}\right)$, at the terminal that also is accounted for in the model. At this point power rectification is not yet considered. Power rectification is not necessary for heating the BLDS. However rectifying would be required if power generated were to provide power to augment charge, or replace batteries. Power rectification and how it is applied to the model will be further discussed in Section 2.4.

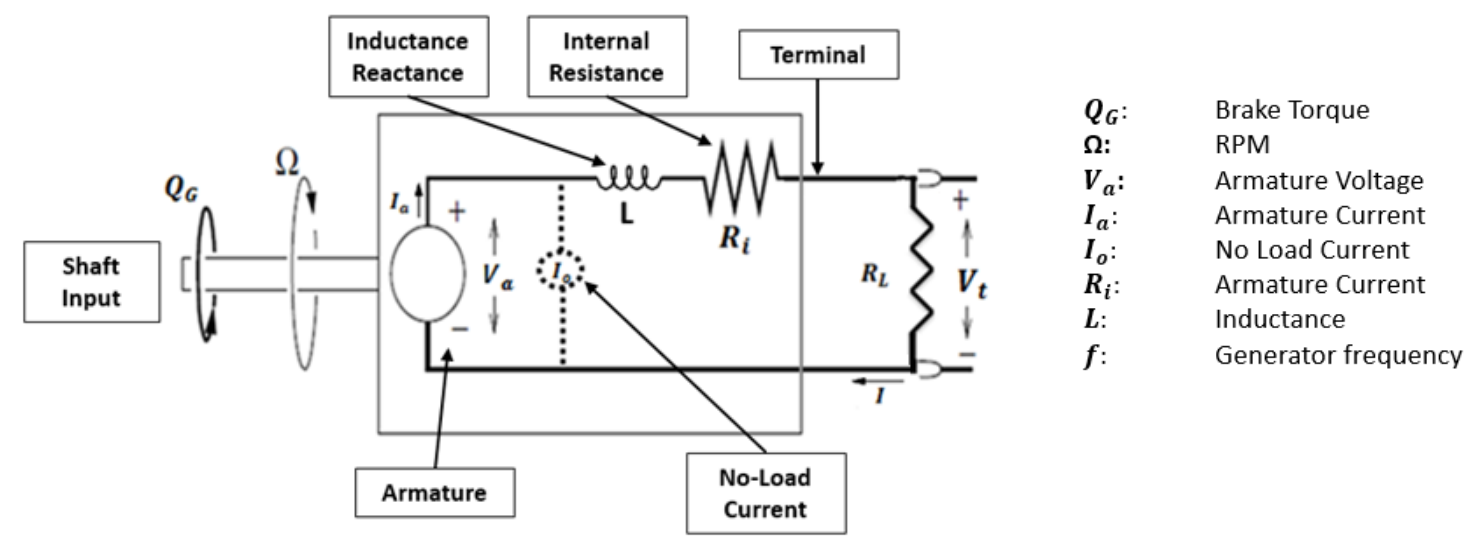

Figure 22. Generator Model Electrical schematic [8]

The following Equations 19-26 are the generator model equations derived from the generator circuit diagram shown in Figure 22. This model is used in predicting generator brake and terminal power as a function of electrical load and speed. Beginning the generator performance analysis at the armature, with the model input of speed, armature voltage is calculated in Equation 19.

$$
V_{a}=\frac{R P M}{K_{v}}
$$




$$
I_{a}=\frac{P_{\text {brake }}}{V_{a}}
$$

We then calculate the circuit current with the following equation. Here the armature voltage is divided by the total resistance. Note that the total resistance includes resistance at the load, generator internal resistance and inductance reactance.

$$
\mathrm{I}=\frac{V_{a}}{R_{L}+R_{i}+X_{\text {ind }}}
$$

Terminal power can then be calculated using Equation 22

$$
P=V_{t} I
$$

In order to estimate brake torque and power, armature current is solved for using Equation 23. Note that the armature current is the ideal current without accounting for the friction and windage losses that are represented by the no-load current; Equation 23 applies these losses in order to solve for the circuit current.

$$
I=I_{a}-I_{o}
$$

Rearranging Equation 24, armature current is solved.

$$
I_{a}=\mathrm{I}+I_{o}
$$

With armature current known brake power is solved with Equation 20 and torque can be solved for with Equation 25.

$$
Q_{G}=\frac{P_{\text {brake }}}{\omega}
$$


Terminal electrical power over input brake power gives the generator efficiency.

$$
\eta_{m}=\frac{P}{P_{\text {brake }}}
$$

Now the generator model equations can be used to develop torque, power, and efficiency curves as shown in Figure 23 and Figure 24.Note that this model is a function of electrical load and speed - a different performance curve is generated for different loads at the terminal. For the plots shown in Figure 23 and Figure 24, the model was run at an electrical load of $5 \mathrm{Ohms}$ for speeds up to 45,000 rpm. The same performance parameters for the motor used in the motor model are applied- these manufacturer specifications are displayed in Figure 18.

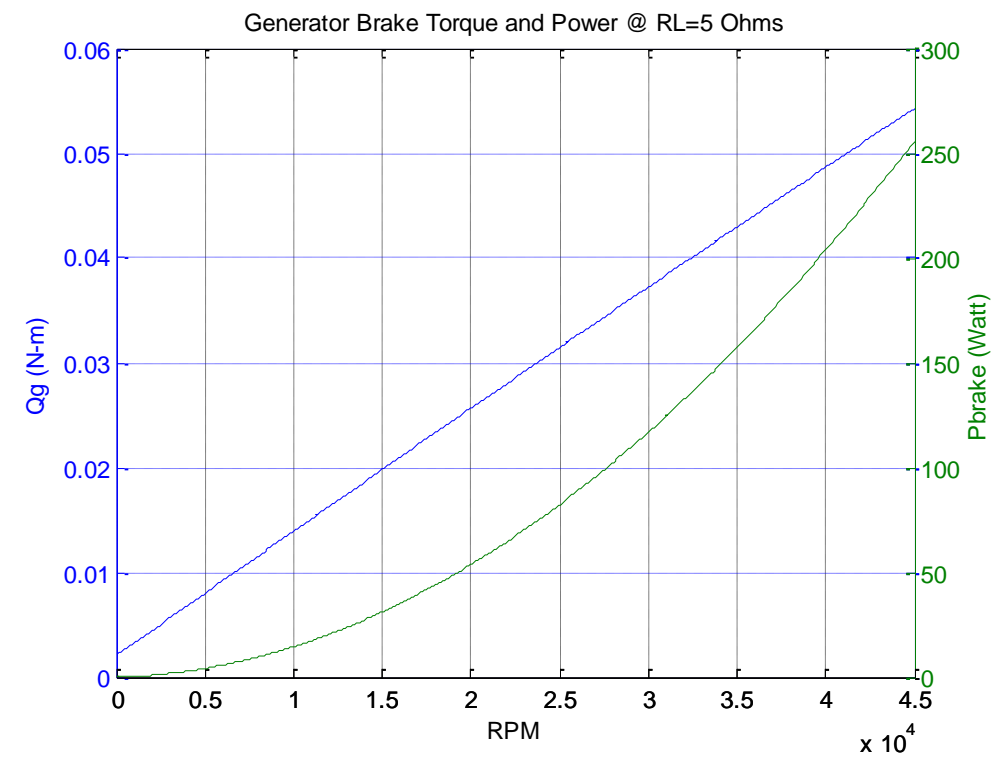

Figure 23. Generator Model Predicted Torque and Shaft Power at 5 Ohms 


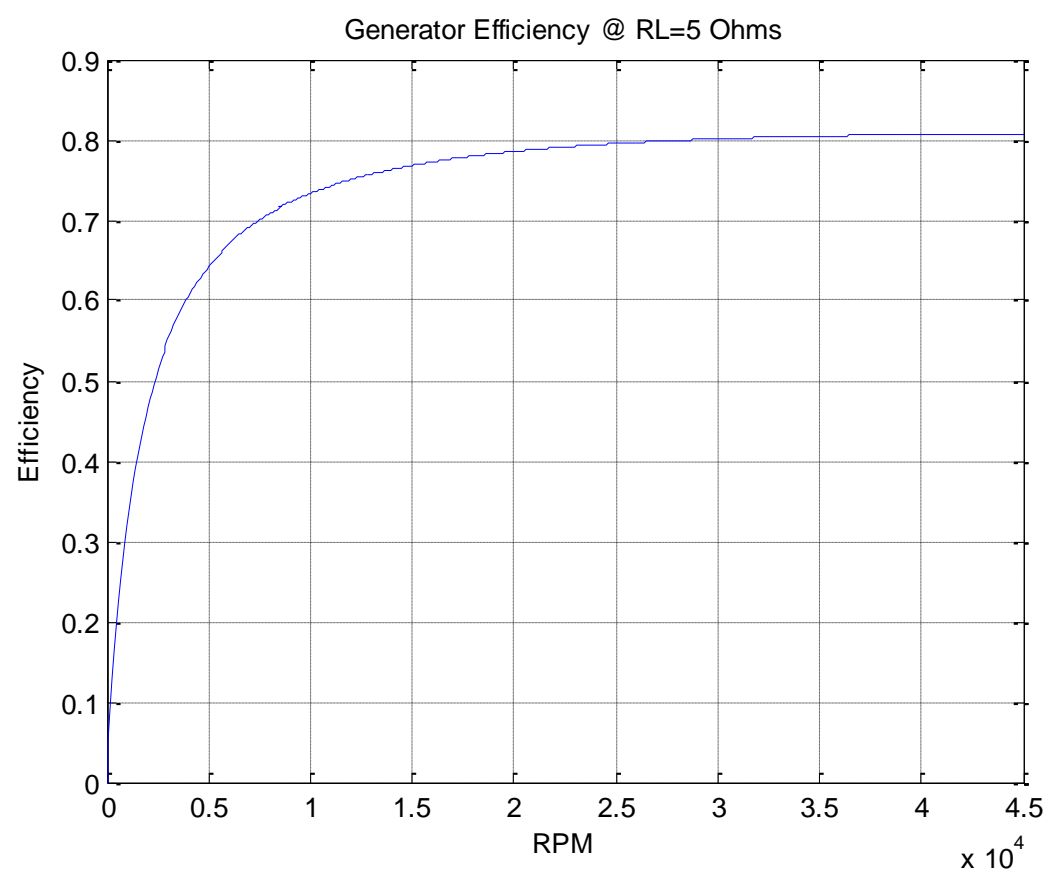

Figure 24.Generator Model Predicted Efficiency at $5 \mathrm{Ohms}$

Now for the case where brake torque and power are known and electrical load is unknown, the model is run for different electrical loads and plotted as shown in Figure 25. Using the charts of Figure 25, electrical load can be determined for a known brake torque and speed. Looking at the charts of Figure 25, it might seem counter-intuitive that low torque is predicted at a higher resistance however, it is important to understand that high resistance means lower electrical load. For example, as resistance goes up less current flows through the circuit; as resistance approaches infinity, the circuit is essentially open. Considering this, higher torques are observed at lower resistance and lower torque at higher resistance. 

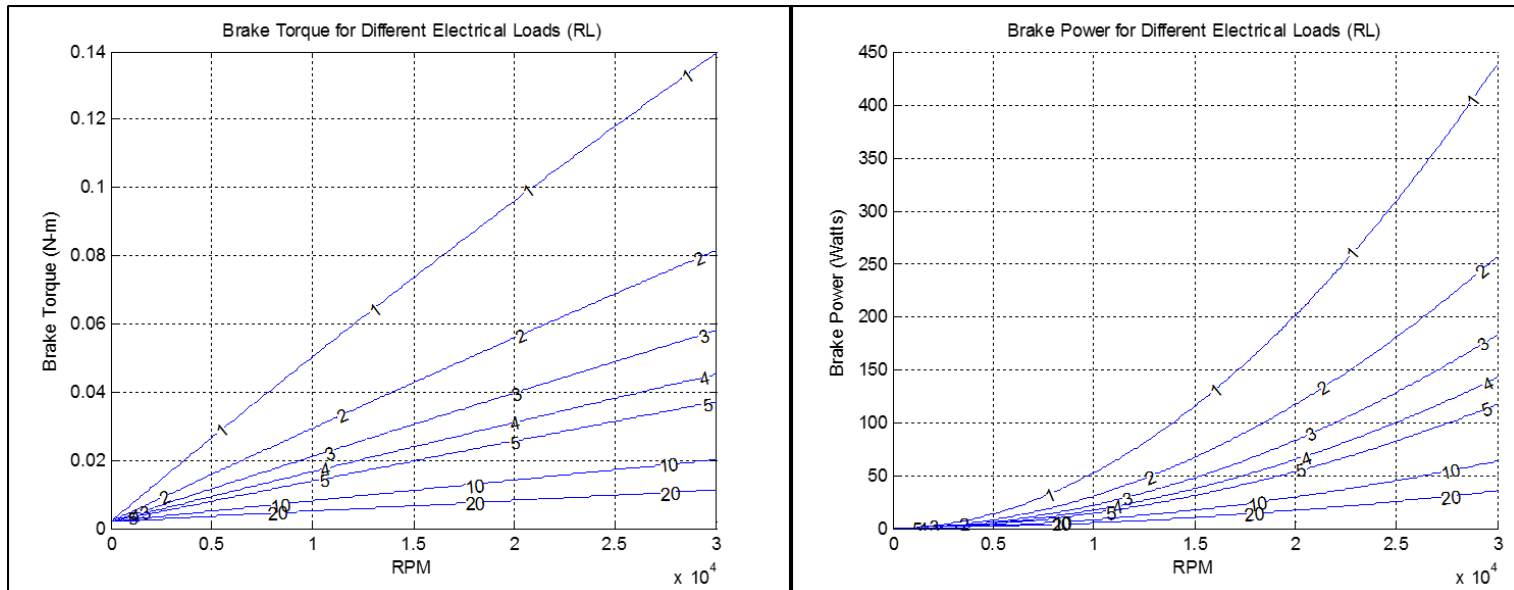

Figure 25. Brake Torque and Power for different Electrical Loads

Efficiency contour charts generated by the model as a function of brake power and speed, shown in Figure 26, can then be used to estimate generator efficiency.

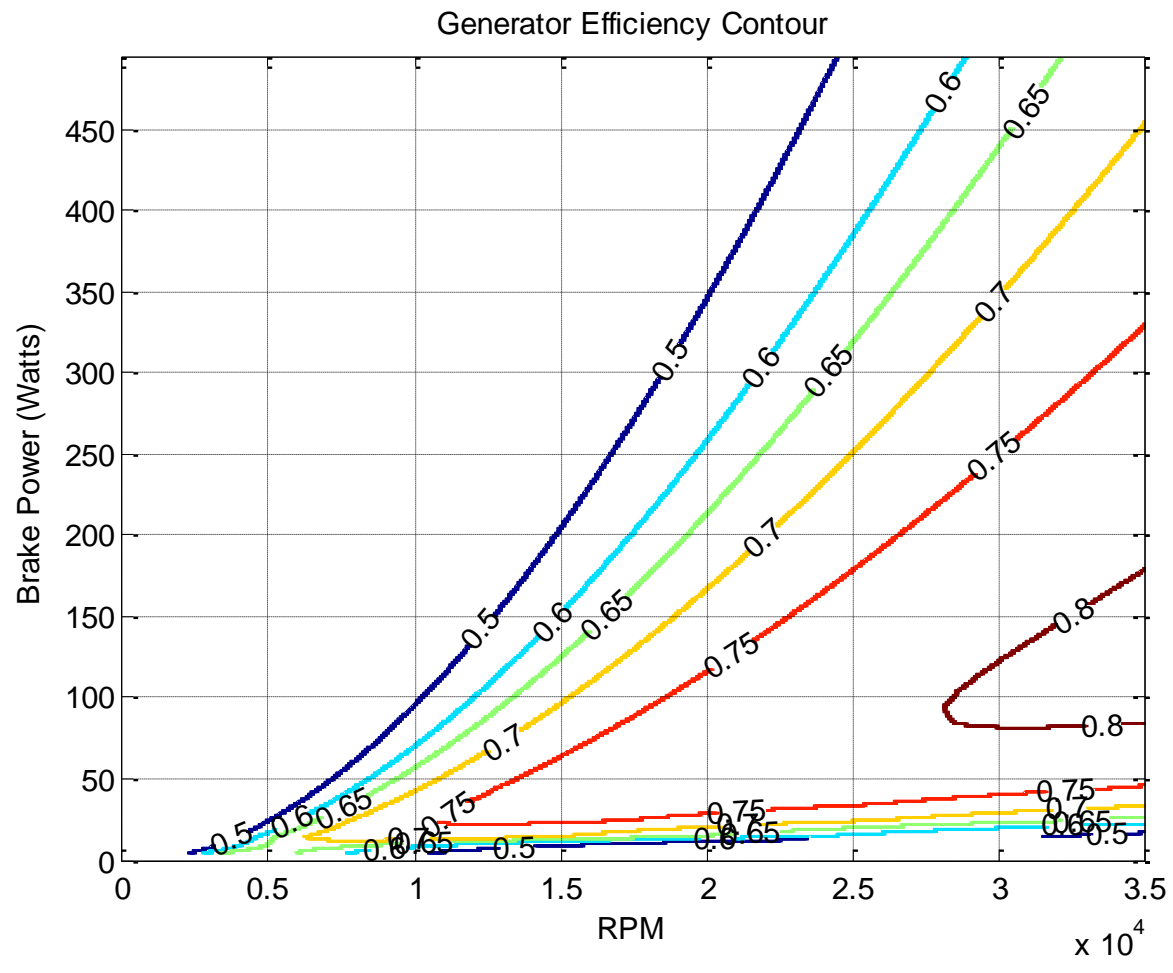

Figure 26. Generator Model Efficiency Contour Chart 


\subsection{Power Rectification}

For our application of powering a heating element for the BLDS it may be desired to convert AC current to DC current. This section will now focus on power rectification and how it is applied in the generator model. Converting AC to DC is primarily done through the use of diodes which are commonly integrated into rectifier circuits. A diode is an electrical device that allows current flow through one direction and blocks current in the opposite direction. The diode is analogous to a mechanical check valve. Typically diodes are composed of semiconductors with a nonlinear current - voltage relationship, as shown in Figure 27.

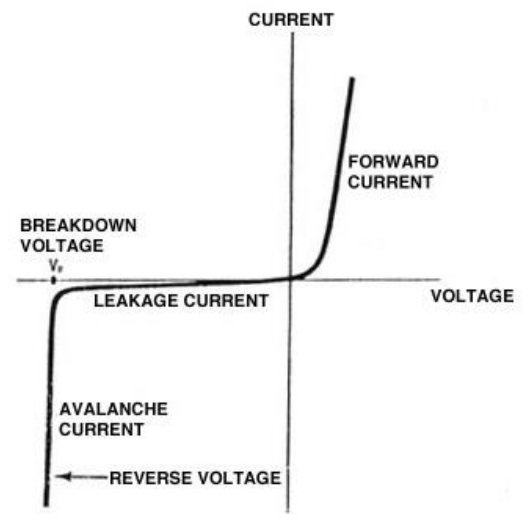

Figure 27. Diode Current - Voltage relationship [19]

As seen in Figure 27 above, semiconductor diodes conduct only when a threshold voltage or forward voltage has been achieved in the diodes forward direction, also known as "forward bias". At voltages lower than the threshold voltage, the diode circuit is considered open. Whenever we have negative voltage the diode is considered "negative bias" and acts to block current in the opposite direction with exception of a small leakage current on the order of milliamps. A negative biased diode will block current until a 
breakdown voltage has been achieved, at which point current will dramatically increase in the negative direction.

Diodes are combined to form several types of rectifiers such as half-wave, fullwave, single-phase and multi-phase. The half-wave rectifier only lets half of the AC wave through while blocking the other half. Through the integration of 4 diodes the fullwave rectifier is able to allow the full $\mathrm{AC}$ wave through by essentially flipping the negative half $\mathrm{AC}$ wave to positive on the $\mathrm{DC}$ side.

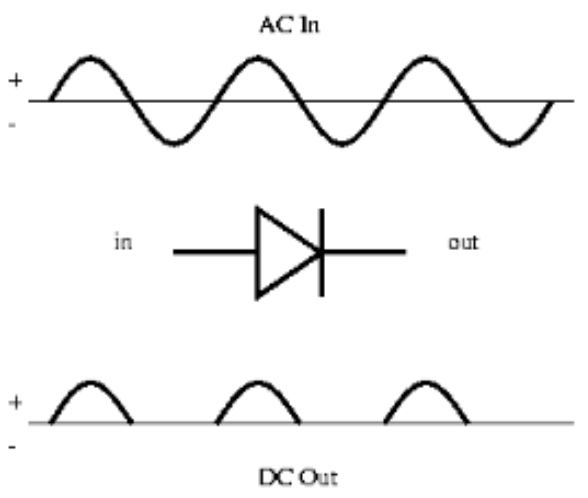

Figure 28. Half Wave Rectification [20]

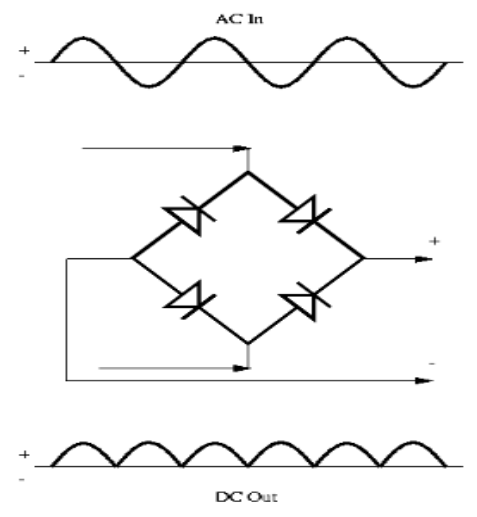

Figure 29. Full Wave Rectification [20]

Since the brushless generator produces 3-phase power, a 3-phase full wave rectifier is used to rectify its output. A 3-phase rectifier is effectively 3 single full wave rectifiers put together. Referencing Figure 30, it can be seen that the 3-phase rectifier is composed of 6 diodes with each diode having a forward voltage drop of approximately 1.2 volts (dependent on current). 

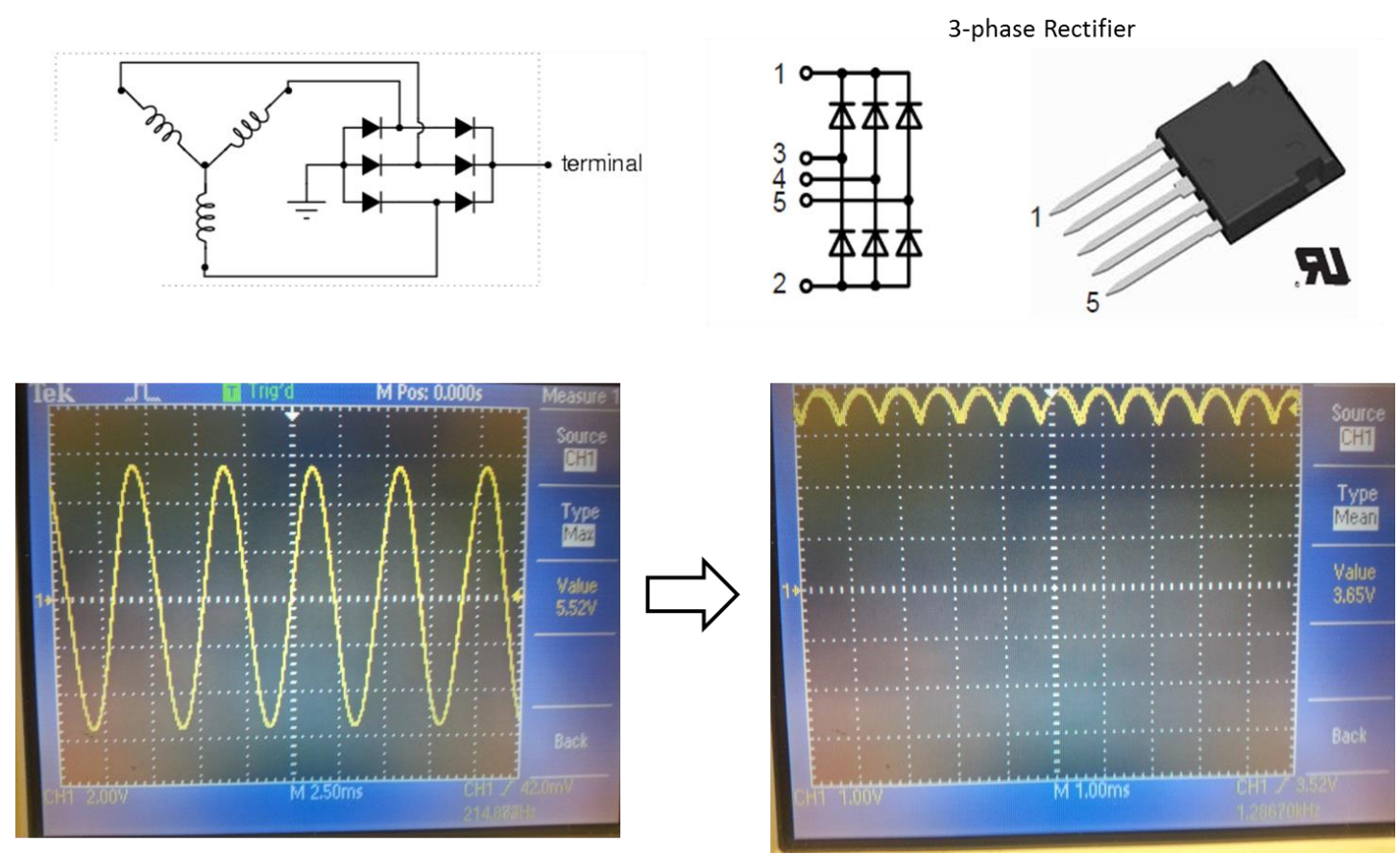

Figure 30. Voltage rectification using 3-phase bridge rectifier [21]

Figure 31 below displays the current-voltage relationship for the rectifiers used in model evaluation testing (IXYS FUO 22 Three Phase Rectifier Bridge [21]). Using this chart the forward voltage for each diode may be estimated based on estimated current values. The diode's forward voltage can then be applied in the generator model equation, Equation 21

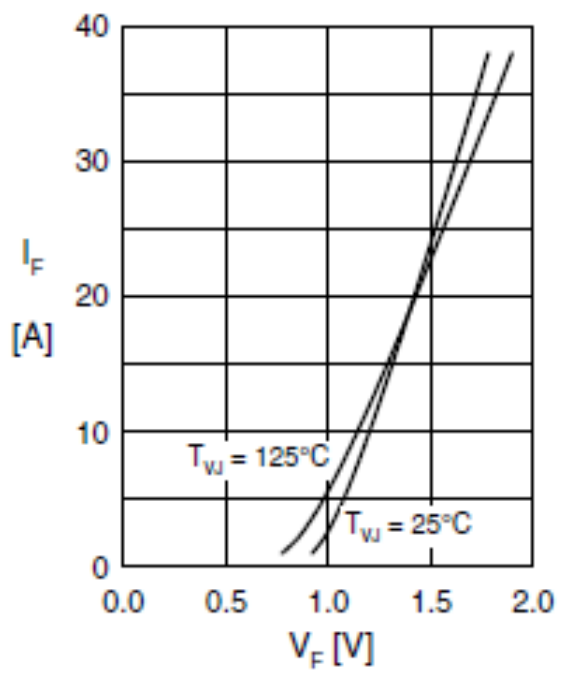

Figure 31. Current - Voltage per Diode in IXYS FUO 22 Three Phase Rectifier Bridge [21] 
Because only 1 diode is "on" per phase, the 3-phase rectifier is represented in Figure 8 with only 2 diodes present in the phase-to-phase representation (forward \& backward bias) [9].

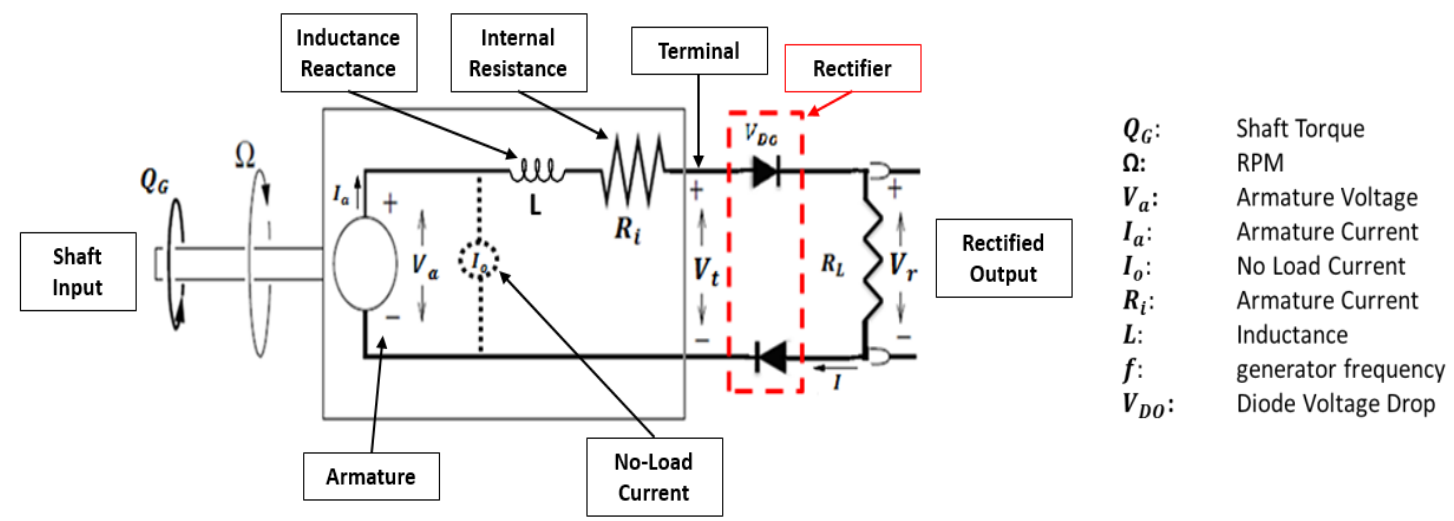

Figure 32. Generator Model Electrical Schematic [8] [9]

In going from $\mathrm{AC}$ to $\mathrm{DC}$ it is important to consider the relationship between peak voltage $\left(V_{\text {peak }}\right)$, rms voltage $\left(V_{r m s}\right)$, and average voltage $\left(V_{\text {average }}\right)$. Using a (Fluke) multimeter, measurements are made in rms for AC and average for DC. When applying generator Equations 19- 26 it is necessary to convert to the appropriate form. Equation 27 describes the relation between $V_{r m s}$ and $V_{\text {peak }}$ for a single phase AC signal. Equation 28 describes the relation between $V_{\text {peak }}$ and $V_{\text {average }}$ and applies to the rectified DC signal when using a 3-phase rectifier.

$$
\begin{gathered}
V_{r m s}=\frac{V_{\text {peak }}}{\sqrt{2}} \\
V_{\text {average }}=\frac{3}{\Pi} V_{\text {peak }}
\end{gathered}
$$


Combining both Equations 27 and 28, we get Equation 29 which is the DC equivalent voltage when going from $\mathrm{AC}$ to $\mathrm{DC}$ when neglecting the voltage drop across the rectifier diodes [9].

$$
V_{D C}=V_{\text {average }}=\frac{3}{\Pi} \sqrt{2} V_{\text {rms }} \text { [9] }
$$

Now in applying rectifier losses we apply a simplified approach to diode circuit analysis where a diode is treated as voltage sources once diode threshold voltage is achieved. Diode internal resistance for this analysis is neglected. In applying the rectifier losses to the generator model, the circuit current equation is modified to include a voltage drop for two diodes per phase (Equation 30). For the BLDS heating application it's important to remember that the power losses at the rectifier are dissipated as heat and could be used as a heat source for the BLDS if located within the system.

$$
\mathrm{I}=\frac{V_{a}-2 V_{D O}}{R_{L}+R_{i}+X_{\text {ind }}}
$$

Now with rectifier losses accounted for, brake torque and power curves, shown in Figure 33 and Figure 34, are again generated at an electrical load of 5 Ohms for speeds up to $45,000 \mathrm{rpm}$. Note that at low speeds where the generated armature voltage is below rectifier threshold voltage, the circuit is considered open resulting in a constant torque proportional to the generator no-load current parameter. Comparing model results with and without rectifier losses applied, it can be seen that the differences are significant. For example, at 30,000 rpm, without rectifier losses, the model predicts the generator at $80 \%$ efficient; model results with rectifier losses applied predict an efficiency of $72.5 \%$. With a difference of $7.5 \%$ shift in efficiency, it is therefore recommended to include rectifier losses in the generator model 


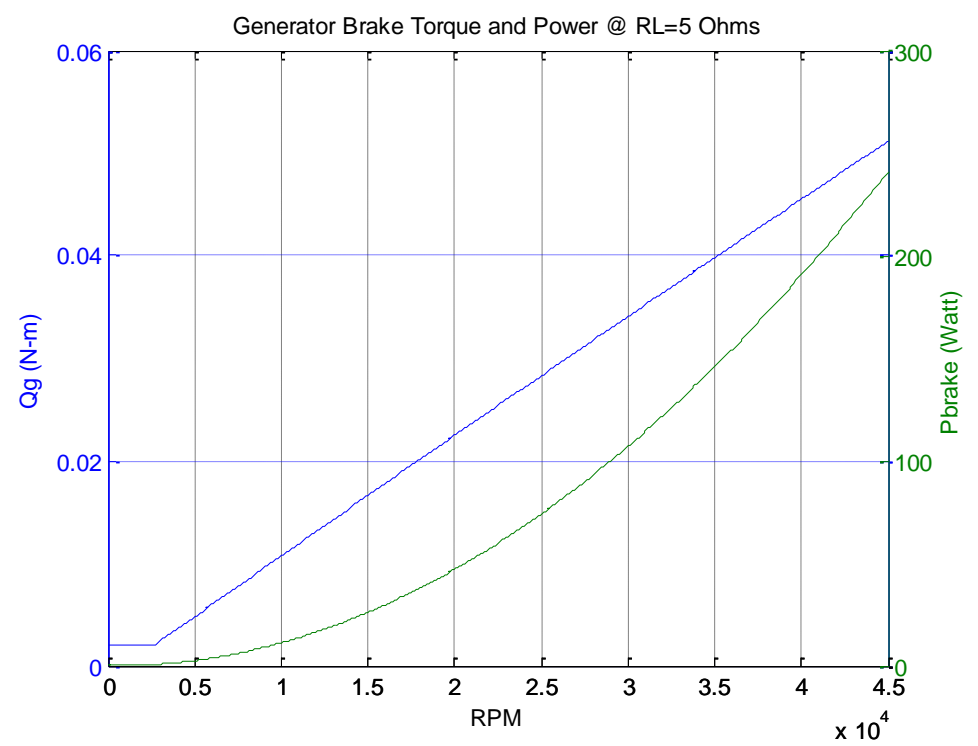

Figure 33. Generator Model Predicted Torque and Shaft Power at 5 Ohms (Rectified)

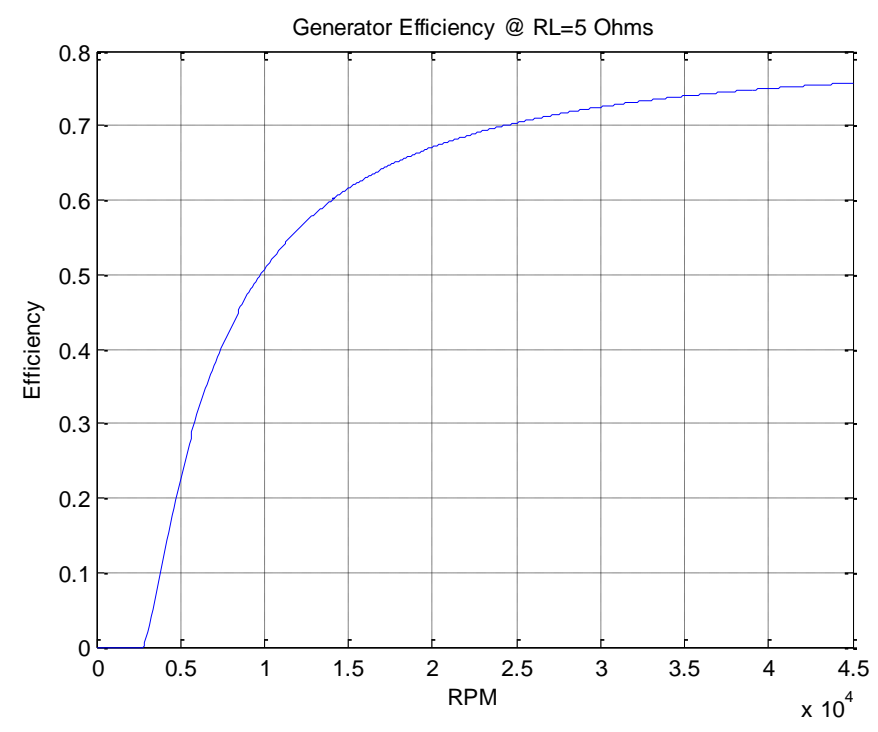

Figure 34. Generator Model Predicted Efficiency at 5 Ohms (Rectified)

\subsection{Generator/Motor Model Comparison}

The basic difference between the motor model and the generator model is in which direction current flows. For the motor, electrical power input is supplied at the terminals in order to excite magnetic fields that in turn produce brake torque at the shaft. Between 
the input power at the terminals and mechanical torque at the shaft, losses due to internal resistance and frictional torque are applied, resulting in a net mechanical torque. Alternatively for the generator, a gross input shaft power is supplied at the shaft to generate an electrical output at the generator terminals. Here due to friction and windage, mechanical power losses are already incurred before a net power is generated. The generated power then incurs further losses due to internal resistance and reactance. Because the power generated is $\mathrm{AC}$, additional resistance due to the change in current with phase angle known as reactance is experienced. Additionally, rectifier losses will be applied when converting AC to DC. The table below depicts the major differences in how terminal power is calculated between both models.

\section{Table 4. Motor/Generator Equation Comparison}

\begin{tabular}{|c|cc|}
\hline & Motor Model & Generator Model \\
\hline Terminal Current & $I=I_{a}+I_{o}$ & $I=I_{a}-I_{o}$ \\
\hline Terminal Voltage & $V=V_{a}+I R_{i}$ & $V=V_{a}-I R_{i}-I X_{\text {ind }}-V_{\text {rectifier }}$ \\
\hline Armature Current & & $I_{a}=\frac{P_{\text {brake }}}{V_{a}}$ \\
\hline Armature Voltage & $V_{a}=\frac{R P M}{K_{v}}$ \\
\hline Shaft Torque & $Q_{G}=\frac{P_{\text {brake }}}{\omega}$ \\
\hline Shaft Power & & $I_{a}=\frac{P_{\text {brake }}}{V_{a}}$ \\
\hline Efficiency & $\eta_{\mathrm{m}}=\frac{\mathrm{P}_{\text {shaft }}}{\mathrm{P}}$ & $\eta_{\mathrm{m}}=\frac{\mathrm{P}}{\mathrm{P}_{\text {shaft }}}$ \\
\hline
\end{tabular}




\subsection{Generator Model Evaluation (Validation) Testing}

Prior to conducting generator model validation testing, it is necessary to first verify generator manufacturer specifications such as $\mathrm{Kv}, \mathrm{Ri}$ and Io. In verifying the speed constant $(\mathrm{Kv})$, the test setup of Figure 35 was implemented. Here the Line-to-Line voltage and RPM are measured as the generator is rotated at different speeds by another motor. The voltage is measured at any two lead wires from the generator with no load electrical load at the terminals.

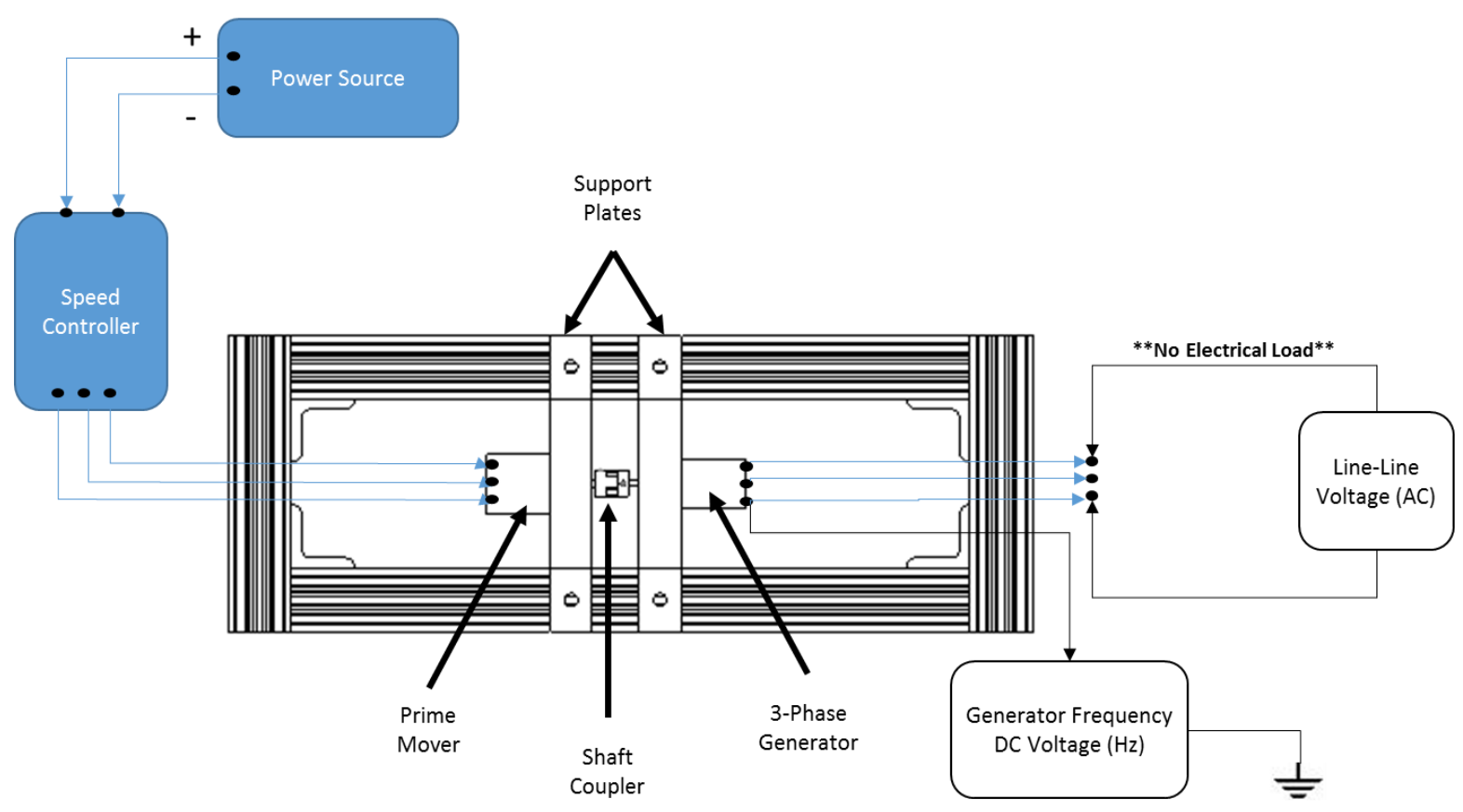

Figure 35. Generator Kv Test Schematic

Figure 36 shows an annotated photograph of the test schematic given in Figure 35. 


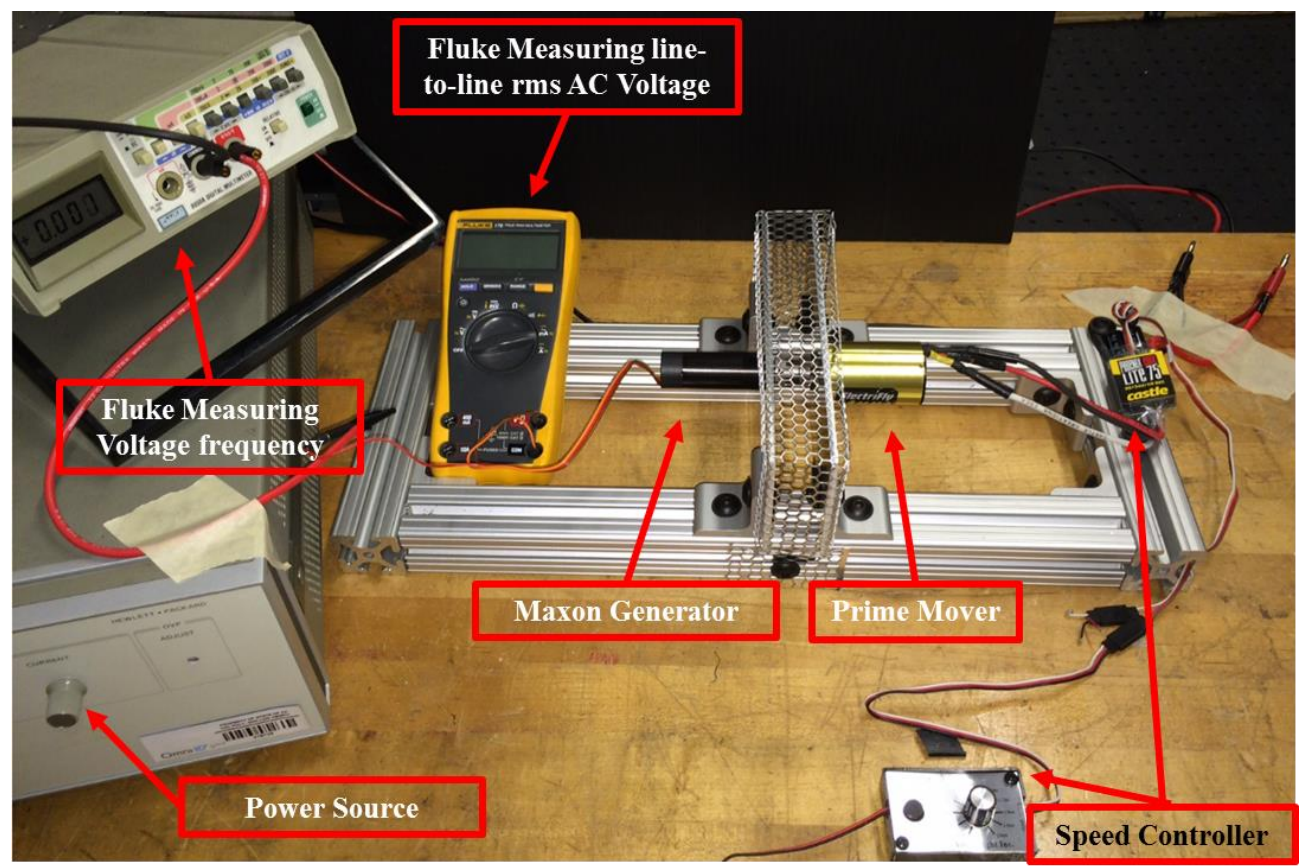

Figure 36. Generator Kv Test Setup

Because the Fluke multimeter reads voltage in true rms, Equations $31 \& 32$ are used to determine peak voltage. Peak voltage is desired in verifying $\mathrm{Kv}$ because the Line-toLine voltage represents the Armature voltage or back emf (shown in Figure 32) and it is from this peak voltage that losses are applied to, before converting to DC. RPM is measured by reading the frequency of one of the generator lead wires and converting to RPM using Equation 26. This method of reading the frequency from one of the generators lead wires is most accurate above 8,000 RPM. Measurements taken below this value tend to be noisy and not reliable due to poor signal amplitude at or below this speed. $\mathrm{Kv}$ is then calculated with Equation 32.

$$
\begin{gathered}
R P M=\frac{f * 2 * 60}{\# \text { poles }} \\
K_{V}=\frac{R P M}{V_{a}}
\end{gathered}
$$


Table 2 displays results for the Kv verification test for the generator at various speeds. The average measured $\mathrm{Kv}$ value for this generator was determined to be 1230 $\mathrm{RPM} /$ volts with a standard deviation of 1,288 RPM/volts. This value for $\mathrm{Kv}$ matched the manufacturer specified Kv of 1230 RPM/volts.

Table 5. Generator Kv Verification Results

\begin{tabular}{|c|c|c|c|c|c|c|c|}
\hline \multicolumn{7}{|c|}{ Prime Mover Input } & \multicolumn{7}{|c|}{ Generator } \\
\hline Volts & I (Amps) & $\mathbf{f ( H z )}$ & RPM & Voltage (RMS) & Voltage (peak) & Kv (peak) & Variance \\
\hline 5.01 & 2.8 & 181.9 & 10914 & 6.2 & 8.8 & 1238.7 & 74.2 \\
\hline 6.02 & 3.2 & 225.8 & 13548 & 7.8 & 11 & 1231.3 & 1.5 \\
\hline 7.01 & 3 & 265 & 15900 & 9.2 & 13 & 1226.1 & 16.5 \\
\hline 8.02 & 3 & 306.9 & 18414 & 10.6 & 15 & 1227.2 & 8.5 \\
\hline 9.06 & 3.1 & 349.1 & 20946 & 12.1 & 17 & 1229.1 & 1.0 \\
\hline 10.03 & 3.1 & 389.9 & 23394 & 13.5 & 19 & 1229 & 1.3 \\
\hline 11.01 & 3.2 & 430.9 & 25854 & 14.9 & 21 & 1229.4 & 0.5 \\
\hline
\end{tabular}

$$
K_{V}(\text { Average })=1230(\mathrm{rpm} / \mathrm{V}) \quad \text { Standard Dev. }=1,288(\mathrm{rpm} / \mathrm{V})
$$

Internal resistance is indirectly verified according to the schematic of Figure 37, where a power source is connected directly to generator lead wires. To avoid burning up the generator a power resistor is connected in series. Generator internal resistance is measured indirectly by measuring current and voltage drop across the generator lead wires when a DC voltage source is supplied to the circuit. The voltage input for this test was 8 volts and was not varied since input voltage should not affect results. The measured current and voltage values at the generator are then used to calculate the internal resistance as displayed in Table 6. As shown in Table 6, measurements were taken for each wire pair and averaged to get an internal resistance value of $0.271 \mathrm{ohms}$. 


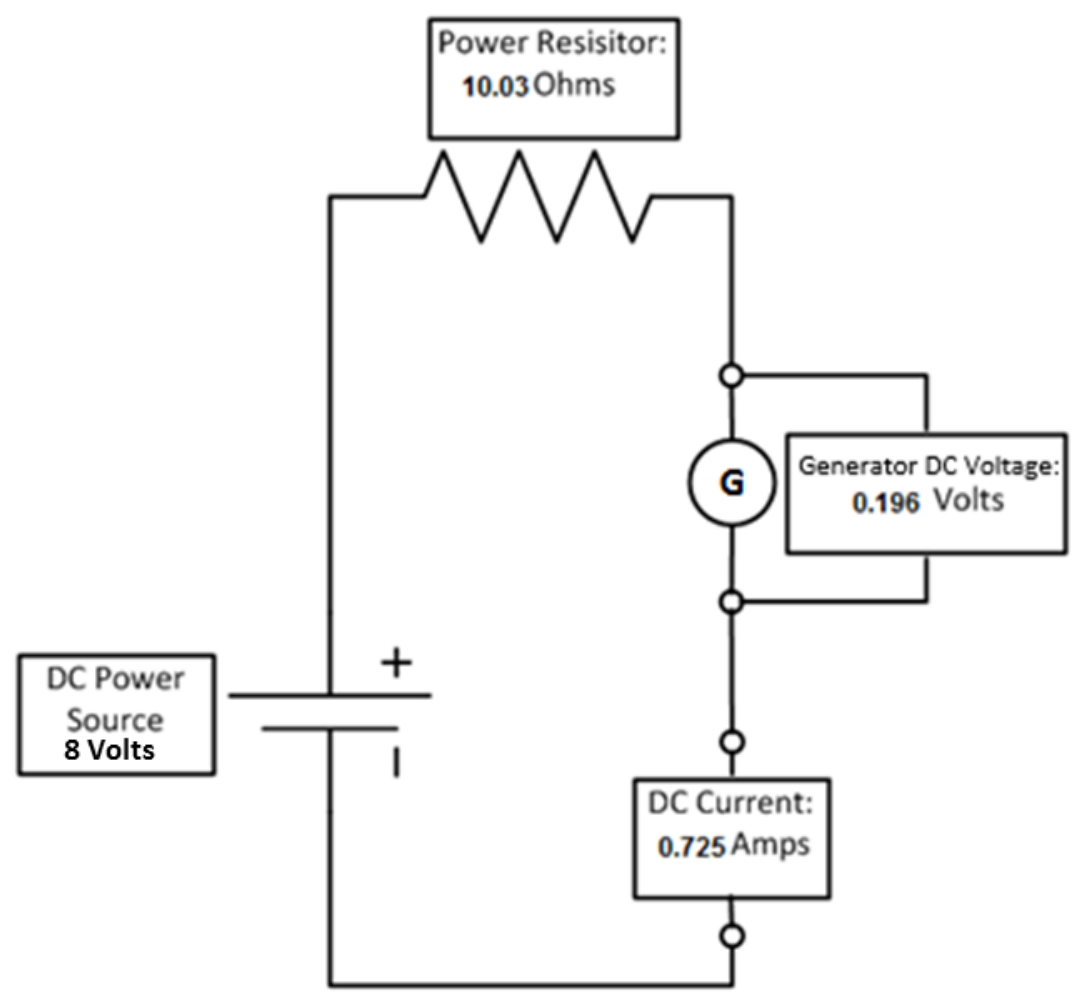

Figure 37. Electrical Schematic of Generator Internal Resistance Measurement

$$
\boldsymbol{R}_{\boldsymbol{i}}=\frac{\boldsymbol{V}}{\boldsymbol{I}}
$$

Table 6. Internal Resistance Measurement Results

\begin{tabular}{|c|c|c|c|}
\hline $\begin{array}{c}\text { Lead Wire } \\
\text { pairs }\end{array}$ & Volts & I (Amps) & Ri (Ohms) \\
\hline orange/brown & 0.196 & 0.725 & 0.270 \\
\hline orange/red & 0.127 & 0.4671 & 0.272 \\
\hline red/brown & 0.127 & 0.4668 & 0.272 \\
\hline
\end{tabular}

$$
R_{i}(\text { Average })=0.271 \text { Ohms }
$$

A comparison of manufacturer published specifications to the measured values is displayed in Table 7. While it would be ideal to also verify the no-load current Io, we did not have the speed controller for this specific generator in order to run it as a motor and measure no load current. With a close match between published and measured $\mathrm{Kv}$ and Ri 
values it was expected that the no-load parameter also match closely to the published value; therefore it was decided to not verify no-load current and treat it as a constant unless subsequent generator evaluation tests suggested that it was necessary to do so.

\section{Table 7. Generator Parameter Verification}

\begin{tabular}{|c|c|c|}
\hline & $\begin{array}{c}\text { Manufacture } \\
\text { specifications }\end{array}$ & Measured \\
\hline Kv & 1230 & 1230 \\
\hline Ri & 0.269 & 0.27 \\
\hline
\end{tabular}

Following the verification of the speed constant and internal resistance, the generator model was evaluated using the test setup depicted in Figure 38-Figure 39. Similar to the test setup in measuring $\mathrm{Kv}$, the prime mover rotates the generator at varying speeds through the shaft coupler. In evaluating the generator model, the AC voltage out of the three generator lead wires is put through the three-phase rectifier and a resistive electrical load. At the load, voltage and current are measured. The test were conducted at a fixed load resistance for a range of RPM at increments of about 1,000 RPM, then repeated for another fixed load resistor. Resistance for the load was measured using a Fluke multi-meter. 


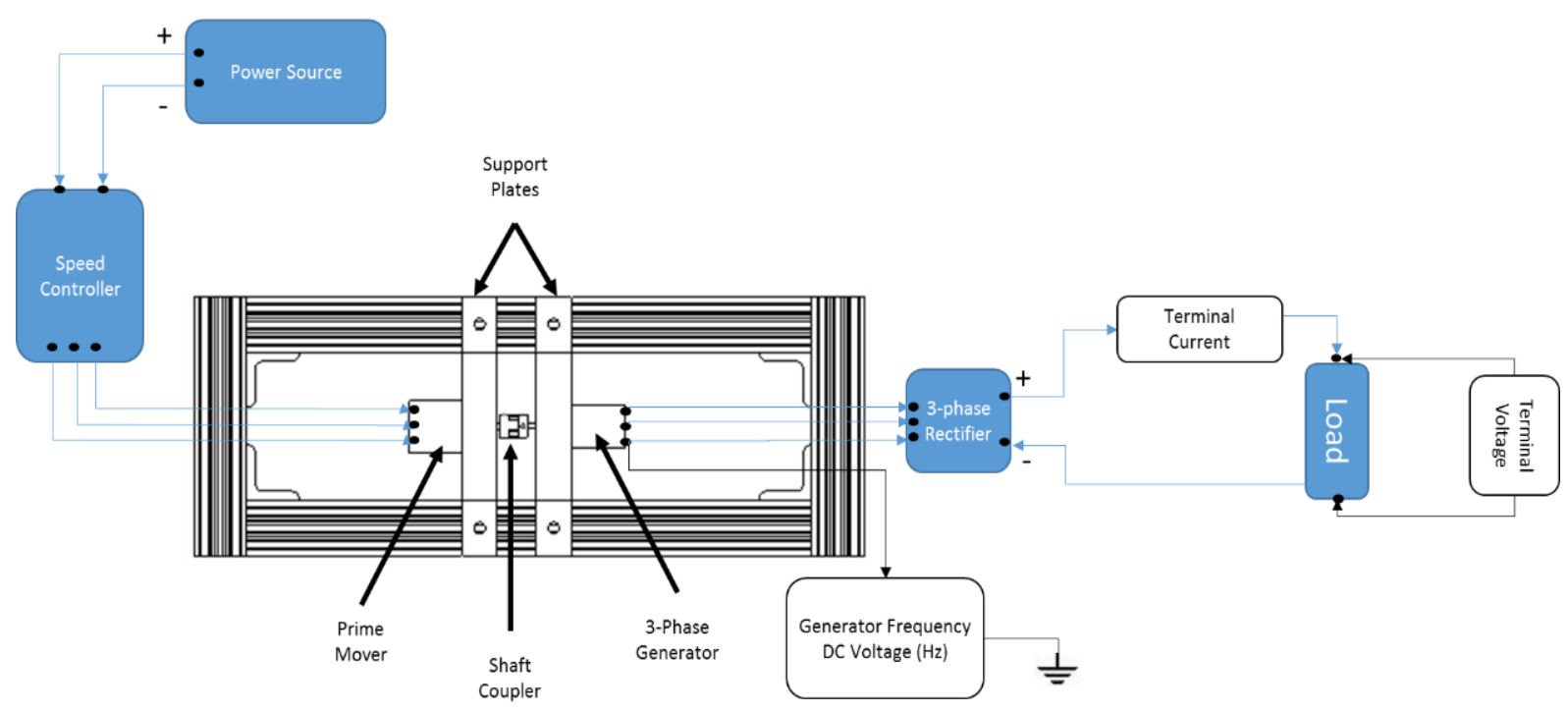

Figure 38. Generator Test Schematic

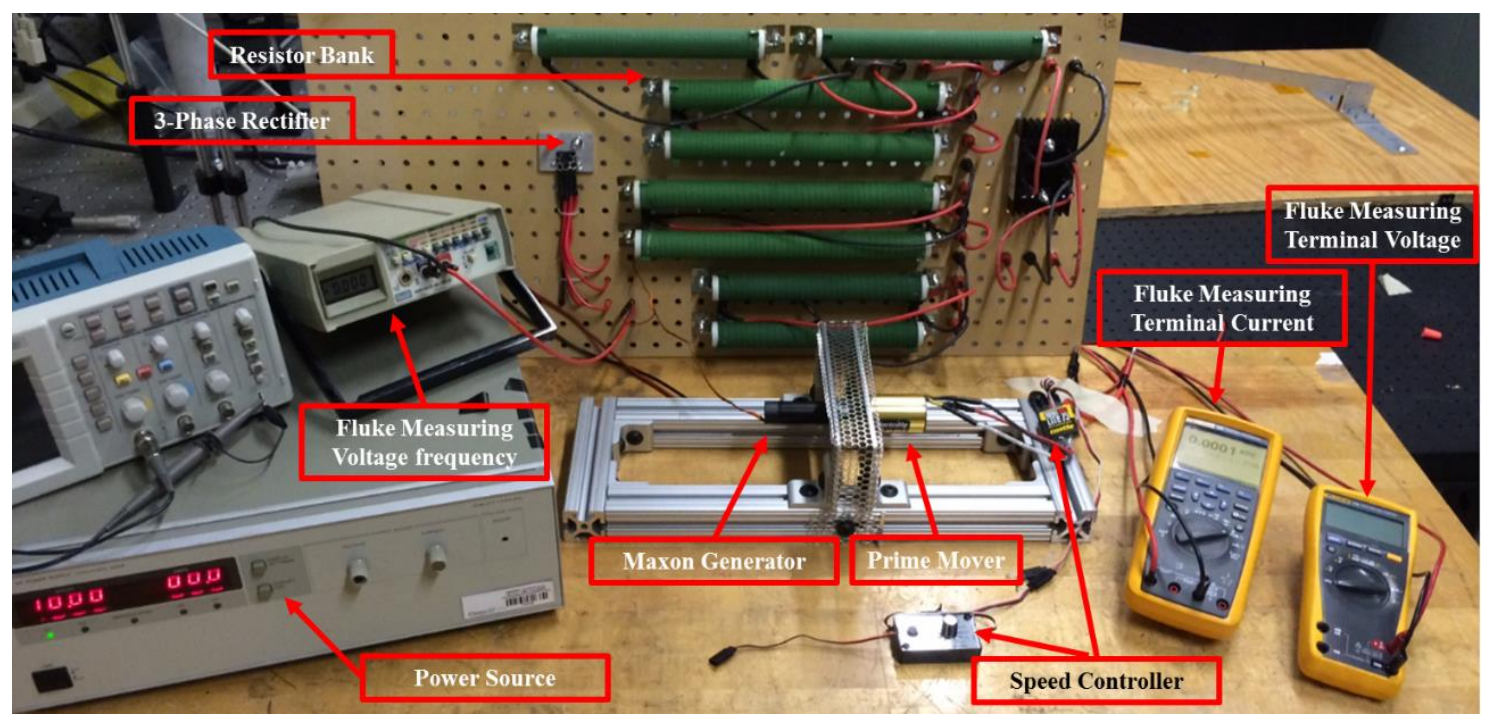

Figure 39. Generator Test Setup

Figure 40 and Table 8 show results of the generator evaluation test at an electrical load of $3.02 \mathrm{Ohms}$ and compares those results to the calculated values using the generator model. It is observed that predicted terminal power values are within a few percent of measured values with an uncertainty below $2 \%$. 


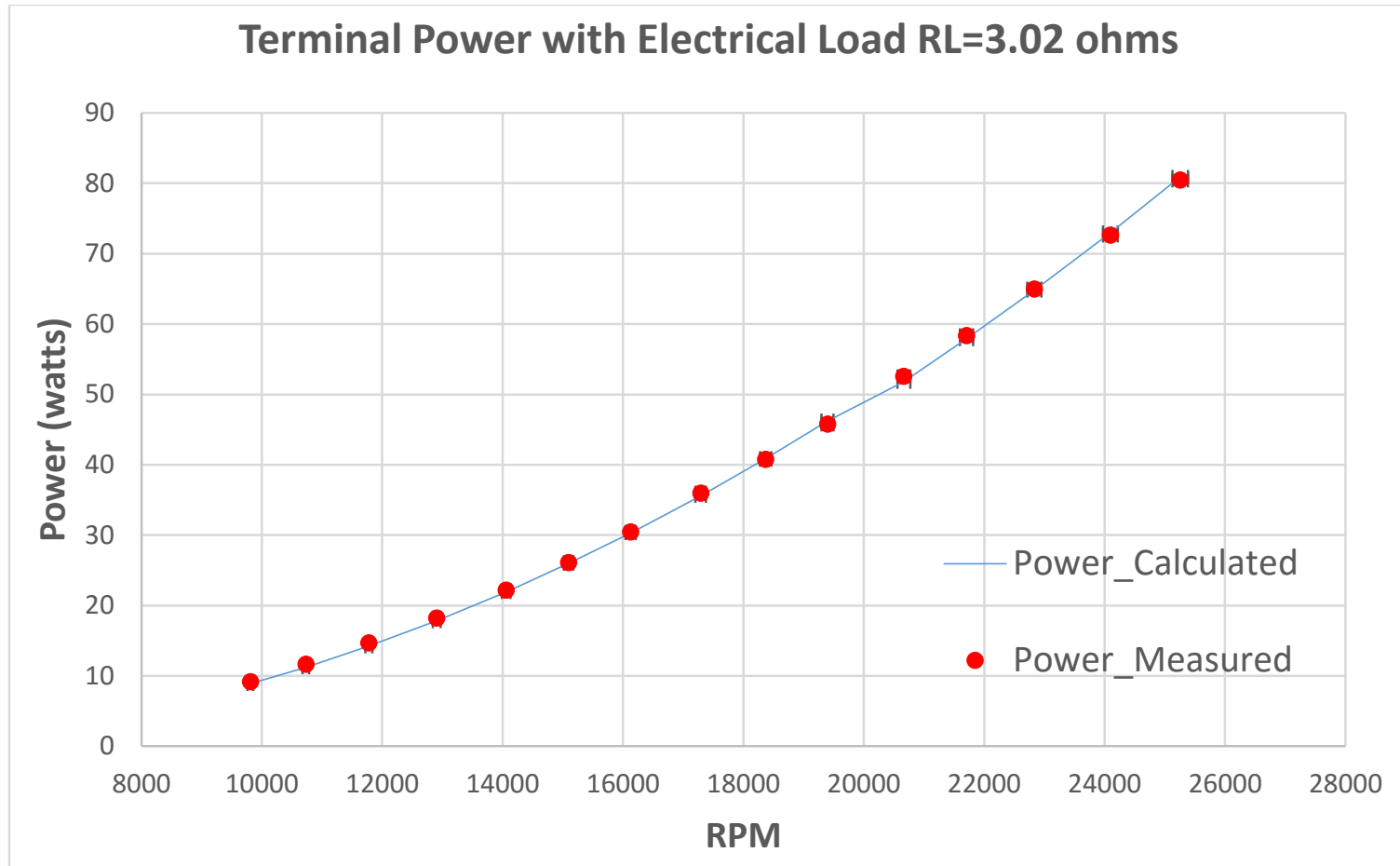

Figure 40. Generator Model Test Results at 3.02 Ohms

Table 8. Generator Model Test Results at 3.02 Ohms

\begin{tabular}{|c|c|c|c|c|c|c|c|c|}
\hline \multirow[b]{2}{*}{$\mathbf{f}(\mathrm{Hz})$} & \multirow[b]{2}{*}{ RPM } & \multicolumn{3}{|c|}{ Calculated Parameters } & \multicolumn{3}{|c|}{ Measured Parameters } & \multirow[b]{2}{*}{ \% Error } \\
\hline & & I (Amps) & Vr (Volts) & Power(Watts) & I(Amps) & Vr (Volts) & Power(Watts) & \\
\hline 163.5 & 9810 & 1.72 & 5.18 & 8.89 & 1.75 & 5.25 & 9.19 & -3.24 \\
\hline 178.9 & 10734 & 1.93 & 5.83 & 11.24 & 1.977 & 5.9 & 11.66 & -3.62 \\
\hline 196.3 & 11778 & 2.17 & 6.55 & 14.23 & 2.21 & 6.64 & 14.67 & -3.06 \\
\hline 215.1 & 12906 & 2.43 & 7.34 & 17.83 & 2.467 & 7.38 & 18.21 & -2.05 \\
\hline 234.3 & 14058 & 2.69 & 8.14 & 21.93 & 2.72 & 8.15 & 22.17 & -1.08 \\
\hline 251.6 & 15096 & 2.93 & 8.86 & 25.97 & 2.95 & 8.85 & 26.11 & -0.52 \\
\hline 268.8 & 16128 & 3.17 & 9.57 & 30.32 & 3.19 & 9.54 & 30.43 & -0.38 \\
\hline 288.2 & 17292 & 3.43 & 10.37 & 35.61 & 3.49 & 10.31 & 35.98 & -1.03 \\
\hline 306.2 & 18372 & 3.68 & 11.11 & 40.89 & 3.69 & 11.05 & 40.77 & 0.28 \\
\hline 323.3 & 19398 & 3.91 & 11.82 & 46.23 & 3.91 & 11.71 & 45.79 & 0.96 \\
\hline 344.4 & 20664 & 4.14 & 12.51 & 51.82 & 4.19 & 12.54 & 52.54 & -1.38 \\
\hline 361.8 & 21708 & 4.38 & 13.22 & 57.89 & 4.41 & 13.23 & 58.34 & -0.78 \\
\hline 380.6 & 22836 & 4.63 & 13.99 & 64.81 & 4.657 & 13.95 & 64.97 & -0.25 \\
\hline 401.6 & 24096 & 4.92 & 14.85 & 72.97 & 4.92 & 14.76 & 72.62 & 0.49 \\
\hline 420.9 & 25254 & 5.18 & 15.63 & 80.88 & 5.17 & 15.56 & 80.45 & 0.55 \\
\hline
\end{tabular}

While generator model evaluation test results provide confidence in the generator model's ability to accurately predict generator electrical performance at a given rpm, it 
does not provide an evaluation of the model prediction of generator shaft torque. The only direct way to verify torque would be to directly measure it using an in-line shaft torque transducer or perhaps a torque cradle. An alternative approach that will not measure torque directly but will give some indication of whether the generator model is producing good estimates for brake torque is to calculate brake torque for a given motored generator test, separate from the generator model, using the dc motor model for the prime mover, then compare torque values to the torque predicted by the generator model. To do this, it is first necessary to implement the DC motor equations (Chapter 2.2) to predict brake torque for the prime mover. Prior to applying the motor model equations it is first necessary to verify motor manufacturer specifications for $\mathrm{Kv}, \mathrm{Ri}$ and Io. Because the motor that is being used as the prime mover is $2+$ years old and has already experienced significant wear, the motor parameters are expected to deviate from the manufacturer specifications. The motor parameters were measured in the same manner as those for the generator, except that it was possible to measure Io. Table 9 displays the manufacturer specified parameters and the measured values. Here we see that the $\mathrm{Kv}$ parameter significantly deviates from what the manufacturer specified with a 38\% error. A possible explanation of for this significant deviation in $\mathrm{Kv}$ is loss of performance of the permanent magnets due to overheating or over magnetizing. Note that the manufacturer did not provide a value for internal resistance for this motor. Also, after measuring the no-load current, it was determined that the actual no-load current value significantly varied linearly with speed and is not a constant 1.9 Amps as the manufacturer specified. Because measured No-Load current is not constant it was excluded from Table 9 and is instead shown in Figure 41. 
Table 9. Motor Parameter Verification [Ammo BLDC (part\# 35-56-1800kv)]

\begin{tabular}{|c|c|c|}
\hline & $\begin{array}{c}\text { Manufa } \\
\text { cture } \\
\text { specifications }\end{array}$ & Measured \\
\hline Kv [RPM/volts] & 1800 & 2491.33 \\
\hline Ri [ohms] & - & 0.20012 \\
\hline lo [amps] & 1.9 & - \\
\hline
\end{tabular}

The no-load current for the DC motor is plotted below in Figure 41. Because the noload current varies linearly with speed, a trend line was set and used in calculating motor torque output at various speeds. In the motor model the linear fit was used to establish the input no-load current for the corresponding velocity. Because for this motor the no-load current varied significantly with speed, here the no-load was not applied in the motor model as a constant and varied with speed as depicted in Figure 41.

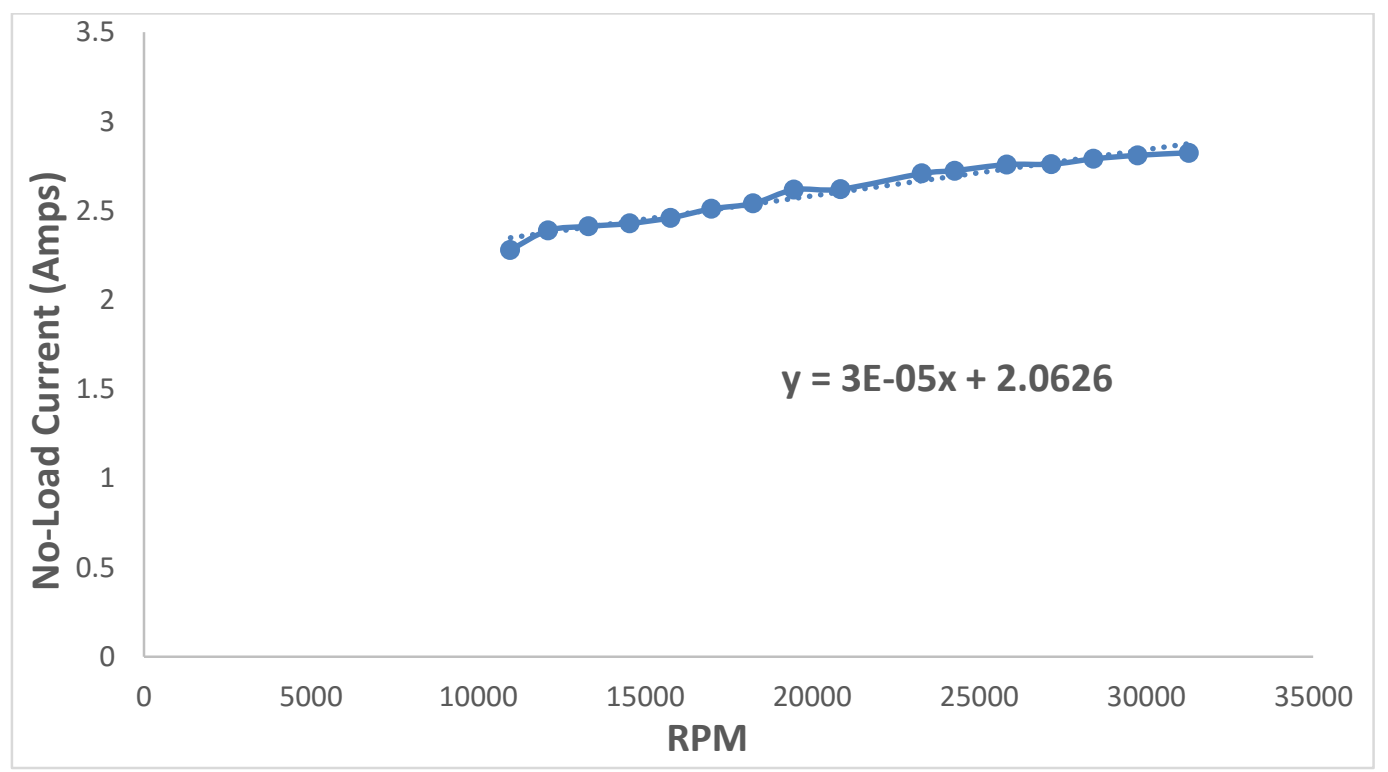

Figure 41. DC Motor No-Load Current 
Now for a motored generator test where the Ammo BLDC (part\# 35-56-1800kv) motored the Maxon generator with a $2.3 \mathrm{ohm}$ electrical load at the terminal, DC motor brake torque and power values were predicted using motor model Equations 12 through 18 . Inputs to the model were speed and voltage - output results can be seen below in Table 10.

Table 10. DC Motor Shaft Torque Calculation

\begin{tabular}{|c|c|c|c|c|c|c|c|c|c|c|}
\hline $\mathbf{P}$ (watts) & $\begin{array}{c}\mathbf{V} \\
\text { (volts) }\end{array}$ & I (amps) & $\mathbf{f}(\mathrm{Hz})$ & $\mathbf{R P M}$ & $\begin{array}{c}\text { Io } \\
\text { (amps) }\end{array}$ & $\begin{array}{c}\text { la } \\
\text { (amps) }\end{array}$ & $\begin{array}{c}\text { Va } \\
\text { (volts) }\end{array}$ & $\begin{array}{c}\text { Pbrake } \\
\text { (watts) }\end{array}$ & Eta (\%) & $\begin{array}{c}\text { Torque } \\
\text { (N-m) }\end{array}$ \\
\hline 28.80 & 4.5 & 6.4 & 156.9 & 9414 & 2.31 & 4.09 & 4.37 & 17.87 & 62.03 & 0.018 \\
\hline 36.00 & 5 & 7.2 & 173.6 & 10416 & 2.34 & 4.86 & 4.86 & 23.60 & 65.55 & 0.022 \\
\hline 42.90 & 5.5 & 7.8 & 190.4 & 11424 & 2.37 & 5.43 & 5.34 & 29.03 & 67.68 & 0.024 \\
\hline 49.80 & 6 & 8.3 & 208.6 & 12516 & 2.40 & 5.90 & 5.83 & 34.44 & 69.16 & 0.026 \\
\hline 57.85 & 6.5 & 8.9 & 226.5 & 13590 & 2.43 & 6.48 & 6.32 & 40.94 & 70.76 & 0.029 \\
\hline 66.50 & 7 & 9.5 & 243.75 & 14625 & 2.45 & 7.05 & 6.81 & 47.99 & 72.17 & 0.031 \\
\hline 75.75 & 7.5 & 10.1 & 261.8 & 15708 & 2.48 & 7.62 & 7.30 & 55.60 & 73.4 & 0.034 \\
\hline 85.60 & 8 & 10.7 & 280.4 & 16824 & 2.51 & 8.19 & 7.79 & 63.76 & 74.48 & 0.036 \\
\hline 96.05 & 8.5 & 11.3 & 300.3 & 18018 & 2.54 & 8.76 & 8.27 & 72.46 & 75.43 & 0.038 \\
\hline 108.00 & 9 & 12 & 317.2 & 19032 & 2.57 & 9.43 & 8.76 & 82.61 & 76.49 & 0.041 \\
\hline 119.23 & 9.5 & 12.55 & 337 & 20220 & 2.60 & 9.95 & 9.25 & 92.01 & 77.17 & 0.044 \\
\hline 136.00 & 10 & 13.6 & 354.7 & 21282 & 2.63 & 10.97 & 9.73 & 106.72 & 78.47 & 0.048 \\
\hline 142.80 & 10.5 & 13.6 & 374.7 & 22482 & 2.66 & 10.94 & 10.23 & 111.87 & 78.34 & 0.048 \\
\hline
\end{tabular}

Brake torque values are then calculated independently from the motor model using the generator model with with terminal load of 2.33 ohms. Brake torque values calculated through the generator model are displayed in Table 11. Torque predictions from both the motor and generator models are then compared in Figure 43 and with a percent difference shown in Table 12. 


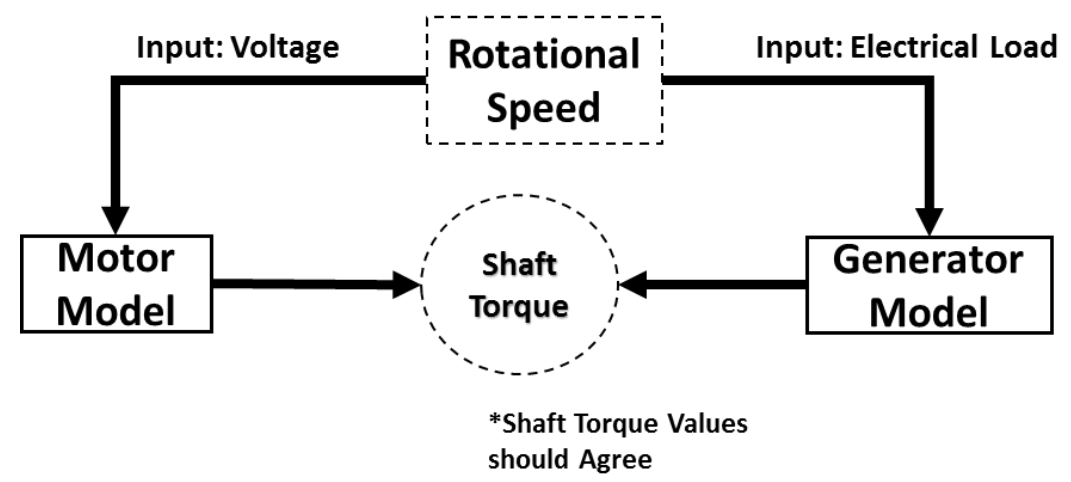

Figure 42. Torque Verification diagram

Table 11. Generator Shaft Torque Calculation

\begin{tabular}{|c|c|c|c|c|c|c|}
\hline $\mathbf{f ( H z )}$ & $\mathbf{R P M}$ & $\mathbf{w}(\mathbf{r a d} / \mathbf{s})$ & $\mathbf{V}_{\mathbf{a}(\text { peak) }}$ (Volts) & $\mathbf{I}_{\mathbf{a} \text { (peak) }}(\mathbf{A m p s})$ & $\mathbf{P}_{\text {brake }}$ (Watts) & Torque (N-m) \\
\hline 156.9 & 9414 & 985.8 & 7.654 & 2.41 & 18.44 & 0.019 \\
\hline 173.6 & 10416 & 1090.8 & 8.468 & 2.71 & 22.99 & 0.021 \\
\hline 190.4 & 11424 & 1196.3 & 9.288 & 3.02 & 28.06 & 0.023 \\
\hline 208.6 & 12516 & 1310.7 & 10.176 & 3.35 & 34.12 & 0.026 \\
\hline 226.5 & 13590 & 1423.1 & 11.049 & 3.68 & 40.64 & 0.029 \\
\hline 243.75 & 14625 & 1531.5 & 11.890 & 3.99 & 47.44 & 0.031 \\
\hline 261.8 & 15708 & 1644.9 & 12.771 & 4.32 & 55.12 & 0.034 \\
\hline 280.4 & 16824 & 1761.8 & 13.678 & 4.65 & 63.61 & 0.036 \\
\hline 300.3 & 18018 & 1886.8 & 14.649 & 5.01 & 73.35 & 0.039 \\
\hline 317.2 & 19032 & 1993.0 & 15.473 & 5.31 & 82.16 & 0.041 \\
\hline 337 & 20220 & 2117.4 & 16.439 & 5.59 & 91.86 & 0.043 \\
\hline 354.7 & 21282 & 2228.6 & 17.302 & 5.90 & 102.13 & 0.046 \\
\hline 374.7 & 22482 & 2354.3 & 18.278 & 6.26 & 114.36 & 0.049 \\
\hline
\end{tabular}


Table 12. Motor/Generator Shaft Torque

\begin{tabular}{|c|c|c|c|c|}
\hline $\mathbf{f}(\mathbf{H z})$ & RPM & Motor Torque $(\mathbf{N}-\mathbf{m})$ & Generator Torque $(\mathbf{N}-\mathbf{m})$ & \% Diff \\
\hline 156.9 & 9414 & 0.018 & 0.019 & 3.15 \\
\hline 173.6 & 10416 & 0.022 & 0.021 & 2.61 \\
\hline 190.4 & 11424 & 0.024 & 0.023 & 3.39 \\
\hline 208.6 & 12516 & 0.026 & 0.026 & 0.94 \\
\hline 226.5 & 13590 & 0.029 & 0.029 & 0.73 \\
\hline 243.75 & 14625 & 0.031 & 0.031 & 1.15 \\
\hline 261.8 & 15708 & 0.034 & 0.034 & 0.87 \\
\hline 280.4 & 16824 & 0.036 & 0.036 & 0.23 \\
\hline 300.3 & 18018 & 0.038 & 0.039 & 1.23 \\
\hline 317.2 & 19032 & 0.041 & 0.041 & 0.55 \\
\hline 337 & 20220 & 0.043 & 0.043 & 0.17 \\
\hline 354.7 & 21282 & 0.048 & 0.046 & 4.39 \\
\hline 374.7 & 22482 & 0.048 & 0.049 & 2.20 \\
\hline
\end{tabular}

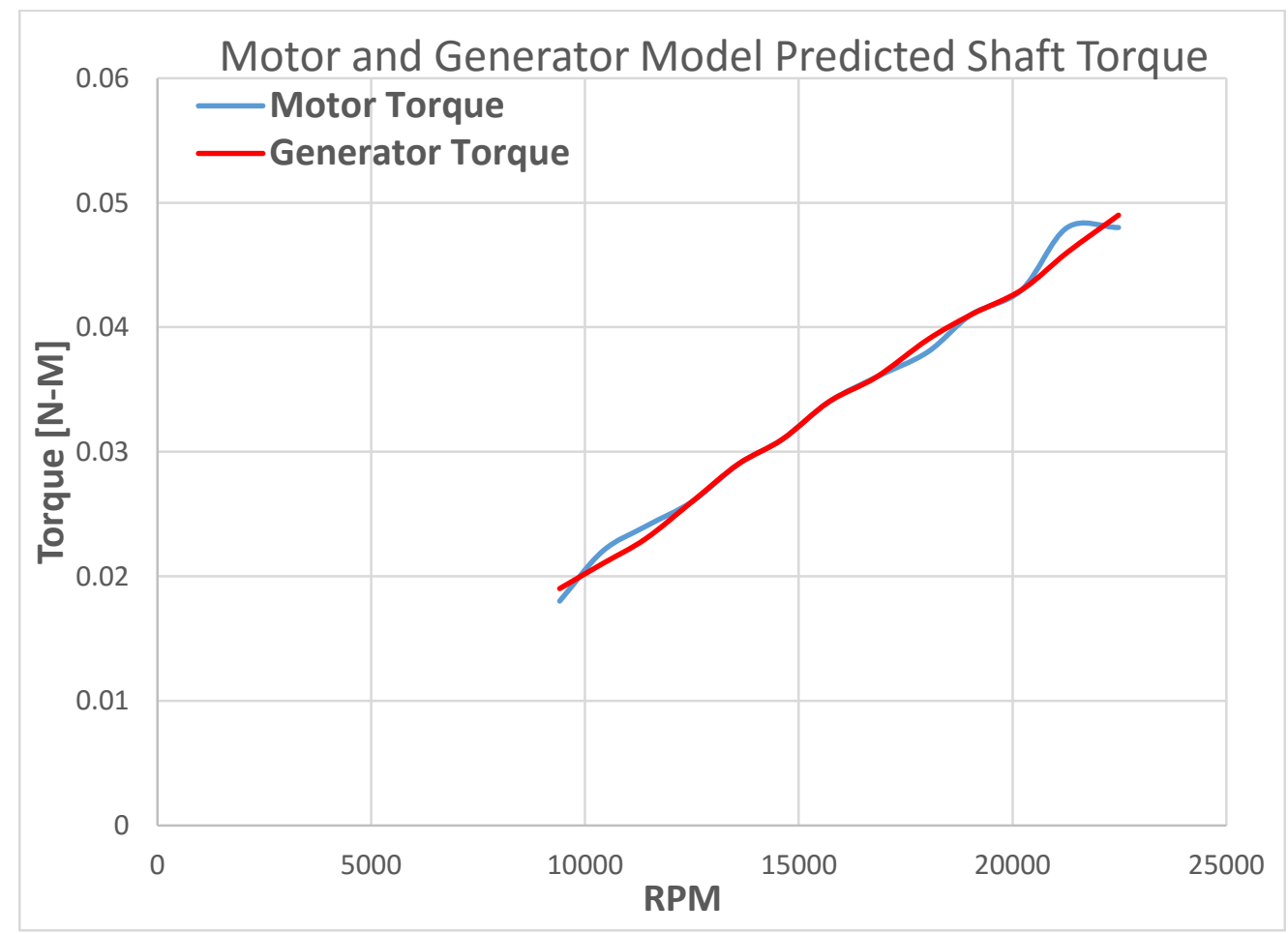

Figure 43. Motor and Generator Model Predicted Shaft Torque 
In addition to computing shaft torque independently through the prime mover motor model and the generator model, both models can be coupled in series beginning with the source power to the DC motor as an input and terminal power as an output. Input power and current were measured at the source using two Fluke multi-meters. The power losses at the speed controller were neglected and assumed to be minimal since the controller was set to maximum and instead the power source was used as the actual control by varying voltage for all trials. Generator output power is then calculated through the coupled motor and generator models and compared to actual measured terminal power values. Terminal voltage and current were also measured using Fluke multi-meters at the terminal load.

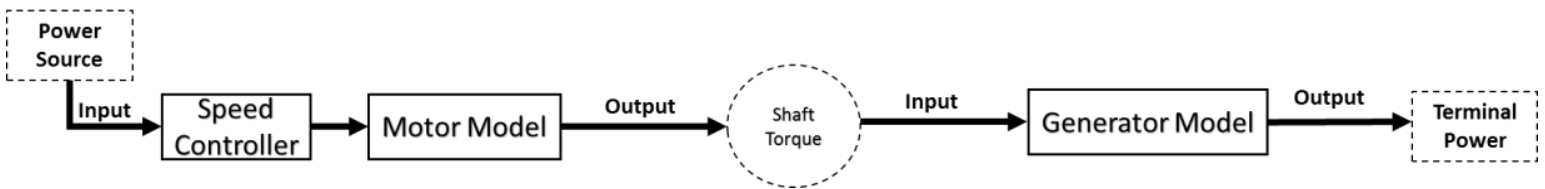

Figure 44. Motor to Generator Model Validation Test Diagram

Table 13. Motor to Generator Terminal Power Calculation

\begin{tabular}{|c|c|c|c|c|c|c|c|c|c|c|c|}
\hline \multicolumn{9}{|c|}{ MOTOR } & \multicolumn{9}{|c|}{ GENERATOR } \\
\hline RPM & $\mathbf{V}$ & $\mathbf{I}$ & Pshaft & Torque (N-m) & $\mathbf{V}_{\mathbf{a}(\text { peak) }}$ & $\mathbf{I}_{\mathbf{a}(\text { peak })}$ & $\mathbf{I}_{\text {(peak) }}$ & $\mathbf{I}_{(\text {DC) }}$ & $\mathbf{V}_{\mathbf{r} \text { (peak) }}$ & $\mathbf{V}_{\text {(DC) }}$ & P (watts) \\
\hline 9414 & 4.5 & 6.4 & 17.87 & 0.018 & 7.654 & 2.334 & 2.071 & 1.978 & 4.89 & 4.67 & 9.24 \\
\hline 10416 & 5 & 7.2 & 23.60 & 0.022 & 8.468 & 2.787 & 2.524 & 2.41 & 5.58 & 5.33 & 12.85 \\
\hline 11424 & 5.5 & 7.8 & 29.03 & 0.024 & 9.288 & 3.126 & 2.863 & 2.734 & 6.31 & 6.03 & 16.47 \\
\hline 12516 & 6 & 8.3 & 34.44 & 0.026 & 10.176 & 3.385 & 3.122 & 2.981 & 7.13 & 6.81 & 20.29 \\
\hline 13590 & 6.5 & 8.9 & 40.93 & 0.029 & 11.049 & 3.705 & 3.442 & 3.287 & 7.91 & 7.56 & 24.84 \\
\hline 14625 & 7 & 9.5 & 47.99 & 0.031 & 11.89 & 4.036 & 3.773 & 3.603 & 8.66 & 8.27 & 29.81 \\
\hline 15708 & 7.5 & 10.1 & 55.60 & 0.034 & 12.771 & 4.354 & 4.091 & 3.906 & 9.46 & 9.03 & 35.28 \\
\hline 16824 & 8 & 10.7 & 63.76 & 0.036 & 13.678 & 4.661 & 4.398 & 4.2 & 10.28 & 9.82 & 41.23 \\
\hline 18018 & 8.5 & 11.3 & 72.45 & 0.038 & 14.649 & 4.946 & 4.683 & 4.472 & 11.17 & 10.67 & 47.71 \\
\hline 19032 & 9 & 12 & 82.61 & 0.041 & 15.473 & 5.339 & 5.076 & 4.847 & 11.89 & 11.35 & 55.03 \\
\hline 20220 & 9.5 & 12.55 & 92.01 & 0.043 & 16.439 & 5.597 & 5.334 & 5.094 & 12.78 & 12.21 & 62.18 \\
\hline 21282 & 10 & 13.6 & 106.71 & 0.048 & 17.302 & 6.168 & 5.905 & 5.639 & 13.49 & 12.88 & 72.64 \\
\hline 22482 & 10.5 & 13.6 & 111.87 & 0.048 & 18.278 & 6.121 & 5.858 & 5.594 & 14.48 & 13.83 & 77.34 \\
\hline
\end{tabular}


Table 14 compares calculated terminal power from the motor to generator model to actual measured terminal power. It can be seen that the percent error is typically a few percent and everywhere within $10 \%$. Based on the condition of the motor and how its performance parameters varied significantly with RPM, it can be assumed that the majority of the error is at the motor. Although a percent error less than a few percent establishes confidence in both motor and generator models, direct torque measurements would still be desirable to fully evaluate the model.

Table 14. Motor to Generator Model Calculated Terminal Power Compared to Actual

\begin{tabular}{|c|c|c|c|c|c|c|c|c|}
\hline \multicolumn{2}{|c|}{} & \multicolumn{3}{c|}{ CALCULATED } & \multicolumn{3}{c|}{ MEASURED } & \multirow{2}{*}{ \% Error } \\
\cline { 1 - 9 } $\mathbf{f}(\mathbf{H z})$ & $\mathbf{R P M}$ & $\mathbf{I}(\mathbf{D C})$ & $\mathbf{V}(\mathbf{D C})$ & $\mathbf{P}(\mathbf{D C})$ & $\mathbf{I}(\mathbf{D C})$ & $\mathbf{V}(\mathbf{D C})$ & $\mathbf{P}(\mathbf{D C})$ & \\
\hline 156.9 & 9414 & 1.98 & 4.61 & 9.11 & 2.08 & 4.8 & 9.98 & -8.76 \\
\hline 173.6 & 10416 & 2.41 & 5.24 & 12.64 & 2.4 & 5.49 & 13.18 & -4.10 \\
\hline 190.4 & 11424 & 2.73 & 5.92 & 16.17 & 2.69 & 6.15 & 16.54 & -2.24 \\
\hline 208.6 & 12516 & 2.98 & 6.67 & 19.90 & 3 & 6.87 & 20.61 & -3.46 \\
\hline 226.5 & 13590 & 3.29 & 7.40 & 24.32 & 3.3 & 7.57 & 24.98 & -2.65 \\
\hline 243.75 & 14625 & 3.60 & 8.09 & 29.14 & 3.6 & 8.25 & 29.70 & -1.88 \\
\hline 261.8 & 15708 & 3.91 & 8.81 & 34.43 & 3.9 & 8.93 & 34.83 & -1.13 \\
\hline 280.4 & 16824 & 4.20 & 9.57 & 40.19 & 4.21 & 9.65 & 40.63 & -1.09 \\
\hline 300.3 & 18018 & 4.47 & 10.38 & 46.44 & 4.54 & 10.4 & 47.22 & -1.64 \\
\hline 317.2 & 19032 & 4.85 & 11.03 & 53.45 & 4.82 & 11.05 & 53.26 & 0.36 \\
\hline 337 & 20220 & 5.09 & 11.84 & 60.33 & 5.15 & 11.81 & 60.82 & -0.80 \\
\hline 354.7 & 21282 & 5.64 & 12.46 & 70.25 & 5.43 & 12.44 & 67.55 & 4.00 \\
\hline 374.7 & 22482 & 5.59 & 13.38 & 74.85 & 5.76 & 13.19 & 75.97 & -1.47 \\
\hline
\end{tabular}




\section{ROTOR MODEL}

A rotor model based on simple blade element theory has been developed with the intention of establishing a baseline rotor design tool that can take a given rotor geometry and rotation rate; and predict torque created on the rotor by aerodynamic forces at a given relative airspeed. This tool will allow variation of rotor design parameters such as number of blades, hub and tip diameter, blade angle, blade twist, and taper to effectively predict rotor performance; enabling rotor optimization and rotor/generator performance matching. Classical momentum theory and blade element analysis are employed in predicting rotor performance for a given size and geometry; the induced flow caused by the rotor wake and aero-elastic rotor blade deformation are neglected in this analysis. Also note that the analysis can be applied to both propellers or turbines and that prediction values will be positive for a propeller and negative for a turbine. A second rotor analysis tool, Drela \& Youngren open source model, X-Rotor [22] is also being used. X-Rotor includes the influence of the wake's induced flow, and is therefore assumed to provide more accurate results. However, X-Rotor also does not include aeroelastic blade deformation under load. Both analysis tools employ user-input data for blade section lift and drag. For the present case, that data is only crudely approximated. The following subsections detail on the actuator disk analysis used in determining max theoretical performance; the blade element model used to predict rotor performance; and the X-Rotor performance predictions and how they compare to results obtained from the blade model [22]. 


\subsection{Actuator Disk Theory}

A simple one-dimensional (no swirl) steady, inviscid model based on Newton's 2nd law is used to establish maximum theoretical performance of an ideal rotor at various operating conditions. This model considers a control volume with streamtube boundaries and two cross-sections as the inlet and outlet; represented as control volume 1-4 in Figure 45. The ideal "bare" (unducted) rotor is represented as uniformly loaded, permeable, infinitely thin actuator disk. Control volumes before and after the actuator disk are also considered in this analysis; shown in Figure 45 as control volumes 1-2 and 3-4 [13].

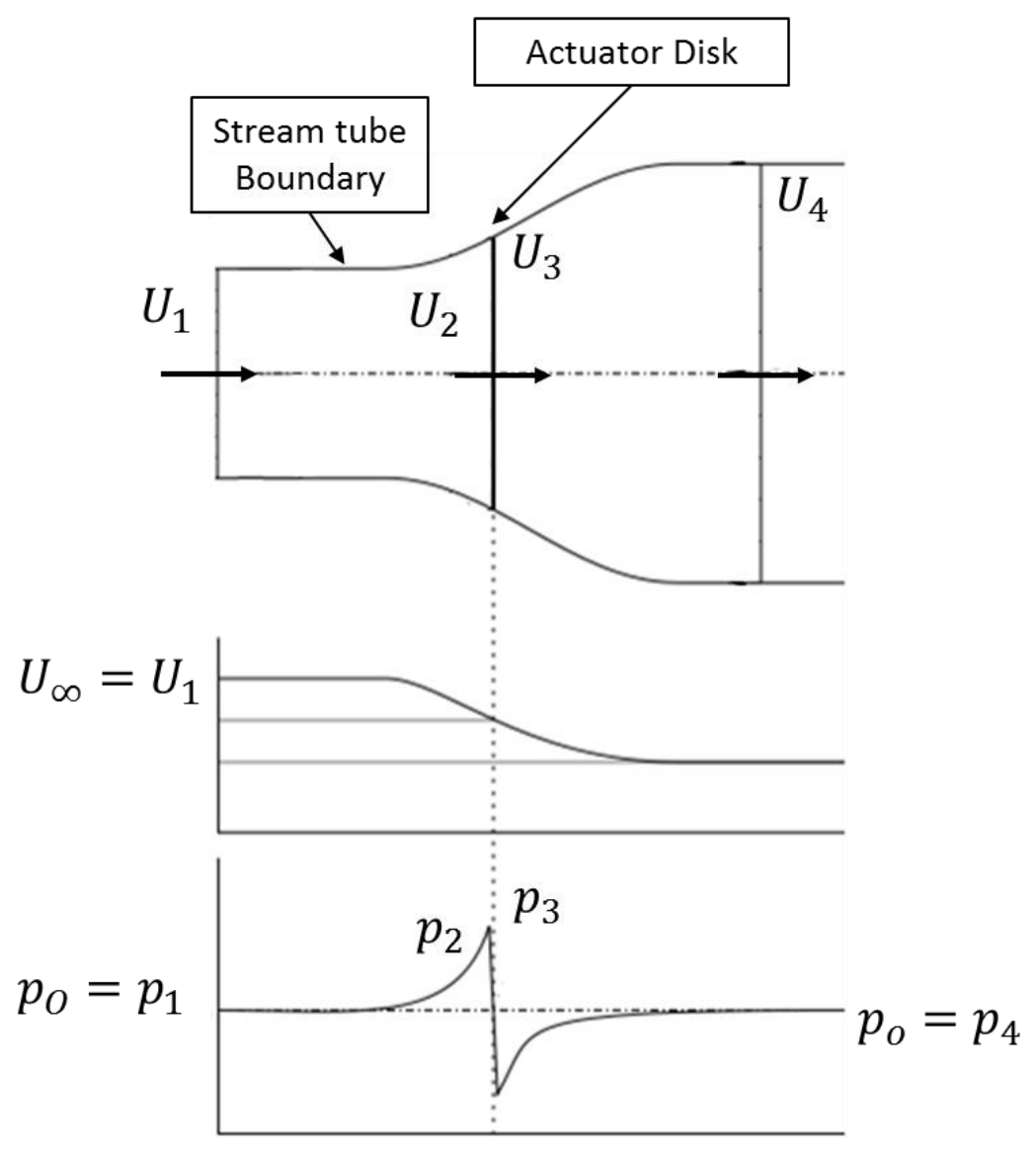

Figure 45. Turbine Actuator Disk 
In applying the actuator disk analysis, it is assumed that pressure far upstream and downstream are equal and equivalent to the surrounding ambient pressure.

$$
p_{1}=p_{4}
$$

Velocity across the actuation area is assumed equal, with a discontinuity in pressure as shown in Figure 45.

$$
U_{2}=U_{3}
$$

First, Bernoulli's equation is applied to control volumes 1-2 and 3-4.

$$
\begin{aligned}
& p_{1}+\frac{1}{2} \rho U_{1}{ }^{2}=p_{2}+\frac{1}{2} \rho U_{2}{ }^{2} \\
& p_{3}+\frac{1}{2} \rho U_{3}{ }^{2}=p_{4}+\frac{1}{2} \rho U_{4}{ }^{2}
\end{aligned}
$$

The change in pressure fore and aft of the actuator disk is solved for by combining equations 36 and 37 as shown below

$$
p_{3}-p_{2}=\frac{1}{2} \rho\left(U_{4}{ }^{2}-U_{1}{ }^{2}\right)
$$

Applying Newton's 2nd law to the actuator disk at 2-3, the net thrust is calculated. The thrust force is an axial force on the actuator disk as a result of momentum change and will result as negative for a wind turbine.

$$
\begin{gathered}
T=P_{3} A_{3}-P_{2} A_{2} \\
T=\left(p_{3}-p_{2}\right) A_{d i s k}
\end{gathered}
$$

Alternatively, thrust is determined by applying conservation of momentum to calculate the change in momentum between control areas 1-4 


$$
\begin{aligned}
& T=\dot{m} U_{4}-\dot{m} U_{1} \\
& T=\dot{m}\left(U_{4}-U_{1}\right)
\end{aligned}
$$

Substituting Equation 38 and equating Equations 39 and 40, the velocity at the actuator disk can be solved for:

$$
\begin{aligned}
\left(p_{3}-p_{2}\right) A_{d i s k} & =\dot{m} U_{4}-\dot{m} U_{1} \\
\frac{1}{2} \rho\left(U_{4}{ }^{2}-U_{1}{ }^{2}\right) A_{d i s k} & =\dot{m}\left(U_{4}-U_{1}\right)
\end{aligned}
$$

Simplifying we get equation (42), which shows that the velocity at the disk is the average airspeed between upstream and downstream.

$$
U_{2}=\frac{\left(U_{4}+U_{1}\right)}{2}
$$

Here we introduce the axial induction factor (a), which represents the fractional change in airspeed between the freestream and the actuator disk face; for a turbine, (a) is negative.

$$
a=\left(\frac{\left(U_{2}-U_{1}\right)}{U_{1}}\right)
$$

Equation 43 can then be rearranged to solve for velocity at the disk face in terms of induction factor

$$
U_{2}=U_{1}(1+a)
$$

Substituting equation 44 into 42 will solve for downstream velocity, equation (45). From this equation it can be seen that downstream velocity decreases to zero as the inflow factor approaches -0.5 . 


$$
U_{4}=U_{1}(1+2 a)
$$

With downstream velocity solved for, an energy balance for the 1-4 control volume can be applied in order to solve for power.

$$
P_{\text {extracted }}=\frac{1}{2} \dot{m} U_{4}{ }^{2}-\frac{1}{2} \dot{m} U_{1}^{2}
$$

After substituting for mass flow rate, extracted power can be calculated in equation 47

$$
P_{\text {extracted }}=\rho A_{\text {disk }} \frac{\left(U_{1}+U_{4}\right)}{2} * \frac{\left(U^{2}{ }_{4}-U_{1}{ }^{2}\right)}{2}
$$

Coefficient of power and thrust is then calculated using the customary definition for a wind turbine: by dividing power extracted by power available in the freestream for a given swept area.

$$
\begin{gathered}
C_{P}=\frac{P_{\text {extracted }}}{P_{\text {available }}}=\frac{P_{\text {extracted }}}{\left(\rho U_{1}{ }^{3} A_{\text {disk }}\right) \frac{1}{2}} \\
C_{T}=\frac{\text { Thrust }}{\text { Dynamic Force }}=\frac{\frac{1}{2} \rho\left(U_{4}{ }^{2}-U_{1}{ }^{2}\right) A_{\text {disk }}}{\rho\left({U_{4}}^{2}-U_{1}{ }^{2}\right) A_{\text {disk }} \frac{1}{2}}
\end{gathered}
$$

We are now able to calculate the maximum theoretical coefficient of power by taking the derivative of Equation 48, setting it equal to zero and solving for (a). At an induction factor of $a=-1 / 3, C_{P, \max }=.59$. This value is also known as Betz Limit [13] ; this value is the maximum theoretical power that can be extracted from the freestream air for a given swept area. Note that for a turbine the induction factor is negative due to the velocity decreasing from the streamtube inlet to the face of the actuator disk, whereas for a propeller this factor is positive. Figure 46 , displays $C_{P}$ and $C_{t}$ as a function of induction 
factor. In Figure $47 C_{P}$ is plotted for a 3.25 in. diameter disk at freestream airspeed of $160 \mathrm{ft} / \mathrm{s}$ at standard sea level conditions.

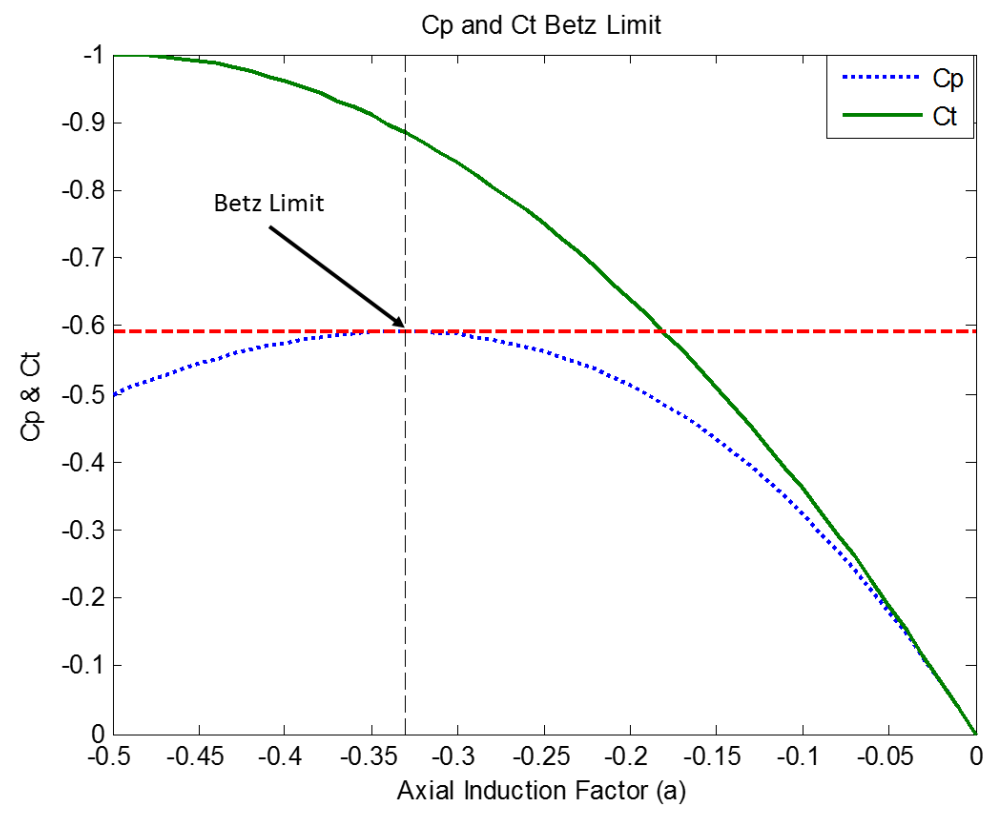

Figure 46. Power and Thrust Coefficients

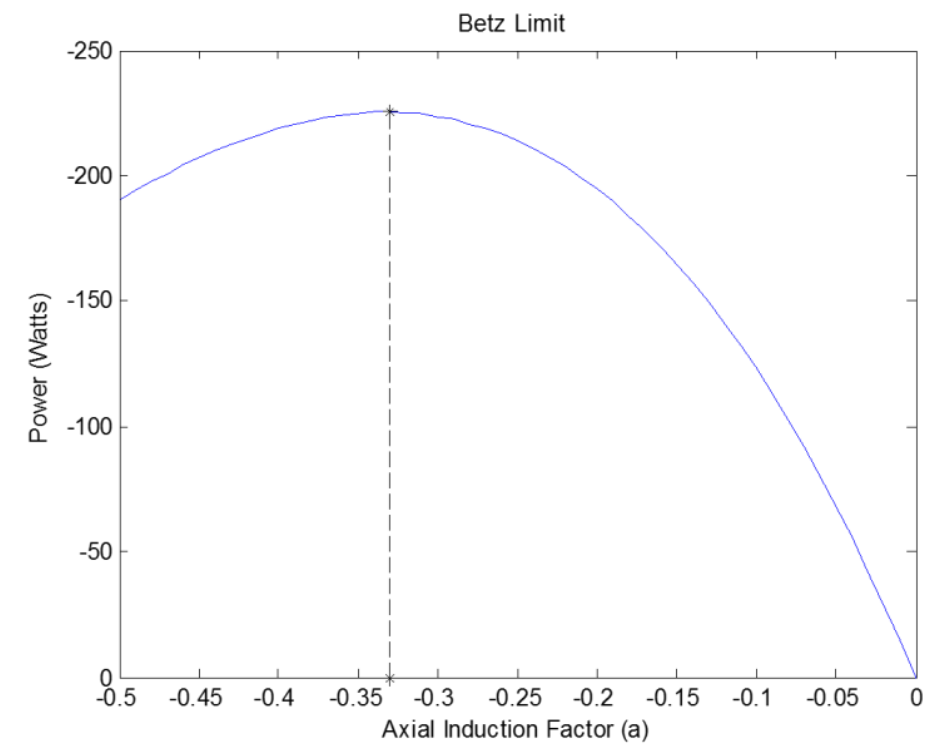

\section{Figure 47. Power Curve for a 3.25 in. Diameter Rotor}

Reality suggests that the Betz Limit will not be attained due to non-ideal conditions such as viscous drag, rotating wake ("swirl"), having a finite number of blades, and turbine tip losses that deduct from $C_{P, \max }$. However, this analysis does provide an upper bound on 
predicted power extracted and will give a good idea of the turbine sizing requirements for a desired extracted power. In Figure 48, power extracted has been predicted using actuator disk analysis for the baseline rotor which is 3.25 inches in diameter. As shown below, the analysis was conducted at different altitudes, at four different airspeeds. At the vertical dotted line in each plot below, respective Betz limits are identified [11] [13].
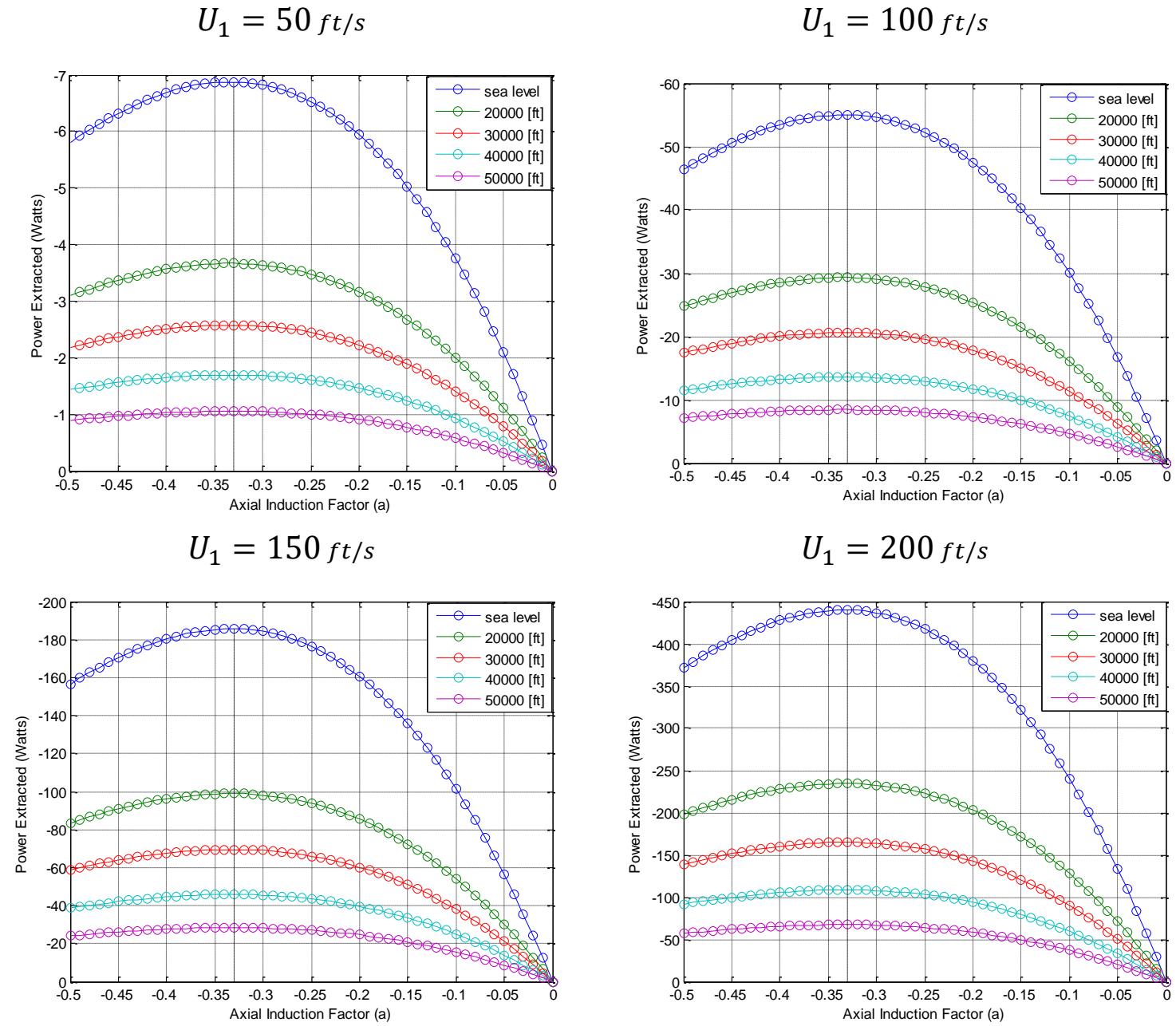

Figure 48. Actuator Disk Power Extracted for Different Axial Velocities at Varying Axial Induction Factors. (Dotted Line Represents Betz Limit) 


\subsection{Blade Element Theory}

In establishing a rotor model, a basic blade element analysis was conducted in order to predict rotor performance for a given rotor geometry and rotation rate at a specified airspeed. Unlike actuator disk theory, blade element theory considers a finite number of blades and involves the partitioning of rotor blades into independent sections along the length of the blade as shown in Figure 49.

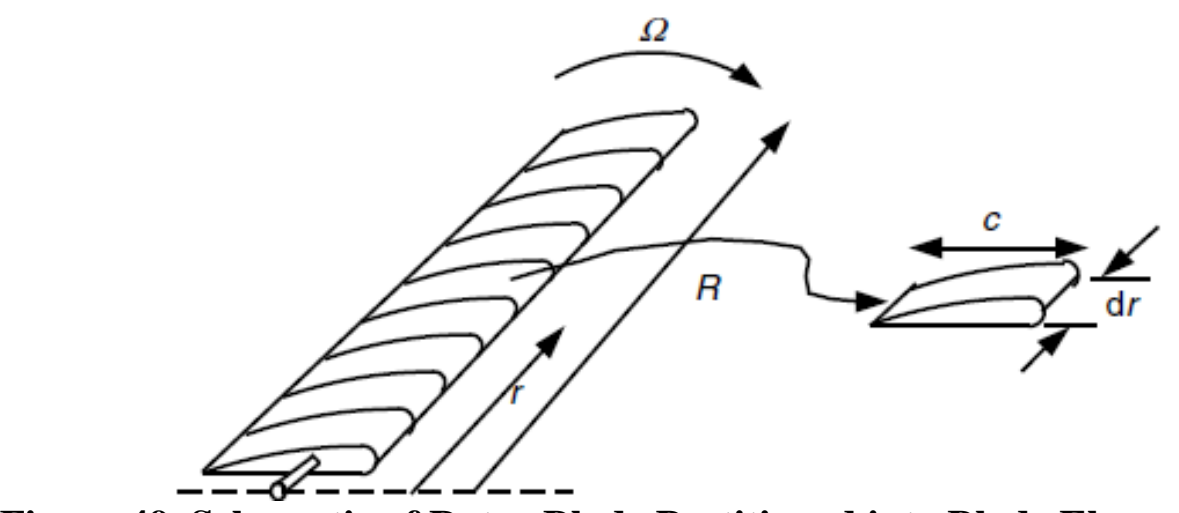

Figure 49. Schematic of Rotor Blade Partitioned into Blade Elements [13]

At each section, thrust and torque are calculated through a force balance that is conducted using 2-D airfoil lift and drag data. Each section is analyzed independently of the other assuming no aerodynamic interaction between sections. Sectional thrust and torque values can then be summed up in order to predict the performance of the entire rotor. This analysis is limited to 2-D, incompressible flow and does not take into account induced flow effects. Induced flow effects refers to the spanwise flow associated with an airfoil of finite aspect ratio. The effects are commonly known as vortices which lie along the span of an airfoil and extend downstream. Effects of these vortices include a downward component of velocity that is known as "downwash". Downwash results in the change in direction of the relative air stream. The rotation of airflow due to downwash 
effectively decreases the angle of attack. The blade model presented does not account for this phenomenon However, it should be sufficient to get a rough approximation of rotor performance [13] [11].

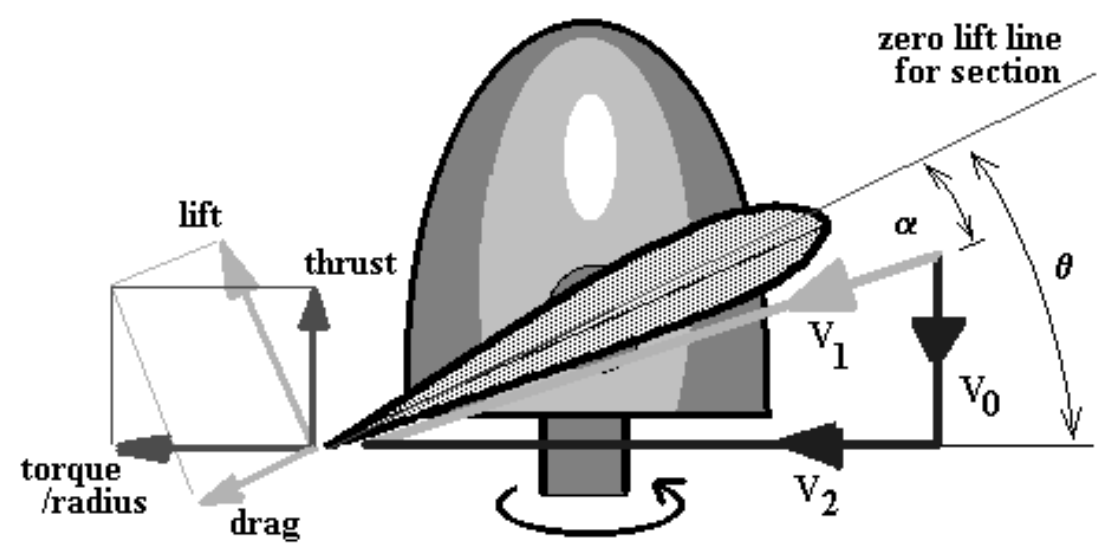

Figure 50. Blade Velocity and Force Breakdown [12]

In conducting blade element analysis the inner most element is analyzed first. It is first necessary to determine relative velocity $V_{1}$ over the blade; for this, axial and tangential velocity components must be determined. Recalling from blade actuator theory, velocity undergoes a fractional decrease in velocity from the streamtube inlet to the face of the disk. This decrease in velocity is characterized by an axial induction factor which is negative for turbines. Below in equation (50), the axial velocity component at the face of the disk is the freestream velocity plus the freestream velocity multiplied by the induction factor [13] [12].

$$
V_{o}=V_{\infty}(1+a)
$$

The angular velocity component is dependent on the blades' angular velocity. Here an angular induction factor $b$ is introduced. This factor was not previously considered in actuator disk theory because the flow was assumed 1-dimensional (no swirl). For a turbine the angular induction factor $b$ is also negative. 


$$
V_{2}=\omega r(1-b)
$$

Once the axial and angular velocity components have been solved for, the resultant relative velocity is calculated in equation 52 .

$$
V_{1}=\sqrt{V_{o}{ }^{2}+V_{2}{ }^{2}}
$$

Angle of attack $\alpha$ is the angle between the airfoil chord line and relative velocity. Now that relative velocity has been determined, $\alpha$ can now be calculated through Equation 54, where $\theta$, is the blade angle and $\varphi$ is the relative velocity angle and also the angle between airfoil lift and thrust.

$$
\varphi=\theta-\alpha
$$

Equation 53 is rearranged to solve for $\alpha$ :

$$
\alpha=\theta-\tan ^{-1} \frac{V_{o}}{V_{2}}
$$

Sectional thrust and torque equations are written below, where sectional lift $(l)$ and drag (d) forces are portioned to thrust and torque.

$$
\begin{aligned}
\Delta T & =(l \cos \emptyset-d \sin \emptyset) \\
\Delta Q & =(d \cos \emptyset-l \sin \emptyset) r
\end{aligned}
$$

Lift and drag are calculated in equations (57) and (58) below, where $c$ is the chord length, and $C_{l}$ and $C_{d}$ are the sectional coefficients of lift and drag, respectively. 


$$
\begin{aligned}
& l=C_{l} \frac{1}{2} \rho V_{1}{ }^{2} c d \Delta r \\
& d=C_{d} \frac{1}{2} \rho V_{1}^{2} c \Delta r
\end{aligned}
$$

Below lift and drag equations (57) and (58) have been substituted into equations (55) and (56) to solve for thrust and torque.

$$
\begin{gathered}
\Delta T=\frac{1}{2} \rho V_{1}^{2} c\left(C_{l} \cos \emptyset-C_{d} \sin \emptyset\right) B \Delta r \\
\Delta Q=\frac{1}{2} \rho V_{1}^{2} c\left(C_{l} \cos \emptyset+C_{d} \sin \emptyset\right) B r \Delta r
\end{gathered}
$$

We now apply conservation of momentum to develop thrust and torque equations considering the streamtube control volume 1-4 as depicted in Figure 45

$$
\begin{gathered}
\Delta \mathrm{T}=\rho 2 \rho \pi V_{o}\left(V_{4}-V_{\infty}\right) \\
V_{o}=\frac{\left(V_{\infty}+V_{4}\right)}{2} \Longrightarrow V_{4}=V_{\infty}(1+2 a) \\
\Delta T=\rho 4 \pi r V_{\infty}^{2} a(1+a) \Delta r \\
\Delta Q=\rho 4 \pi r^{3} V_{\infty} b(1+a) \omega \Delta r
\end{gathered}
$$

Thrust and torque equations developed through conservation of momentum are now equated with those developed in the force balance (Equations 59 and 60) in order to solve for axial and angular induction factors $a$ and $b$. As outlined in Figure 51, the process between equations 50 and 64 is iterated until induction factors converge within a specified tolerance. 


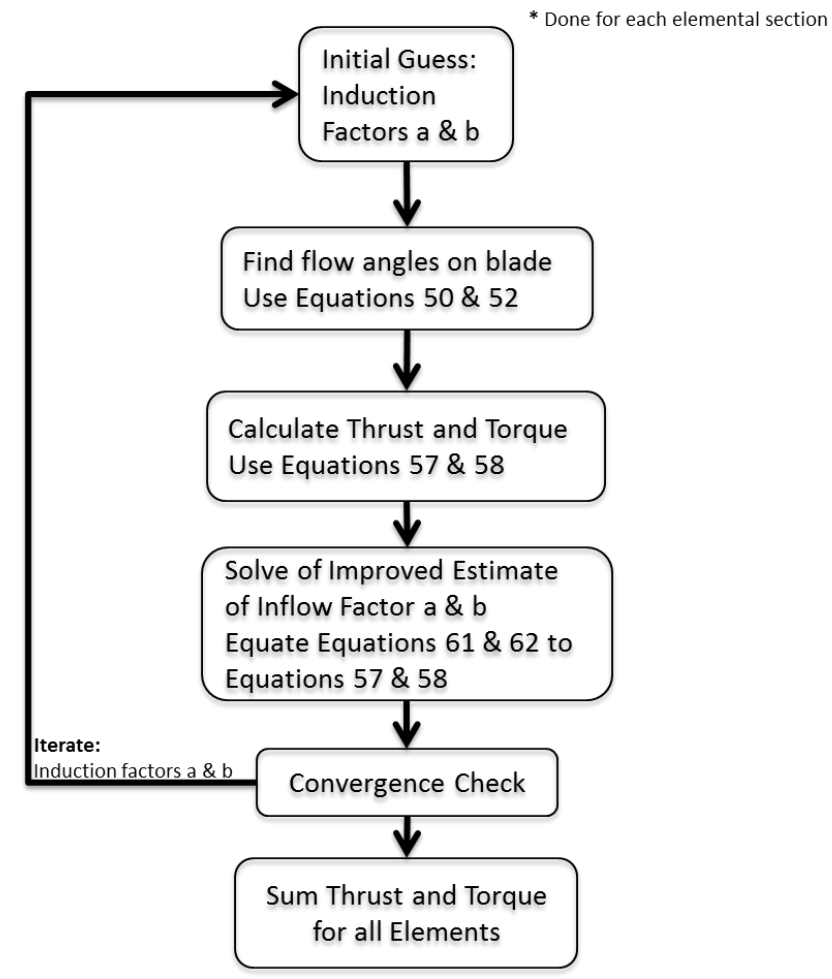

\section{Figure 51. Blade Element Model Iteration Diagram}

Once induction factors for each blade element have converged, sectional thrust, torque and power are summed to represent the total thrust and power generated by the entire rotor.

$$
\begin{gathered}
T=\sum \Delta T \\
Q=\sum \Delta Q \\
P=\sum \Delta Q * \omega
\end{gathered}
$$

Inputs to the blade model include rotor diameter, blade angle, chord, blade twist; and $C_{l}$ and $C_{d}$ values as functions of angle-of-attack and Reynolds number for a particular airfoil. For the baseline rotor design, the goal was to select rotor geometry for a low 
solidity rotor with a diameter as big as would be acceptable in the Cal Poly $2 \mathrm{x} 2 \mathrm{ft}$ wind tunnel; and to select one "simple" and one more complex blade geometry as a test of the design tools. Target rpm and power ranges that were aimed for with the rotor design were between 15,000 and $30,000 \mathrm{rpm}$; and up to 150 watts of generated power. These target operating ranges were based off size and operational limitations of available off-the-shelf generators.

Geometric parameters for the two candidate evaluation rotors selected; are shown in Table 15.

Table 15. Rotor Geometric Parameters

\begin{tabular}{|r|c|c|}
\hline & Rotor $\mathbf{1}$ & Rotor $\mathbf{2}$ \\
\hline Number of Blades: & 3 & 3 \\
\hline Hub Diameter: & $1 \mathrm{in}$ & $1 \mathrm{in}$ \\
\hline Tip Diameter: & $3.25 \mathrm{in}$ & $3.25 \mathrm{in}$ \\
\hline Chord: & $13 \mathrm{~mm}$ & $13 \mathrm{~mm}$ \\
\hline Airfoil (NACA): & 2412 & 2412 \\
\hline Re: & 80,000 & 80,000 \\
\hline Root Blade Angle: & $25^{\circ}$ & $40^{\circ}$ \\
\hline Tip Blade Angle: & $25^{\circ}$ & $15^{\circ}$ \\
\hline Twist Distribution: & None & Linear \\
\hline
\end{tabular}

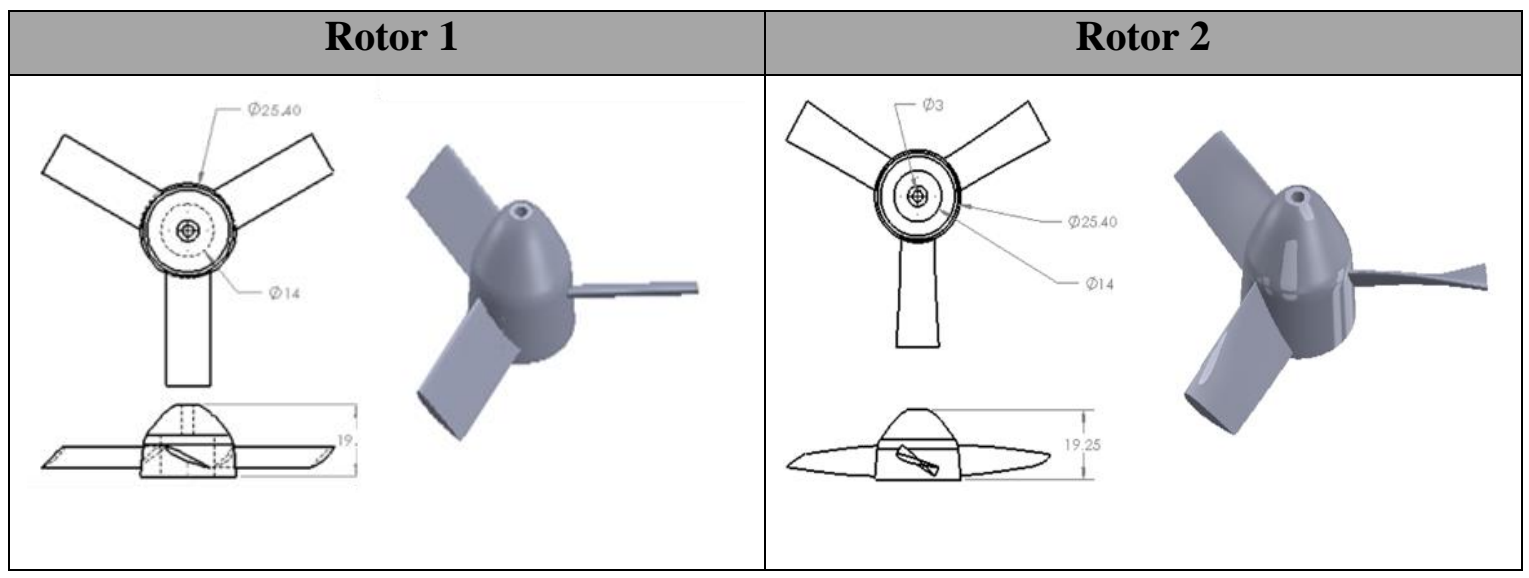

Figure 52. Baseline Rotors 1 \& 2 
It was decided to analyze two different rotors: one with twist (Rotor 2), and one with no twist (Rotor 1). Rotor 2 has a linear twist distribution with $25^{\circ}$ of blade twist. The blade angle for Rotor 1 is approximately equal to the blade angle of Rotor 2 at two-thirds length from the blade root. This was determined based on the assumption that the majority of thrust and torque is produced in that region of the blade. It is estimated that with the straight blade rotor partially operating under stalled conditions, that the twistedblade rotor, which maintains angle of attack at or near L/D max, will generate more power at its design RPM.

The airfoil selected for the candidate rotors was the NACA 2412; shown in Figure 53. This airfoil was also used in previous proof-of-concept work.

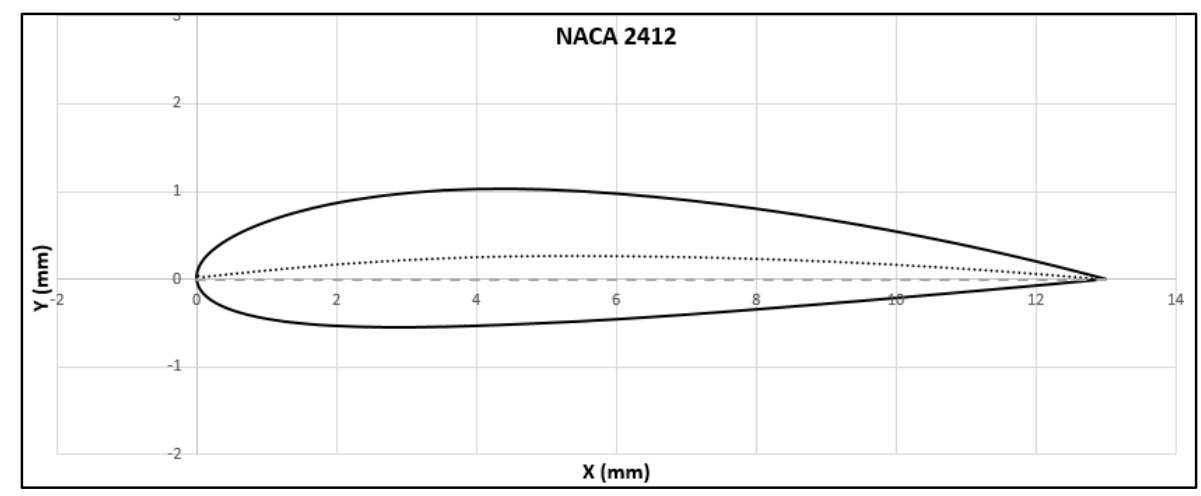

Figure 53. Selected Rotor Blade Airfoil (NACA 2412)

For the Naca 2412 airfoil, coefficient of lift and drag values were extracted from the QBlade v0.6 software [23]. QBlade is an open source turbine calculation software that is integrated into Drela's airfoil and analysis tool, XFOIL [24]. Rather than using XFOIL directly, it was decided to use QBlade since it provides a simpler graphical user interface (GUI) for generating airfoil lift and drag polars using the XFOIL source code [23] [22]. 


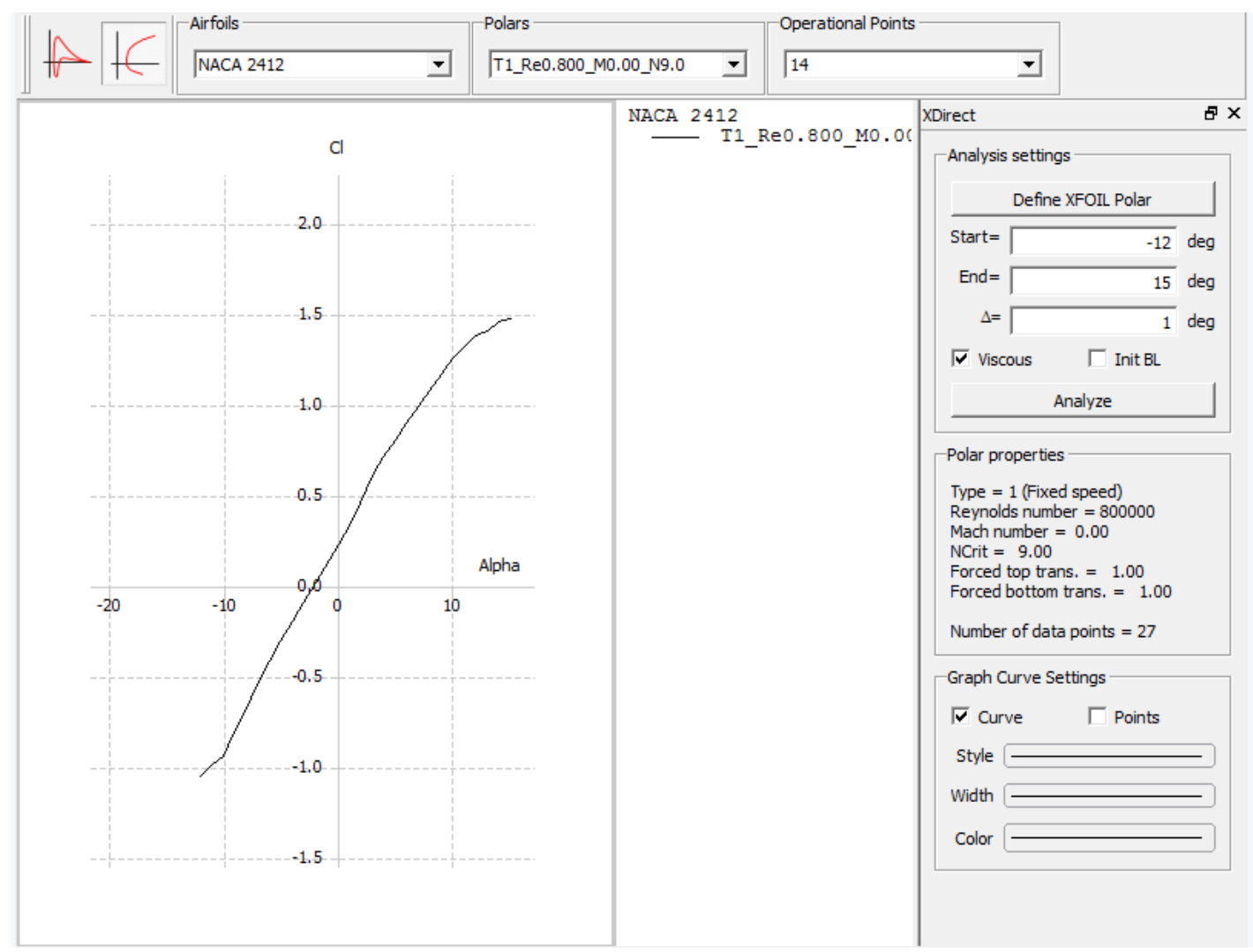

Figure 54. QBlade GUI for Analyzing Airfoil CL and CD [23] [22]

The XFOIL code is able to analyze both viscous and inviscid flow over a 2-D airfoil and provide lift and drag predictions for angles-of-attack beyond CLmax. Although the lift and drag predictions are within the range of interest for any aircraft or turbine that maintains the airfoil within the pre-stall range, slow axial airspeeds will drive turbines to operate with partially stalled blades. This is especially prevalent in rotors that have a fixed blade angle with no blade twist. Additionally, blade element models will typically temporarily iterate through post-stall angles of attack. In order to accommodate the analysis of partially stalled rotor blades and the application of blade element codes, it is necessary to extend the angle-of-attack range to $\pm 180^{\circ}$. QBlade offers an extrapolation module that can be used to extrapolate XFOIL generated lift and drag polars within the 
pre-stall region to $\pm 180^{\circ}$. The program offers two methods of extrapolation; the Montgomery extrapolation and the Viterna-Corrigan post stall model [23] [22].

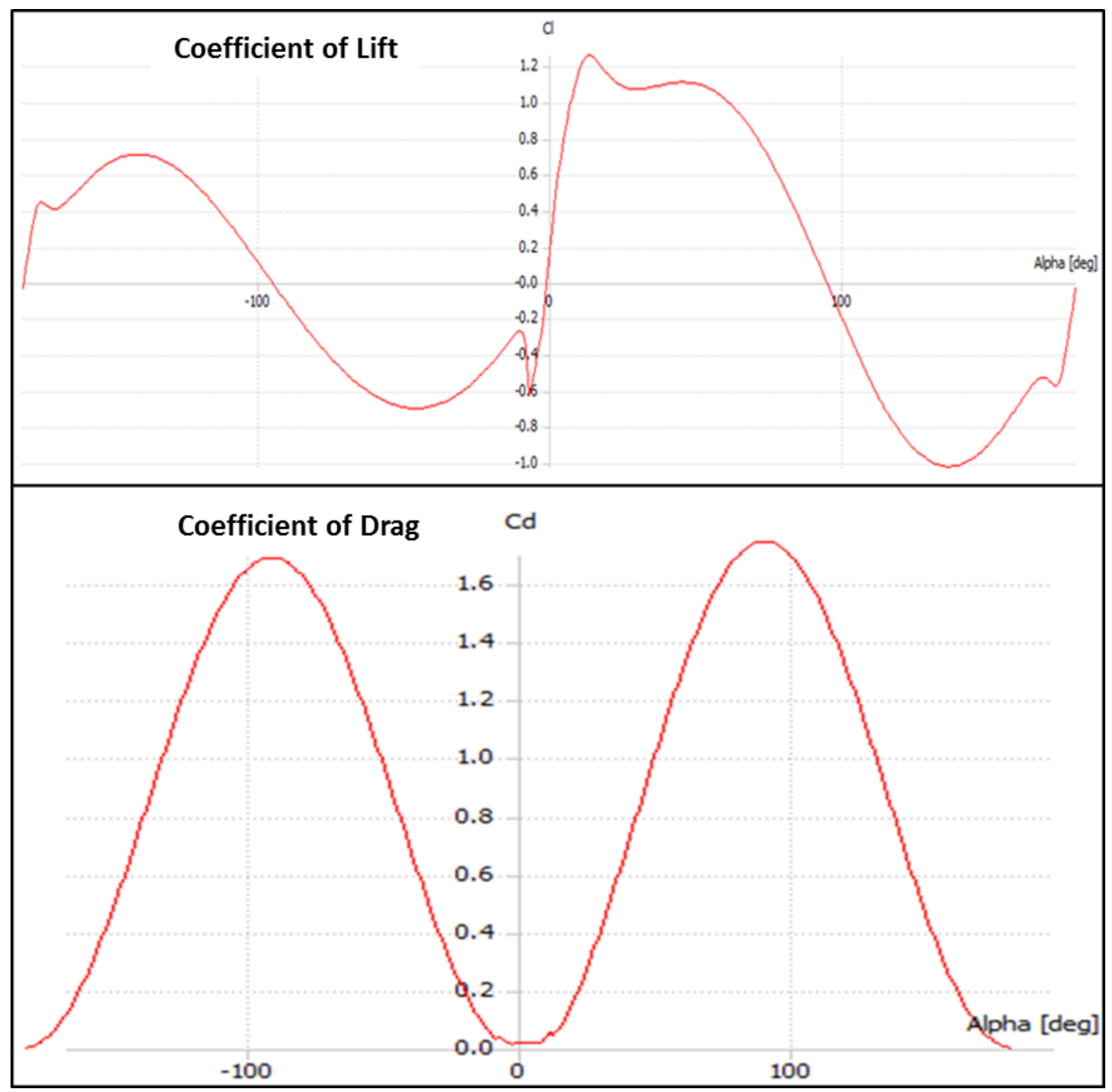

Figure 55. Montgomery Extrapolated NACA 2412 Lift and Drag curves at Re:80,000; Using QBlade Extrapolation Module [23] [22]

For this analysis, the Montgomery extrapolation was selected. For this method, lift and drag curves within the pre-stall range are needed - these are generated and extracted from XFOIL. The extrapolation is then conducted with the assumption that flow near or around $0^{\circ}$ and $180^{\circ}$ behaves linearly and can be treated as potential flow, at other angles-ofattack flow is assumed to approximately behave like a stalled, thin plate. As seen in 
Figure 56 transformation function is generated to blend both the potential flow straight line and the flat plate curve.

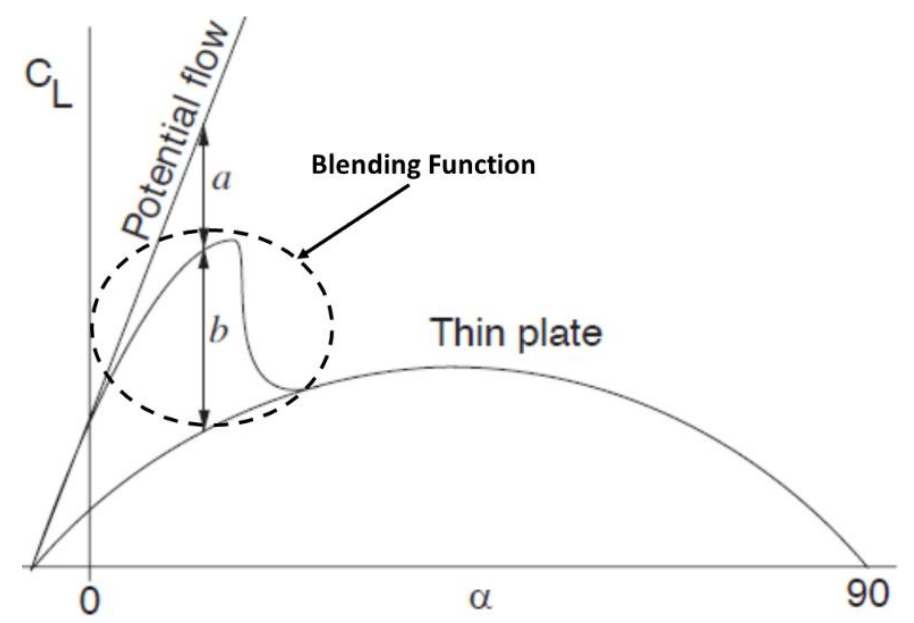

Figure 56. Blending Function for Combining Potential and Thin Plate Flow for Montgomery Extrapolation Method [25]

Because we are more concerned with turbine performance with unstalled blades, it is sufficient to visually form the blending function using the sliders provided by the QBlade $360^{\circ}$ extrapolation module user interface. The methodology in which QBlade develops this extrapolation is detailed in reference [25].

Along with realizing the need to extrapolate lift and drag polars, it is also important to identify the need to invert the airfoil orientation as compared to that used for a propeller or fan. For a turbine, blades will be operating at negative angles of attack. At negative angles of attack, it is desired to invert the airfoil in order to attain the desired lift and drag performance. The inverted NACA 2412 airfoil along with the inverted $C_{l}$ values are shown in Figure 57 below. 


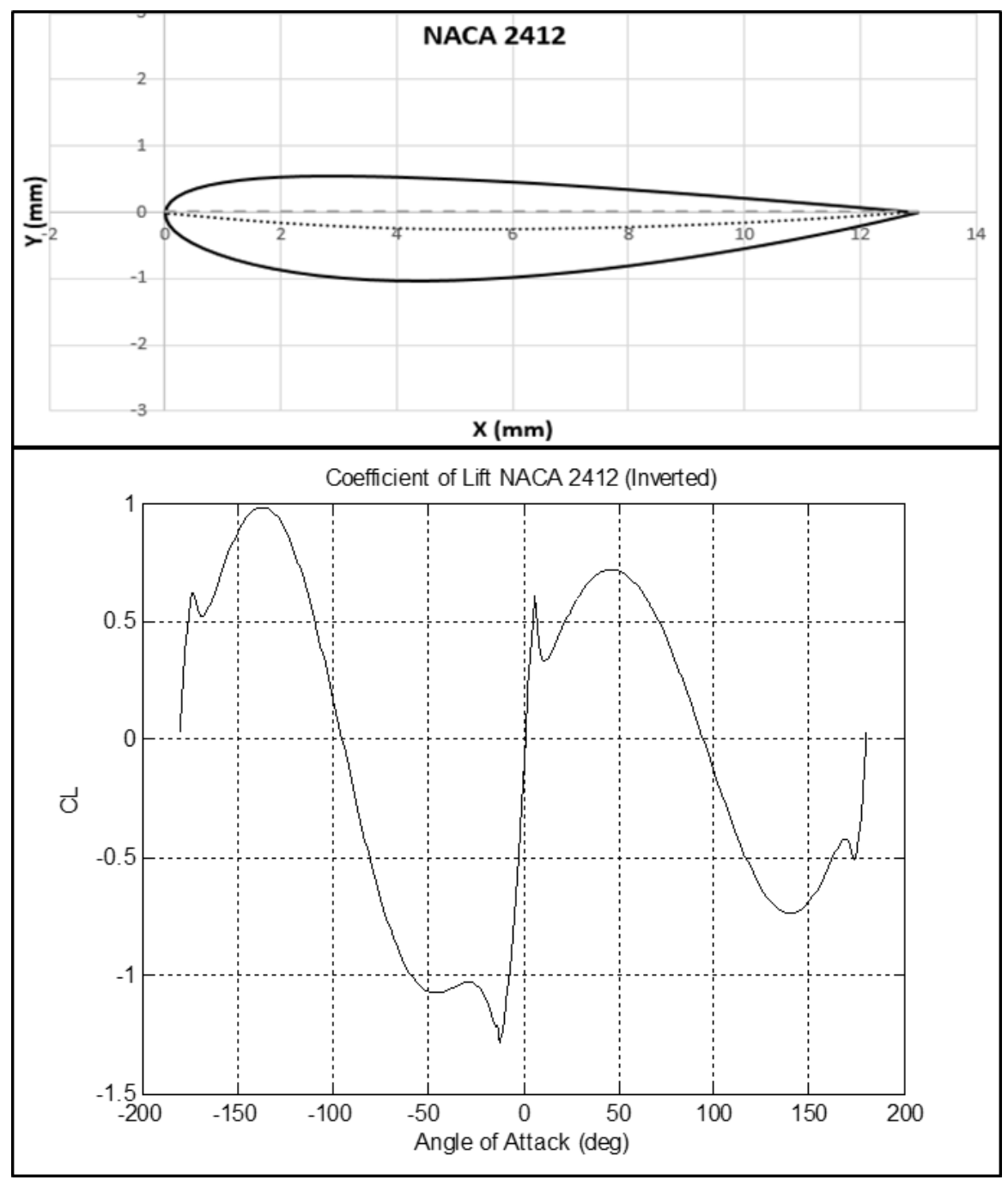

Figure 57. Inverted NACA 2412 [23] [22]

Blade element model torque and power predictions for the straight blade (Rotor 1) and twisted blade (Rotor 2) rotors are shown in Figure 58 and Figure 59, respectively. For both model runs the blades were partitioned into 20 elements and the axial airspeed was set at $110 \mathrm{mph}$ at standard sea level conditions for a range of rotational speeds. As seen in Figure 58 below, peak power for rotor- 1 is predicted at $21000 \mathrm{rpm}$ with a peak power of 110 watts. For rotor-2, peak power is predicted at $21000 \mathrm{rpm}$ with a peak power of 131 watts. Table 30 and Table 31 in Appendix E displays calculated parameters for each element at the peak rotor operating point $(21000 \mathrm{rpm})$ for both the straight blade and 
twisted blade rotor. By observing the sectional Angles of attack for the straight blade it can be seen that it is predicted to be operating with a partially stalled blade. It is also observed that close to the blade tip the model shows thrust and power being developed. It is important to recall that this analysis has not been corrected for tip losses or induced flow and that in reality minimal power is produced at the rotor blade tips. The sectional parameters displayed in Table 31 for Rotor 2 show that the rotor is operating unstalled and at or near L/D max.
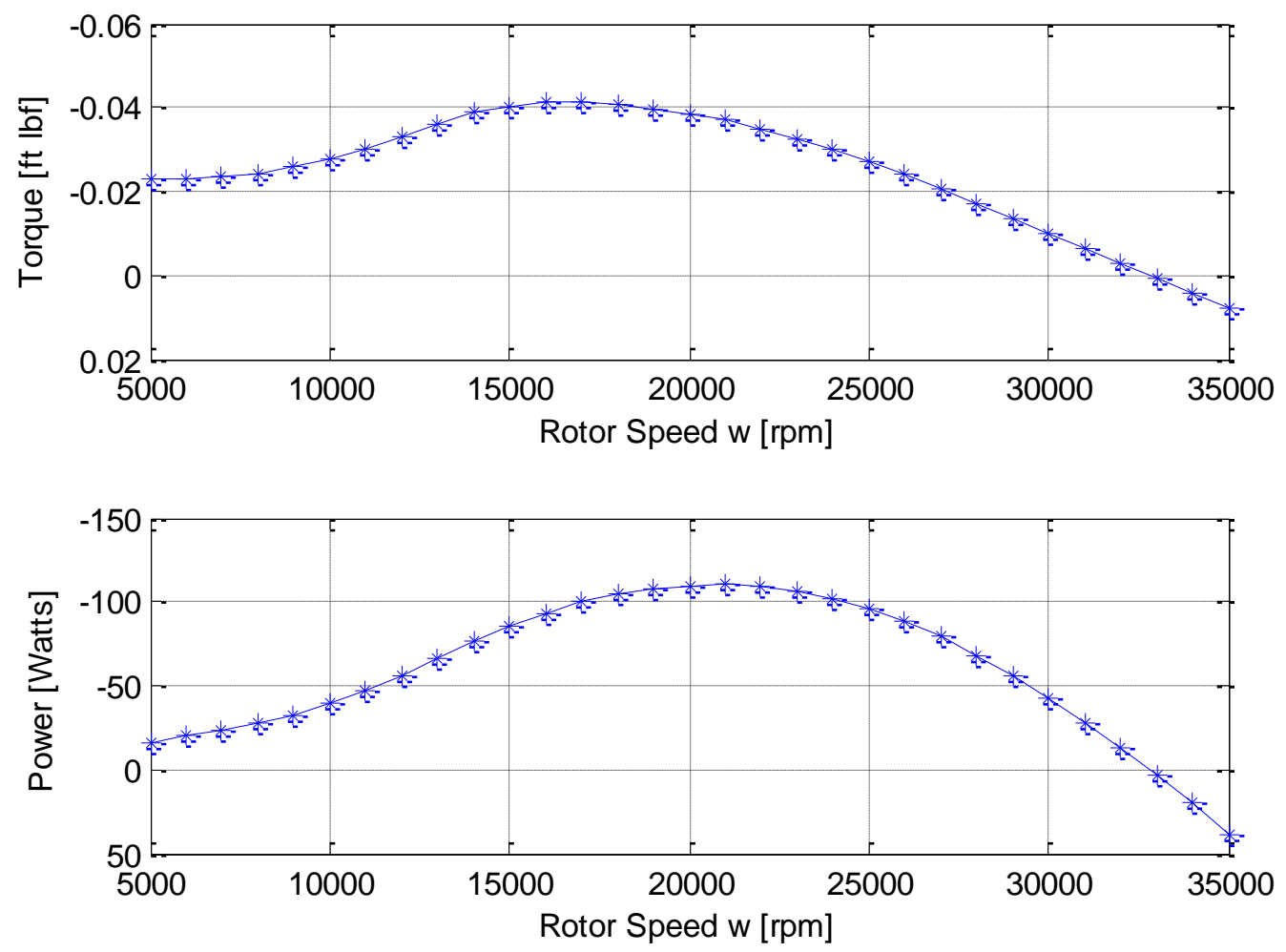

Figure 58. Blade Element Model Power and Torque Predictions for Rotor-1 Model for Airspeed of $110 \mathrm{mph}$ 

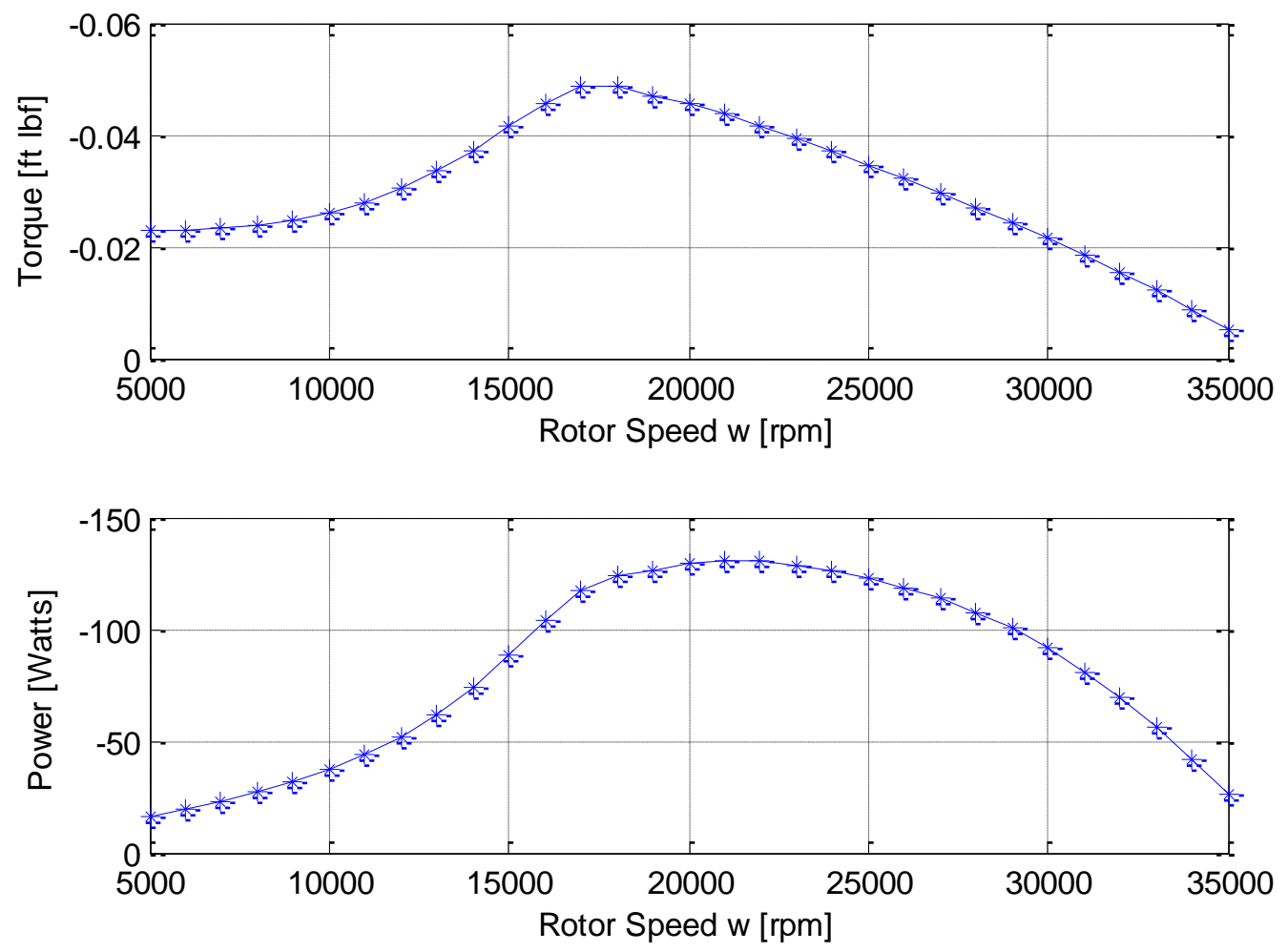

Figure 59. Blade Element Model Power and Torque Predictions for Rotor-2 Model for Airspeed of $110 \mathrm{mph}$

\subsection{X-Rotor}

Along with the rotor model based on blade element theory, it was also decided to use Drela and Youngren's X-Rotor program [22] to predict rotor performance. X-Rotor uses an extension of classical blade element analysis that includes the influence of the wake's induced flow. In setting up input parameters for X-Rotor, it was important to mirror inputs from our developed blade element model in order to establish a better comparison between models. This was done by setting the same blade geometry, fluid property settings and flight conditions in the X-Rotor analysis as in the blade element model. The following describes how to set up a rotor analysis in X-Rotor [22]. 
The figure below displays X-Rotor's startup menu window that is brought up in the terminal window by typing ./xrotor.

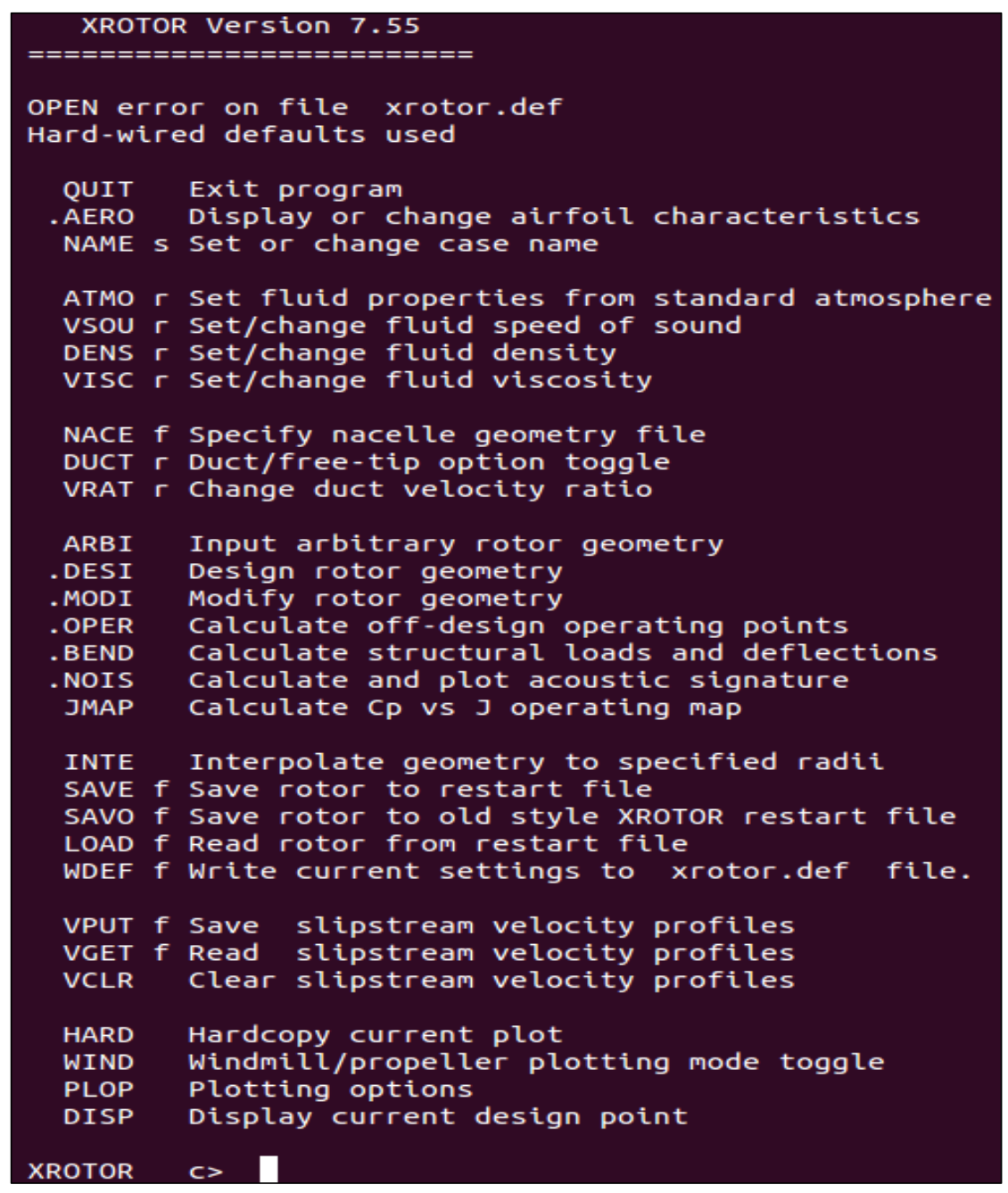

Figure 60. XROTOR Startup Window [22]

Blade airfoil characteristics are defined by typing the AERO command. This will prompt the following window which displays default airfoil data. From this submenu, a new airfoil section can be entered by typing the NEW command which will prompt a series of questions regarding airfoil lift and drag characteristics; these can be directly taken from XFOIL generated lift and drag curves. If a single airfoil will be used for the entire length of the blade, only one section needs to be created as shown below. In Figure 
61, below, airfoil data for the NACA 2412 at a reference Reynolds number of 80,000 was entered.

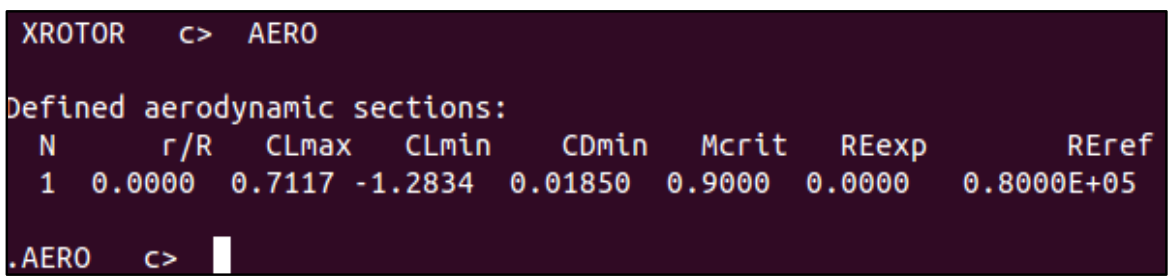

Figure 61. X-Rotor Aerodynamic Submenu [22]

To more thoroughly define the airfoil section, typing EDIT in the terminal window while still under the AERO submenu will prompt the following window. Here more detailed lift and drag values for the NACA 2412 airfoil are entered. Referencing Figure 62, parameters $3,6,11,12$, and 13 were left as default. The rest of the parameters were taken from airfoil lift and drag data.

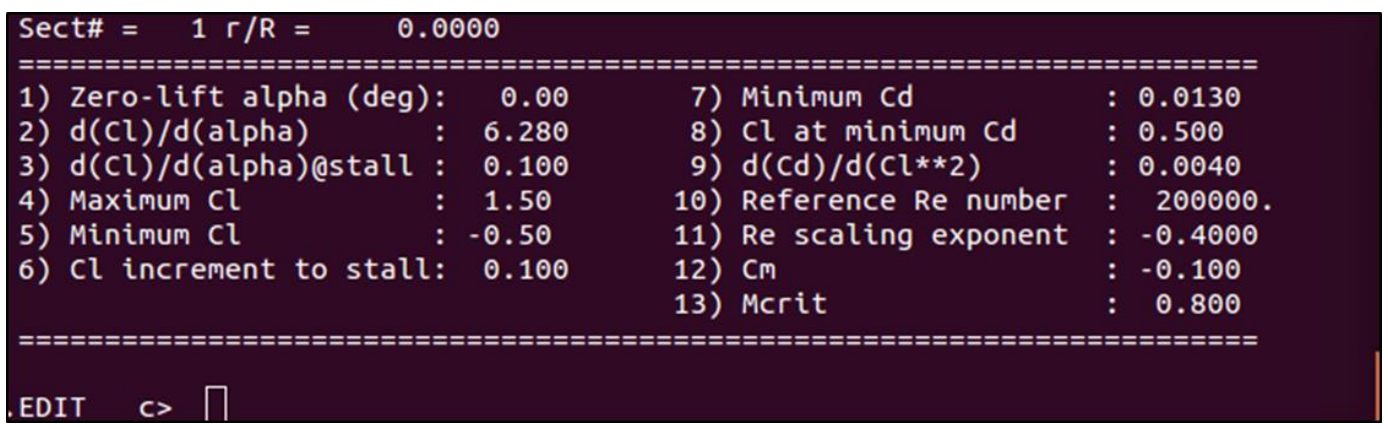

Figure 62. XROTOR Aerodynamic Section Editting Submenu [22]

From this window lift and drag parameters can be changed by simply typing LIFT or DRAG command. Because we are conducting analysis on a turbine rather than a propeller it is also necessary to adjust the lift and drag data to represent an inverted airfoil. In X-Rotor, this is done by typing REFL command under the AERO and EDIT sub menu.

Once the blade airfoil data has been entered, additional blade geometry is specified under the ARBI submenu from the startup window. Here the remaining geometrical 
parameters such as rotor hub/tip radius, number of blades, chord and blade angle are entered. When generating a blade with linear twist it is much more straightforward to enter the root blade angle when entering data in the ARBI submenu, then adjusting the blade twist under the MODI submenu, which has an option to adjust blade twist distribution. Below in Figure 63, blade geometries for both candidate rotors have been specified in X-Rotor.

\section{Straight Blade}

\begin{tabular}{|c|c|c|c|}
\hline$i$ & $r / R$ & $c / R$ & beta(deg \\
\hline 1 & 0.312 & 0.3148 & 25.00 \\
\hline 3 & 0.360 & 0.3148 & 25.00 \\
\hline 5 & 0.451 & 0.3148 & 25.00 \\
\hline 7 & 0.557 & 0.3148 & 25.00 \\
\hline 9 & 0.664 & 0.3148 & 25.00 \\
\hline 11 & 0.763 & 0.3148 & 25.00 \\
\hline 13 & 0.848 & 0.3148 & 25.00 \\
\hline 15 & 0.917 & 0.3148 & 25.00 \\
\hline 17 & 0.965 & 0.3148 & 25.00 \\
\hline 19 & 0.993 & 0.3148 & 25.00 \\
\hline
\end{tabular}

Twisted Blade

\begin{tabular}{|c|c|c|c|}
\hline$i$ & $r / R$ & \multicolumn{2}{|c|}{ c/R beta(deg } \\
\hline 1 & 0.312 & 0.3148 & 39.95 \\
\hline 3 & 0.360 & 0.3148 & 38.19 \\
\hline 5 & 0.451 & 0.3148 & 34.90 \\
\hline 7 & 0.557 & 0.3148 & 31.04 \\
\hline 9 & 0.664 & 0.3148 & 27.17 \\
\hline 11 & 0.763 & 0.3148 & 23.59 \\
\hline 13 & 0.848 & 0.3148 & 20.49 \\
\hline 15 & 0.917 & 0.3148 & 18.01 \\
\hline 17 & 0.965 & 0.3148 & 16.24 \\
\hline 19 & 0.993 & 0.3148 & 15.24 \\
\hline
\end{tabular}

Figure 63. Straight and Twisted Blade Geometry Created in XROTOR [22]

After rotor geometry has been finalized, rotor analysis can be done. From the startup menu, the OPER command will open the operating menu. Here the performance analysis can be conducted. The RPM command prompts an rpm to be entered for which the rotor will be analyzed. Figure 64 shows the window that is displayed once rotor analysis is completed for a specific rpm. From this window we can see the entered geometric and operational parameters along with predicted thrust, torque, and power. 


\begin{tabular}{|c|c|c|c|c|c|c|c|c|c|c|c|}
\hline \multicolumn{2}{|c|}{ Iter } & dGmax & \multicolumn{2}{|c|}{ @Imax } & \multicolumn{2}{|l|}{ gGrms } & Av & Aw & \multicolumn{2}{|c|}{$\mathrm{Be}$} & RLX \\
\hline 1 & \multicolumn{2}{|c|}{$0.126 \mathrm{E}+00$} & \multicolumn{2}{|c|}{19} & \multicolumn{2}{|c|}{$0.238 E-01$} & 0.5984 & 0.5374 & \multicolumn{2}{|c|}{15.038} & 0.2000 \\
\hline 2 & \multicolumn{2}{|c|}{$0.367 E-01$} & \multicolumn{2}{|c|}{17} & \multicolumn{2}{|c|}{$0.862 E-02$} & 0.5984 & 0.5374 & \multicolumn{2}{|c|}{15.038} & 0.2000 \\
\hline 3 & \multicolumn{2}{|c|}{$0.285 E-01$} & \multicolumn{2}{|c|}{17} & \multicolumn{2}{|c|}{$0.671 E-02$} & 0.5984 & 0.5374 & \multicolumn{2}{|c|}{15.038} & 1.0000 \\
\hline 4 & \multicolumn{2}{|c|}{$-0.607 E-03$} & \multicolumn{2}{|c|}{18} & \multicolumn{2}{|c|}{$0.876 E-04$} & .5984 & 0.5374 & 15 . & 038 & 1.0000 \\
\hline 5 & 0 & $.344 E-0$ & & 18 & $0.519 \mathrm{E}$ & 07 & .5984 & 0.5374 & 15. & 038 & 1.0000 \\
\hline & $f=== \pm=$ & $=====$ = $=$ & $=== \pm==$ & $=== \pm$ & $======$ & I===+==+= & $=======$ & $== \pm===$ & $=====$ & $f====$ & $:==$ \\
\hline & e Tip & Potent & tial & Forr & ulation & Solution & n: Sav & $\begin{array}{r}\text { d blade } \\
\text { Wake }\end{array}$ & adv. r & atio: & 0.53742 \\
\hline no. & blade & es : 3 & & & rad & us (m) & 0.04 & & adv. ra & tio: & 0.59842 \\
\hline thr & ust ( $N$ ) & : & -2.81 & & pow & $r(W)$ & -95.8 & & torque( & $(N-m):$ & $-0.482 E-01$ \\
\hline Eff & ticienc & cy : & 1.4430 & & spe & $d(\mathrm{~m} / \mathrm{s})$ & 49.1 & & rpm & : & 18999.998 \\
\hline Eff & $=$ induc & ced: & 1.3534 & & Eff & ideal : & 1.10 & & Tcoef & : & -0.3540 \\
\hline Tna & $\operatorname{ccel}(\mathrm{N})$ & ) : & -0.0 & 0000 & hub & rad.(m): & 0.01 & & disp. r & ad. & 0.0127 \\
\hline Tvi & $\operatorname{sc}(\mathrm{N})$ & : & -0.0 & 0508 & Pvi & $c(W) \quad:$ & 4.50 & & & & \\
\hline rho & $\left(\mathrm{kg} / \mathrm{m}^{3}\right.$ & 3) & 1.226 & 600 & Vso & Ind (m/s): & 340.0 & & $\mathrm{mu}(\mathrm{kg} / \mathrm{m}$ & $(-5)$ & $0.1780 \mathrm{E}-04$ \\
\hline & $\cdots$ & $\cdots$ & $\cdots$ & $\cdots$ & $\cdots$ & & $-\cdots$ & $\cdots$ & $\cdots$ & $\cdots$ & - \\
\hline & дта : & 0.300 & 961 & & & & & & & & \\
\hline & & & Ct: & & .49132 & Cp: & -0.640 & & & 87999 & \\
\hline & & & Tc: & & .35399 & PC: & -0.245 & adv & & 59842 & \\
\hline$i$ & $r / R$ & $C / R$ & beta( & (deg) & ) $\mathrm{CL}$ & Cd & $\operatorname{RE} \times 10^{\wedge} 3$ & Mach & effi & effp & na.u/u \\
\hline 1 & 0.312 & 0.3148 & 339. & 95 & -1.247 & 0.0325 & 49.95 & 0.164 & 1.436 & 1.055 & 0.000 \\
\hline 3 & 0.360 & 0.3148 & 38. & 19 & -1.216 & 0.0296 & 51.62 & 0.170 & 1.378 & 1.050 & 0.000 \\
\hline 5 & 0.451 & 0.3148 & 34. & 90 & -1.154 & 0.0271 & 55.23 & 0.181 & 1.299 & 1.048 & 0.000 \\
\hline 7 & 0.557 & 0.3148 & 31. & .04 & -1.077 & 0.0256 & 60.20 & 0.198 & 1.257 & 1.050 & 0.000 \\
\hline 9 & 0.664 & 0.3148 & 27 . & 17 & -1.000 & 0.0246 & 65.81 & 0.216 & 1.258 & 1.054 & 0.000 \\
\hline 11 & 0.763 & 0.3148 & 23. & 59 & -0.921 & 0.0238 & 71.44 & 0.235 & 1.300 & 1.061 & 0.000 \\
\hline 13 & 0.848 & 0.3148 & 20. & 49 & -0.824 & 0.0229 & 76.63 & 0.252 & 1.385 & 1.073 & 0.000 \\
\hline 15 & 0.917 & 0.3148 & 18. & 01 & -0.687 & 0.0218 & 81.09 & 0.266 & 1.523 & 1.095 & 0.000 \\
\hline 17 & 0.965 & 0.3148 & 16. & 24 & -0.498 & 0.0206 & 84.63 & 0.278 & 1.733 & 1.147 & 0.000 \\
\hline 19 & 0.993 & 0.3148 & & 24 & -0.261 & 0.0194 & 87.08 & 0.286 & 2.025 & 1.364 & 0.000 \\
\hline
\end{tabular}

Figure 64. X-Rotor Rotor Analysis Results [22]

The rotor analysis was conducted for the same rpm ranges as in the rotor model based on blade element theory $(5,000-30,000 \mathrm{rpm})$. Results for the blade element model and X-Rotor are plotted and compared in Figure 65 Figure 67. Comparing the power curve peaks, it can be seen that the blade element rotor model overpredicts maximum generated power when compared to the X-Rotor program predictions by approximately $30 \%$. It is expected for the blade element model to overpredict power, since induced flow effects have not been included in our model whereas these 3-D effects are included in the X-Rotor model. These power prediction charts can now be used to match the rotor to a generator by comparing performance charts and matching performance curves, as will be explained in the next chapter 


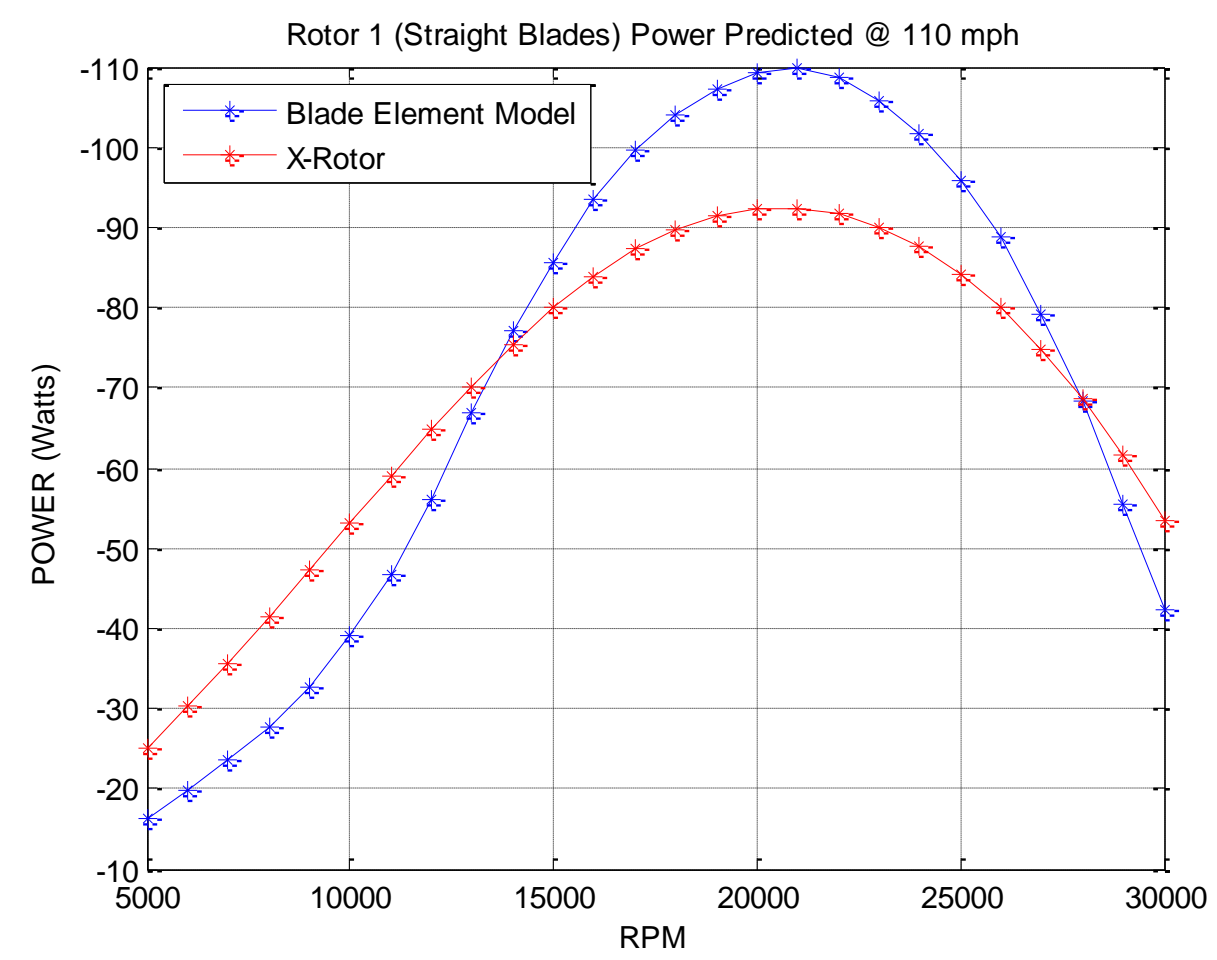

Figure 65. Rotor 1 (straight blades) Predicted Power @ 110 mph (sea level)

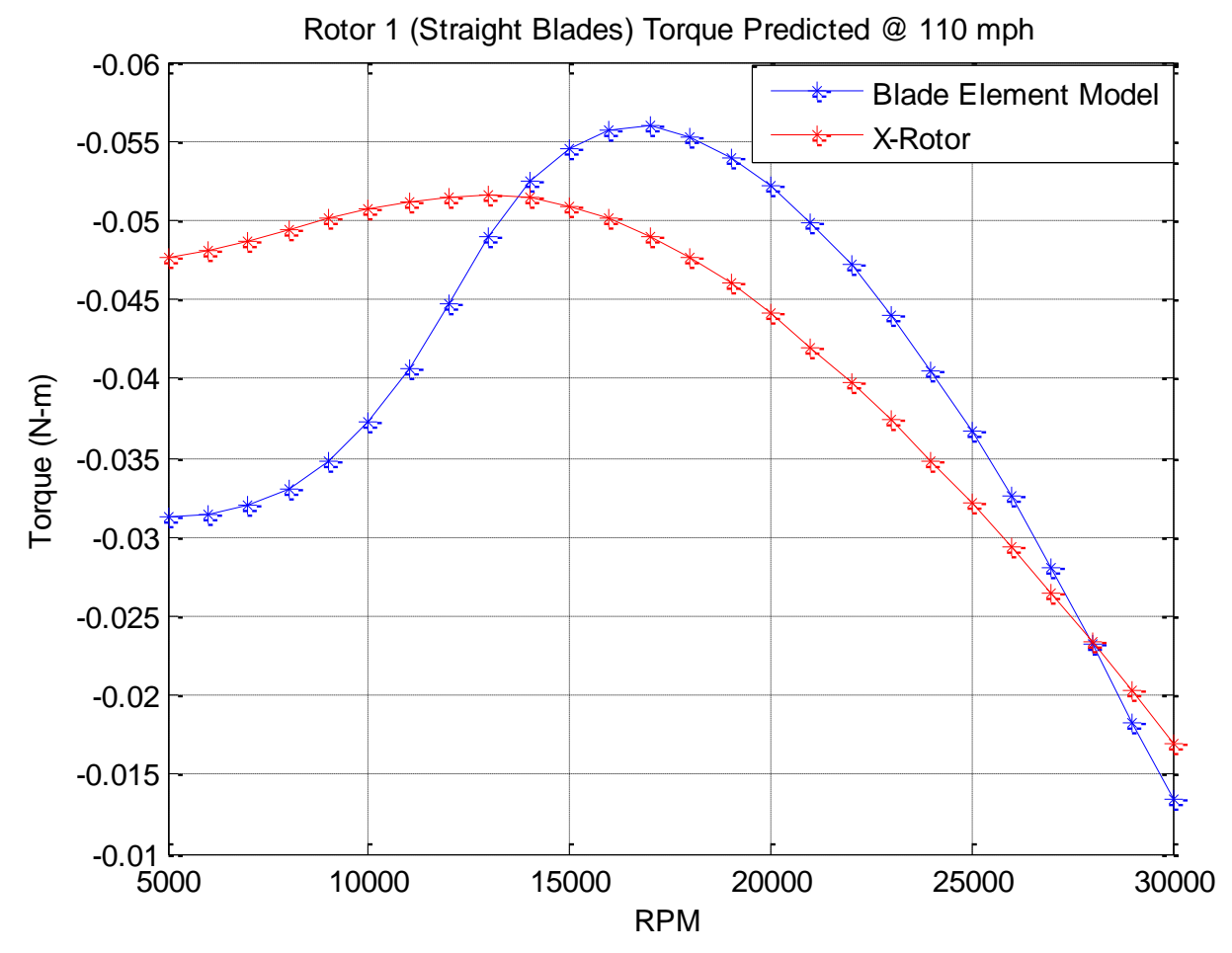

Figure 66. Rotor 1 (straight blades) Predicted Torque @ 110 mph (sea level) 


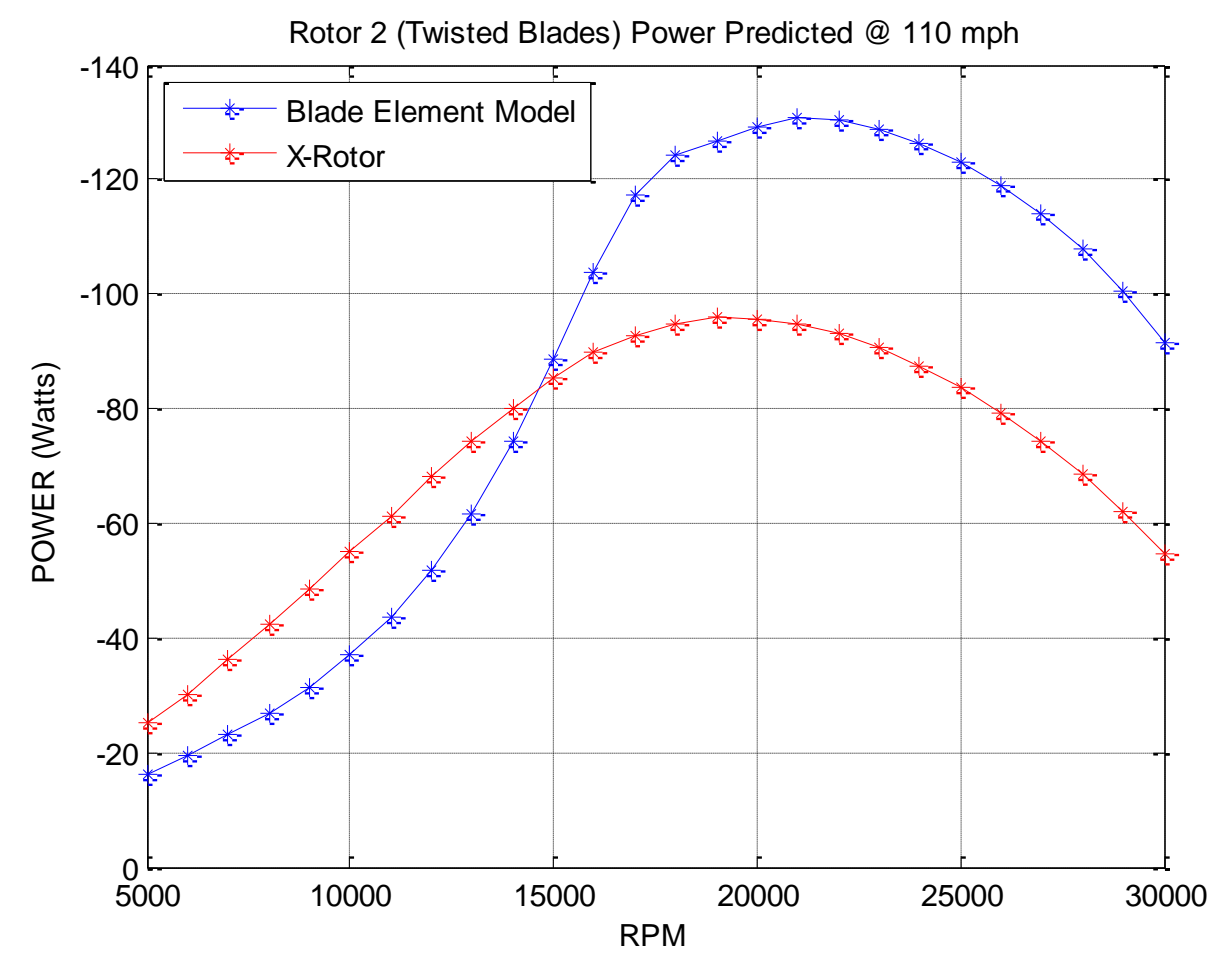

Figure 67. Rotor 2 (twisted blades) Predicted Power @ 110 mph (sea level)

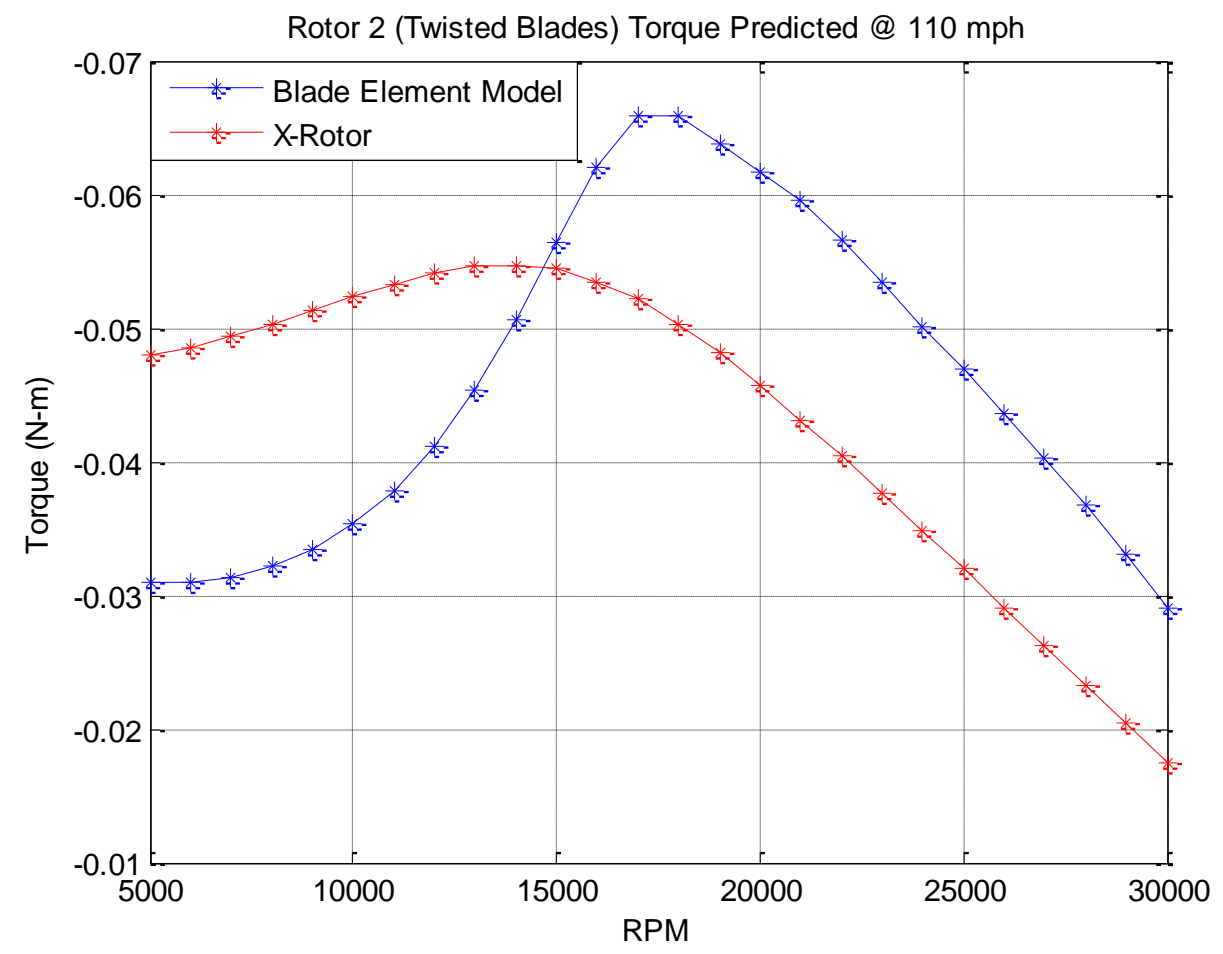

Figure 68. Rotor 2 (twisted blades) Predicted Torque @ $110 \mathrm{mph}$ (sea level) 


\section{ROTOR/GENERATOR MATCHING}

Rotor/generator matching involves taking known rotor performance data and matching it to a generator to enable the prediction of how the rotor will perform with a particular generator. Figure 69 illustrates the process of rotor/generator matching. Starting at the left side of the diagram, we see inputs to the rotor and generator design tools. Inputs include rotor geometry, atmospheric conditions and axial airspeed for the rotor model, and generator manufacturer specifications of a particular off-the-shelf generator for the generator model. Additionally generator-operating limitations such as maximum voltage $(\mathrm{V})$, current $(\mathrm{A})$, speed (rpm) and power $(\mathrm{W})$ should be considered to ensure that rotor performance maintains generator operation within continuous operating limits. Using the design tools, performance for both the rotor and generator is predicted. Performance data is then brought together to establish efficiency at the rotor peak power operating point with respect to the generator maximum efficiency operating point. This is done by plotting rotor brake power overlaid on a generator efficiency chart; from this chart efficiency at peak rotor brake power is identified and compared to the generator maximum efficiency operating point. An example of a good rotor/generator match, peak rotor brake power would lie in the operating range of generator maximum efficiency. Next the generator electrical load is identified; for this, rotor brake torque and power plots are overlaid on generator brake torque and power plots for various electrical loads. Here electrical loads for maximum rotor power and for generator maximum efficiency are identified. The rotor/generator matching conducted for the baseline rotors and generator will now be presented in the following paragraph. 


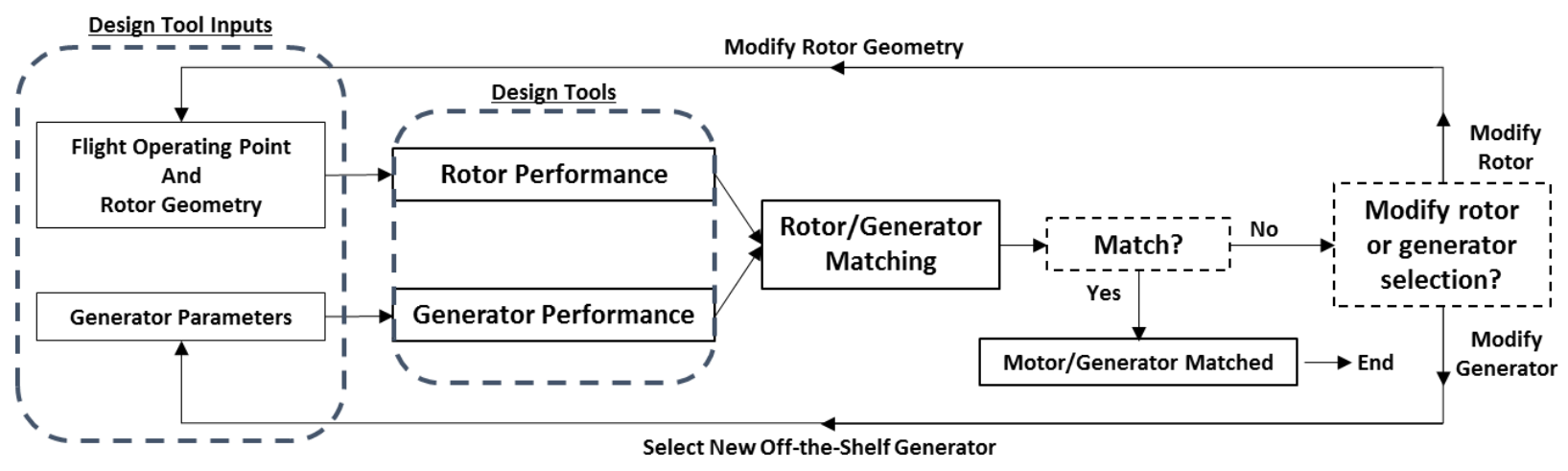

Figure 69. Rotor/Generator Matching Process

In matching the baseline rotor to a generator, we first observe rotor performance. Baseline rotor performance was established in Chapter 3 using two rotor models, a blade element model and X-Rotor; performance predictions are shown in Figure 58 and Figure 59 for rotor- 1 and 2, respectively, operating at sea level conditions at an airspeed of 110 mph. Geometric inputs to the rotor model are displayed in Table 15. Initial selection of a generator to be matched to a rotor should be based on the $\mathrm{Kv}$ parameter; High $\mathrm{Kv}$ for high speed operating rotor and low $\mathrm{Kv}$ for low speed operating rotor. Generator performance is then established using the generator model from Chapter 2. Inputs to the generator model are the manufacturer specifications for the BLDC Maxon generator (\#386677) shown in Figure 18 and manufacturer specified current-voltage data for the 3phase bridge rectifier in Figure 31. Generator performance including rectifier losses is shown in Figure 70 and Figure 71 . The Generator Efficiency plot shown in Figure 70 displays generator efficiency as a function of brake power and speed. Figure 71 displays generator brake power and torque as a function of speed for electrical loads ranging from 1-20 Ohms. With both rotor and generator performance data, the rotor can now be matched to the generator. 


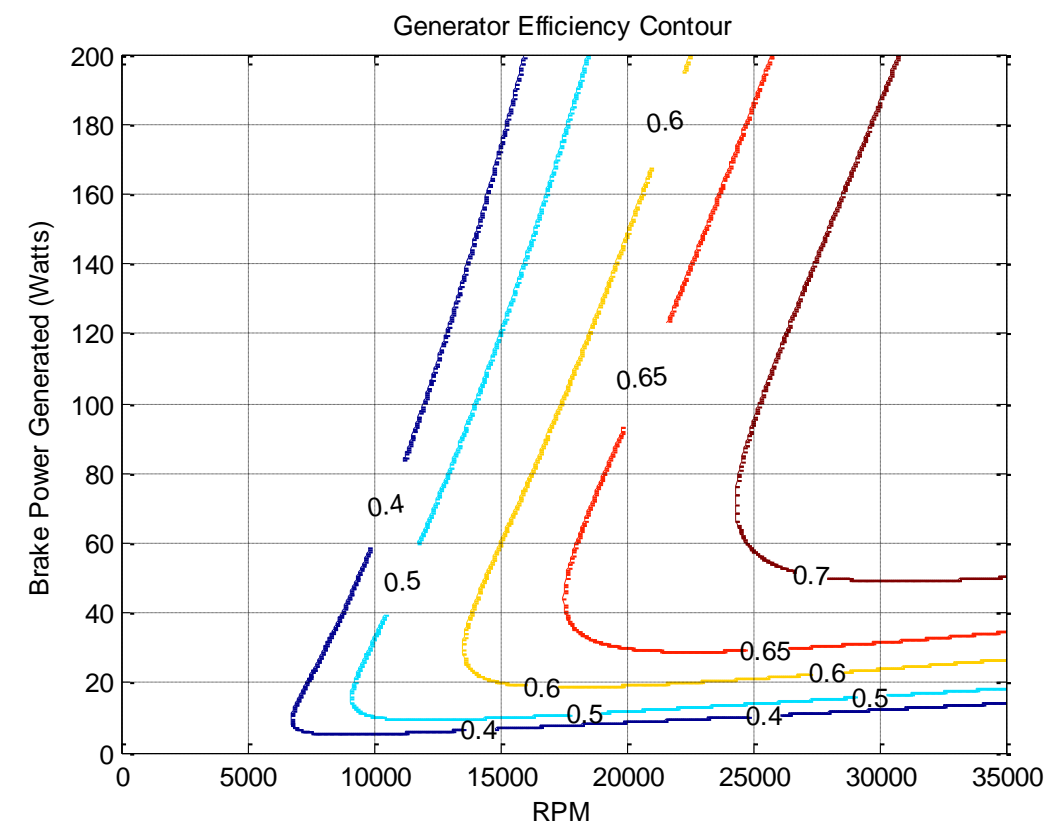

Figure 70. Maxon (\#386677) Generator Efficiency Contour Map
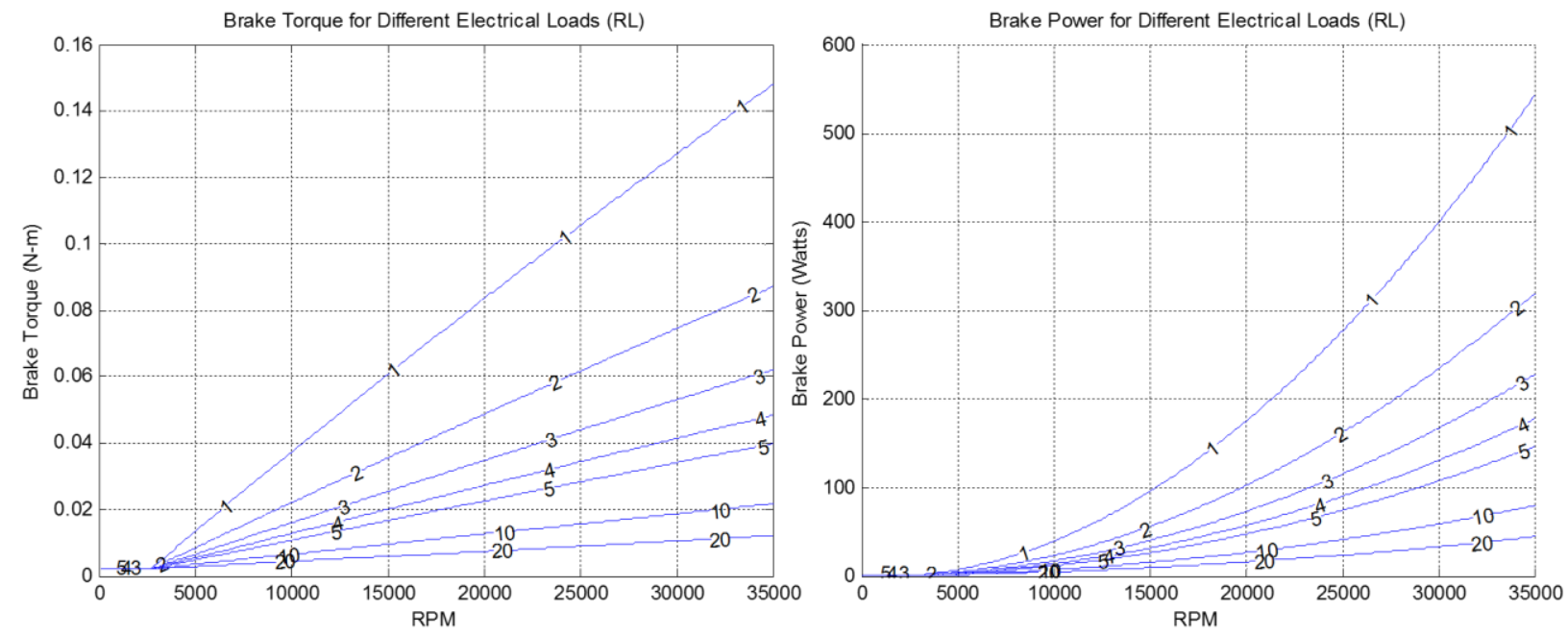

Figure 71. Maxon (\#386677) Generator Brake Torque and Power for Terminal Loads 1-20 Ohms

Performance predictions from both the rotor and generator models have been combined in Figure 72 to determine efficiency at peak rotor brake power and compare that point to the generator maximum efficiency operating point. The region of maximum efficiency for the generator is at $70 \%$ beginning at a velocity of approximately 24,000 
rpm and brake power of 50 watts. Blade peak predicted performance lies in the 65-66 percent region. Although it would be ideal for the peak rotor power to match generator maximum efficiency, this generator provided a match that is sufficient for our purposes. For this rotor a generator with lower $\mathrm{Kv}$ would adjust the region of maximum efficiency to lie nearer to the rotor's peak power or alternatively a rotor which achieves peak power generated at a higher rpm (above 30,000).

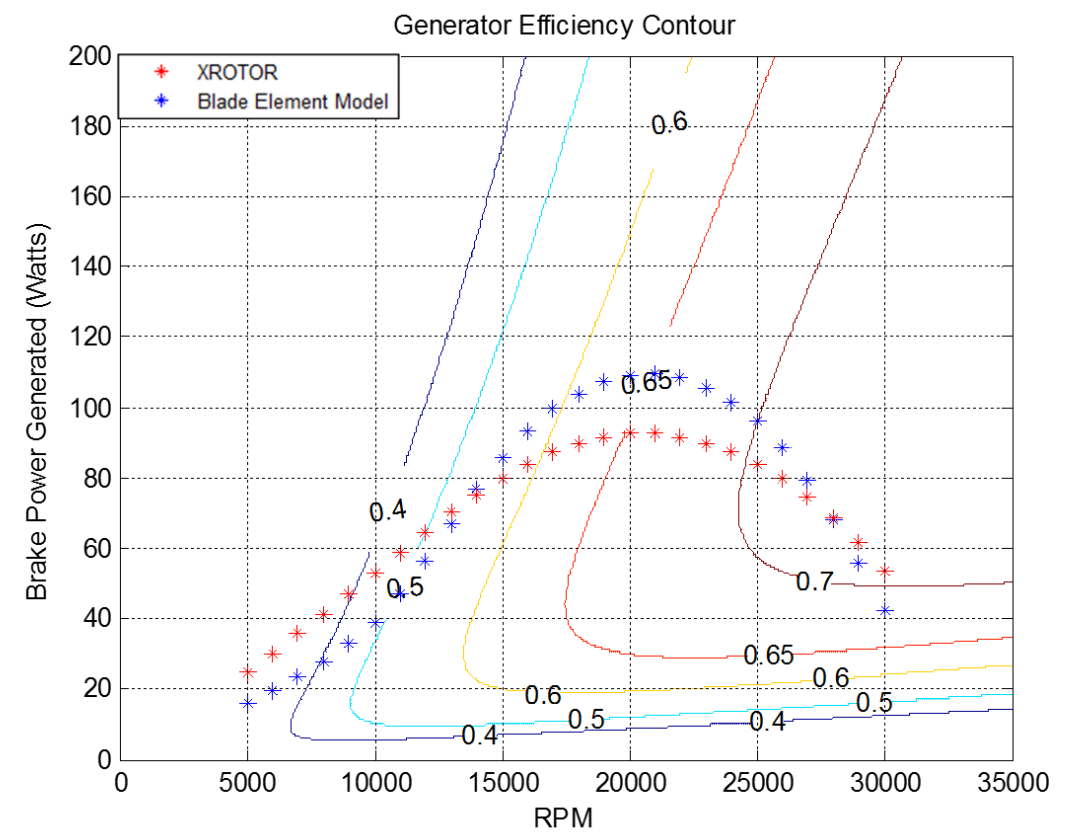

Figure 72. Rotor-1 Brake Power Plotted onto Generator Efficiency Contour [Generator: Maxon \#386677]; [ @ sealevel, 110 mph, Betz Limit=230 Watts]

Now it is necessary to determine the range of electrical loads at the generator terminal for the given predicted rotor brake power. This is done in Figure 73 with the predicted rotor brake torque and power curves plotted over generator (shaft) brake torque and power for electrical loads ranging from 1 to $20 \mathrm{ohms}$. Looking at the efficiency data from Figure 72 and electrical load data from Figure 73, it can be seen that selecting a load of 2 Ohms would allow the rotor to perform at maximum peak power of 109 Watts at $65 \%$ efficiency. At a load of $5 \mathrm{ohms}$, the rotor would produce less power, albeit at a 
higher generator efficiency (79 Watts @ 71\% efficiency). Although higher efficiencies are experienced while operating at $5 \mathrm{ohms}$, terminal power output is higher with a load of 2 ohms by approximately 15 Watts.

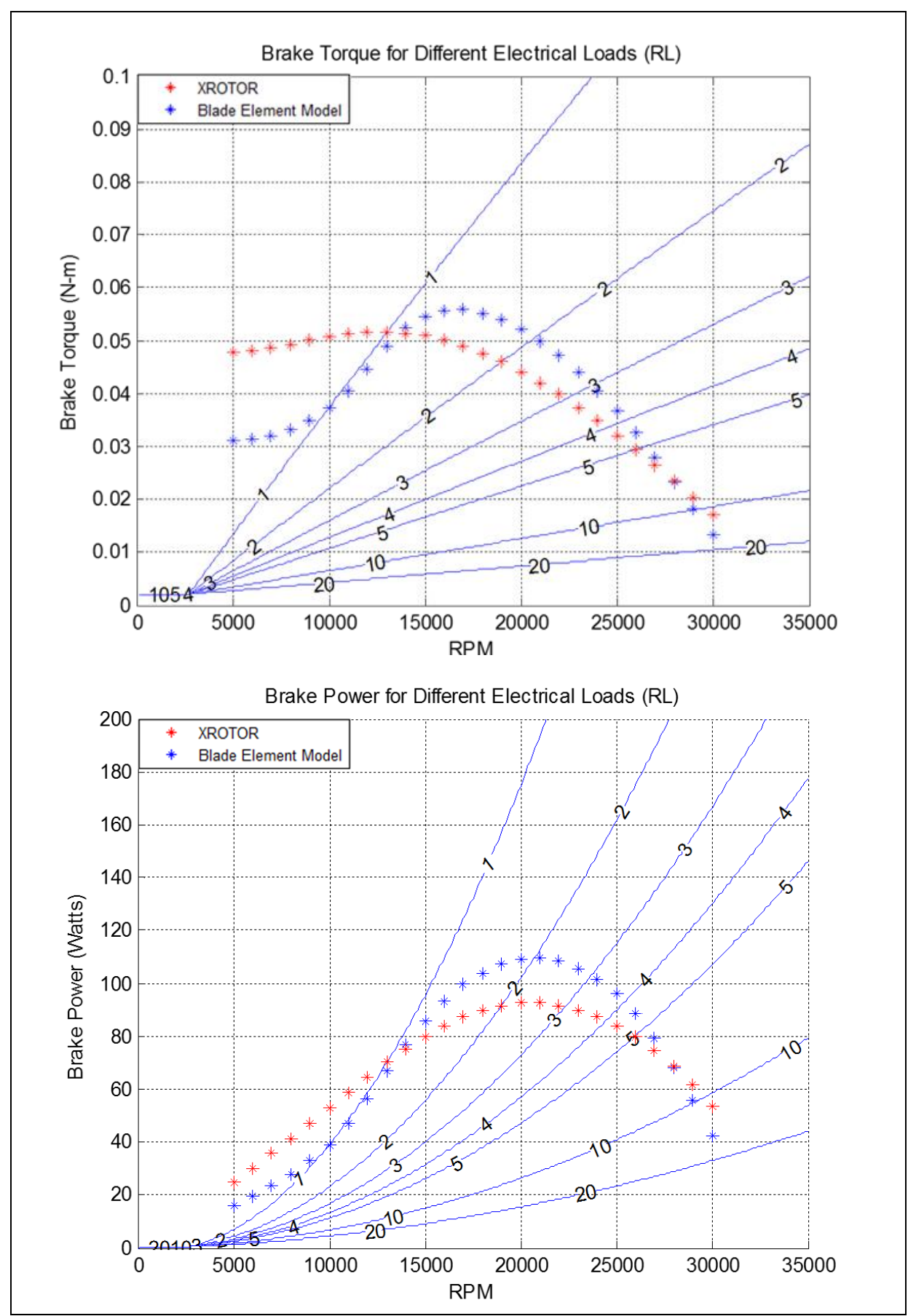

Figure 73. Rotor 1 Brake Torque and Power Curves Overlaid Generator Brake Torque and Power plots fort varying Electrical Loads of 1-20 Ohms 
Table 16 provides a summary of the rotor-generator performance for rotor- 1 at peak rotor brake power as seen from the plots in Figure 72 and Figure 73.

Table 16. Rotor-Generator Performance at Maximum Rotor Power Operating Point for Rotor-1

\begin{tabular}{|c|c|c|c|c|c|c|c|}
\hline Rotor & RPM & $\begin{array}{c}\text { Max } \\
\text { Brake } \\
\text { Power } \\
\text { (Watts) }\end{array}$ & $\begin{array}{c}\text { Current } \\
\text { (Amps) }\end{array}$ & $\begin{array}{c}\text { Terminal } \\
\text { Voltage }\end{array}$ & $\begin{array}{c}\text { Terminal } \\
\text { Power } \\
\text { (Watts) }\end{array}$ & $\begin{array}{c}\text { Terminal } \\
\text { Load RL } \\
\text { (ohms) }\end{array}$ & $\begin{array}{c}\text { Generator } \\
\text { Efficiency } \\
\text { (\%) }\end{array}$ \\
\hline $\begin{array}{c}\text { Blade } \\
\text { Element }\end{array}$ & 21,000 & 109.75 & 5.89 & 12.16 & 71.59 & 2.06 & 65.2 \\
\hline X-Rotor & 21,000 & 92.4 & 4.91 & 12.49 & 61.44 & 2.54 & 66.5 \\
\hline
\end{tabular}

Rotor- 2 was matched to the same generator and in the same manner as rotor- 1. Rotor-2 performance and generator performance have been combined in Figure 74 and Figure 75 to determine efficiency at peak rotor brake power and to determine the range of electrical loads at the generator terminal for the given predicted rotor brake power.

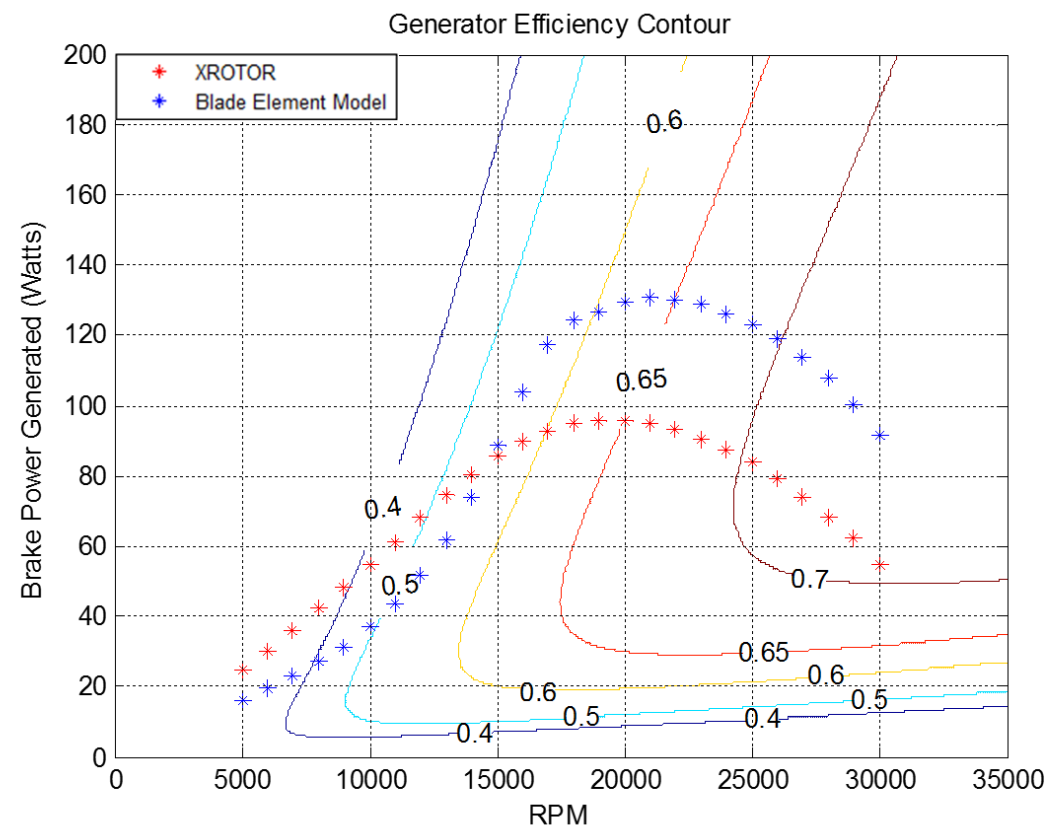

Figure 74. Rotor-2 Generator Efficiency Contour Plot

Looking at the predicted power curve for the rotor model in Figure 74 and Figure 75, it can be seen that selecting a load of 1.6 - 2 ohms would allow rotor- 2 to perform at peak 
power of 131 watts at $63 \%$ efficiency. At a load of 5 ohms, the rotor would produce less power at a higher generator efficiency (100 watts @ 72\% efficiency). Although higher efficiencies are experienced while operating at $5 \mathrm{ohms}$, terminal power output is higher with a load of 2 ohms by approximately 10 watts.

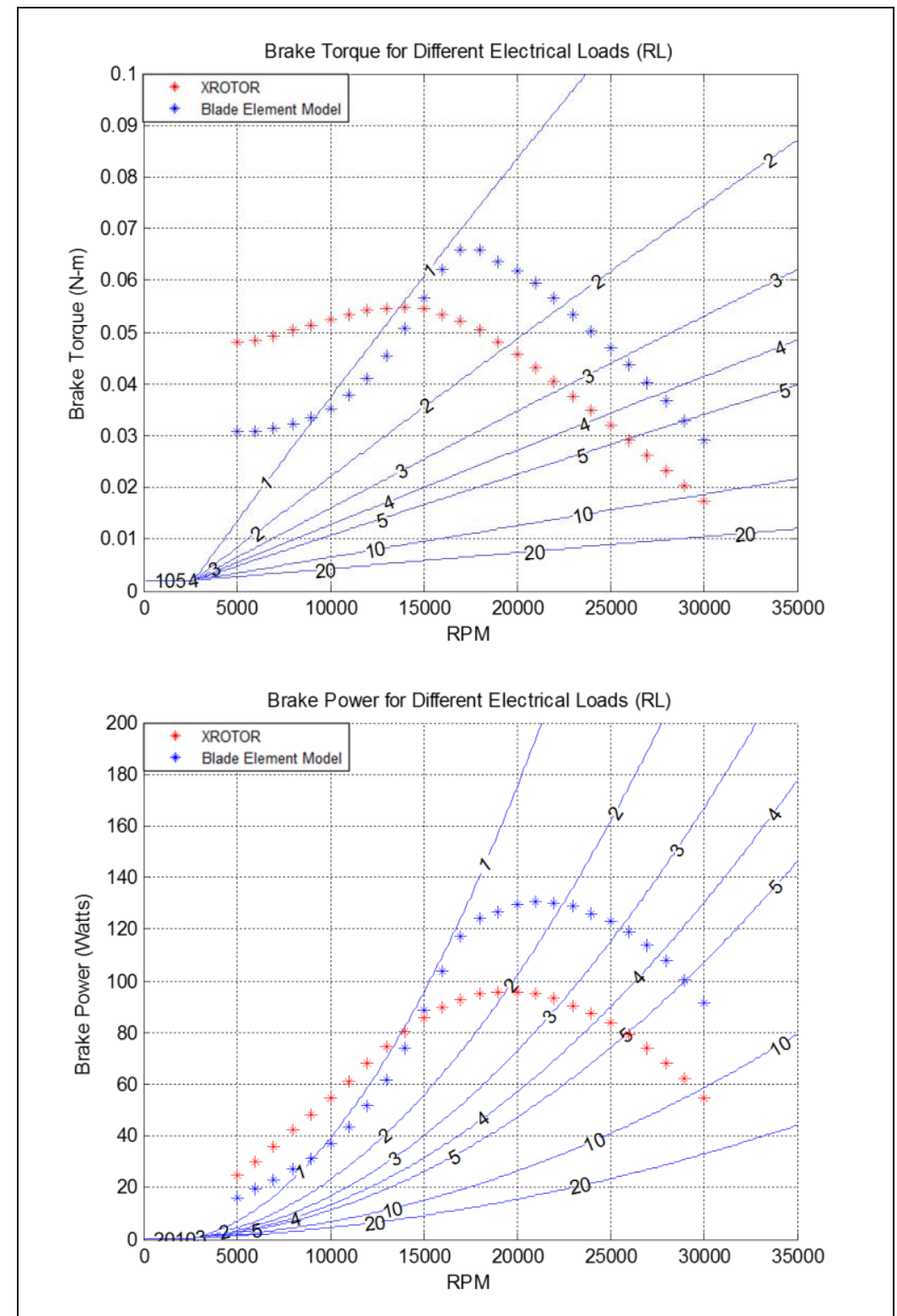

Figure 75. Rotor Brake Torque and Power Curves Overlaid Generator Brake Torque and Power plots fort varying Electrical Loads of 1-20 Ohms 
Table 17 provides a summary of the rotor-generator performance at peak rotor brake power for rotor-2, as seen from the plots in Figure 74 and Figure 75.

Table 17. Rotor-Generator Performance at Max Rotor Power Operating Point for Rotor-2

\begin{tabular}{|c|c|c|c|c|c|c|c|}
\hline $\begin{array}{c}\text { Rotor } \\
\text { Model }\end{array}$ & RPM & $\begin{array}{c}\text { Max Shaft } \\
\text { Pwr } \\
\text { (Watts) }\end{array}$ & $\begin{array}{c}\text { Current } \\
\text { (Amps) }\end{array}$ & $\begin{array}{c}\text { Terminal } \\
\text { Voltage }\end{array}$ & $\begin{array}{c}\text { Terminal } \\
\text { Pwr } \\
\text { (Watts) }\end{array}$ & $\begin{array}{c}\text { Terminal } \\
\text { Load } \\
\text { (ohms) }\end{array}$ & $\begin{array}{c}\text { Generator } \\
\text { Efficiency } \\
\text { (\%) }\end{array}$ \\
\hline $\begin{array}{c}\text { Blade } \\
\text { Element } \\
\text { Model }\end{array}$ & 21000 & 130.9 & 7.07 & 11.7 & 83.1 & 1.66 & 63.5 \\
\hline X-Rotor & 19000 & 95.8 & 5.67 & 10.72 & 60.8 & 1.89 & 63.5 \\
\hline
\end{tabular}

Comparing how rotor- 1 and rotor- 2 match with the generator, rotor- 1 is slightly a better match by about 2-3 percent efficiency. Generally a rotor with untwisted blades generates less brake power than a rotor with twisted blades however if the operating peak of the lower performing rotor lies in a higher generator efficiency region than the higher performing rotor, it is possible for the rotor that generates less brake power (Untwisted) to produce a higher terminal electrical power output than the higher performing rotor. Both rotors matched in this thesis operate at an acceptable efficiencies for the purpose of model evaluation testing.

Following baseline rotor/generator matching, an example of a different generator matched to rotor-1 will be presented. For the purpose of distinguishing between generators, the generator previously matched to the baseline rotors will be referred to as "Generator-A", and the generator to be matched in this example as "Generator-B". The generator matched in this example is the BLDC Maxon generator \#386678, shown in Figure 76. 


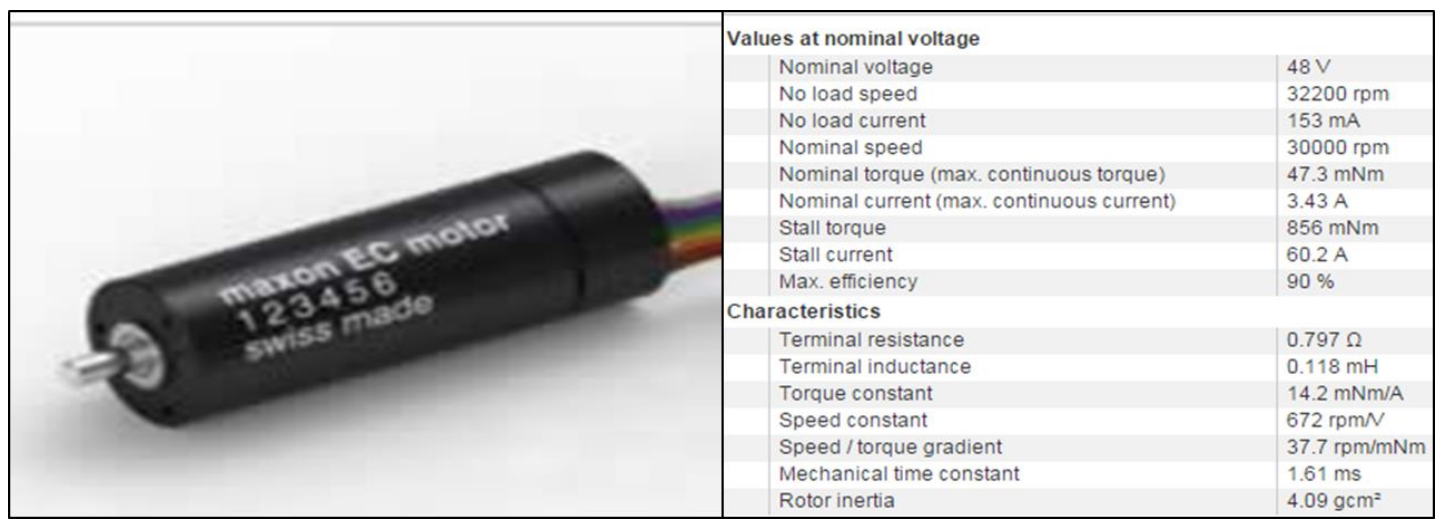

Figure 76. Generator-B Manufacturer Specifications [Maxon \#386678] [18]

Parameters for both generators A and B are shown and compared below in Table 18 . Here we see that the $\mathrm{Kv}$ for generator-B is just over half of that of generator-A; with a lower $\mathrm{Kv}$ the generators internal resistance and inductance reactance is higher. The following Figure 77 andFigure 78 show the same type of plots produced for baseline generator matching only now rotor-1 is being matched to generator-B.

Table 18. Generator A and B Manufacturer Specifications

\begin{tabular}{|c|c|c|}
\hline Parameters & Generator-A & Generator-B \\
\hline Kv [rpm/V] & 1230 & 672 \\
\hline Ri [Ohms] & 0.269 & 0.797 \\
\hline lo [Amps] & 0.263 & 0.153 \\
\hline L [H] & 0.000035 & 0.000118 \\
\hline
\end{tabular}




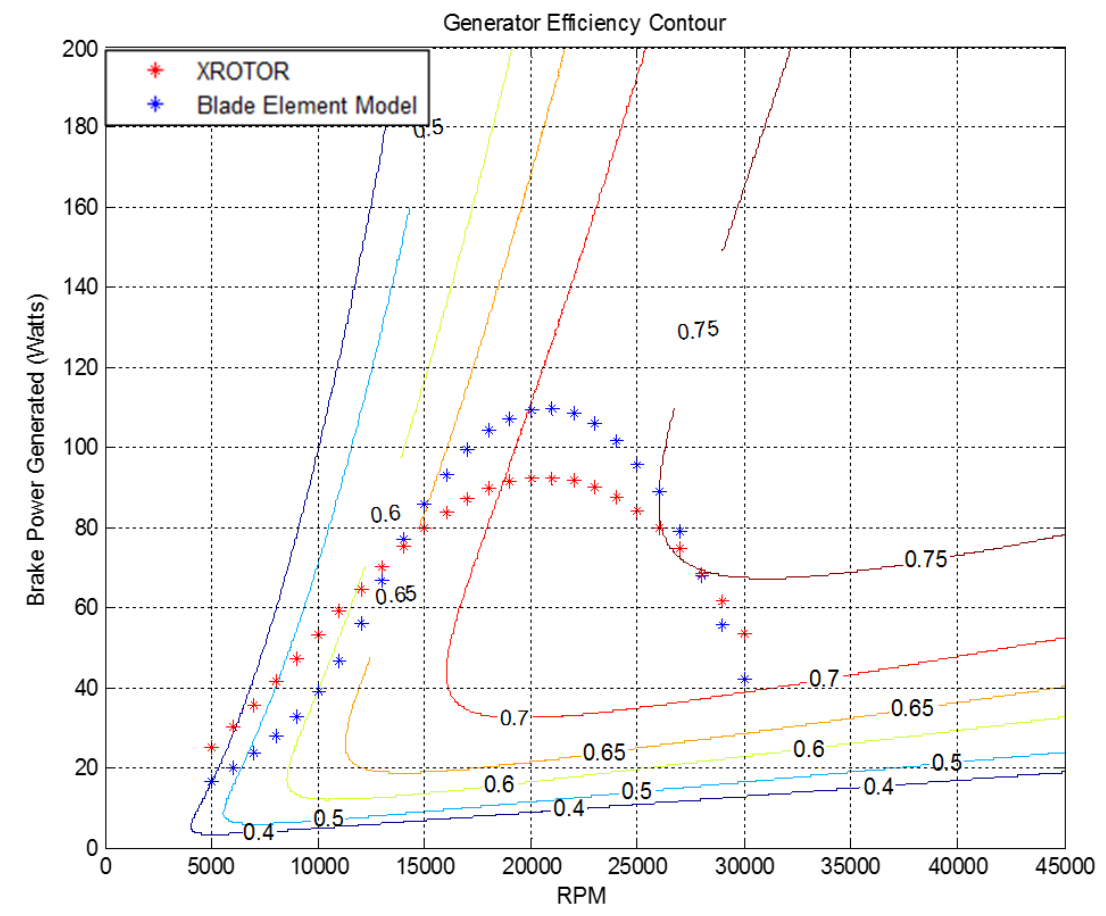

Figure 77. Rotor-1 \& Generator B Efficiency Contour

The region of max efficiency for generator-B is at about $75 \%$ beginning at a velocity of approximately $26,000 \mathrm{rpm}$ and brake power of about 50 watts. Rotor peak predicted performance lies in the $70-72 \%$ efficiency region. It can be seen that generator-B is slightly a better match then generator-A by about $5 \%$ efficiency at peak rotor operating point. 

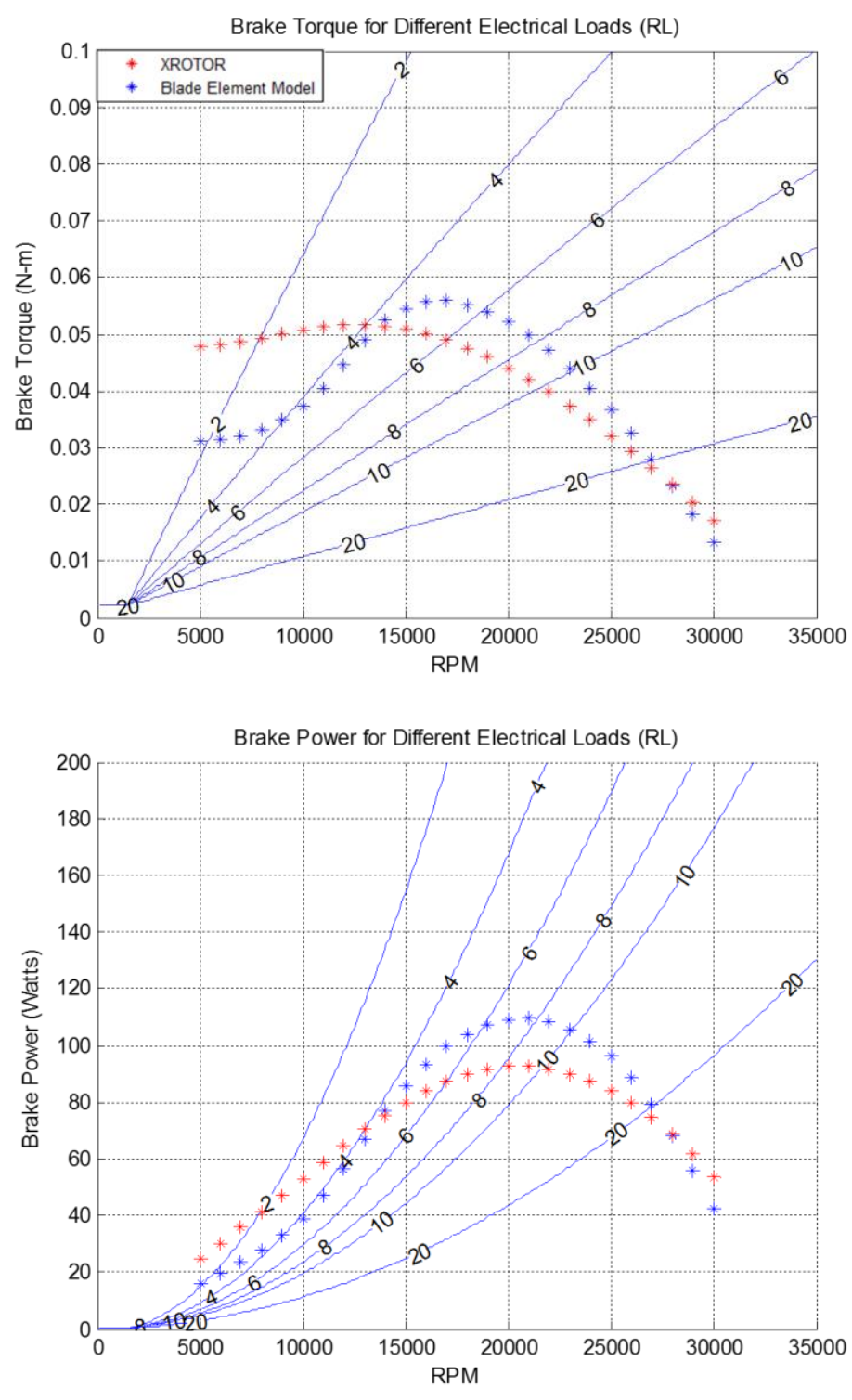

\section{Figure 78. Rotor-1 Brake Torque and Power Curves Overlaid Generator-B Brake Torque and Power plots fort varying Electrical Loads of 1-20 Ohms}

Now looking at the predicted power curve for rotor-1 plotted over generator-B performance plots in both Figure 77 and Figure 78, it can be seen that selecting a load of 7.6 ohms would allow the rotor to perform at peak power of 109 watts at $71 \%$ efficiency. At a load of $20 \mathrm{ohms}$, the blade would produce less power at a higher generator efficiency (70 watts@75\% efficiency). Although higher efficiencies are experienced while operating at $20 \mathrm{ohms}$, terminal power output is higher with a load of $7.6 \mathrm{ohms}$ by 
approximately 12 watts. Table 19 provides a summary of the rotor-generator performance at peak rotor brake power for rotor-1, as seen from the plots in Figure 77 and Figure 78.

\section{Table 19. Generator-B Efficiency at Maximum Rotor-1 Power Operating Point}

\begin{tabular}{|c|c|c|c|c|c|c|c|}
\hline $\begin{array}{c}\text { Rotor } \\
\text { Model }\end{array}$ & RPM & $\begin{array}{c}\text { Max } \\
\text { Brake } \\
\text { Power } \\
\text { (Watts) }\end{array}$ & $\begin{array}{c}\text { Current } \\
\text { (Amps) }\end{array}$ & $\begin{array}{c}\text { Terminal } \\
\text { Voltage }\end{array}$ & $\begin{array}{c}\text { Terminal } \\
\text { Power } \\
\text { (Watts) }\end{array}$ & $\begin{array}{c}\text { Terminal } \\
\text { Load } \\
\text { (ohms) }\end{array}$ & $\begin{array}{c}\text { Generator } \\
\text { Efficiency } \\
\text { (\%) }\end{array}$ \\
\hline $\begin{array}{c}\text { Blade } \\
\text { Element }\end{array}$ & 21000 & 109.75 & 3.2 & 24.35 & 78.11 & 7.6 & 71.2 \\
\hline X-Rotor & 21000 & 92.4 & 2.7 & 24.9 & 66.7 & 9.3 & 72.2 \\
\hline
\end{tabular}

Although generator-B is a slightly better match for rotor-1 than generator-A, it is not a perfect match. A more better match would be if the rotor-1 peak brake power occurred at or above a speed of about $26,000 \mathrm{rpm}$, closer to the maximum generator efficiency point or alternatively if generator-B maximum efficiency occurred at the rotor-1 peak brake power speed of 21,000 rpm. For selecting an electrical load for the generator, the general trend suggest that for low speeds a higher resistance will result in lower power generation and lower efficiencies and for high speeds a higher resistance will result in higher power generated and higher efficiencies. In selecting a generator to match to a rotor, it is important to understand how parameters effect performance. It is clear that anything that contributes to losses such as resistance, inductance reactance, no-load current, and rectifier losses will decrease generator maximum efficiency. Kv generally affects the speed at which maximum efficiency occurs. For high Kv electrical machines, max efficiency will occur at higher speeds than low $\mathrm{Kv}$ electrical machines. Understanding how internal resistance and inductance trend with $\mathrm{Kv}$ also aids in the selection of an appropriate generator. High $\mathrm{Kv}$ machines operate at relatively higher speeds and lower torque; have thicker wire and fewer windings, resulting in lower internal resistance and low inductance reactance. Lower $\mathrm{Kv}$ machines operate at 
relatively higher torque, lower speeds and have thinner wire with more windings resulting in higher internal resistance and higher inductance reactance. Based on this, rotors that perform at relatively low speeds will match better with a low $\mathrm{Kv}$ generator and rotors operating at high speeds will match better with a high $\mathrm{Kv}$ generator. A better match for the baseline rotors $1 \& 2$ would be a generator of lower $\mathrm{Kv}$ compared to the baseline generator $\mathrm{Kv}$ of 1230 . However, the baseline rotor generator combination selected for this thesis performs at a sufficient level for conducting model evaluation test. 


\section{BASELINE ROTOR/GENERATOR VALIDATION TEST}

Baseline rotor/generator validation test have been conducted to evaluate both generator and rotor design tools. Leading up to testing, both rotor and generator models were implemented in determining rotor design and in matching the rotor to an off-theshelf brushless DC motor used as a generator. Through rotor/generator matching, generator efficiency was assessed for the range of speeds and loads over which the rotor

operates. With confidence in the generator model established through motored-generator testing described in Chapter 2.6 and the candidate validation rotor designed and matched to a generator, the assembly and wind tunnel testing of the turbine generator was conducted. This involved designing and manufacturing the candidate validation rotors, a rotor/generator adapter, generator housing and a test stand to support the turbinegenerator assembly in the Cal Poly $2 \times 2 \mathrm{ft}$. wind tunnel. Testing was then conducted with varying electrical loads at wind tunnel speeds up to $110 \mathrm{mph}$. Results were then compared to rotor and generator model predictions. Based on the comparison of test results and model predicted performance, sources of discrepancy are assessed so that the models can be modified to more closely predict performance.

\subsection{Apparatus Design and Development}

Following baseline rotor/generator matching and leading up to wind tunnel evaluation testing, turbine components were designed and manufactured. Components included the candidate baseline rotors, rotor/generator adapter, generator housing, Maxon 
generator, and test stand. The exploded view of the complete turbine assembly is illustrated in Figure 79.

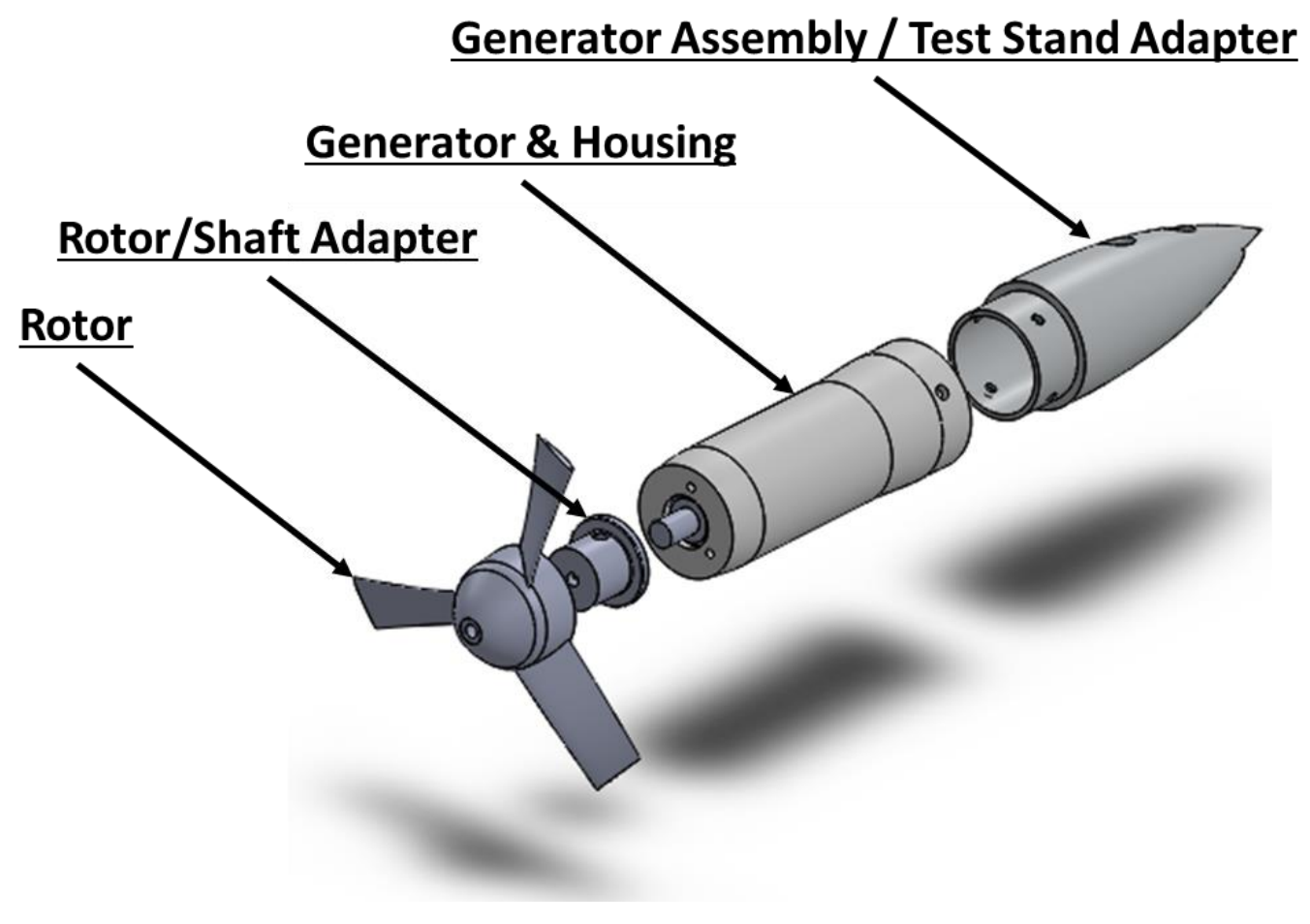

Figure 79. Turbine Generator Assembly

\subsubsection{Rotor}

The geometry for the two-candidate rotor designs were previously presented in Chapter 3.2 and have been referred to as rotor-1 and rotor-2. Geometry for these rotors can be seen in Table 15 and Figure 52. In designing the rotors, previous rotor design work was used as a starting point. Similar to previous designs, the rotor was designed with a hollow space within the hub where the rotor/generator adapter could fit. The rotor was then secured to the adapter with a $3 \mathrm{~mm}$ screw that went in through the tip of the hub then screwing into the adapter. The hub diameter is $25.4 \mathrm{~mm}$ (1 inch) and was based on the generator diameter $(22 \mathrm{~mm})$ and the wall thickness of the generator housing face 
$(2 \times 1.7 \mathrm{~mm})$ which makes the generator housing face approximately equal to the hub diameter. As mentioned before, because our rotor analysis tools are more accurate for a low solidity rotor it was decided to design a rotor with three blades, equally spaced at $120^{\circ}$ apart. Rotor solidity refers to the ratio of total blade area over the total swept area. A high solidity rotor would be considered at a solidity of about 0.8 , for this rotor the goal was to maintain a solidity below 0.5 . 


\subsubsection{Rotor/Generator Adapter}

The rotor/generator adapter, shown below in Figure 80, is the device that couples the rotor to the generator shaft. The adapter has a diameter of $14 \mathrm{~mm}$ that fits into an equally sized cavity in the rotor hub and has a flange that provides a seat for the rotor hub that extends out to a $20 \mathrm{~mm}$ diameter. At the bottom of the adapter, a $4 \mathrm{~mm}$ hole with a depth of $6 \mathrm{~mm}$ allows the generator shaft to be secured to the adapter with the use of two $3 \mathrm{~mm}$ set screws. At the top of the adapter there is a $3 \mathrm{~mm}$ tapped hole that allows a screw going through the tip of the rotor hub to be secured to the adapter. With the tightening of the top screw and the tight fit between the adapter and the hub, the rotor does not slip about the adapter.

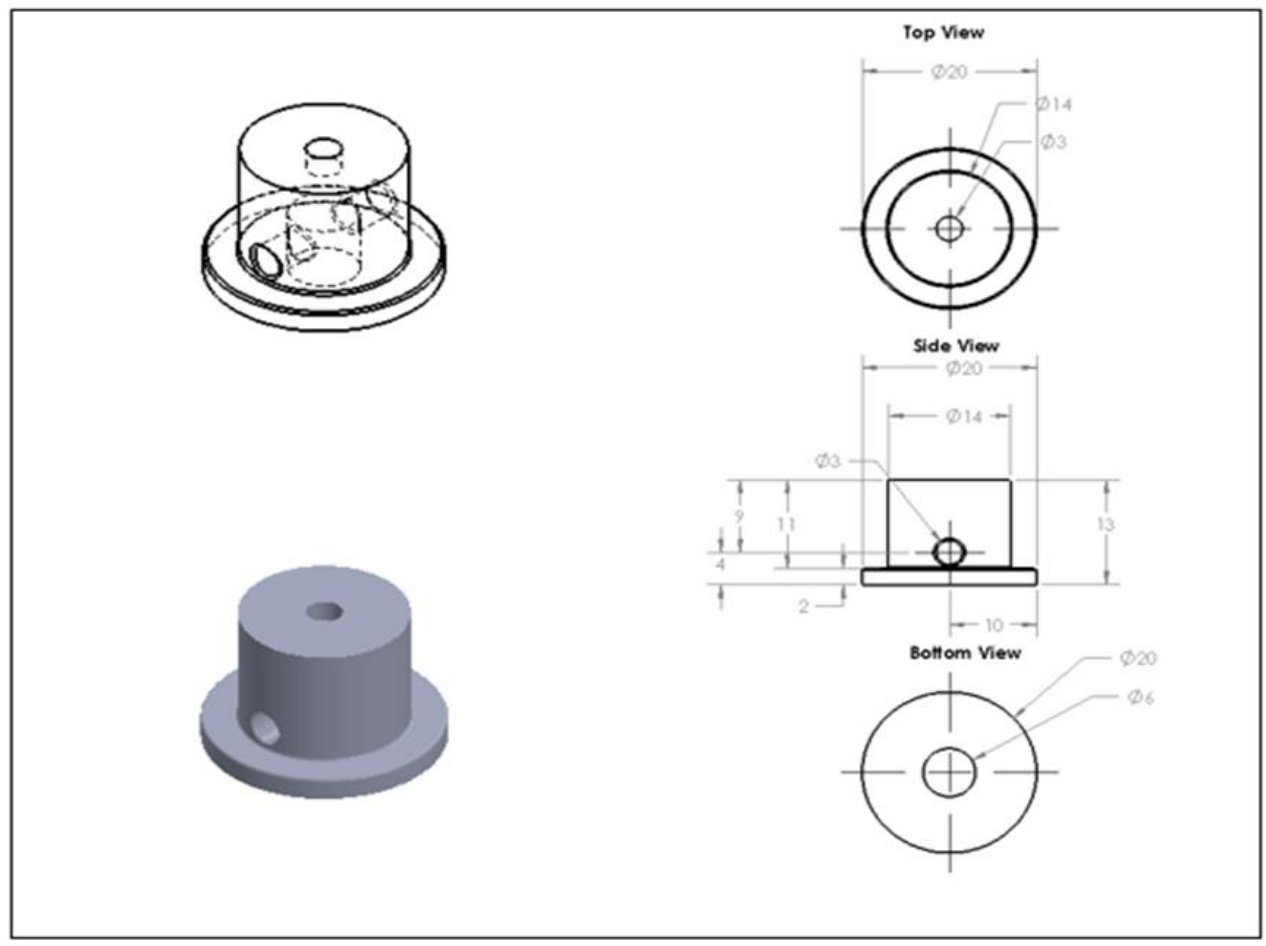

Figure 80. Rotor/Generator Adapter 


\subsubsection{Generator Housing}

The generator housing design was a modification of an original design by Schab [26] who contributed to previous $\mu$ RAT testing. The housing is composed of two parts, front and aft, the front part of the generator housing is where the generator is enclosed and attaches to the housing with three $2 \mathrm{~mm}$ screws at the face. The aft part of the housing attaches to the front part of the housing and has a slot that mounts onto the test stand and is secured with two screws. A half-inch diameter opening at the underside of the aft housing allows the generator wires to exit the generator housing.

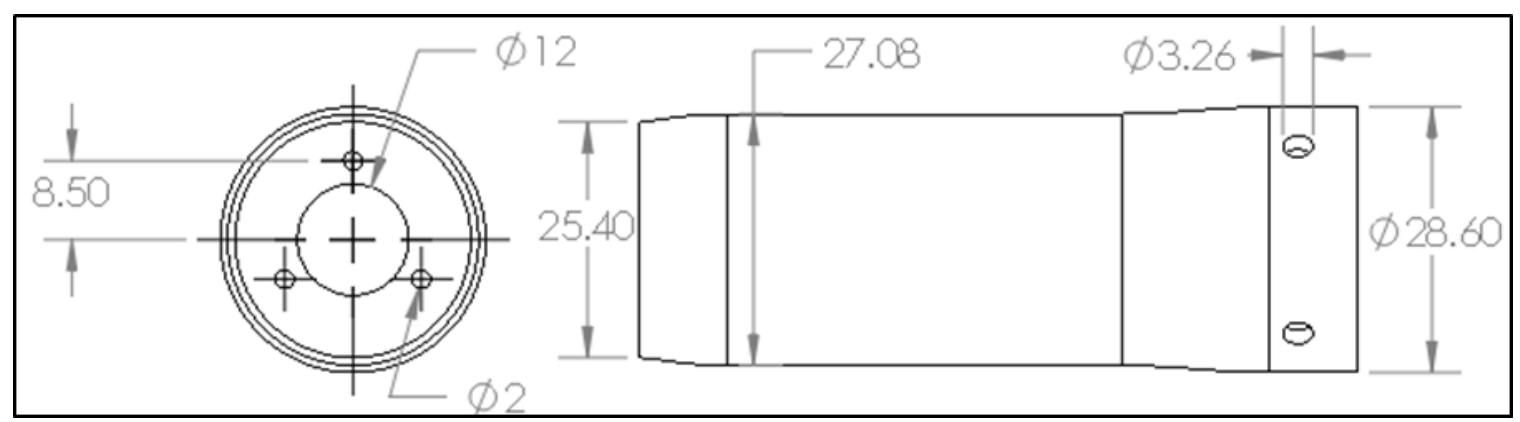

Figure 81. Front part of generator housing

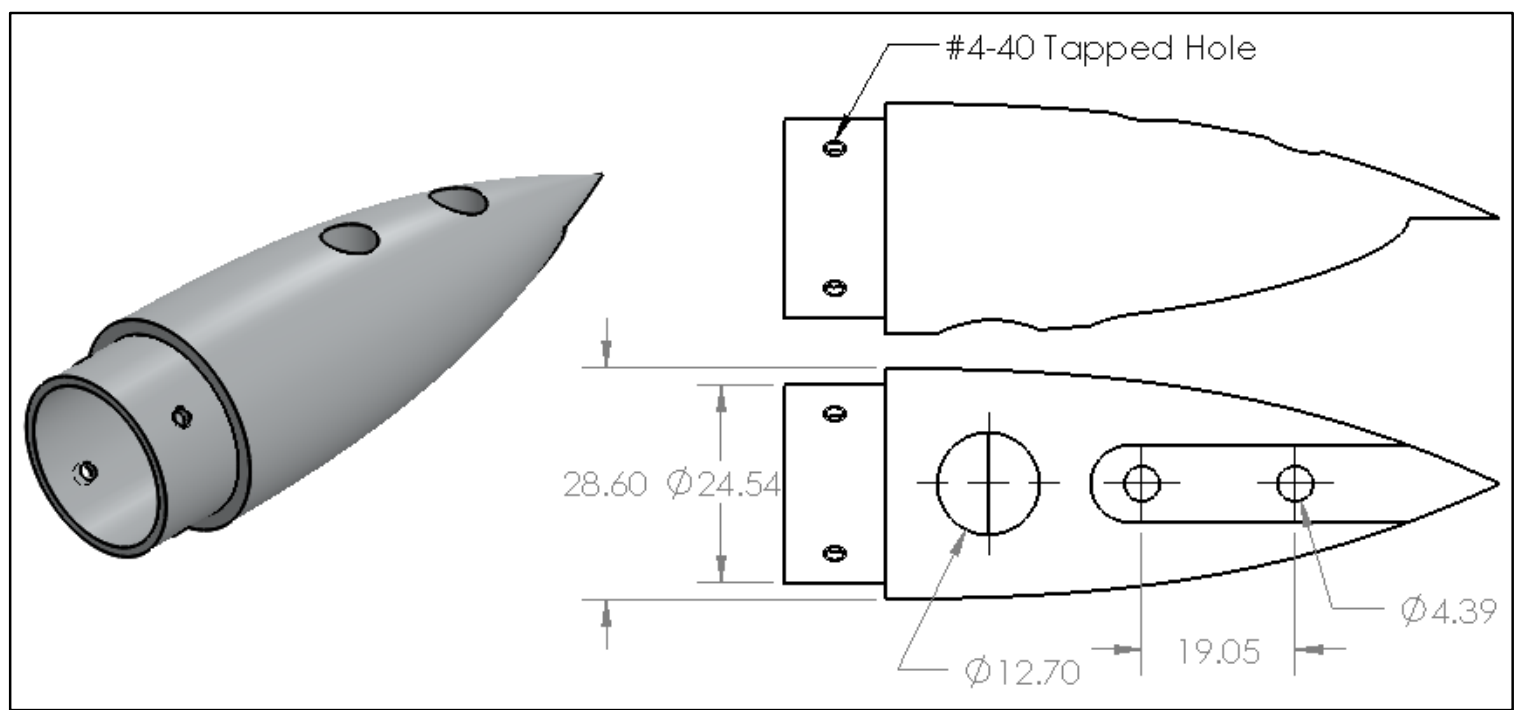

Figure 82. Aft part of generator housing [26] 


\subsubsection{Test Stand}

The Test Stand of Figure 83 is what holds the turbine at the center of the Cal Poly $2 \times 2 \mathrm{ft}$. wind tunnel. Two cross bars attach to the wind tunnel bottom plate. The turbine mounting point is at the top of a vertical bar that is supported by two cross-bars, 2 forward bracing bars, and L-brackets assembled as shown in Figure 83. This test stand was reused from previous work [26].

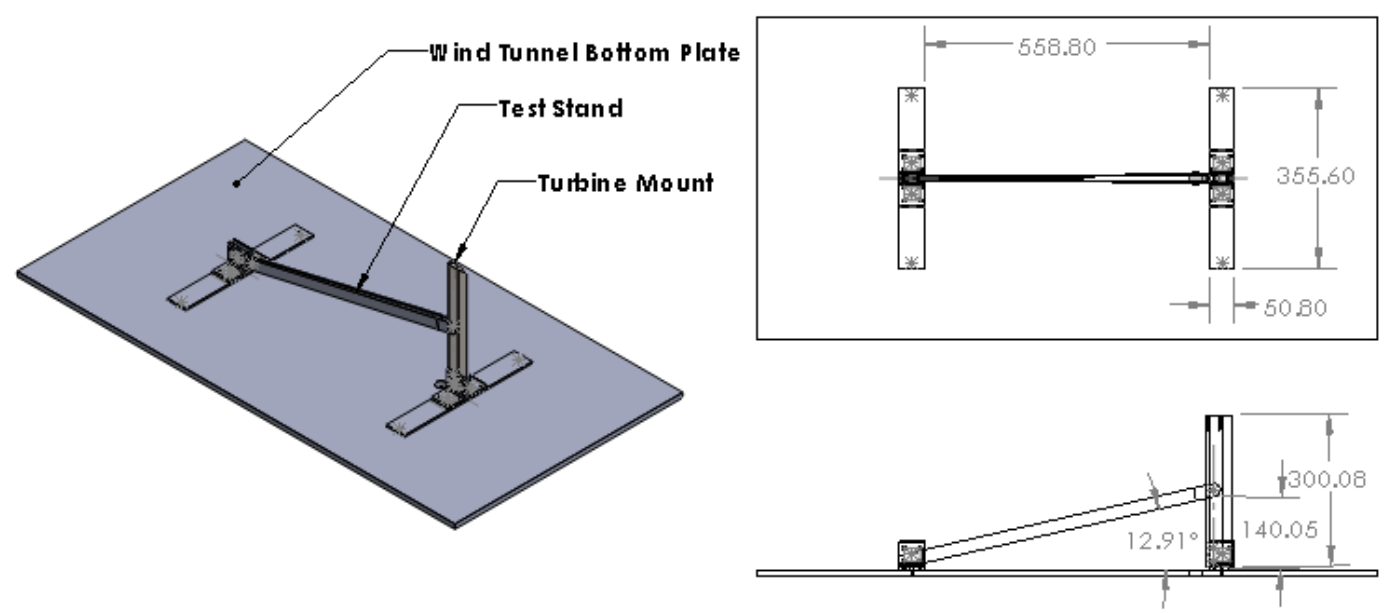

Figure 83. Test Stand Attached to Bottom Wind Tunnel Plate [26]

Figure 84 displays the generator assembly attached to the Test Stand which is secured onto the wind tunnel bottom plate. It can be seen that the turbine is cantilevered onto the mounting bar of the test stand and is parallel to the wind tunnel bottom plate.

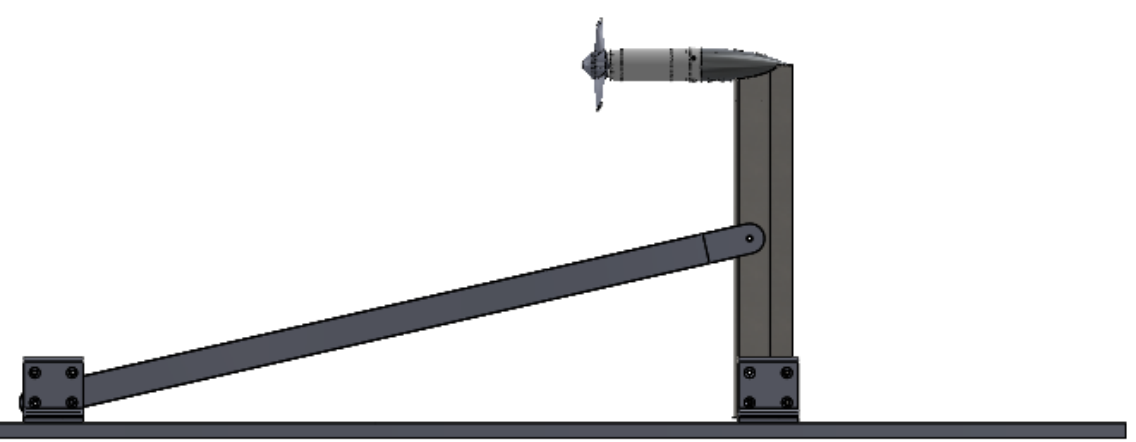

Figure 84. Turbine Generator Mounted on Test Stand [26] 


\subsection{Validation Test Results}

The turbine generator validation test was conducted in the Cal Poly $2 \times 2 \mathrm{ft}$, wind tunnel at speeds ranging from about $71-110 \mathrm{mph}$; a schematic of the setup is displayed in Figure 85. Starting from the left side of the diagram, the air flow is provided by the wind tunnel which turns the wind turbine. The wind turbine produces $\mathrm{AC}$ power which is rectified to DC power through the 3-phase bridge rectifier. Direct current then flows through an electrical load (resistor bank) where terminal voltage and current are measured. Axial airflow is measured by measuring differential pressure between upstream and downstream contraction static pressure rings; this method of measuring airspeed was selected over using a pitot tube in order to avoid any interference with airflow directly in front of the rotor. RPM was determined by measuring the frequency from one of the generator lead wires. The test setup represented in the schematic of Figure 85 is shown in Figure 86.

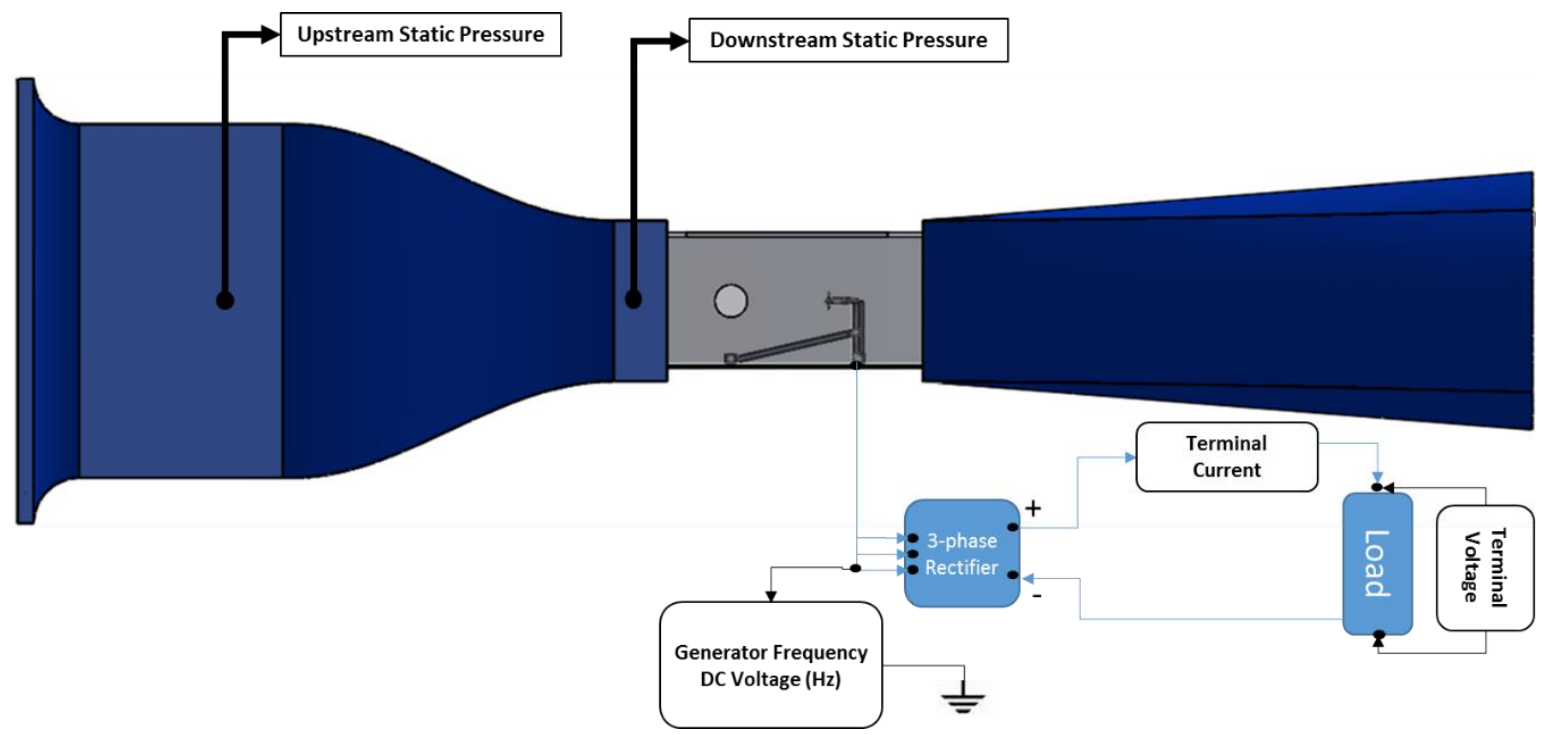

Figure 85. Turbine Generator Validation Test Schematic [26] 


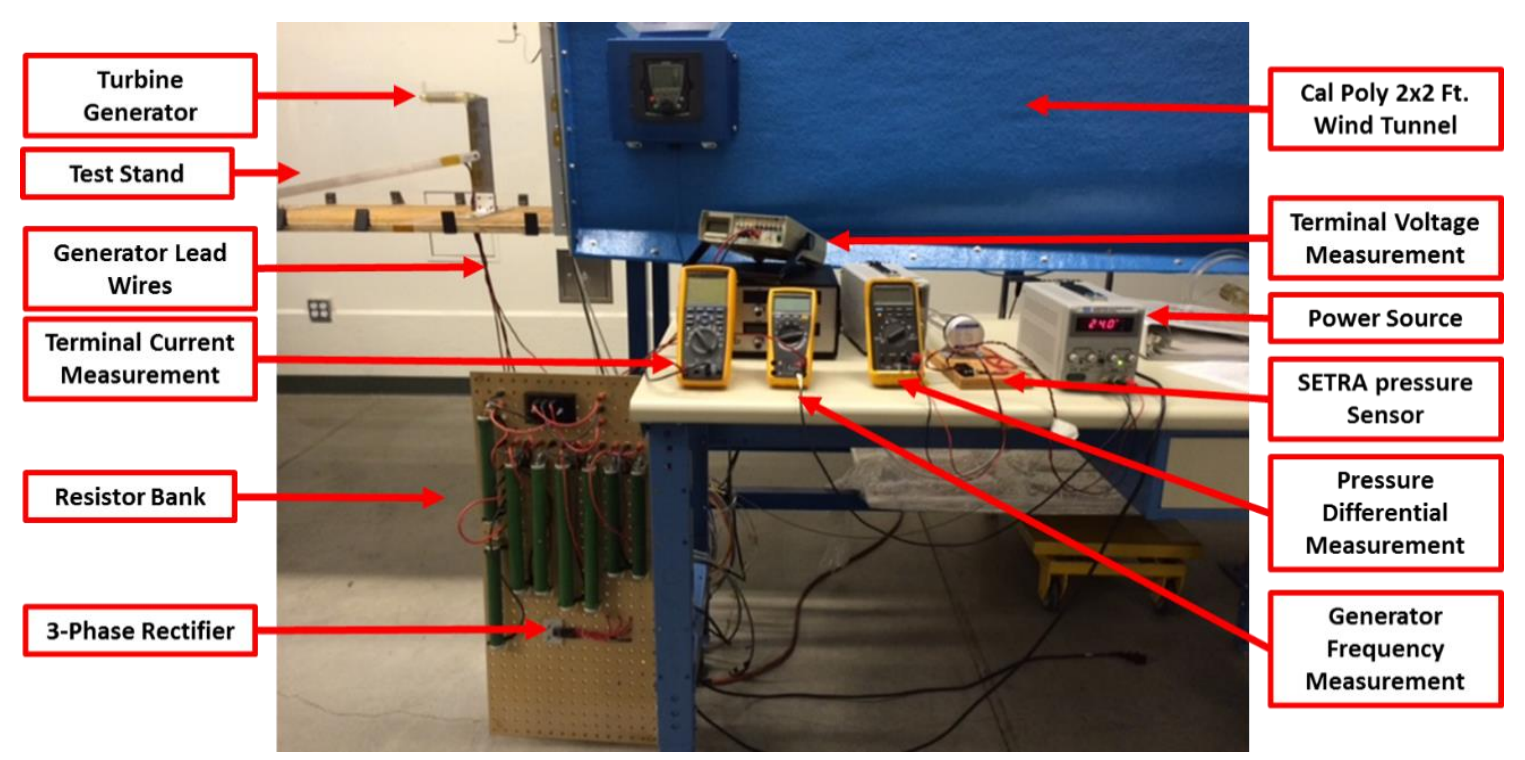

Figure 86. Rotor/Generator Test Setup

Table 20 gives the contraction pressure coefficients obtained from an empty wind tunnel calibration. This wind tunnel contraction calibration data is used to determine axial air speed at the tunnel reference location in the center of the cross-section and $1 \mathrm{ft}$ downstream of the contraction exit by using the $C_{p, n}$ value that corresponds to the measured differential pressure then through Equation 69, reference dynamic pressure, $\mathrm{q}$, is solved for and axial flow velocity is calculated from q.

Table 20. Differential Pressures and Pressure Coefficients across the Wind Tunnel Nozzle

\begin{tabular}{|c|c|c|c|c|c|}
\hline $\begin{array}{c}\text { Blower } \\
\text { motor } \\
\text { frequency }\end{array}$ & $\mathbf{2 0 ~ H z}$ & $\mathbf{3 0} \mathbf{~ H z}$ & $\mathbf{4 0} \mathbf{~ H z}$ & $\mathbf{5 0} \mathbf{H z}$ & $\mathbf{6 0} \mathbf{~ H z}$ \\
\hline$\Delta \mathbf{P n}(\mathbf{P a})$ & 151.546 & 351.514 & 631.067 & 985.495 & 1403.740 \\
\hline $\mathbf{C p , n}$ & 1.0025 & 0.9989 & 0.9899 & 0.987 & 0.9842 \\
\hline
\end{tabular}

$$
\begin{gathered}
C_{p, n}=\frac{\Delta P_{n}}{q_{r e f}} \\
q_{r e f}=\frac{\Delta P_{n}}{C_{p, n}}
\end{gathered}
$$


For the turbine generator validation test the wind tunnel was run at 40, 50, and $60 \mathrm{~Hz}$, corresponding to nominal flow speeds of 71-110 mph. Dynamic pressure and airspeed calculations are shown in Table 21 for both rotor-1 (the straight blade rotor) and rotor- 2 (twisted blade rotor) tests at these nominal conditions. These axial velocity values are then entered into the blade element rotor model and the X-Rotor model for each velocity tested.

Table 21. Airspeed Calculation for Rotor-1 and Rotor-2 Test

\begin{tabular}{|c|c|c|c|c|c|c|c|c|c|c|}
\hline \multirow[b]{2}{*}{$\mathrm{f}(\mathrm{Hz})$} & \multicolumn{5}{|c|}{ Straight Blade } & \multicolumn{5}{|c|}{ Twisted Blade } \\
\hline & $\Delta \mathbf{P}$ & $C p$ & $q$ & $V(f t / s)$ & $V(m p h)$ & $\Delta \mathrm{P}$ & $\mathrm{Cp}$ & $q$ & $V(f t / s)$ & $V(m p h)$ \\
\hline $40 \mathrm{~Hz}$ & 608.65 & 0.99 & 637.3 & 107.59 & 73.36 & 610.41 & 0.99 & 637.3 & 107.59 & 73.36 \\
\hline $50 \mathrm{~Hz}$ & 954.99 & 0.987 & 998.3 & 134.66 & 91.81 & 957.31 & 0.987 & 998.3 & 134.66 & 91.81 \\
\hline $60 \mathrm{~Hz}$ & 1366.95 & 0.984 & 1426 & 160.94 & 109.73 & 1370.26 & 0.984 & 1426 & 160.94 & 109.73 \\
\hline
\end{tabular}

At each of the three test airspeeds, the turbine generator was operated with electrical loads ranging from about 1 to 20 ohms. Test results can be seen in Figure 88- Figure 91, along with the blade element and X-Rotor model comparisons. 


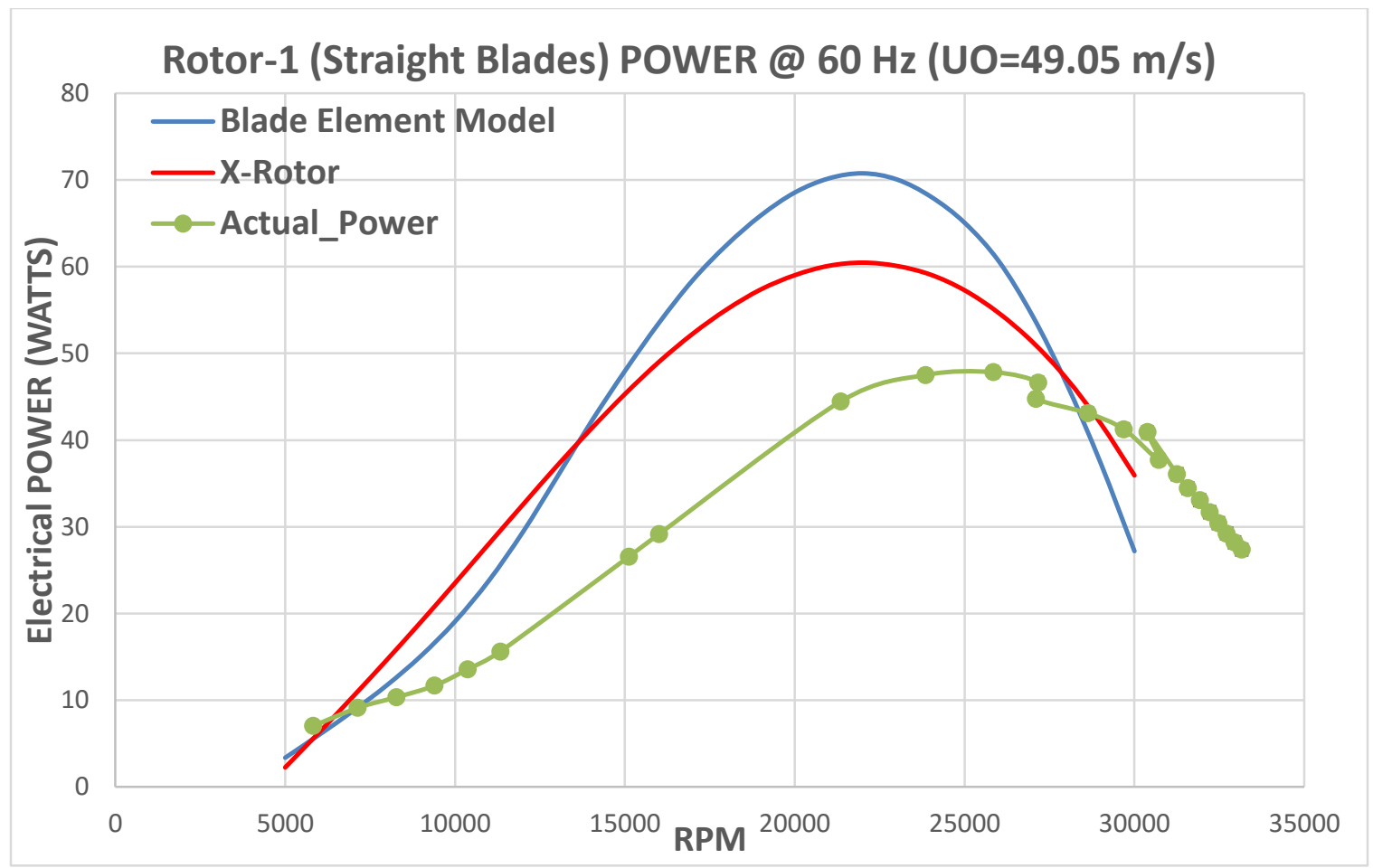

Figure 87. Rotor-1 Power @ 49.05m/s compared to model predictions

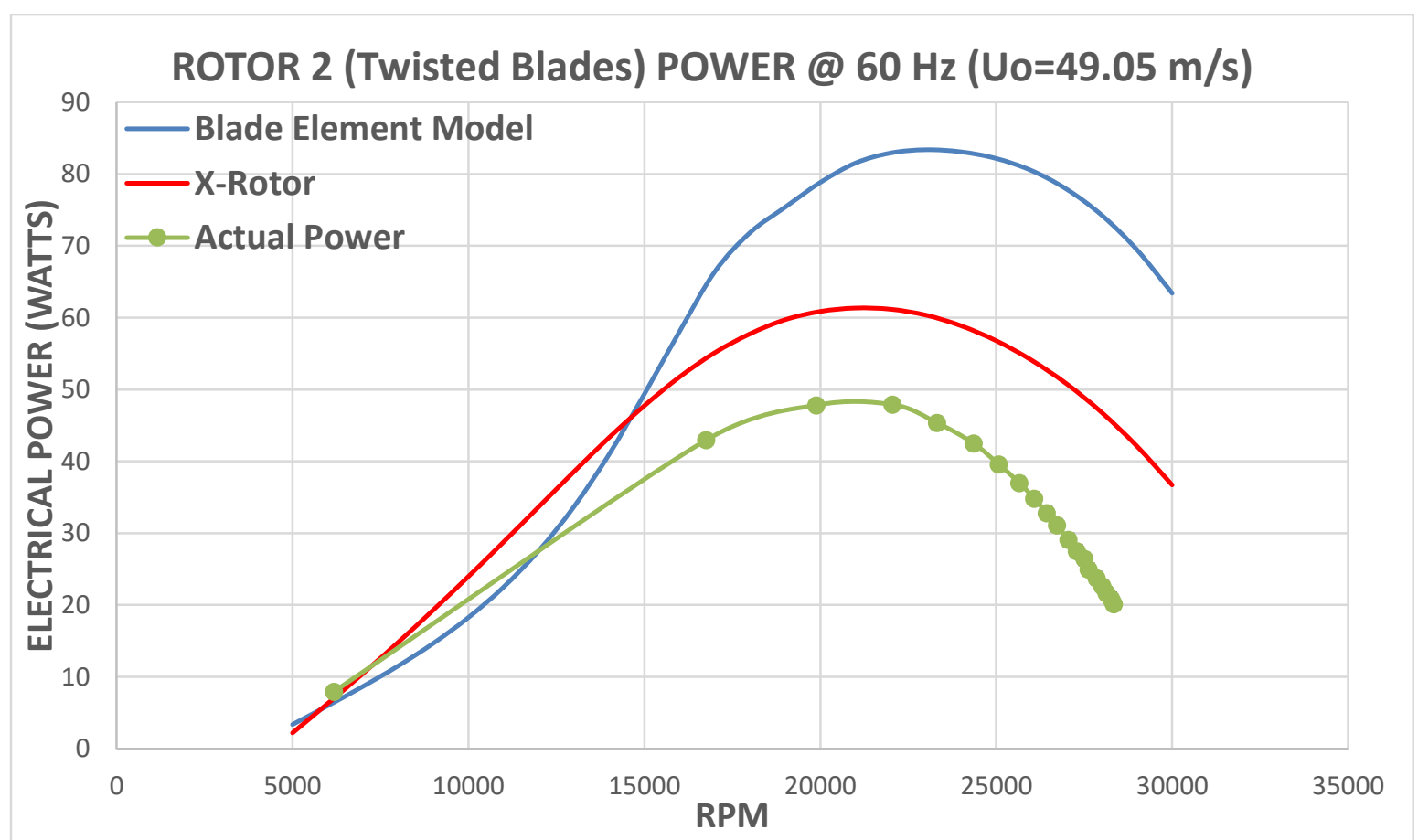

Figure 88. Rotor 2 Power @ 49.05m/s compared to model predictions 


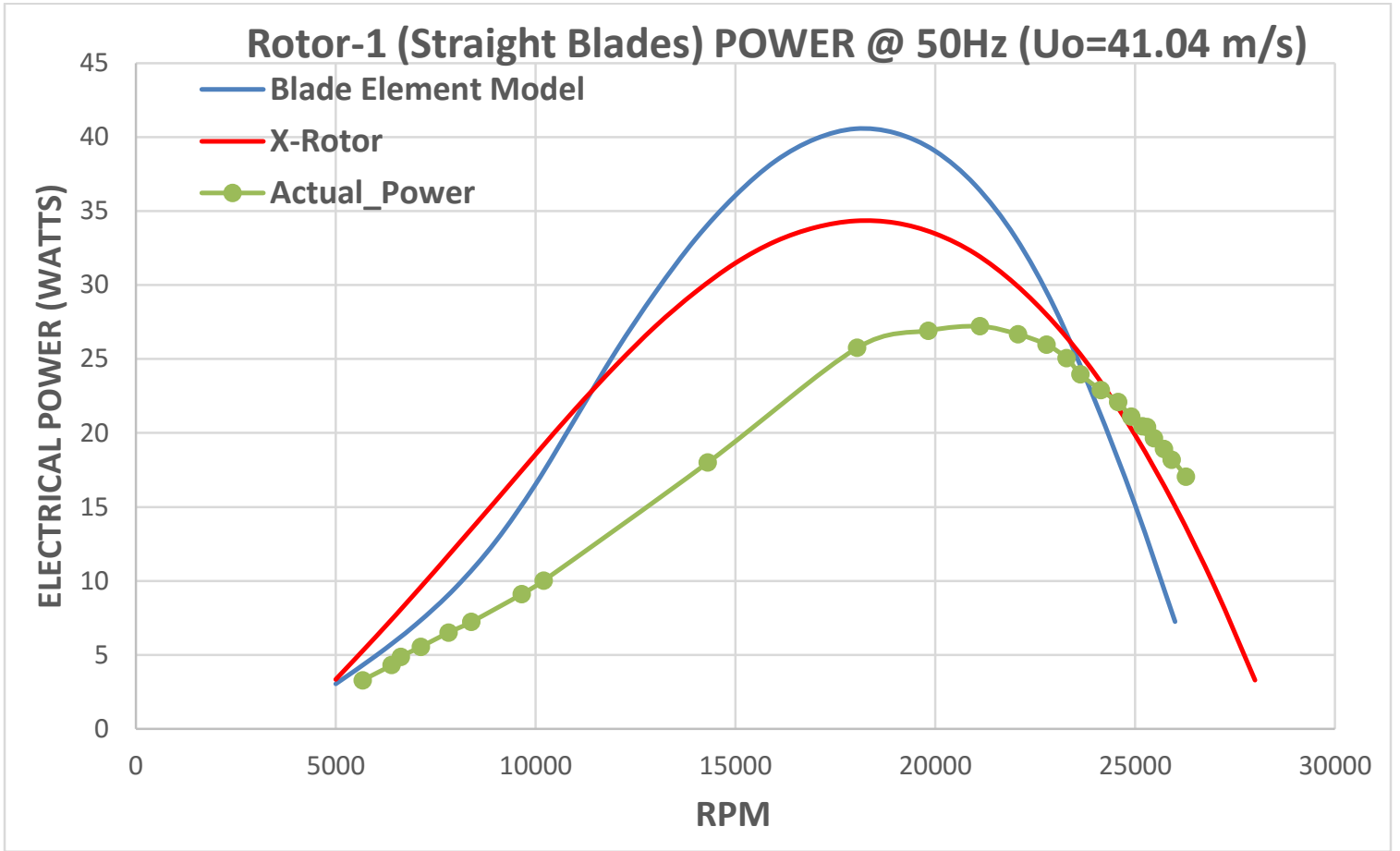

Figure 89. Rotor-1 Power @ 41.04m/s compared to model predictions

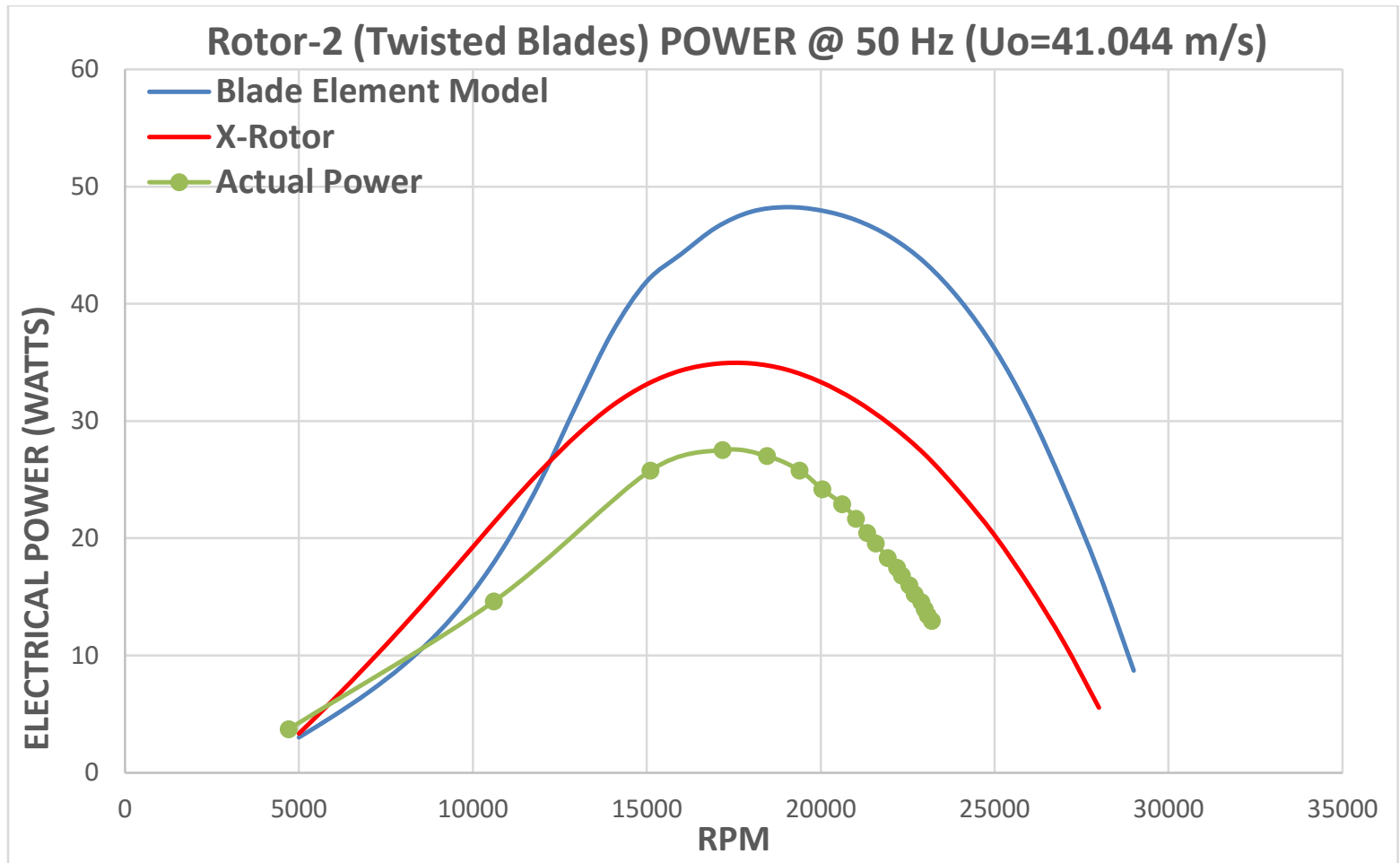

Figure 90. Rotor 2 Power @ 41.04m/s compared to model predictions 


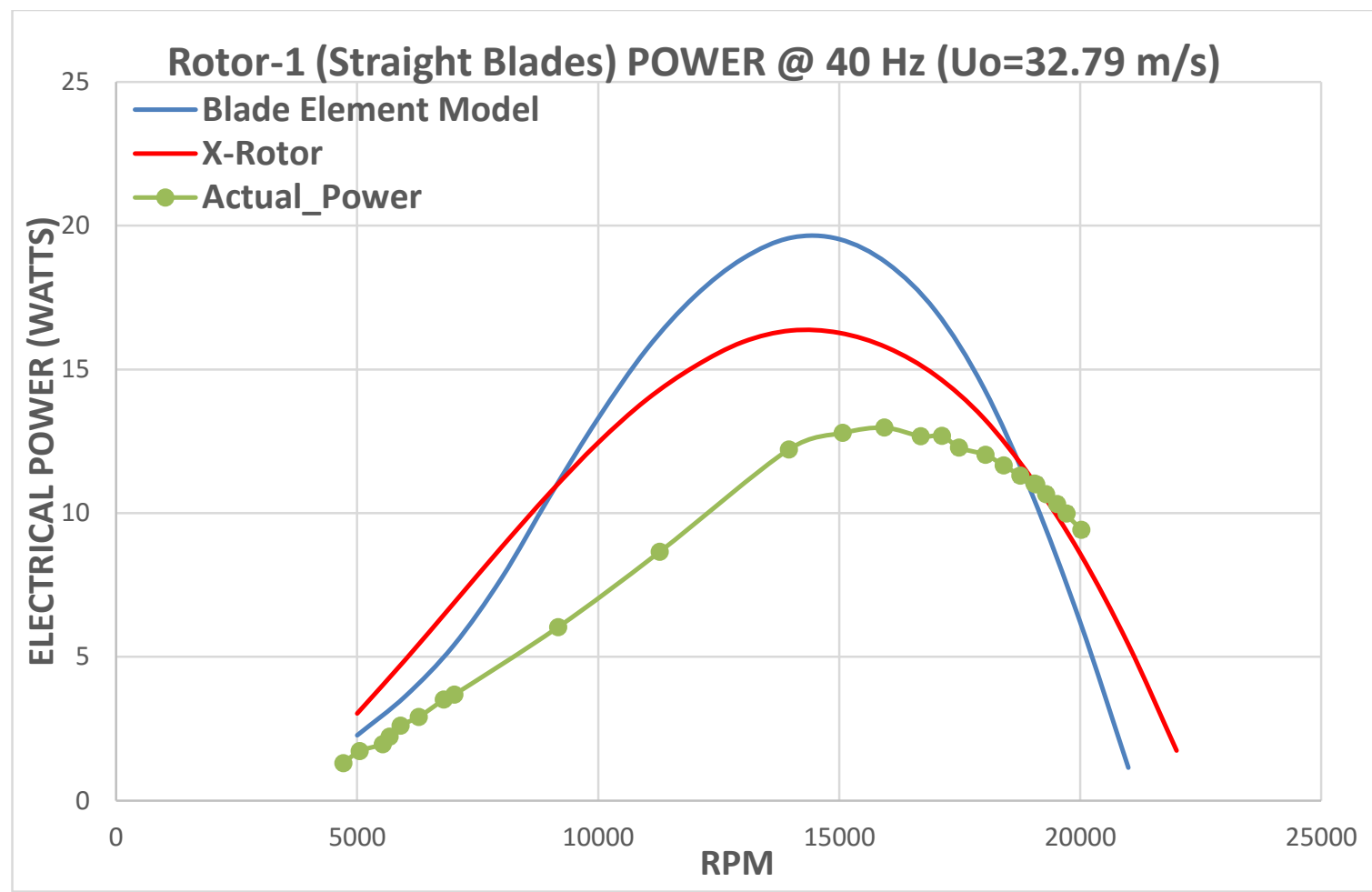

Figure 91. Rotor-1 Power @ 32.79 m/s compared to model predictions

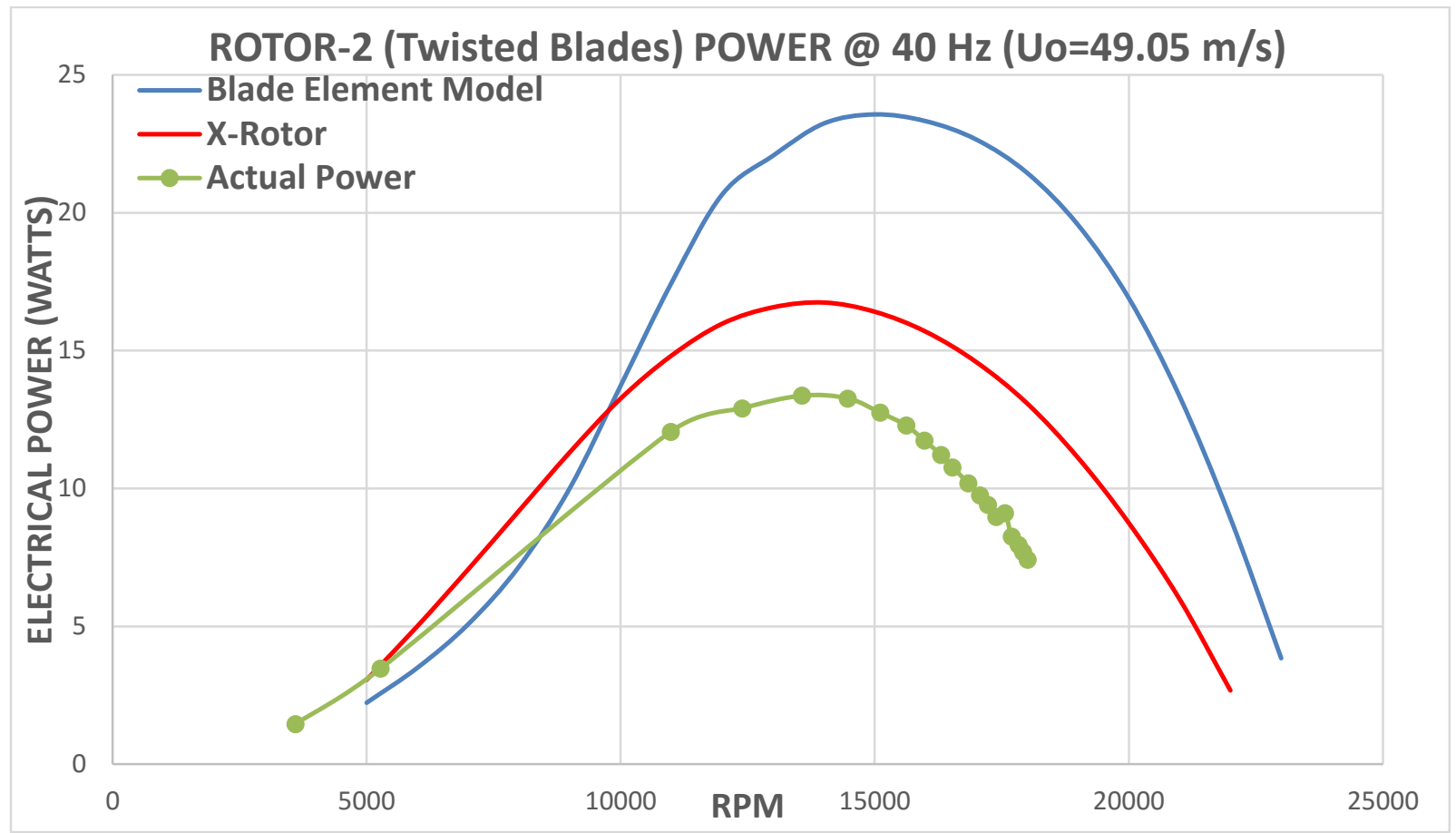

Figure 92. Rotor-2 Power @ 32.79m/s compared to model predictions 


\subsection{Discussion}

It can be seen that the measured and predicted results for generated power seem to follow similar trends, but the measured power output is significantly lower than predicted by either the blade element or X-Rotor/ generator models. Generally, the measured power at peak power was observed to be $20-30 \%$ lower than predicted by X-Rotor combined with the proposed generator model for both rotor-1 and rotor-2; the blade element model in combination with the proposed generator model predicts significantly higher at about $50 \%$ higher for rotor- 1 and up to $75 \%$ higher for rotor- 2 . Additionally, it was observed that rotor-1's measured peak power occurred at a higher RPM than predicted, whereas the RPM for peak power predicted for rotor-2 (twisted-blade) occurs at about the same value that was predicted. Some of the differences between predicted and measured power may be attributed to the accuracy of the generator model, and in particular to the prediction of generator shaft torque. However, based on the earlier motor-driven generator test results, it is believed that most of the discrepancy is due to inaccuracy in the rotor performance modelling. For example, both rotor models require lift/drag data which is crudely modelled — especially for stalled blades — and, aero-elastic deformation of the rotor blades is not included in the model. In addition, no attempt has yet been made to include induced flow and finite span effects in the blade element model; these influences are expected to make its predictions too high for maximum power. It is therefore concluded that the proposed generator model is probably sufficient although a direct torque measurement would be desirable; further development of the $\mu$ RAT design tools should focus on an improved rotor performance model. The possibility that aeroelastic deformation could be part of the reason for the over-prediction of the power could 
be tested by fabricating and testing a stiffer (metal) rotor with the same geometry as one of the rotors tested here.

\subsection{Rotor Model Tip Loss Corrections}

At this point it was decided to examine whether the lack of inclusion of induced flow effects was indeed responsible for the large difference between the blade element rotor model and X-Rotor predictions. As previously mentioned, the blade element rotor model does not account for Induced flow effects associated with an airfoil of finite aspect ratio. At the blade tips, bounded vortices that lie along the span of an airfoil will cause air to flow around the tip of the blade resulting in low lift generation at the blade tip. The current blade element model uses simple 2-D airfoil data and therefore calculates substantial lift generated at the blade tip. The Prandtl tip loss model provides a simple and easy-to-implement approximate treatment of this effect and in effort to account for the losses at the blade tip due to wing tip vortices the Prandtl tip loss corrections have been implemented in the blade element model. Prandtl's factor $\left(F_{p}\right)$ is defined below in Equation 70

$$
F_{p}=\frac{2}{\pi} \arccos e^{-f}
$$

Where

$$
f=\frac{B}{2} \frac{R-r}{r \sin \varnothing}
$$

For the expression for $f$, B represents the number of blades, $\mathrm{R}$, is the blade outer radius, r, represents the local radius of each element and $\emptyset$ is the relative velocity angle. Figure 
93 shows the Prandtl tip loss factor as a function of normalized radius for rotor-2 at peakgenerated power at an airspeed of $110 \mathrm{mph}$.

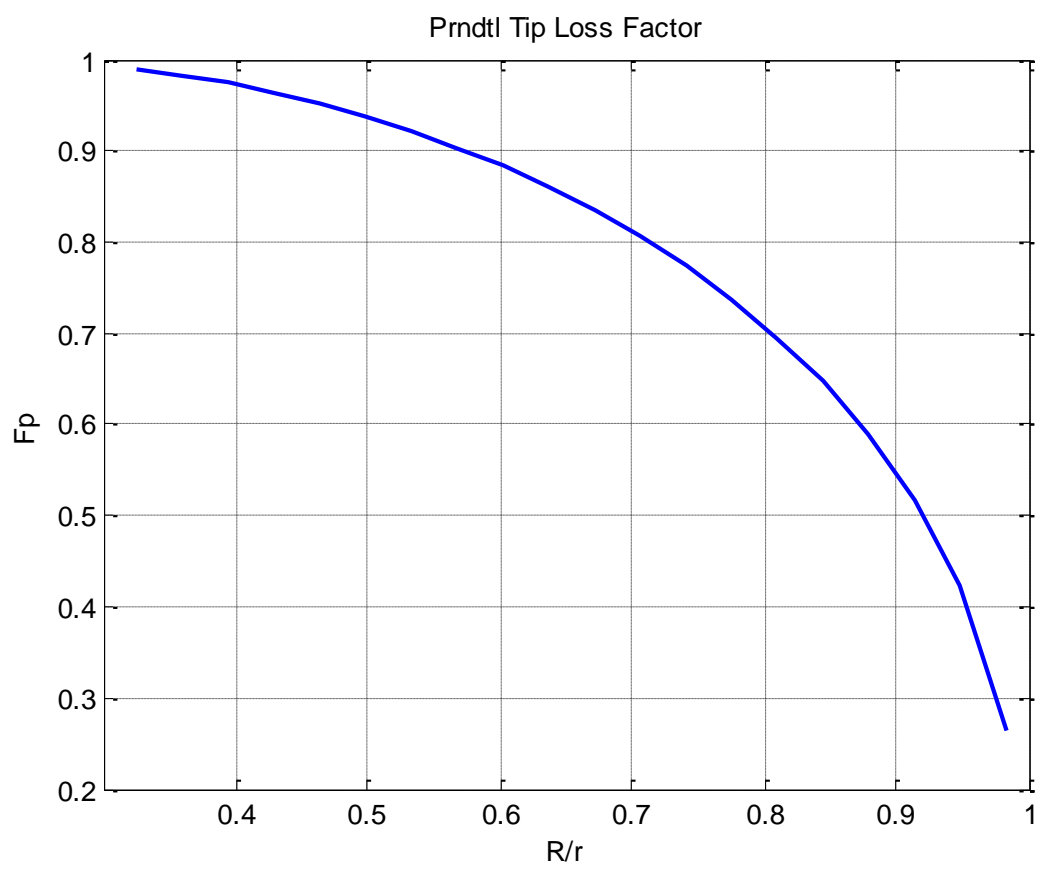

Figure 93. Prandtl Tip Loss Factor (Fp) as a Function of Normalized Radius

In implementing this factor, sectional thrust and torque equations presented in chapter 3.2 are modified (Equations 63 and 64). Below the Prandtl factor has been applied to both equations.

$$
\begin{gathered}
\Delta T=F_{p} * \rho 4 \pi r V_{\infty}{ }^{2} a(1+a) \Delta r \\
\Delta Q=F_{p} * \rho 4 \pi r^{3} V_{\infty} b(1+a) \omega \Delta r
\end{gathered}
$$

The difference in coefficient of lift along the rotor blade, with and without the tip loss factor can be seen in Figure 94 and Figure 95 for rotor-2 at peak-generated power at an airspeed of $110 \mathrm{mph}$. Here we see how the sectional torque with the factor applied more 
closely models the effects of tip losses with the sectional torque approaching zero closer to the tip of the blade.

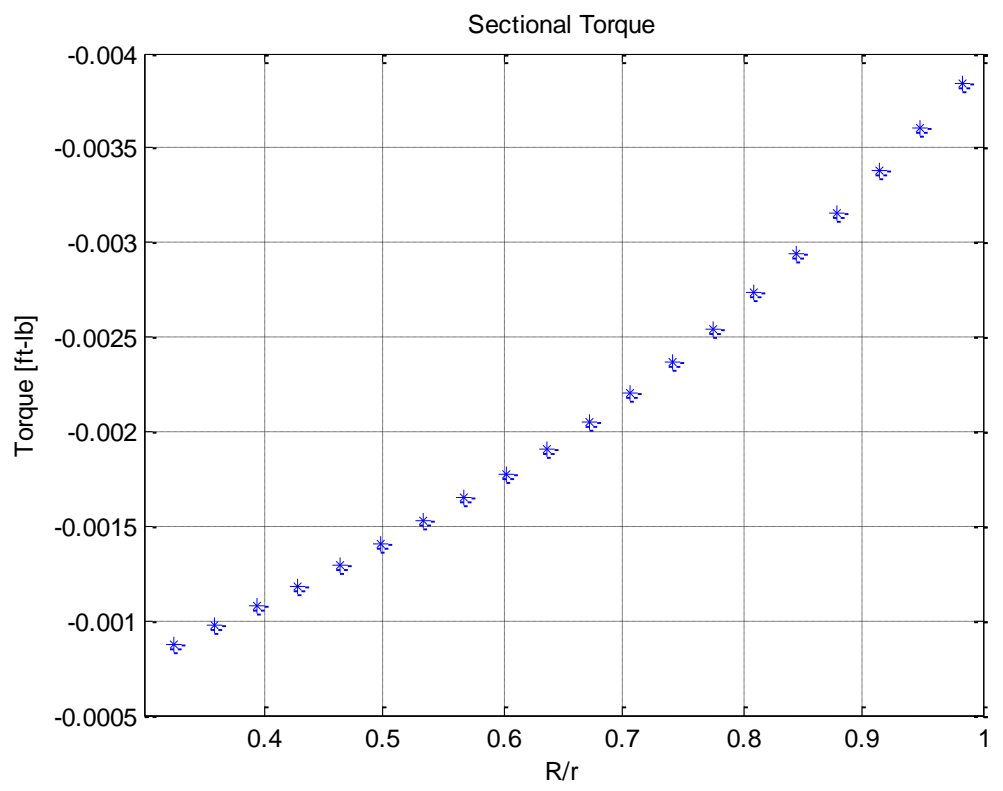

Figure 94. Sectional Torque without Tip Loss Factor

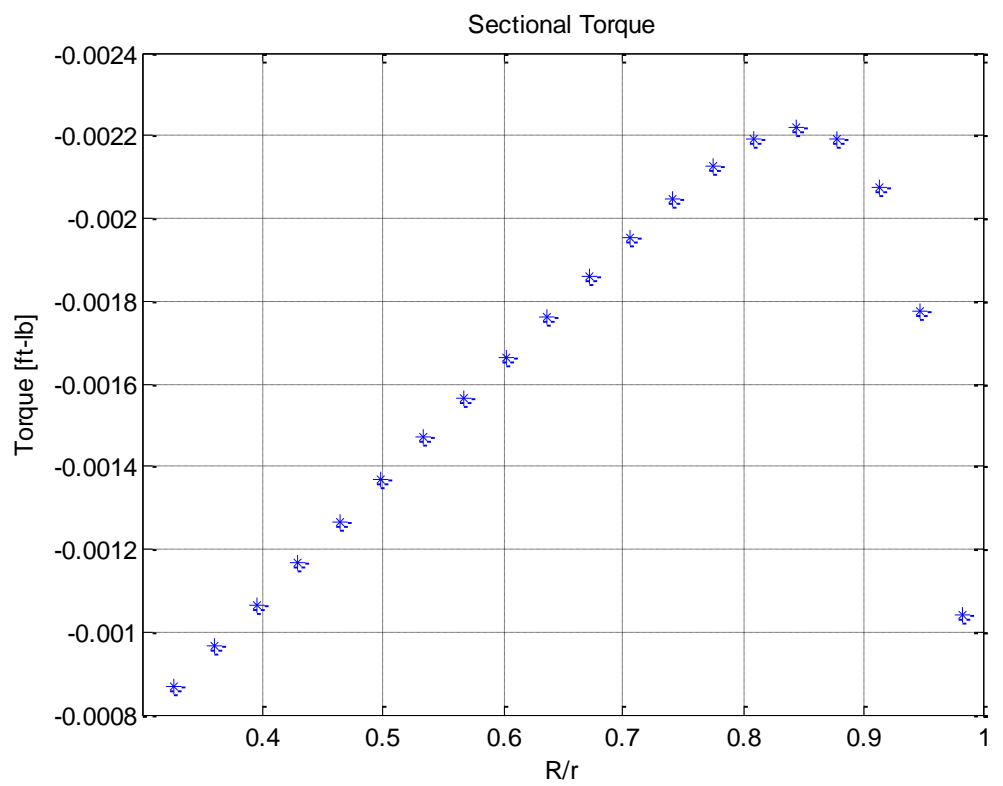

Figure 95. Sectional Torque with Tip Loss Factor 
The following figures apply the Prandtl tip loss factor to the blade element model for the same flight conditions and for the same baseline rotors as in the model evaluation test in Chapter 5.2. Here we see that the blade element rotor model with the Prandtl tip loss factor applied generally predicts a significantly lower generated power - much closer to X-Rotor results than the rotor model without the tip loss factor. Looking at predictions for rotor-1 at all three speeds, peak power between the blade element model with tip-loss comes within about $1.5 \%$ difference of X-Rotor at approximately the same speeds. Peak power for the blade element rotor model is shifted to the right of X-Rotor peak power by about 1,000 rpm. For rotor- 2 at all three speeds, peak power between the blade element model with tip-loss comes within about 5-8\% difference of X-Rotor at similar speeds. Just like in the case for rotor- 1 , for rotor- 2 the peak power for the blade element rotor model is shifted to the right of X-Rotor peak power by about $1,000 \mathrm{rpm}$. Looking at model comparisons to actual measured results Figure 96 and Figure 101 ) it is apparent that the blade element model with Prandtl tip-loss effects more closely models flow experienced by the actual rotor and the predicted power results compare closely to $\mathrm{X}$ Rotor results. Applying this factor brings predictions with the blade element model from 50-75 \% error to within $25-40 \%$ error of blade evaluation test results. For these reasons the Prandtl tip loss factor, or perhaps a more sophisticated model to account for induced flow effects, should be incorporated in the blade element model. 


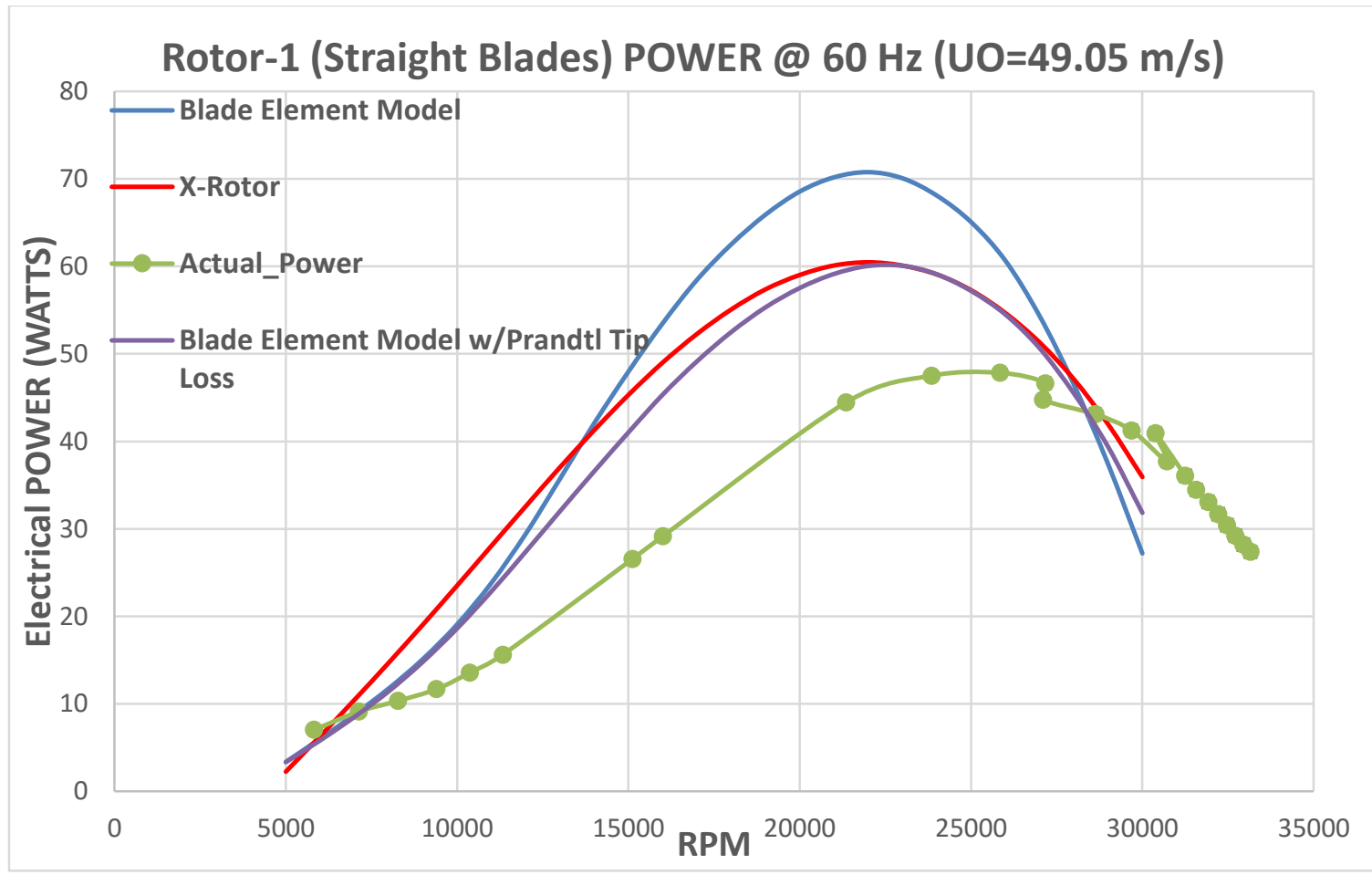

Figure 96. Rotor-1 Power @ 49.05m/s compared to model predictions

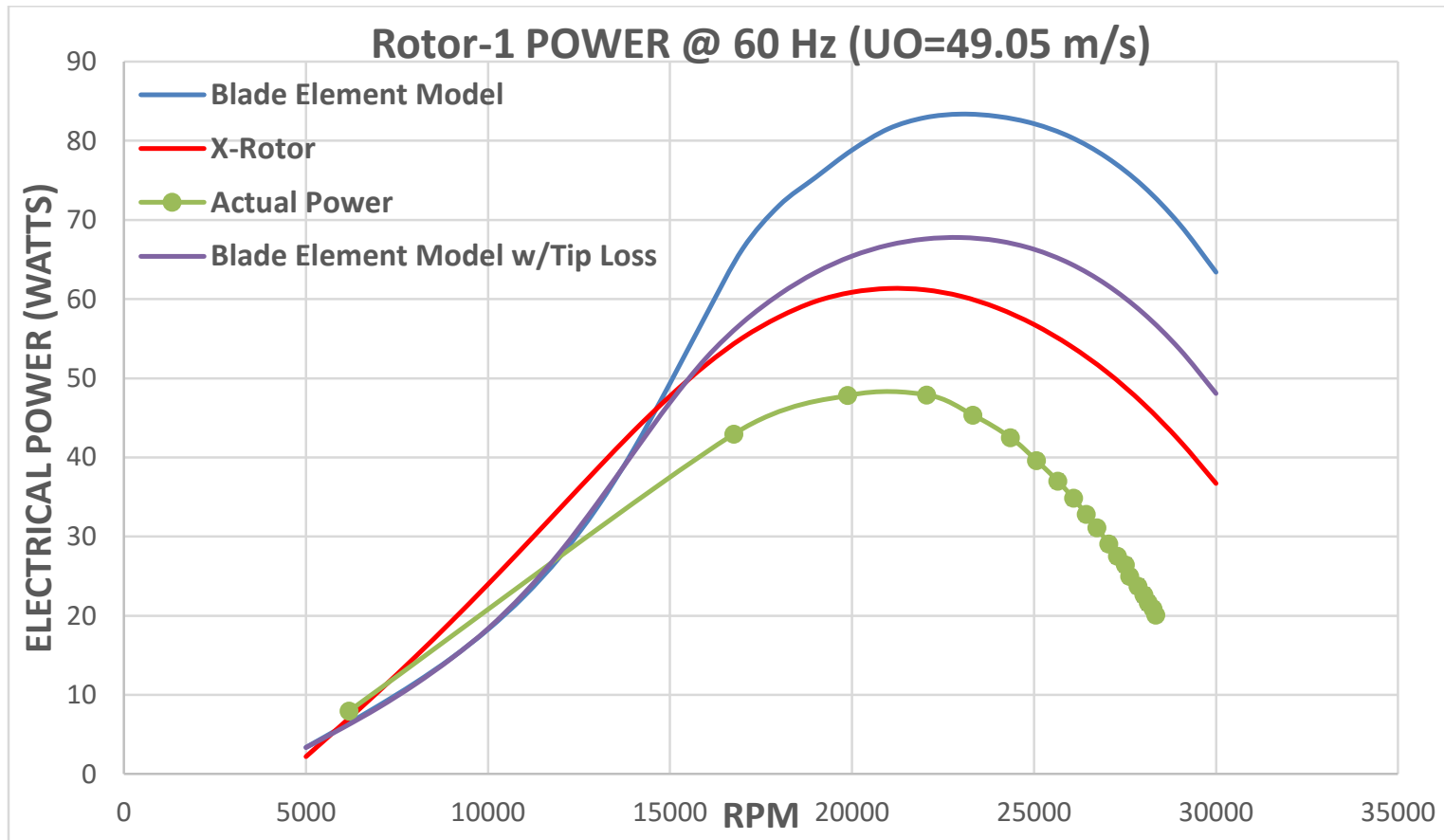

Figure 97. Rotor-2 Power @ 49.05m/s Compared to Model Predictions 


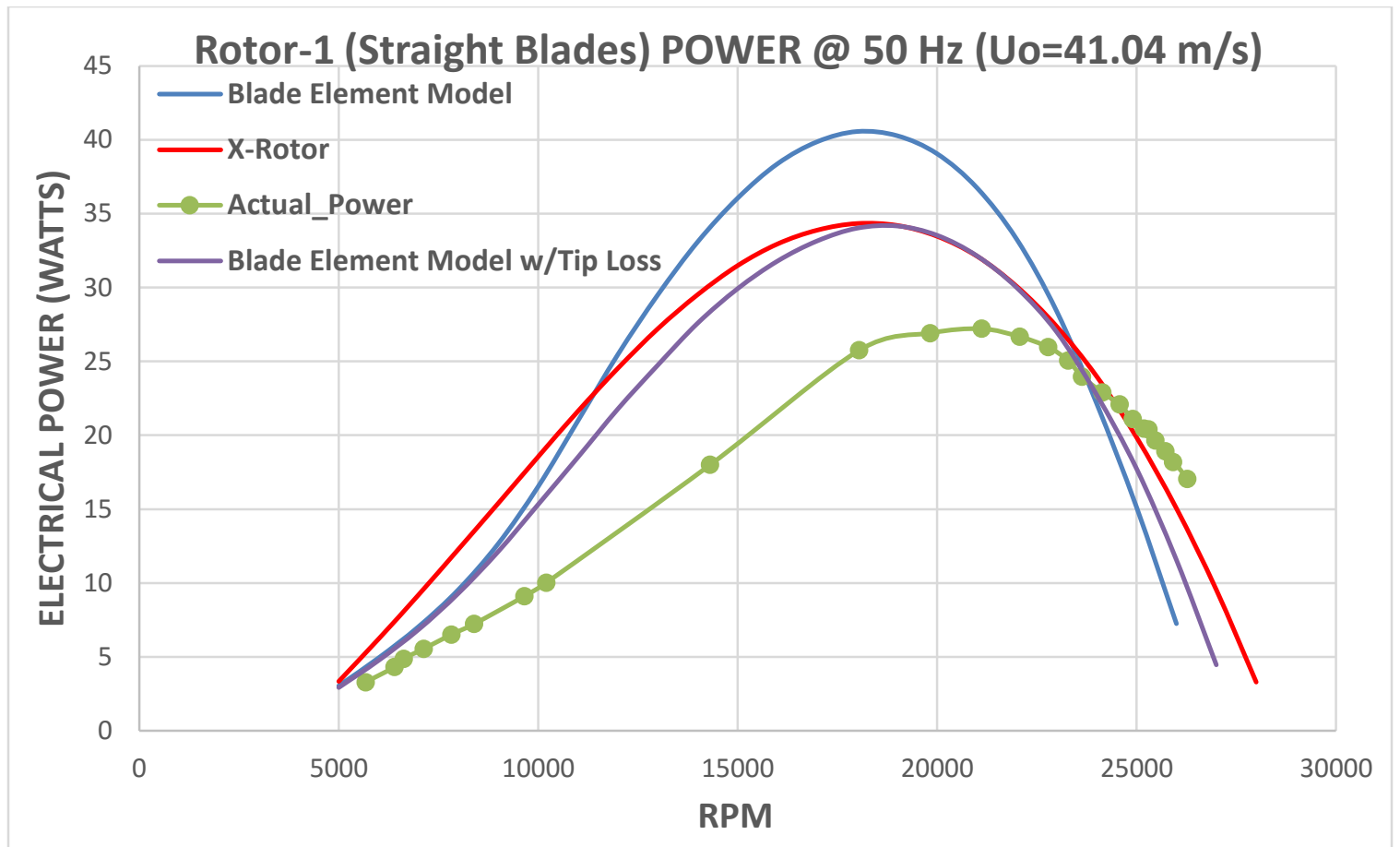

Figure 98. Rotor-1 Power @ 41.04m/s Compared to Model Predictions

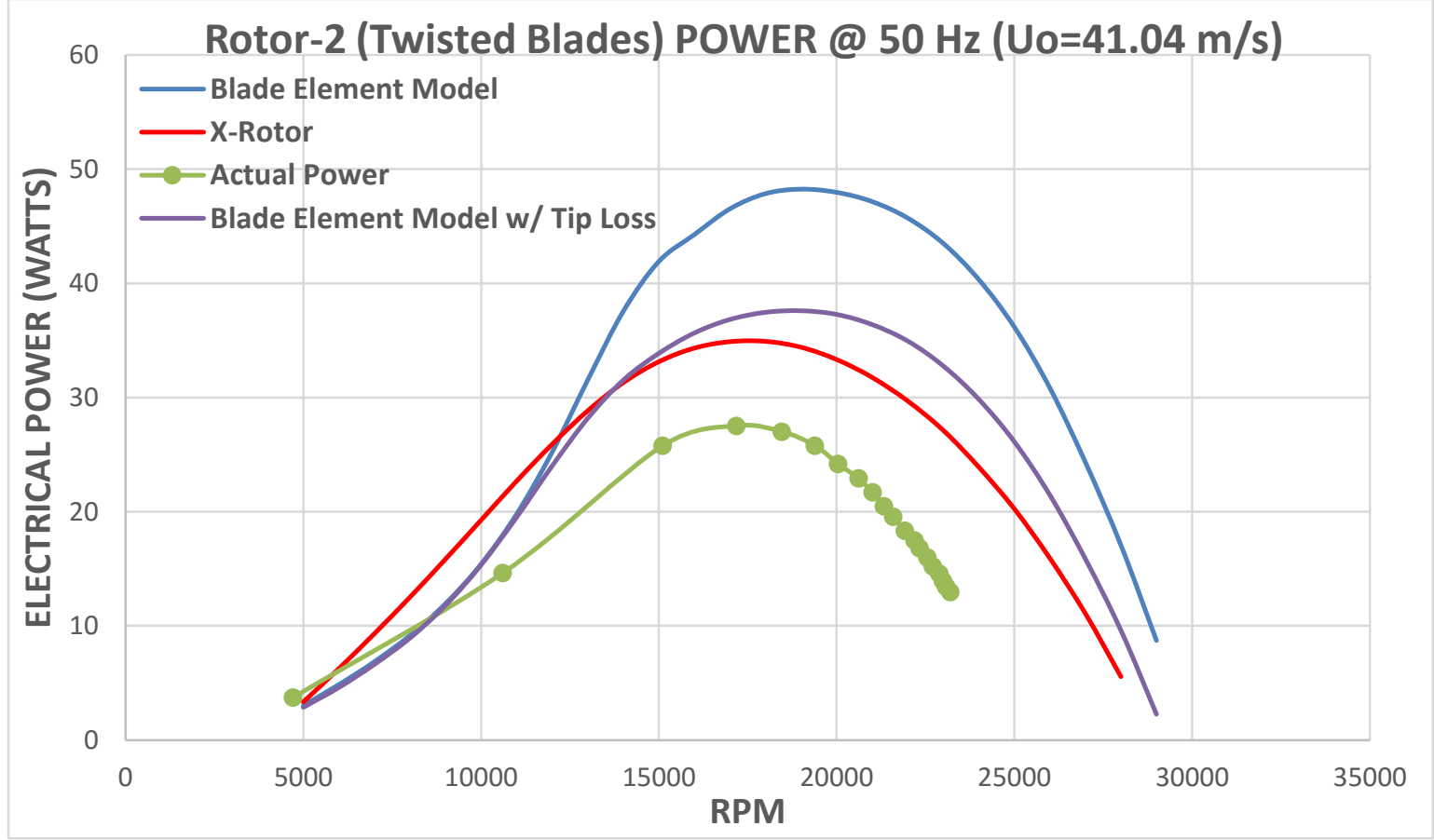

Figure 99. Rotor-2 Power @ 41.04m/s Compared to Model Predictions 


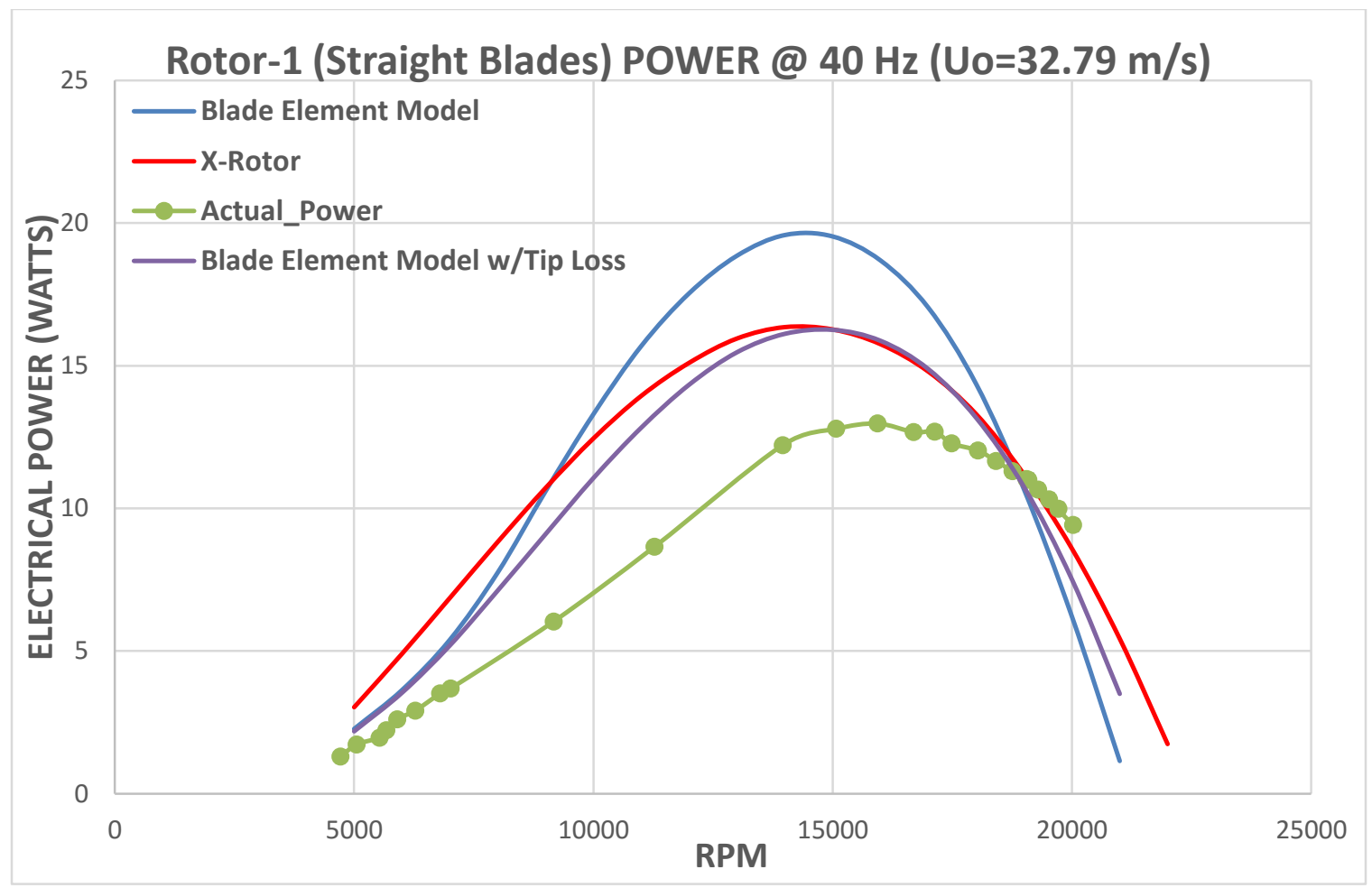

Figure 100. Rotor-1 Power @ 32.79 m/s Compared to Model Predictions

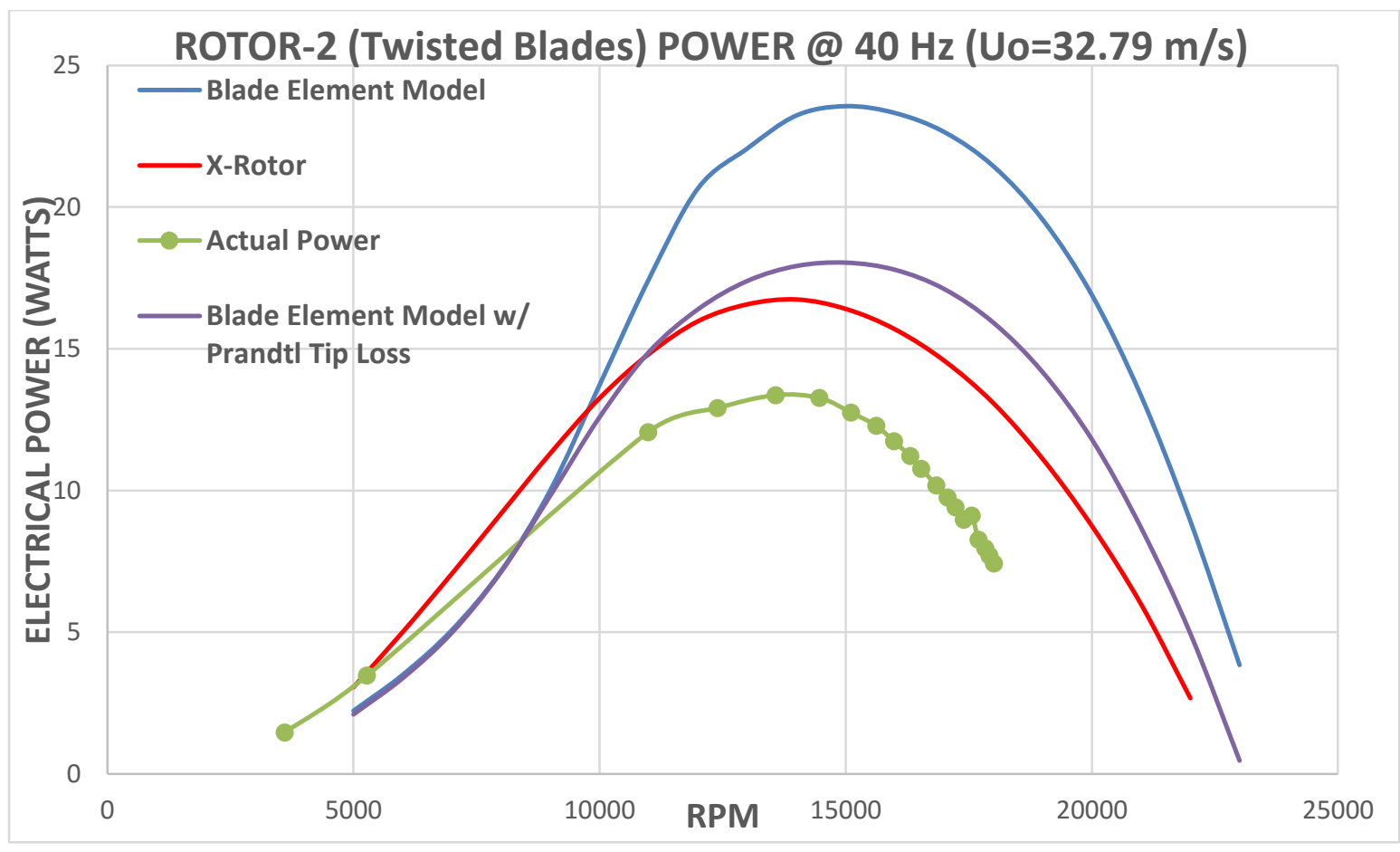

Figure 101. Rotor-2 Power @ 32.79m/s Compared to Model Predictions 


\section{CONCLUSION AND RECOMMENDATIONS}

This thesis project was undertaken to assemble a set of design tools to be employed for the design of a $\mu \mathrm{RAT}$ for specific operating conditions. The $\mu \mathrm{RAT}$ design tools developed consist of turbine rotor and generator models. The primary focus of this thesis was in developing the generator model which can be used to predict the performance of a brushless DC machine operated as a generator. The generator model presented is able to predict generator brake power and output electrical power with and without rectification as a function of shaft speed and electrical load with only basic manufacturer specifications given as inputs. Initially it was a challenge to account for all power losses, however, through model evaluation testing and in comparisons between measured and predicted results it became clear that it was necessary to account for generator no-load current, internal resistance, inductance reactance, terminal load resistance, and rectifier losses. The finalized generator model was then able to predict performance to within a few percent error.

For the turbine rotor model, momentum and basic, 2-D, blade element theory was implemented in conducting rotor performance analysis and geometry selection. Rotor model results were expected to over-predict rotor torque and power due to the model not taking into account induced flow effects. A second model, X-Rotor, that includes induced flow was then used to predict power and for comparison to the rotor model results. Rotor models were then evaluated through wind tunnel validation test conducted on a turbine generator with two different rotors, rotor-1 (untwisted blades) and rotor-2 (twisted blades). Results indicated power predictions to be $50-75 \%$ higher for the blade model and 
20-30\% higher for Xrotor. It was assessed that induced flow effects along with aeroelastic deformation are likely contributors to error between model results and measured values. In effort to approximately account for some of the induced flow effects in the rotor model, the Prandtl tip-loss factor was implemented in the rotor model. With the tiploss factor implemented in the rotor model, predictions were much closer to X-Rotor results and about $20-40 \%$ higher than actual results.

Some of the conclusions that have been established throughout this project include various aspects of the approach taken in characterizing rotor and generator performance and in the methods of model evaluation.

These conclusions are as follows:

1. A model of the performance of a brushless DC machine operated as a generator has been developed that uses readily-available manufacturer specified machine parameters such as internal resistance $\left(R_{i}\right)$, no-load Current $\left(I_{o}\right)$, Speed Constant $\left(K_{V}\right)$ and Inductance (L), and includes rectification of its output if desired.

2. Losses in the generator model due to the rectifier are significant and should not be neglected. For example, the difference between including and excluding rectifier losses in the generator model for the Maxon generator \#386677 operating with a 5-ohm load at $30,000 \mathrm{rpm}$ is about $7.25 \%$.

3. Based on the motor-driven generator test results, it is believed that most of the discrepancy in baseline rotor/generator validation test between predicted and observed power generated is due to inaccuracy in the rotor performance modelling and is concluded that the proposed generator model is probably sufficient although direct torque measurements are desired. 
4. Motor/generator specifications provided by the manufacturer do not necessarily match the values that are published and do not necessarily remain constant with speed. For the Maxon motor actual $\mathrm{Kv}$ and $\mathrm{Ri}$, values were within $0.5 \%$ percent error from what was published. However, for the Ammo motor that was used in the motored generator test, $\mathrm{Kv}$ values had a $38 \%$ error and the no-load current was not a constant 1.9 Amps, as published, and varied significantly with speed.

5. Rotors that perform at relatively low speeds will match better with a low $\mathrm{Kv}$ generator and rotors operating at high speeds will match better with a high $\mathrm{Kv}$ generator.

6. The RPM measurement method of reading the frequency from one of the generators lead wires is most accurate above 8,000 RPM. Measurements taken below this value tend to be noisy and not as reliable.

7. Cogging in motor/generators is torque that stems from the interaction between the permanent magnets and the teeth of the rotor/stator that follows the trend depicted in Figure 16. For the generator it is an undesirable characteristic since cogging will require a higher cut in torque from the blades and cause velocity and torque ripples. For evaluating generator results, velocity and torque ripples are not desired due to resulting power wave distortion that is not accounted for in the generator model.

8. Blade element rotor model predictions are significantly higher than actual results due to the model not accounting for 3-D flow effects. Applying the Prandtl tip loss factor to the rotor model accounts for some of these losses associated with the flow at the blade tip. Applying this factor brings predictions with the blade element model from 50-75\% error to within 25-30\% error compared with experimental measurements for the baseline rotor tests. 
Based on the results and conclusions of this project, the following are the recommendations for future work:

- Further development of the $\mu$ RAT design tools should focus on an improved rotor performance model.

- If desired, direct torque measurements with a torque transducer or torque cradle should be undertaken to more thoroughly evaluate the generator model. However, model evaluation conducted in this thesis should be sufficient.

- Rectifier losses should always be accounted for in the generator model. To minimize rectifier losses, Schottky rectifiers could be considered.

- Motor/generator published specifications should be used in rotor/generator matching. However, Once the generator is in hand, generator performance specifications should always be verified using the methods in Chapter 2.5.

- For model evaluation test for a rotor/generator that operates below or near 8,000 RPM an alternate method for accurately reading RPM than the one used in this thesis should be investigated.

- Although matching a generator to a rotor may be an iterative method as suggested by Figure 69, initial selection of a generator to be matched to a rotor should be based on the $\mathrm{Kv}$ parameter; High $\mathrm{Kv}$ for high speed operating rotor and low $\mathrm{Kv}$ for low speed operating rotor.

- Generators with cogging torque should be avoided. If unavoidable, it will be required that the blade cut-in torque overcomes both the cogging torque along with the no-load torque. 
- The Prandtl tip loss factor should be incorporated in the blade element model. 


\section{REFERENCES}

[1] R. V. Westphal, Interviewee, The Boundary Layer Data System. [Interview]. 22014-2015.

[2] H. H. Oo, Interviewee, $2 \mathrm{~mm}$ Foil Scrim Pyrogel Insulation in Still Air and Wind Tunnel Test. [Interview]. Jun-Jul 2014.

[3] Woodbank Communications Ltd, "Electrical Machines - Electric Drives (Fundamentals)," 2005. [Online]. Available: http://www.mpoweruk.com/machines.htm. [Accessed Jan 2015].

[4] S. J. Chapman, Electric Machinery Fundamentals, New York, NY: McGrawHill, 2005.

[5] "Electric Meters \& Motors," [Online]. Available: http://boomeria.org/physicslectures/secondsemester/electricity/metersmotors/mete rsmotors.html. [Accessed Jan 2015].

[6] "Working Principal of DC Motor," 2013. [Online]. Available: http://workingprincipalofdcmotor.blogspot.com/. [Accessed Jan 2015].

[7] J. Hauge, D. Hutcheson and P. "Scott", "Boundary Layer Data System (BLDS) Heating System," San Luis Obispo, 2009. 
[8] M. Drela, "DC Motor / Propeller Matching Lab 5 Lecture Notes," 03 Mar 2005. [Online]. Available: http://web.mit.edu/drela/Public/web/qprop/motorprop.pdf. [Accessed 1-30 Jun-Jul 2015].

[9] D. Wood, Small Wind Turbines Analysis, Design, and Application, Calgary: Springer, 2011.

[10] Centurion Energy, Alternative Energy, "Types of Wind Turbines," 2013.

[11] H. Glauert, The Elements of Aerofoil and Airscrew Theory, vol. 2nd ed, New York, NY: Cambridge University Press, 1947.

[12] D. J. Auld, "Aerodynamics for Students, Analysis of Propellers," AMME, University of Sydney, 1996-2006. [Online]. Available: http://wwwmdp.eng.cam.ac.uk/web/library/enginfo/aerothermal_dvd_only/aero/propeller/pr op1.html. [Accessed May-Jun 2015].

[13] J. F. Manwell, J. G. McGowan and A. L. Rogers, Wind Energy Explained Theory, Design and Application, Chichester, West Sussex: John Wiley \& Sons Ltd., 2009.

[14] Maxon Motor ag, "Motor Data and Operating Ranges of Maxon DC Motors," Maxon Motors, 2010. [Online]. Available: www.maxonmotor.com/academy. [Accessed 291 2015]. 
[15] W. Storr, "Basic Electronics Tutorial," 22 2015. [Online]. Available:

http://www.electronics-tutorials.ws/inductor/ac-inductors.html . [Accessed 22 2015].

[16] Z. Q. Zhu and D. Howe, "Influence of Design Parameters on Cogging Torque in Permanent Magnet Machines," IEEE Transations on energy conversion, vol. 15, no. 4, pp. 1-5, 2000.

[17] The Electric Energy, "What is a Brushless DC Electric Motor," [Online]. Available: http://theelectricenergy.com/what-is-a-brushless-dc-electric-motor/ . [Accessed 291 2015].

[18] M. Motor, "Maxon Motor usa," [Online]. Available: http://www.maxonmotorusa.com/maxon/view/content/index. [Accessed Jan 2015].

[19] OpenWetWare, "Diodes," [Online]. Available: http://openwetware.org/wiki/20.309:DiodePrimer . [Accessed 291 2015].

[20] MarineInsight, "Understanding Rectifier and Rectifier Circuits," [Online]. Available: http://www.marineinsight.com/tech/marine-electrical/uses-ofrectifier-and-rectifier-circuits-on-ship/.

[21] IXYS, Three Phase Rectifier Bridge FUO22-12N, 2007.

[22] M. Drela and H. Youngren, "XROTOR User Guide," MIT, 2003. 
[23] D. Marten and J. Wendler, "QBlade Guidelines v0.6," tu-berlin, 2013.

[24] M. Drela and H. Youngren, "XFOIL Subsonic Airfoil Development System," MIT, 11 December 2000. [Online]. Available:

http://web.mit.edu/drela/Public/web/xfoil/. [Accessed Jun-Dec 2014].

[25] B. Montgomerie, "Methods for Root Effects, Tip Effects and Extending the Angle of Attack Range to $\pm 180^{\circ}$, with Application to Aerodynamics for Blades on Wind Turbines and Propellers," FOI - Swedish Defence Research Agency, 2004.

[26] B. Schab, MicroRAT Test; Shrouded and Un-Shrouded Turbine Performance Comparison, San Luis Obispo, CA, 2010. 
APPENDICES

\section{APPENDIX A. ROTOR MODEL MATLAB}

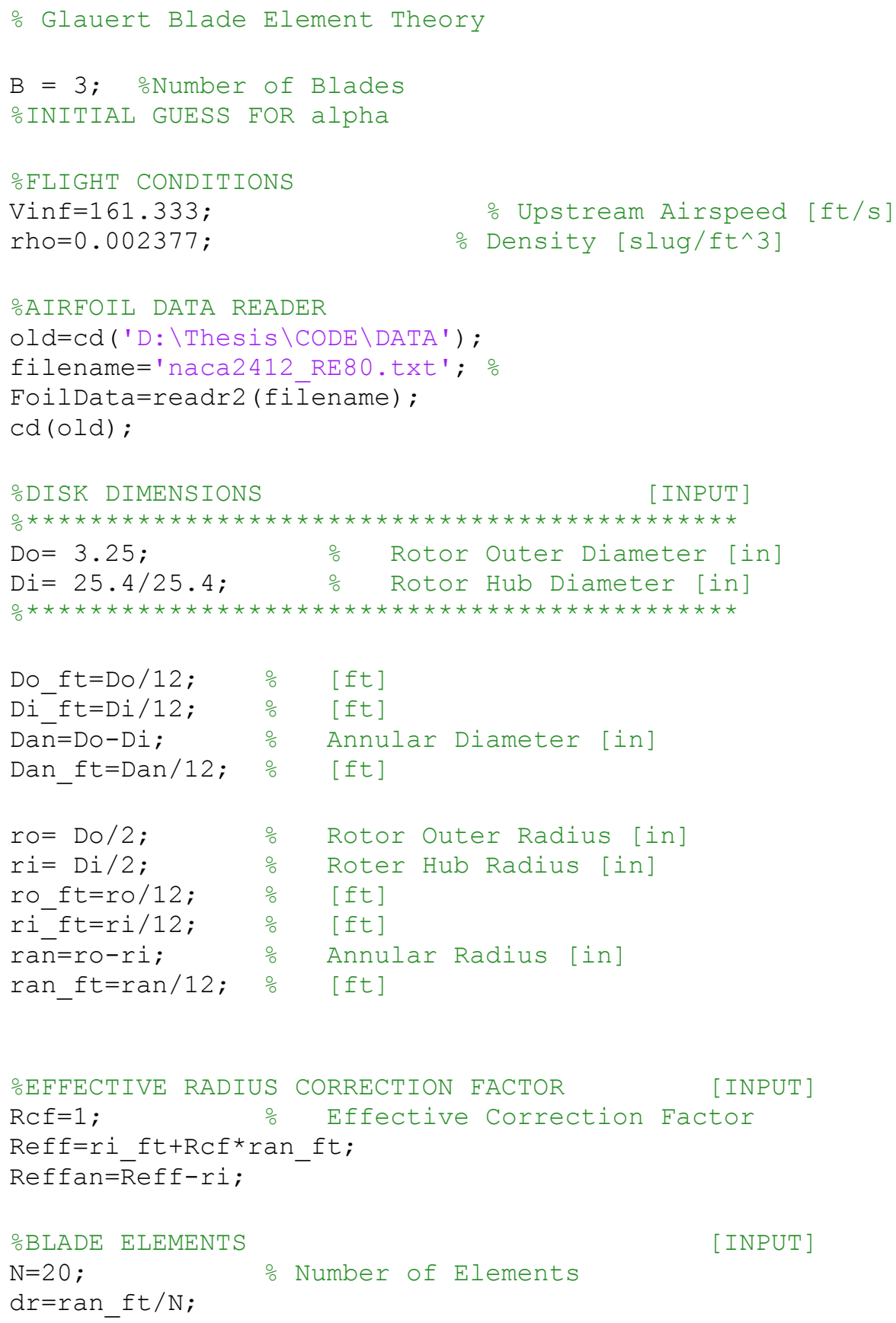




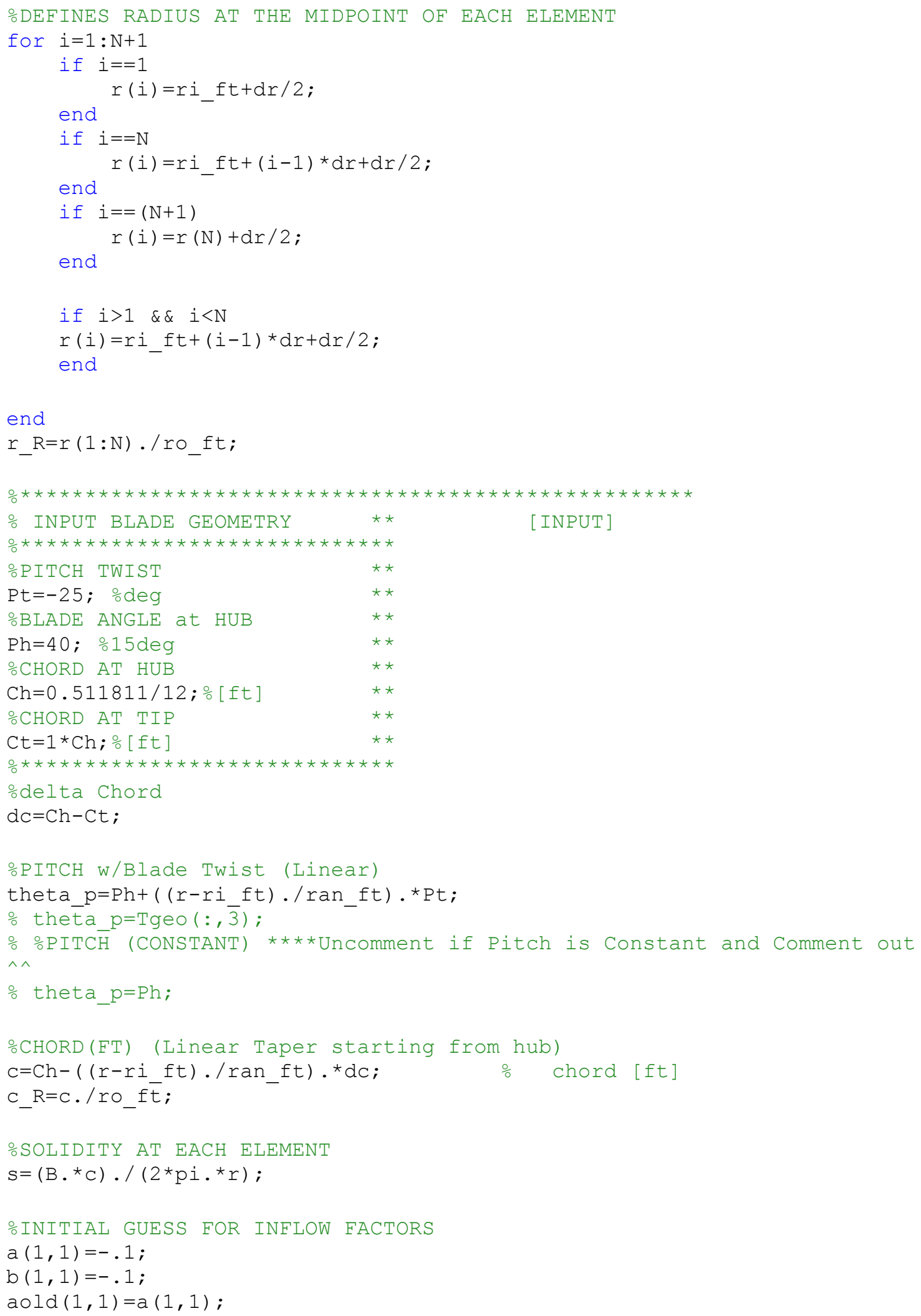




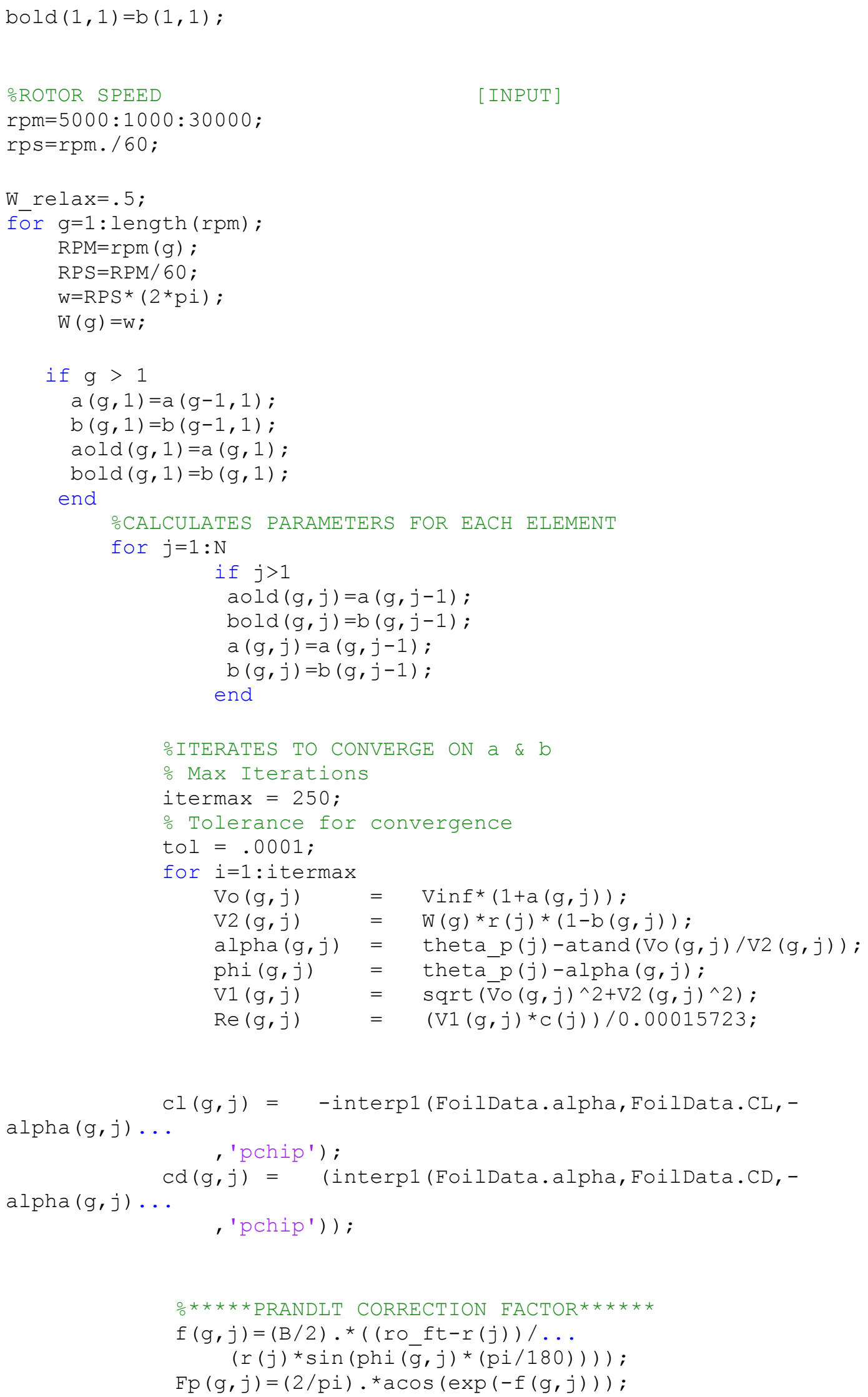


end

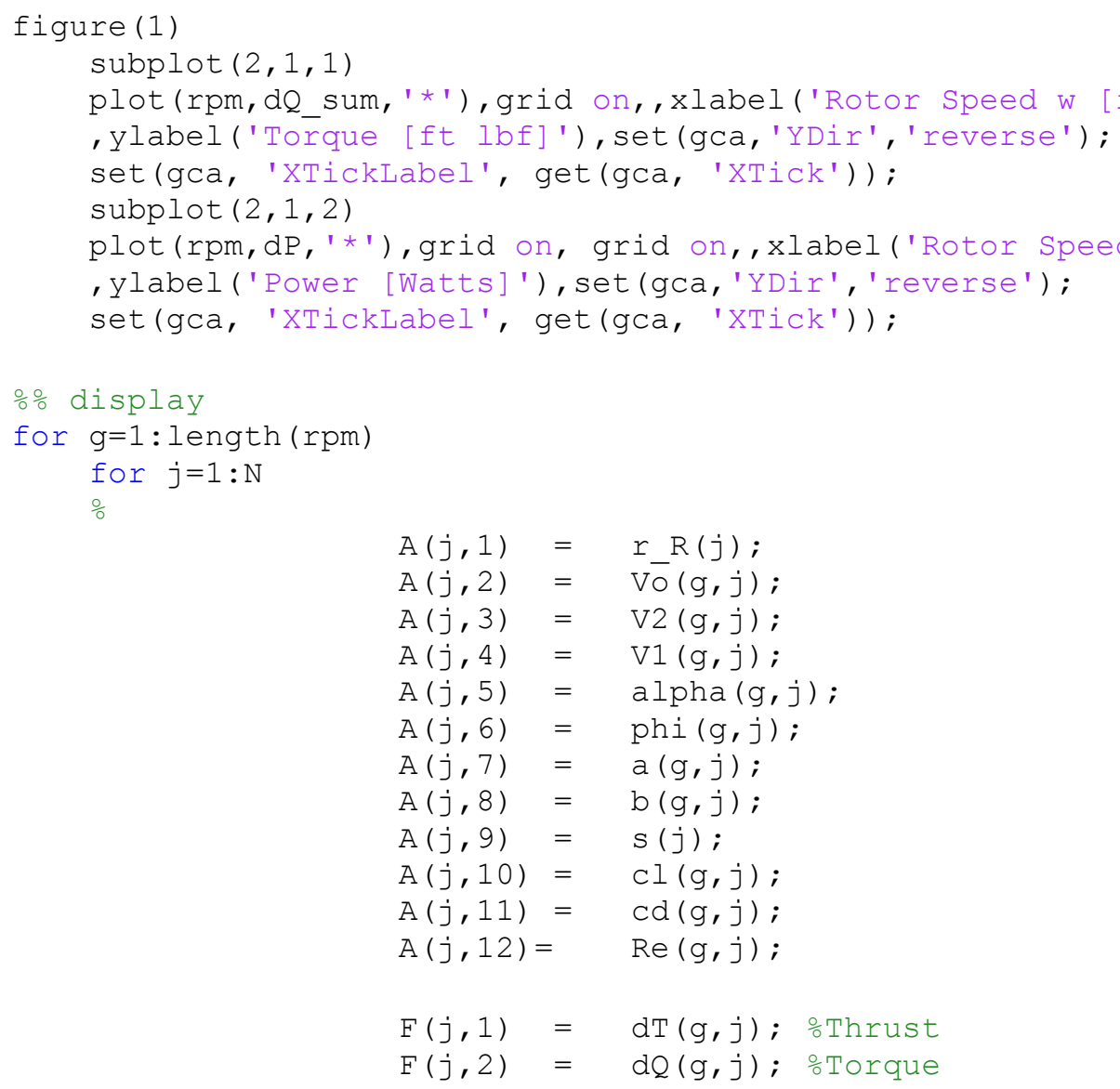




\section{APPENDIX B. GENERATOR MODEL MATLAB}

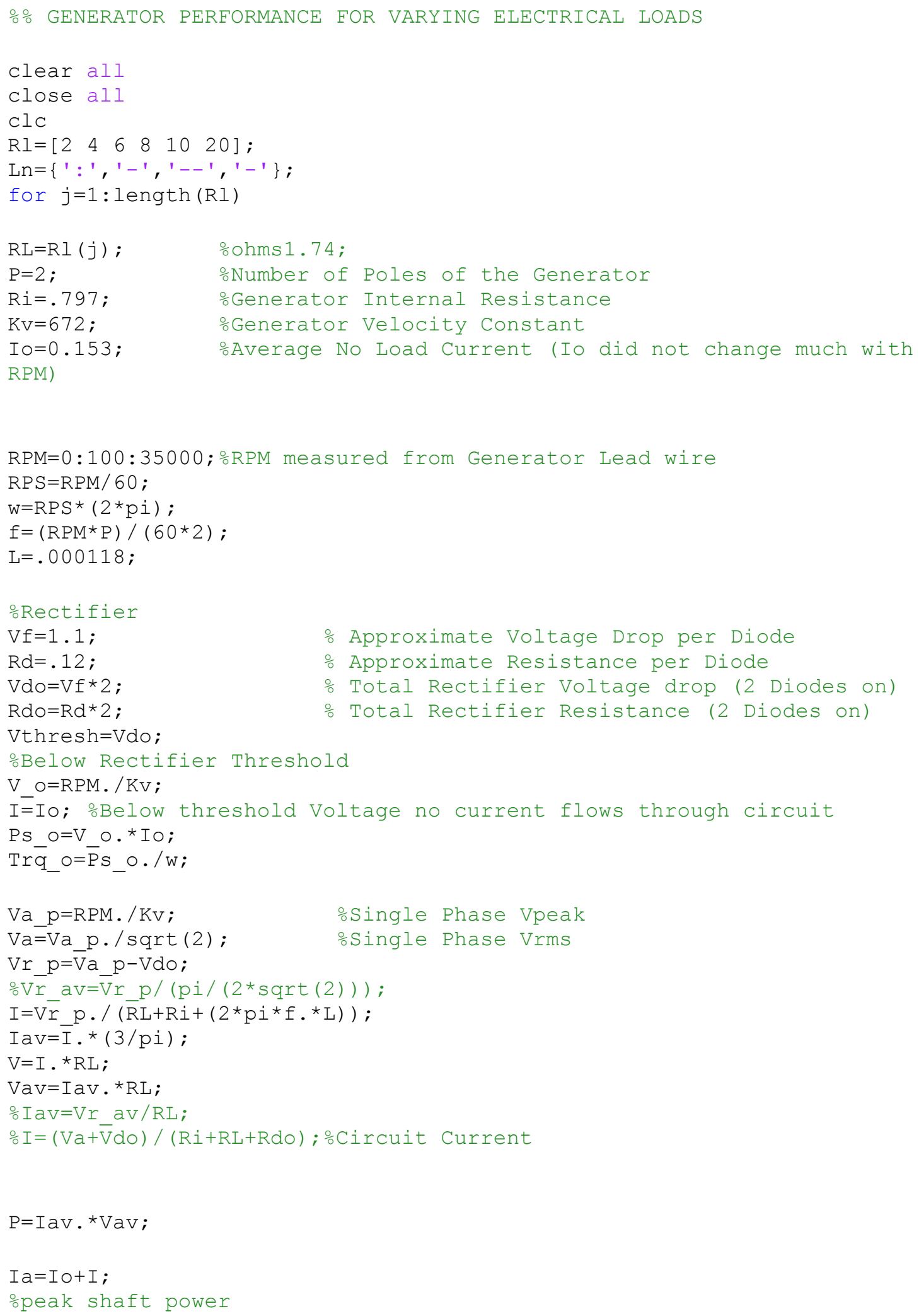




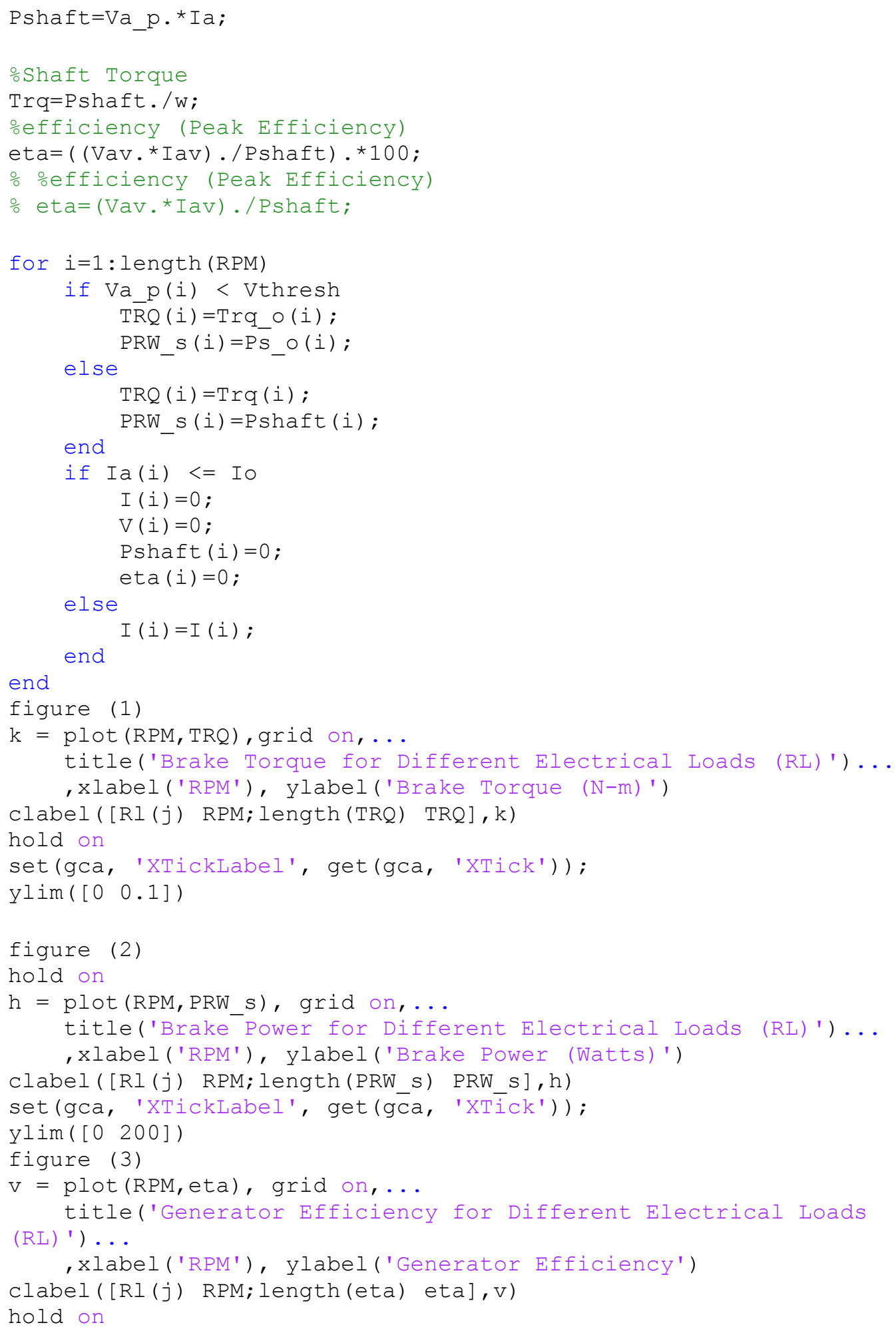




\section{B.1 Generator Model Efficiency Contour Charts}

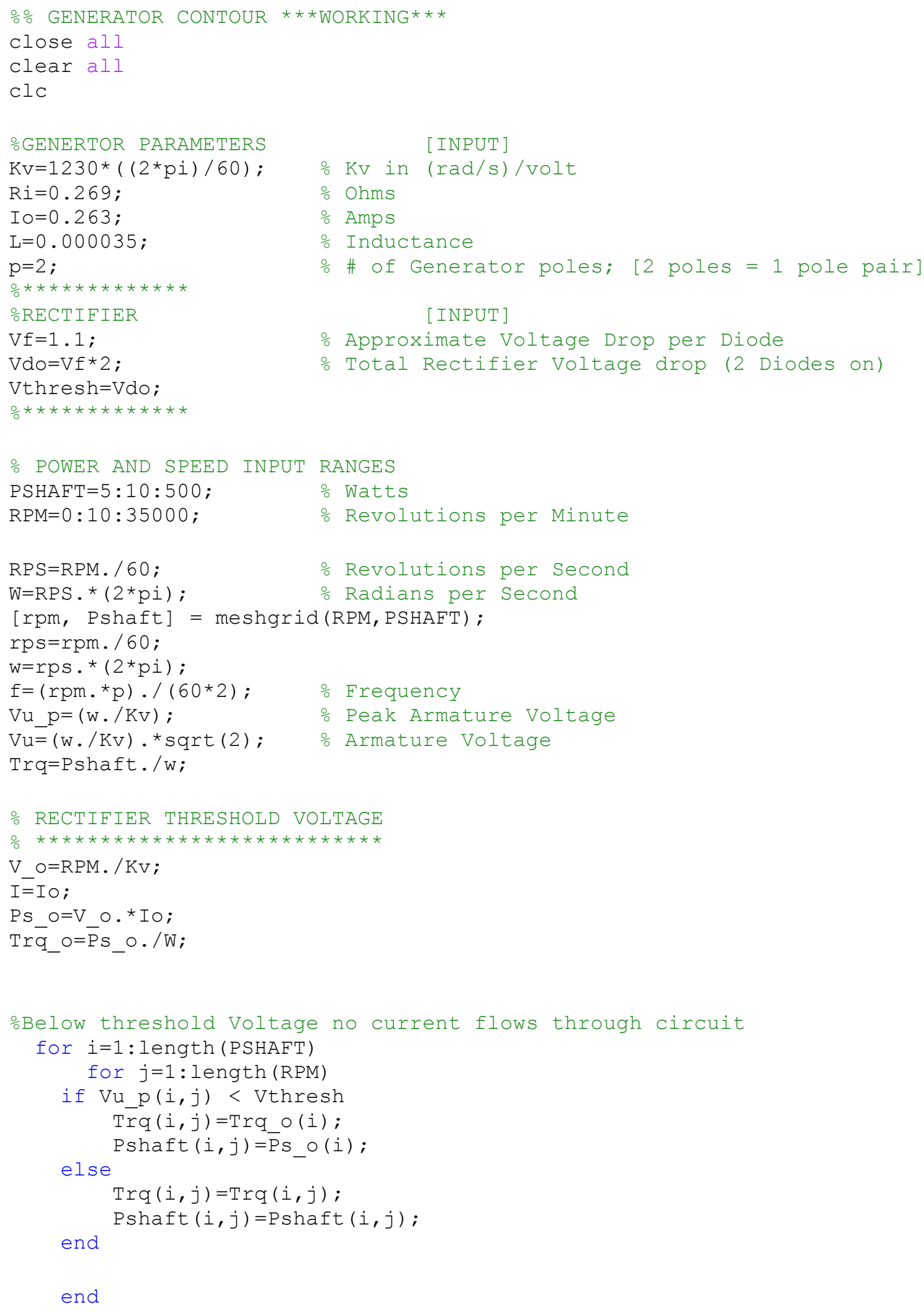




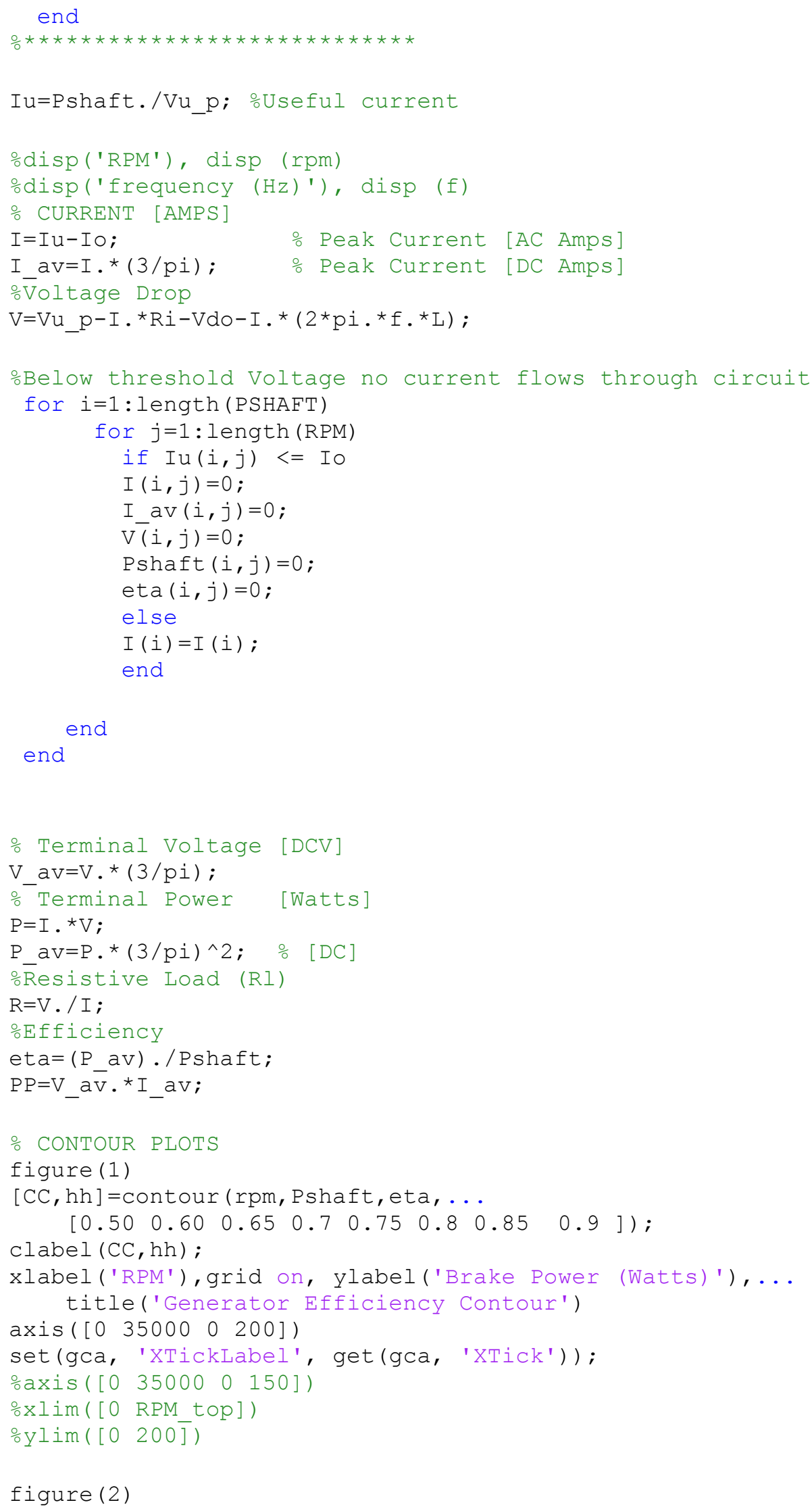


$[\mathrm{CC}, \mathrm{hh}]=$ contour $\left(\mathrm{rpm},\left(\mathrm{V}_{-} \mathrm{av} \cdot{ }^{\star} \mathrm{I}_{-} \mathrm{av}\right)\right.$, eta, ...

clabel ( $\mathrm{CC}, \mathrm{hh})$;

xlabel ('RPM'), grid on, ylabel ('Terminal Power (Watts)'),... title('Generator Efficiency Contour')

$\operatorname{axis}\left(\left[\begin{array}{llll}0 & 35000 & 0 & 200\end{array}\right)\right.$

set (gca, 'XTickLabel', get(gca, 'XTick'));

\%xlim([0 RPM_top ])

$\% y \lim \left(\left[\begin{array}{ll}0 & 200\end{array}\right]\right)$ 


\section{APPENDIX C. MOTOR MODEL MATLAB}

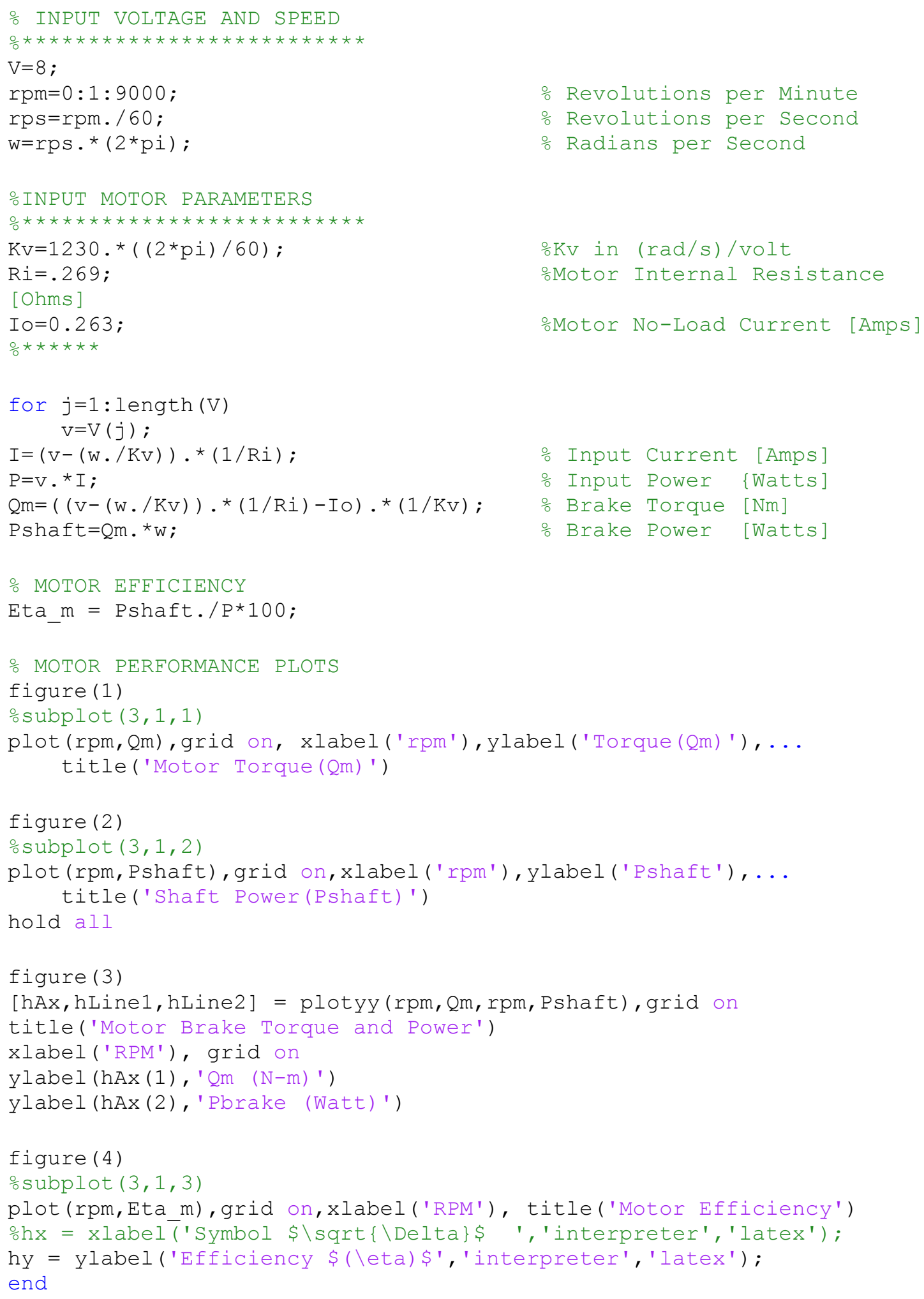




\section{1 Motor Model Efficiency Contour Charts Matlab}

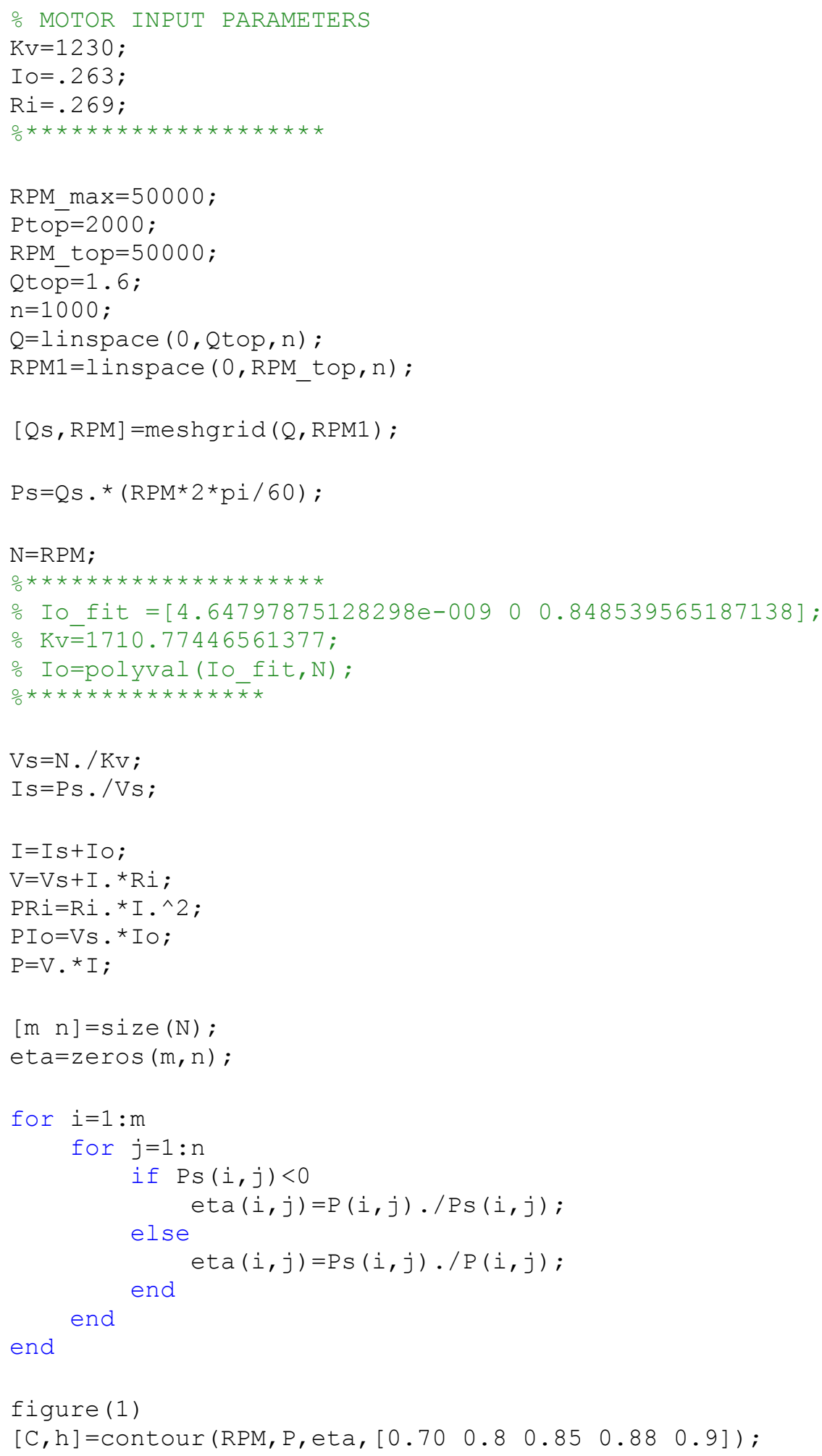


clabel $(\mathrm{C}, \mathrm{h})$;

xlabel('RPM'), grid on, ylabel('Input Power (Watts)'), title('Motor Efficiency Contour')

$x \lim ([0$ RPM top])

$y \lim \left(\left[\begin{array}{ll}0 & 500\end{array}\right]\right)$

hold all 
APPENDIX D. GENERATOR MODEL EVALUTAION TEST RESULTS

Table 22. Generator Evaluation Test Results (RL=1.04) (Maxon \#386677)

\begin{tabular}{|c|c|c|c|c|c|c|c|c|c|c|c|c|}
\hline \multicolumn{9}{|c|}{ Calculated } & \multicolumn{3}{|c|}{ Measured } & \multirow[b]{2}{*}{$\%$ Error } \\
\hline RPM & $\begin{array}{c}\text { Va (peak) } \\
\text { [Volts] }\end{array}$ & $\begin{array}{c}\text { Reactance } \\
\text { [Ohms] }\end{array}$ & $\begin{array}{c}\mathrm{Va} \text { (rms) } \\
\text { [Volts] }\end{array}$ & $\begin{array}{c}\text { Vdo } \\
\text { [Volts] }\end{array}$ & $\begin{array}{l}\text { I(peak) } \\
\text { [Amps] }\end{array}$ & $\begin{array}{c}\text { I(DC) } \\
\text { [Amps] }\end{array}$ & $\begin{array}{l}\operatorname{Vr}(\mathrm{DC}) \\
\text { [Volts] }\end{array}$ & $\begin{array}{c}\text { P(DC) } \\
\text { [Watts] }\end{array}$ & $\begin{array}{l}\operatorname{Vr}(\mathrm{DC}) \\
\text { [Volts] }\end{array}$ & $\begin{array}{c}\text { I(DC) } \\
\text { [Amps] }\end{array}$ & $\begin{array}{l}\text { P (DC) } \\
\text { [Watts] }\end{array}$ & \\
\hline 8784 & 7.14 & $\begin{array}{l}0.032 \\
\end{array}$ & 5.05 & 2 & 3.831 & 3.658 & 3.804 & 13.92 & 3.75 & 3.76 & 14.10 & -1.30 \\
\hline 9828 & 7.99 & 0.036 & 5.65 & 2 & 4.450 & 4.250 & 4.420 & 18.78 & 4.32 & 4.34 & 18.75 & 0.18 \\
\hline 10758 & 8.75 & 0.039 & 6.18 & 2 & 4.999 & 4.774 & 4.965 & 23.70 & 4.84 & 4.867 & 23.56 & 0.62 \\
\hline 11748 & 9.55 & 0.043 & 6.75 & 2 & 5.581 & 5.329 & 5.542 & 29.54 & 5.36 & 5.39 & 28.89 & 2.24 \\
\hline 12774 & 10.39 & 0.047 & 7.34 & 2 & 6.180 & 5.902 & 6.138 & 36.22 & 5.916 & 5.941 & 35.15 & 3.06 \\
\hline
\end{tabular}

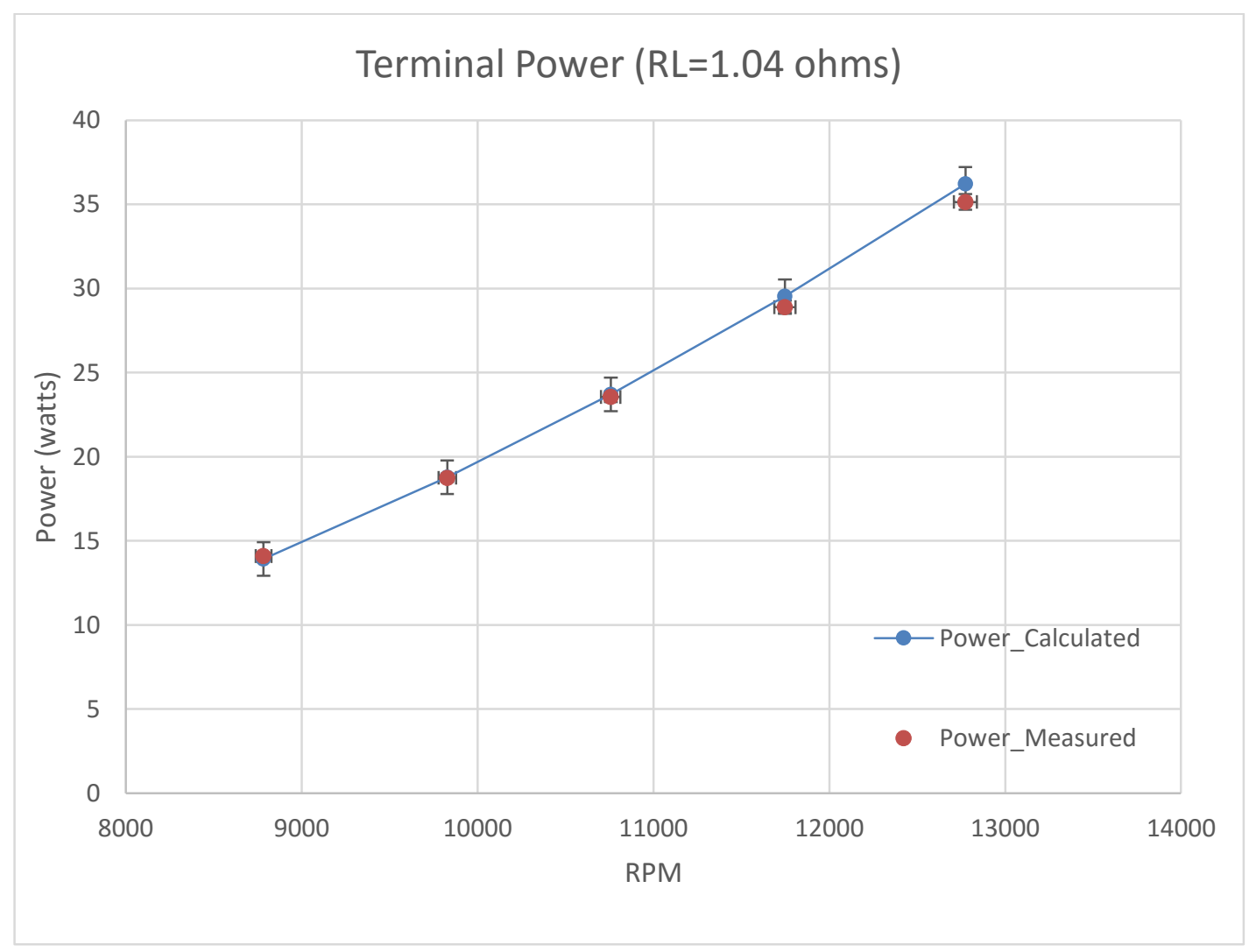

Figure 102. Generator Evaluation Test Results (RL=1.04) (Maxon \#386677) 
Table 23. Generator Evaluation Test Results ( $R L=1.39)$ (Maxon \#386677)

\begin{tabular}{|c|c|c|c|c|c|c|c|c|c|c|c|c|}
\hline \multirow[b]{2}{*}{ RPM } & \multicolumn{8}{|c|}{ Calculated } & \multicolumn{3}{|c|}{ Measured } & \multirow[b]{2}{*}{ \% Error } \\
\hline & $\begin{array}{c}\text { Va (peak) } \\
\text { [Volts] }\end{array}$ & $\begin{array}{c}\text { Reactance } \\
\text { [Ohms] }\end{array}$ & $\begin{array}{l}\text { Va (rms) } \\
\text { [Volts] }\end{array}$ & $\begin{array}{c}\text { Vdo } \\
\text { [Volts] }\end{array}$ & $\begin{array}{l}\text { I(peak) } \\
\text { [Amps] }\end{array}$ & $\begin{array}{c}\text { I(DC) } \\
{[\text { Amps] }}\end{array}$ & $\begin{array}{l}\operatorname{Vr}(\mathrm{DC}) \\
\text { [Volts] }\end{array}$ & $\begin{array}{c}\mathrm{P}(\mathrm{DC}) \\
{[\text { Watts] }}\end{array}$ & $\begin{array}{l}\operatorname{Vr}(\mathrm{DC}) \\
\text { [Volts] }\end{array}$ & $\begin{array}{c}\text { I(DC) } \\
{[\mathrm{Amps}]}\end{array}$ & $\begin{array}{l}\mathrm{P}(\mathrm{DC}) \\
{[\text { Watts] }}\end{array}$ & \\
\hline 9048 & 7.36 & 0.033 & 5.20 & 2 & 3.16 & 3.02 & 4.20 & 12.68 & 4.18 & 3.09 & 12.92 & -1.80 \\
\hline 10182 & 8.28 & 0.037 & 5.85 & 2 & 3.70 & 3.53 & 4.91 & 17.34 & 4.85 & 3.61 & 17.51 & -0.96 \\
\hline 11118 & 9.04 & 0.041 & 6.39 & 2 & 4.14 & 3.95 & 5.49 & 21.71 & 5.41 & 4.03 & 21.80 & -0.41 \\
\hline 12168 & 9.89 & 0.045 & 7.00 & 2 & 4.63 & 4.42 & 6.15 & 27.17 & 6 & 4.47 & 26.82 & 1.32 \\
\hline 13158 & 10.70 & 0.048 & 7.56 & 2 & 5.09 & 4.86 & 6.76 & 32.86 & 6.6 & 4.91 & 32.41 & 1.40 \\
\hline 14100 & 11.46 & 0.052 & 8.11 & 2 & 5.53 & 5.28 & 7.34 & 38.74 & 7.18 & 5.34 & 38.34 & 1.05 \\
\hline 15264 & 12.41 & 0.056 & 8.78 & 2 & 6.07 & 5.79 & 8.05 & 46.65 & 7.8 & 5.802 & 45.26 & 3.08 \\
\hline
\end{tabular}

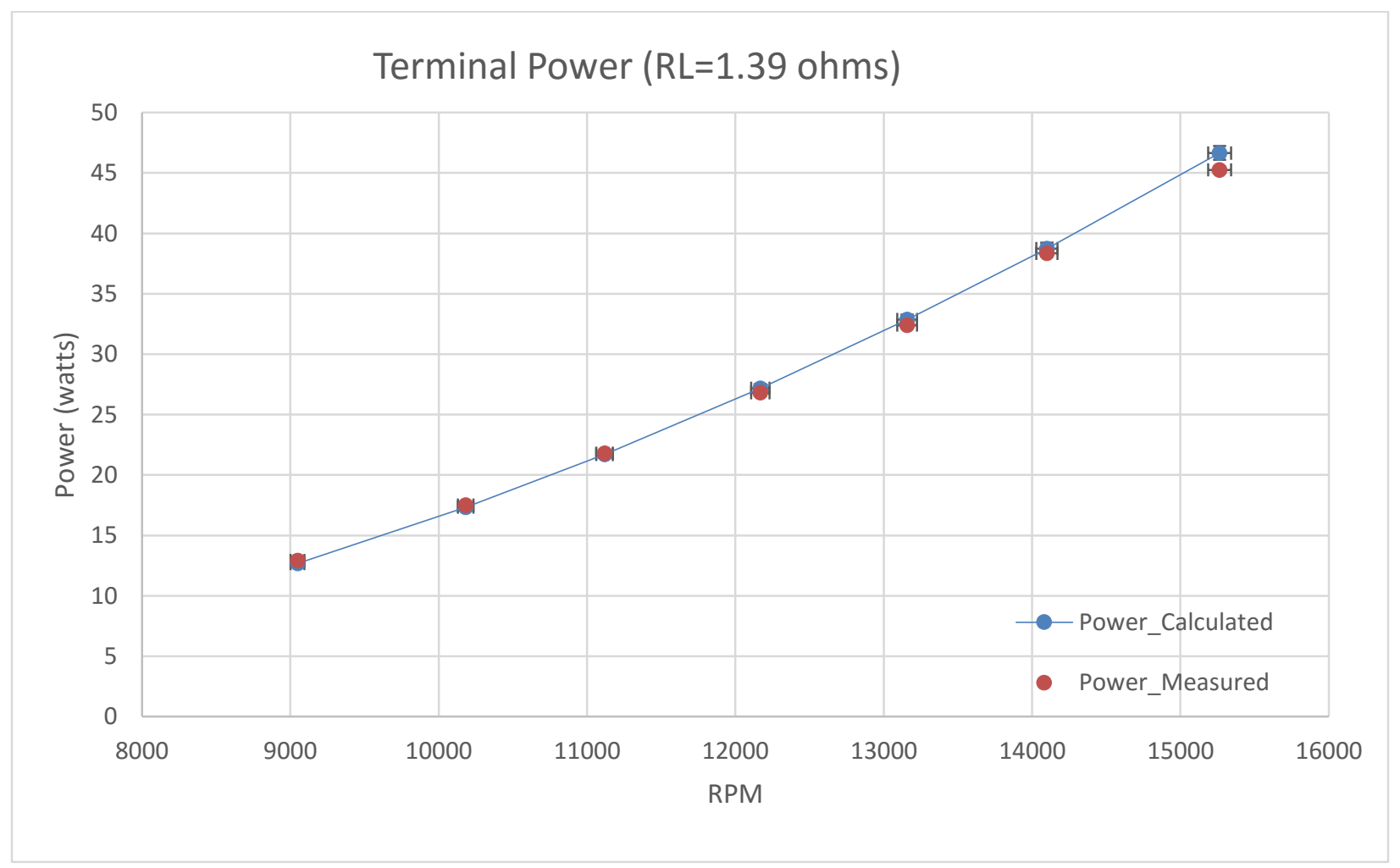

Figure 103. Generator Evaluation Test Results (RL=1.39) (Maxon \#386677) 
Table 24. Generator Evaluation Test Results ( $R L=1.53)$ (Maxon \#386677)

\begin{tabular}{|c|c|c|c|c|c|c|c|c|c|c|c|c|}
\hline \multirow[b]{2}{*}{ RPM } & \multicolumn{8}{|c|}{ Calculated } & \multicolumn{3}{|c|}{ Measured } & \multirow[b]{2}{*}{ \% Error } \\
\hline & $\begin{array}{c}\text { Va (peak) } \\
\text { [Volts] }\end{array}$ & $\begin{array}{c}\text { Reactance } \\
\text { [Ohms] }\end{array}$ & $\begin{array}{c}\text { Va (rms) } \\
\text { [Volts] }\end{array}$ & $\begin{array}{c}\text { Vdo } \\
\text { [Volts] }\end{array}$ & $\begin{array}{l}\text { I(peak) } \\
\text { [Amps] }\end{array}$ & $\begin{array}{c}\text { I(DC) } \\
{[\text { Amps] }}\end{array}$ & $\begin{array}{l}\operatorname{Vr}(\mathrm{DC}) \\
\text { [Volts] }\end{array}$ & $\begin{array}{c}\text { P(DC) } \\
{[\text { Watts] }}\end{array}$ & $\begin{array}{l}\operatorname{Vr}(\mathrm{DC}) \\
\text { [Volts] }\end{array}$ & $\begin{array}{c}\text { I(DC) } \\
{[\mathrm{Amps}]}\end{array}$ & $\begin{array}{c}P(D C) \\
\text { [Watts] }\end{array}$ & \\
\hline 9228 & 7.50 & 0.034 & 5.31 & 2 & 3.00 & 2.87 & 4.38 & 12.56 & 4.3 & 2.9 & 12.47 & 0.73 \\
\hline 10302 & 8.38 & 0.038 & 5.92 & 2 & 3.47 & 3.31 & 5.07 & 16.79 & 5.02 & 3.35 & 16.82 & -0.15 \\
\hline 11304 & 9.19 & 0.041 & 6.50 & 2 & 3.90 & 3.73 & 5.70 & 21.27 & 5.624 & 3.76 & 21.15 & 0.60 \\
\hline 12234 & 9.95 & 0.045 & 7.03 & 2 & 4.31 & 4.11 & 6.29 & 25.89 & 6.2 & 4.14 & 25.67 & 0.85 \\
\hline 13260 & 10.78 & 0.049 & 7.62 & 2 & 4.75 & 4.54 & 6.94 & 31.48 & 6.81 & 4.55 & 30.99 & 1.58 \\
\hline 14340 & 11.66 & 0.053 & 8.24 & 2.2 & 5.11 & 4.88 & 7.46 & 36.37 & 7.45 & 4.97 & 37.03 & -1.77 \\
\hline 15378 & 12.50 & 0.056 & 8.84 & 2.2 & 5.55 & 5.30 & 8.11 & 42.97 & 8.06 & 5.38 & 43.36 & -0.90 \\
\hline 16452 & 13.38 & 0.060 & 9.46 & 2.2 & 6.01 & 5.74 & 8.78 & 50.35 & 8.69 & 5.79 & 50.32 & 0.07 \\
\hline
\end{tabular}

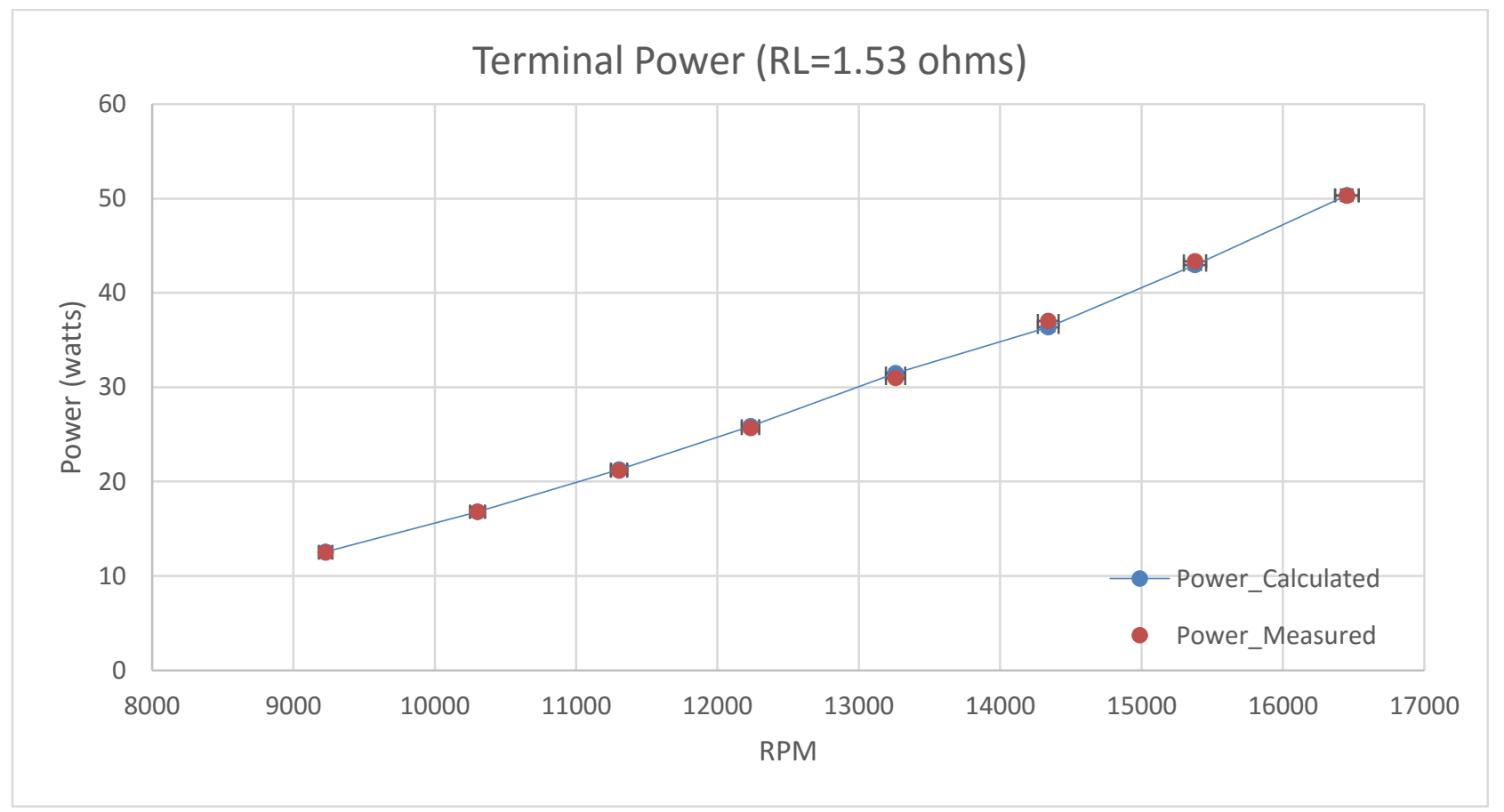

Figure 104. Generator Evaluation Test Results ( $R L=1.53)$ (Maxon \#386677) 
Table 25. Generator Evaluation Test Results ( $R L=1.74)$ (Maxon \#386677)

\begin{tabular}{|c|c|c|c|c|c|c|c|c|c|c|c|c|}
\hline \multirow[b]{2}{*}{ RPM } & \multicolumn{8}{|c|}{ Calculated } & \multicolumn{3}{|c|}{ Measured } & \multirow[b]{2}{*}{ \% Error } \\
\hline & $\begin{array}{c}\text { Va (peak) } \\
\text { [Volts] }\end{array}$ & $\begin{array}{c}\text { Reactance } \\
\text { [Ohms] }\end{array}$ & $\begin{array}{l}\text { Va (rms) } \\
\text { [Volts] }\end{array}$ & $\begin{array}{c}\text { Vdo } \\
\text { [Volts] }\end{array}$ & $\begin{array}{l}\text { I(peak) } \\
\text { [Amps] }\end{array}$ & $\begin{array}{c}\text { I(DC) } \\
\text { [Amps] }\end{array}$ & $\begin{array}{l}\operatorname{Vr}(\mathrm{DC}) \\
\text { [Volts] }\end{array}$ & $\begin{array}{c}\text { P(DC) } \\
\text { [Watts] }\end{array}$ & $\begin{array}{l}\operatorname{Vr}(\mathrm{DC}) \\
\text { [Volts] }\end{array}$ & $\begin{array}{c}\text { I(DC) } \\
{[\mathrm{Amps}]}\end{array}$ & $\begin{array}{c}\text { P (DC) } \\
\text { [Watts] }\end{array}$ & \\
\hline 9618 & 7.82 & 0.035 & 5.53 & 2 & 2.85 & 2.72 & 4.73 & 12.85 & 4.70 & 2.75 & 12.93 & -0.61 \\
\hline 10578 & 8.60 & 0.039 & 6.08 & 2 & 3.22 & 3.08 & 5.35 & 16.47 & 5.32 & 3.10 & 16.49 & -0.12 \\
\hline 11532 & 9.38 & 0.042 & 6.63 & 2 & 3.59 & 3.43 & 5.97 & 20.49 & 5.92 & 3.45 & 20.44 & 0.27 \\
\hline 12498 & 10.16 & 0.046 & 7.18 & 2 & 3.97 & 3.79 & 6.60 & 25.00 & 6.52 & 3.81 & 24.85 & 0.61 \\
\hline 13506 & 10.98 & 0.050 & 7.76 & 2 & 4.36 & 4.16 & 7.25 & 30.17 & 7.15 & 4.18 & 29.88 & 0.97 \\
\hline 14556 & 11.83 & 0.053 & 8.37 & 2.2 & 4.67 & 4.46 & 7.76 & 34.59 & 7.77 & 4.54 & 35.28 & -1.94 \\
\hline 15528 & 12.62 & 0.057 & 8.93 & 2.2 & 5.04 & 4.82 & 8.38 & 40.36 & 8.38 & 4.89 & 40.93 & -1.39 \\
\hline 16596 & 13.49 & 0.061 & 9.54 & 2.2 & 5.45 & 5.21 & 9.06 & 47.18 & 9.00 & 5.25 & 47.25 & -0.14 \\
\hline 17556 & 14.27 & 0.064 & 10.09 & 2.2 & 5.82 & 5.56 & 9.67 & 53.75 & 9.55 & 5.58 & 53.24 & 0.95 \\
\hline
\end{tabular}

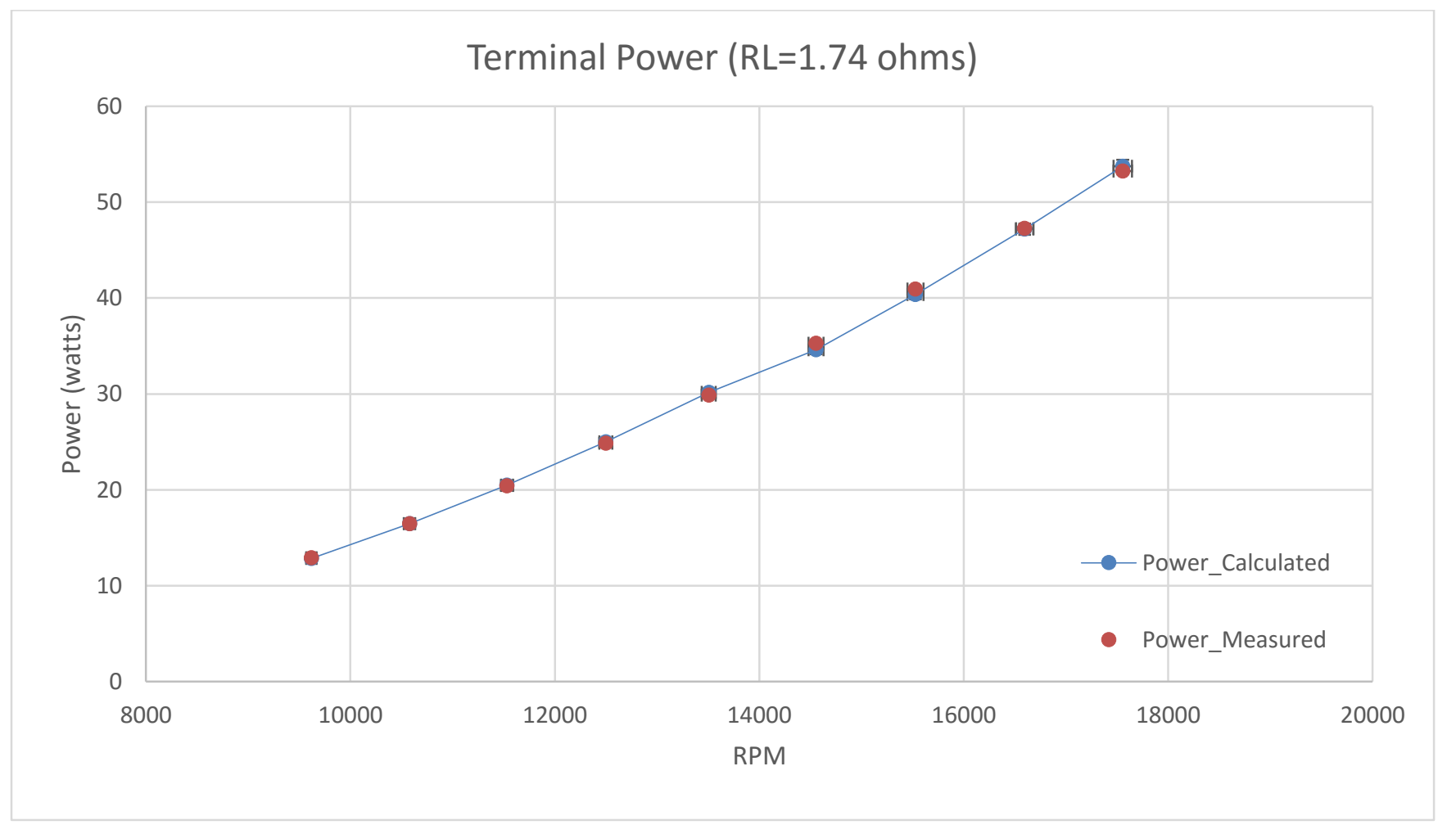

Figure 105. Generator Evaluation Test Results (RL=1.74) (Maxon \#386677) 
Table 26. Generator Evaluation Test Results $(\mathbf{R L}=\mathbf{2 . 0 7})$ (Maxon \#386677)

\begin{tabular}{|c|c|c|c|c|c|c|c|c|c|c|c|c|}
\hline \multirow[b]{2}{*}{ RPM } & \multicolumn{8}{|c|}{ Calculated } & \multicolumn{3}{|c|}{ Measured } & \multirow[b]{2}{*}{$\%$ Error } \\
\hline & $\begin{array}{c}\text { Va (peak) } \\
\text { [Volts] }\end{array}$ & $\begin{array}{c}\text { Reactance } \\
\text { [Ohms] }\end{array}$ & $\begin{array}{c}\text { Va (rms) } \\
\text { [Volts] }\end{array}$ & $\begin{array}{c}\text { Vdo } \\
\text { [Volts] }\end{array}$ & $\begin{array}{l}\text { I(peak) } \\
\text { [Amps] }\end{array}$ & $\begin{array}{c}\text { I(DC) } \\
\text { [Amps] }\end{array}$ & $\begin{array}{l}\operatorname{Vr}(\mathrm{DC}) \\
{[\text { Volts] }}\end{array}$ & $\begin{array}{c}\mathrm{P}(\mathrm{DC}) \\
{[\mathrm{Watts}]}\end{array}$ & $\begin{array}{l}\operatorname{Vr}(\mathrm{DC}) \\
\text { [Volts] }\end{array}$ & $\begin{array}{c}\text { I(DC) } \\
\text { [Amps] }\end{array}$ & $\begin{array}{l}P \text { (DC) } \\
\text { [Watts] }\end{array}$ & \\
\hline 9114 & 7.41 & 0.033 & 5.24 & 2 & 2.28 & 2.18 & 4.51 & 9.81 & 4.58 & 2.25 & 10.31 & -4.84 \\
\hline 10638 & 8.65 & 0.039 & 6.12 & 2 & 2.79 & 2.67 & 5.52 & 14.74 & 5.328 & 2.64 & 14.07 & 4.82 \\
\hline 11472 & 9.33 & 0.042 & 6.60 & 2 & 3.08 & 2.94 & 6.08 & 17.86 & 6.06 & 3 & 18.18 & -1.77 \\
\hline 12582 & 10.23 & 0.046 & 7.23 & 2 & 3.45 & 3.29 & 6.82 & 22.45 & 6.77 & 3.348 & 22.67 & -0.94 \\
\hline 13665 & 11.11 & 0.050 & 7.86 & 2 & 3.81 & 3.64 & 7.53 & 27.42 & 7.475 & 3.64 & 27.21 & 0.78 \\
\hline 14745 & 11.99 & 0.054 & 8.48 & 2 & 4.17 & 3.98 & 8.25 & 32.85 & 8.15 & 4.03 & 32.84 & 0.03 \\
\hline 15756 & 12.81 & 0.058 & 9.06 & 2 & 4.51 & 4.31 & 8.91 & 38.37 & 8.79 & 4.34 & 38.15 & 0.57 \\
\hline 16788 & 13.65 & 0.062 & 9.65 & 2.2 & 4.77 & 4.55 & 9.42 & 42.90 & 9.43 & 4.654 & 43.89 & -2.25 \\
\hline 18030 & 14.66 & 0.066 & 10.37 & 2.2 & 5.18 & 4.94 & 10.24 & 50.61 & 10.185 & 5.037 & 51.30 & -1.35 \\
\hline 19035 & 15.48 & 0.070 & 10.94 & 2.2 & 5.51 & 5.26 & 10.89 & 57.29 & 10.8 & 5.33 & 57.56 & -0.48 \\
\hline 20130 & 16.37 & 0.074 & 11.57 & 2.2 & 5.87 & 5.60 & 11.60 & 65.01 & 11.49 & 5.652 & 64.94 & 0.11 \\
\hline
\end{tabular}

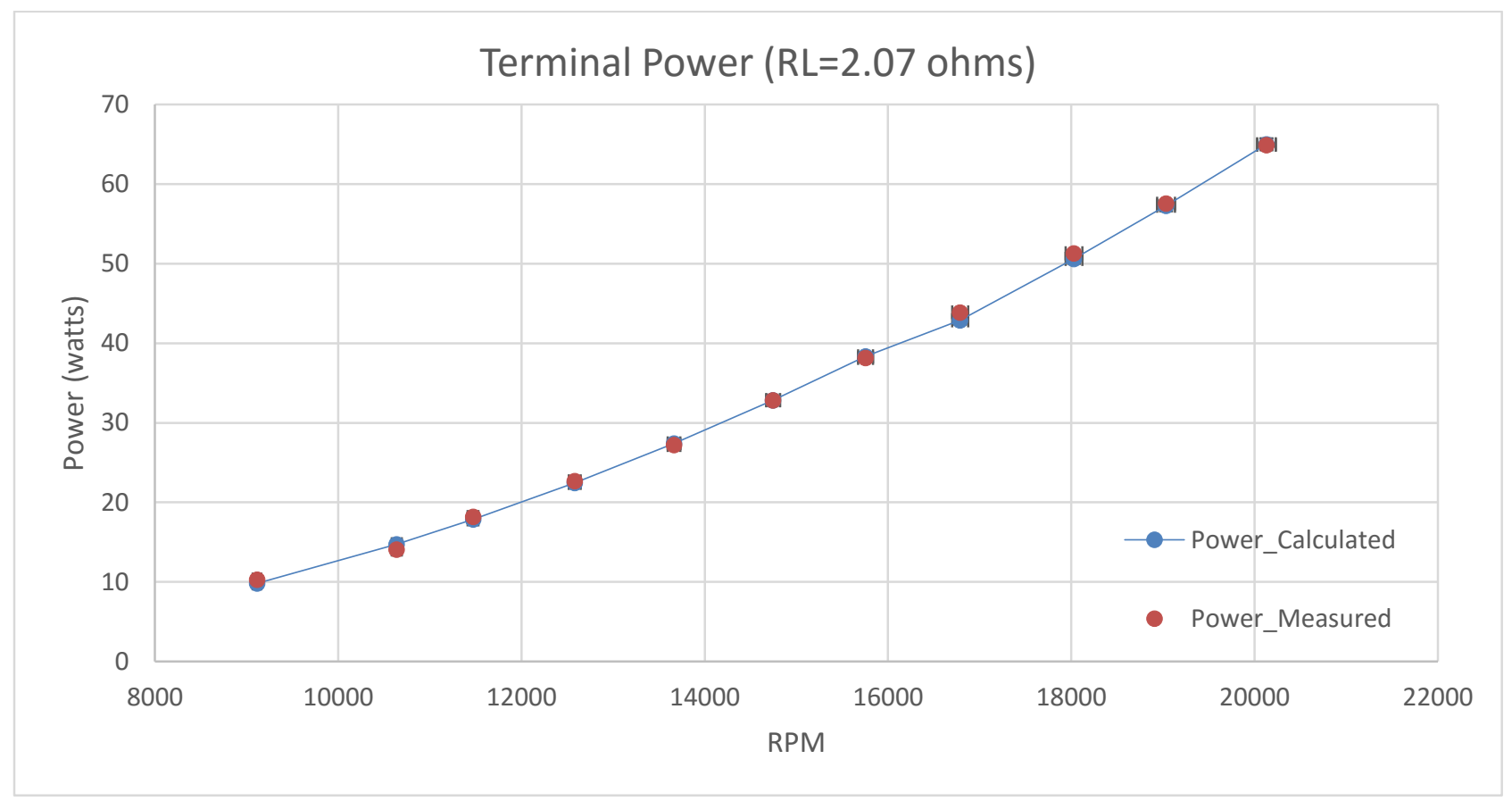

Figure 106. Generator Evaluation Test Results $(\mathbf{R L}=\mathbf{2 . 0 7}$ ) (Maxon \#386677) 
Table 27. Generator Evaluation Test Results $(\mathbf{R L}=2.33)$ (Maxon \#386677)

\begin{tabular}{|c|c|c|c|c|c|c|c|c|c|c|c|c|}
\hline \multirow[b]{2}{*}{ RPM } & \multicolumn{8}{|c|}{ Calculated } & \multicolumn{3}{|c|}{ Measured } & \multirow[b]{2}{*}{ \% Error } \\
\hline & $\begin{array}{c}\text { Va (peak) } \\
\text { [Volts] }\end{array}$ & $\begin{array}{c}\text { Reactance } \\
\text { [Ohms] }\end{array}$ & $\begin{array}{c}\text { Va (rms) } \\
{[\text { Volts] }}\end{array}$ & $\begin{array}{c}\text { Vdo } \\
\text { [Volts] }\end{array}$ & $\begin{array}{l}\text { I(peak) } \\
\text { [Amps] }\end{array}$ & $\begin{array}{c}\text { I(DC) } \\
{[\text { Amps] }}\end{array}$ & $\begin{array}{l}\mathrm{Vr}(\mathrm{DC}) \\
\text { [Volts] }\end{array}$ & $\begin{array}{c}\text { P(DC) } \\
\text { [Watts] }\end{array}$ & $\begin{array}{l}\operatorname{Vr}(\mathrm{DC}) \\
{[\text { Volts] }}\end{array}$ & $\begin{array}{c}\text { I(DC) } \\
{[\mathrm{Amps}]}\end{array}$ & $\begin{array}{l}\text { P (DC) } \\
\text { [Watts] }\end{array}$ & \\
\hline 9384 & 7.63 & 0.034 & 5.39 & 2 & 2.14 & 2.04 & 4.75 & 9.70 & 4.8 & 2.08 & 9.98 & -2.83 \\
\hline 10416 & 8.47 & 0.038 & 5.99 & 2 & 2.45 & 2.34 & 5.46 & 12.77 & 5.49 & 2.4 & 13.18 & -3.06 \\
\hline 11424 & 9.29 & 0.042 & 6.57 & 2 & 2.76 & 2.63 & 6.14 & 16.17 & 6.15 & 2.69 & 16.54 & -2.27 \\
\hline 12516 & 10.18 & 0.046 & 7.20 & 2 & 3.09 & 2.95 & 6.88 & 20.29 & 6.87 & 3 & 20.61 & -1.57 \\
\hline 13590 & 11.05 & 0.050 & 7.81 & 2 & 3.41 & 3.26 & 7.60 & 24.78 & 7.57 & 3.3 & 24.98 & -0.82 \\
\hline 14625 & 11.89 & 0.054 & 8.41 & 2 & 3.73 & 3.56 & 8.29 & 29.51 & 8.25 & 3.6 & 29.70 & -0.62 \\
\hline 15708 & 12.77 & 0.058 & 9.03 & 2 & 4.05 & 3.87 & 9.02 & 34.90 & 8.93 & 3.9 & 34.83 & 0.21 \\
\hline 16824 & 13.68 & 0.062 & 9.67 & 2 & 4.39 & 4.19 & 9.76 & 40.90 & 9.65 & 4.21 & 40.63 & 0.68 \\
\hline 18018 & 14.65 & 0.066 & 10.36 & 2 & 4.74 & 4.53 & 10.56 & 47.83 & 10.4 & 4.54 & 47.22 & 1.29 \\
\hline 19032 & 15.47 & 0.070 & 10.94 & 2.2 & 4.97 & 4.75 & 11.06 & 52.52 & 11.05 & 4.82 & 53.26 & -1.40 \\
\hline 20220 & 16.44 & 0.074 & 11.62 & 2.2 & 5.32 & 5.08 & 11.85 & 60.24 & 11.81 & 5.15 & 60.82 & -0.95 \\
\hline 21282 & 17.30 & 0.078 & 12.23 & 2.2 & 5.64 & 5.39 & 12.55 & 67.57 & 12.49 & 5.43 & 67.82 & -0.37 \\
\hline 22494 & 18.29 & 0.082 & 12.93 & 2.2 & 6.00 & 5.73 & 13.34 & 76.42 & 13.19 & 5.76 & 75.97 & 0.59 \\
\hline
\end{tabular}

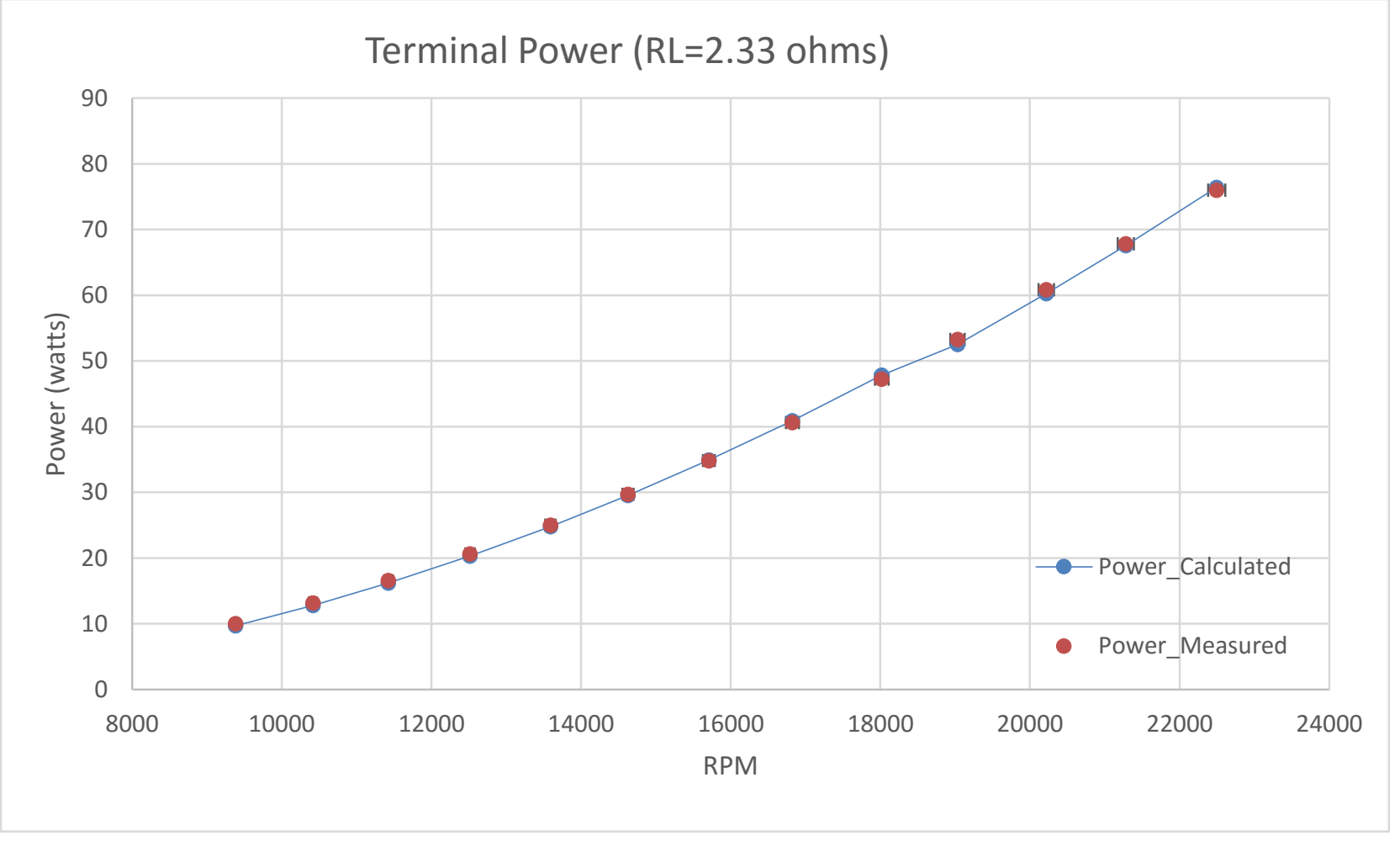

Figure 107. Generator Evaluation Test Results $(\mathrm{RL}=\mathbf{2 . 0 7})$ (Maxon \#386677) 
Table 28. Generator Evaluation Test Results $(\mathbf{R L}=\mathbf{2 . 8 9})$ (Maxon \#386677)

\begin{tabular}{|c|c|c|c|c|c|c|c|c|c|c|c|c|}
\hline \multirow[b]{2}{*}{ RPM } & \multicolumn{8}{|c|}{ Calculated } & \multicolumn{3}{|c|}{ Measured } & \multirow[b]{2}{*}{ \% Error } \\
\hline & $\begin{array}{c}\text { Va (peak) } \\
\text { [Volts] }\end{array}$ & $\begin{array}{c}\text { Reactance } \\
\text { [Ohms] }\end{array}$ & $\begin{array}{l}\text { Va (rms) } \\
\text { [Volts] }\end{array}$ & $\begin{array}{l}\text { Vdo } \\
\text { [Volts] }\end{array}$ & $\begin{array}{l}\text { I(peak) } \\
\text { [Amps] }\end{array}$ & $\begin{array}{c}\text { I(DC) } \\
{[\text { Amps] }}\end{array}$ & $\begin{array}{l}\operatorname{Vr}(\mathrm{DC}) \\
\text { [Volts] }\end{array}$ & $\begin{array}{c}\text { P(DC) } \\
\text { [Watts] }\end{array}$ & $\begin{array}{l}\operatorname{Vr}(\mathrm{DC}) \\
\text { [Volts] }\end{array}$ & $\begin{array}{c}\text { I(DC) } \\
{[\text { Amps] }}\end{array}$ & $\begin{array}{l}\mathrm{P}(\mathrm{DC}) \\
{[\text { Watts] }}\end{array}$ & \\
\hline 9348 & 7.60 & 0.034 & 5.37 & 2 & 1.75 & 1.67 & 4.84 & 8.10 & 4.89 & 1.73 & 8.44 & -3.98 \\
\hline 10476 & 8.52 & 0.038 & 6.02 & 2 & 2.04 & 1.95 & 5.62 & 10.94 & 5.67 & 2.00 & 11.34 & -3.51 \\
\hline 11592 & 9.42 & 0.042 & 6.66 & 2 & 2.32 & 2.21 & 6.40 & 14.16 & 6.44 & 2.27 & 14.62 & -3.11 \\
\hline 12654 & 10.29 & 0.046 & 7.27 & 2 & 2.58 & 2.47 & 7.13 & 17.61 & 7.15 & 2.52 & 18.02 & -2.28 \\
\hline 13800 & 11.22 & 0.051 & 7.93 & 2 & 2.87 & 2.74 & 7.92 & 21.73 & 7.94 & 2.80 & 22.23 & -2.25 \\
\hline 14838 & 12.06 & 0.054 & 8.53 & 2 & 3.13 & 2.99 & 8.64 & 25.83 & 8.63 & 3.05 & 26.32 & -1.86 \\
\hline 15876 & 12.91 & 0.058 & 9.13 & 2 & 3.39 & 3.24 & 9.35 & 30.27 & 9.31 & 3.29 & 30.63 & -1.17 \\
\hline 16974 & 13.80 & 0.062 & 9.76 & 2 & 3.66 & 3.50 & 10.11 & 35.34 & 10.05 & 3.54 & 35.58 & -0.66 \\
\hline 18108 & 14.72 & 0.066 & 10.41 & 2 & 3.94 & 3.77 & 10.88 & 40.98 & 10.78 & 3.81 & 41.07 & -0.24 \\
\hline 19170 & 15.59 & 0.070 & 11.02 & 2.2 & 4.14 & 3.96 & 11.44 & 45.25 & 11.48 & 4.05 & 46.49 & -2.67 \\
\hline 20310 & 16.51 & 0.074 & 11.68 & 2.2 & 4.42 & 4.23 & 12.21 & 51.60 & 12.23 & 4.32 & 52.83 & -2.33 \\
\hline 21468 & 17.45 & 0.079 & 12.34 & 2.2 & 4.71 & 4.50 & 13.00 & 58.46 & 12.97 & 4.57 & 59.27 & -1.37 \\
\hline 22638 & 18.40 & 0.083 & 13.01 & 2.2 & 5.00 & 4.77 & 13.79 & 65.80 & 13.73 & 4.84 & 66.45 & -0.98 \\
\hline 23820 & 19.37 & 0.087 & 13.69 & 2.2 & 5.29 & 5.05 & 14.59 & 73.64 & 14.48 & 5.10 & 73.85 & 0.28 \\
\hline
\end{tabular}

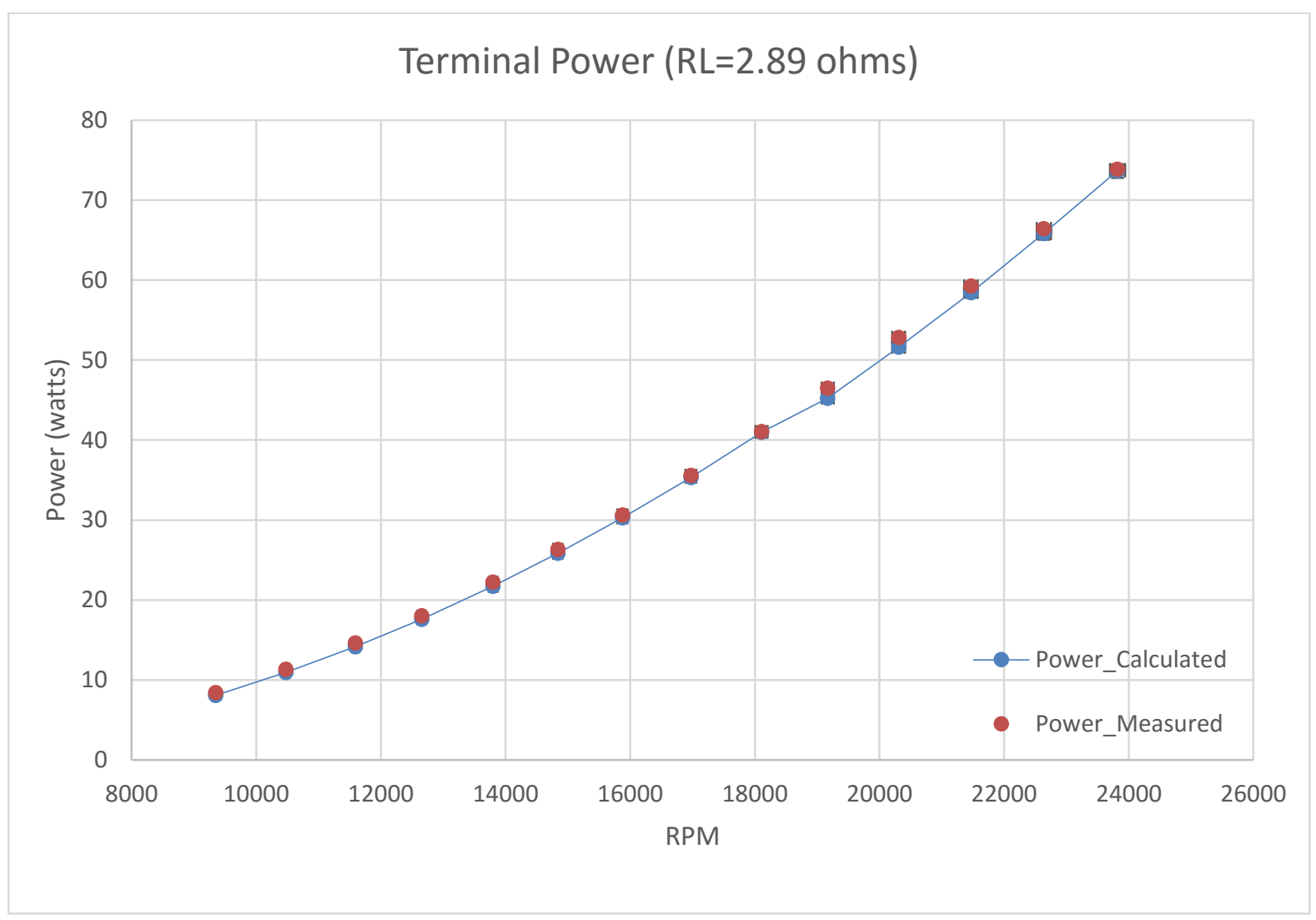

Figure 108. Generator Evaluation Test Results $(\mathrm{RL}=\mathbf{2 . 8 9})$ (Maxon \#386677) 
Table 29. Generator Evaluation Test Results $(\mathbf{R L}=3.02)$ (Maxon \#386677)

\begin{tabular}{|c|c|c|c|c|c|c|c|c|c|c|c|c|}
\hline \multirow[b]{2}{*}{ RPM } & \multicolumn{8}{|c|}{ Calculated } & \multicolumn{3}{|c|}{ Measured } & \multirow[b]{2}{*}{$\%$ Erro } \\
\hline & $\begin{array}{c}\text { Va (peak) } \\
\text { [Volts] }\end{array}$ & $\begin{array}{c}\text { Reactance } \\
\text { [Ohms] }\end{array}$ & $\begin{array}{c}\text { Va (rms) } \\
\text { [Volts] }\end{array}$ & $\begin{array}{c}\text { Vdo } \\
\text { [Volts] }\end{array}$ & $\begin{array}{l}\text { I(peak) } \\
\text { [Amps] }\end{array}$ & $\begin{array}{c}\text { I(DC) } \\
\text { [Amps] }\end{array}$ & $\begin{array}{l}\operatorname{Vr}(D C) \\
\text { [Volts] }\end{array}$ & $\begin{array}{c}\mathrm{P}(\mathrm{DC}) \\
{[\text { Watts] }}\end{array}$ & $\begin{array}{l}\mathrm{Vr}(\mathrm{DC}) \\
\text { [Volts] }\end{array}$ & $\begin{array}{c}\text { I(DC) } \\
\text { [Amps] }\end{array}$ & $\begin{array}{c}\mathrm{P}(\mathrm{DC}) \\
\text { [Watts] }\end{array}$ & \\
\hline 9810 & 7.98 & 0.036 & 5.64 & 2 & 1.80 & 1.72 & 5.18 & 8.89 & 5.25 & 1.75 & 9.19 & -3.24 \\
\hline 10734 & 8.73 & 0.039 & 6.17 & 2 & 2.02 & 1.93 & 5.83 & 11.24 & 5.9 & 1.977 & 11.66 & -3.62 \\
\hline 11778 & 9.58 & 0.043 & 6.77 & 2 & 2.27 & 2.17 & 6.55 & 14.23 & 6.64 & 2.21 & 14.67 & -3.06 \\
\hline 12906 & 10.49 & 0.047 & 7.42 & 2 & 2.54 & 2.43 & 7.34 & 17.83 & 7.38 & 2.467 & 18.21 & -2.05 \\
\hline 14058 & 11.43 & 0.052 & 8.08 & 2 & 2.82 & 2.69 & 8.14 & 21.93 & 8.15 & 2.72 & 22.17 & -1.08 \\
\hline 15096 & 12.27 & 0.055 & 8.68 & 2 & 3.07 & 2.93 & 8.86 & 25.97 & 8.85 & 2.95 & 26.11 & -0.52 \\
\hline 16128 & 13.11 & 0.059 & 9.27 & 2 & 3.32 & 3.17 & 9.57 & 30.32 & 9.54 & 3.19 & 30.43 & -0.38 \\
\hline 17292 & 14.06 & 0.063 & 9.94 & 2 & 3.60 & 3.43 & 10.37 & 35.61 & 10.31 & 3.49 & 35.98 & -1.03 \\
\hline 18372 & 14.94 & 0.067 & 10.56 & 2 & 3.85 & 3.68 & 11.11 & 40.89 & 11.05 & 3.69 & 40.77 & 0.28 \\
\hline 19398 & 15.77 & 0.071 & 11.15 & 2 & 4.10 & 3.91 & 11.82 & 46.23 & 11.71 & 3.91 & 45.79 & 0.96 \\
\hline 20664 & 16.80 & 0.076 & 11.88 & 2.2 & 4.34 & 4.14 & 12.51 & 51.82 & 12.54 & 4.19 & 52.54 & -1.38 \\
\hline 21708 & 17.65 & 0.080 & 12.48 & 2.2 & 4.58 & 4.38 & 13.22 & 57.89 & 13.23 & 4.41 & 58.34 & -0.78 \\
\hline 22836 & 18.57 & 0.084 & 13.13 & 2.2 & 4.85 & 4.63 & 13.99 & 64.81 & 13.95 & 4.657 & 64.97 & -0.25 \\
\hline 24096 & 19.59 & 0.088 & 13.85 & 2.2 & 5.15 & 4.92 & 14.85 & 72.97 & 14.76 & 4.92 & 72.62 & 0.49 \\
\hline 25254 & 20.53 & 0.093 & 14.52 & 2.2 & 5.42 & 5.18 & 15.63 & 80.88 & 15.56 & 5.17 & 80.45 & 0.55 \\
\hline
\end{tabular}

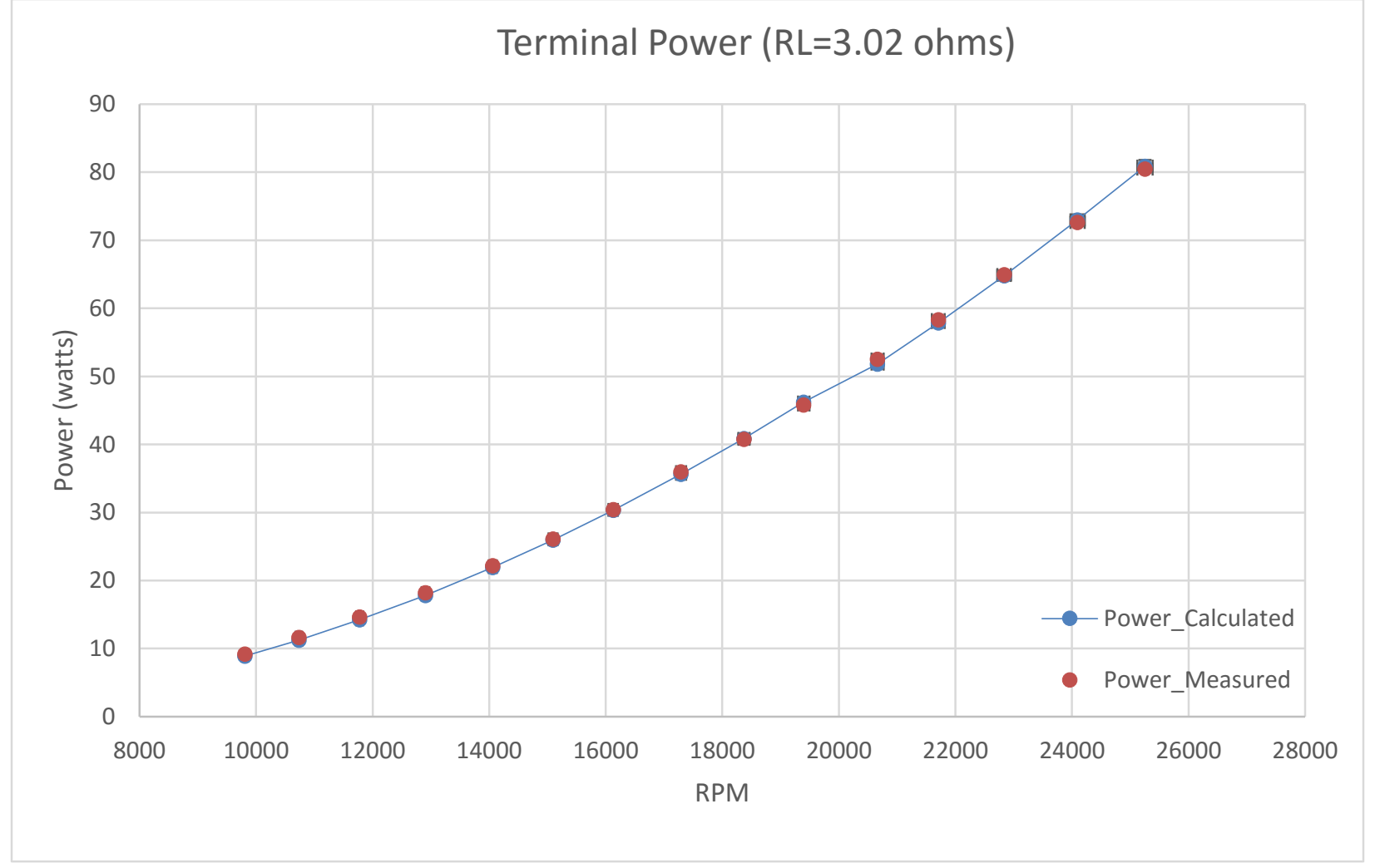

Figure 109. Generator Evaluation Test Results $(\mathrm{RL}=3.02)$ (Maxon \#386677) 
APPENDIX E. BLADE ELEMENT ROTOR MODEL PEAK POWER SECTIONAL RESULTS

Table 30. Rotor-1 Blade Element Rotor Model Sectional Results at Peak Power @ Sea Level, 110 mph and 21,000 RPM

\begin{tabular}{|c|c|c|c|c|c|c|c|c|c|c|c|c|c|c|}
\hline r_R & V0 $[\mathrm{ft} / \mathrm{s}]$ & V2 [ft/s] & V1 [ft/s] & alpha $\left[^{\circ}\right]$ & phi $\left[{ }^{\circ}\right]$ & $a$ & b & solidity & $\mathrm{CL}$ & $C D$ & $\operatorname{Re}$ & dT [lbf] & $\mathrm{dQ}$ [ft-lbf] & dP [Watts] \\
\hline 0.3250 & 137.845 & 113.102 & 178.307 & -25.6 & 50.6 & -0.1460 & -0.1683 & 0.4627 & -1.033 & 0.298 & 48368 & -0.0201 & -0.0006 & -1.813 \\
\hline 0.3596 & 138.409 & 123.444 & 185.460 & -23.3 & 48.3 & -0.1418 & -0.1518 & 0.4182 & -1.049 & 0.241 & 50309 & -0.0215 & -0.0007 & -2.215 \\
\hline 0.3942 & 138.632 & 133.974 & 192.789 & -21.0 & 46.0 & -0.1405 & -0.1405 & 0.3815 & -1.077 & 0.190 & 52297 & -0.0234 & -0.0009 & -2.710 \\
\hline 0.4635 & 137.466 & 155.988 & 207.916 & -16.4 & 41.4 & -0.1487 & -0.1295 & 0.3245 & -1.170 & 0.102 & 56400 & -0.0291 & -0.0013 & -4.019 \\
\hline 0.4981 & 136.102 & 166.915 & 215.370 & -14.2 & 39.2 & -0.1569 & -0.1250 & 0.3019 & -1.220 & 0.067 & 58422 & -0.0327 & -0.0016 & -4.778 \\
\hline 0.5327 & 133.943 & 177.635 & 222.474 & -12.0 & 37.0 & -0.1704 & -0.1197 & 0.2823 & -1.283 & 0.056 & 60349 & -0.0373 & -0.0019 & -5.523 \\
\hline 0.5673 & 134.700 & 186.911 & 230.390 & -10.8 & 35.8 & -0.1649 & -0.1057 & 0.2651 & -1.223 & 0.043 & 62497 & -0.0385 & -0.0020 & -5.892 \\
\hline 0.6019 & 136.096 & 195.806 & 238.457 & -9.8 & 34.8 & -0.1562 & -0.0919 & 0.2498 & -1.150 & 0.035 & 64685 & -0.0391 & -0.0021 & -6.181 \\
\hline 0.6365 & 137.350 & 204.845 & 246.630 & -8.8 & 33.8 & -0.1482 & -0.0801 & 0.2363 & -1.078 & 0.029 & 66902 & -0.0395 & -0.0022 & -6.423 \\
\hline 0.6712 & 138.226 & 214.148 & 254.883 & -7.8 & 32.8 & -0.1429 & -0.0710 & 0.2241 & -1.025 & 0.024 & 69141 & & -0.0023 & -6.722 \\
\hline 0.7058 & 139.074 & 223.591 & 263.314 & -6.9 & 31.9 & -0.1375 & -0.0630 & 0.2131 & -0.967 & 0.022 & 71428 & -0.0411 & -0.0023 & -6.931 \\
\hline 0.7404 & 140.288 & 232.737 & 271.749 & -6.1 & 31.1 & -0.1299 & -0.0548 & 0.2031 & -0.899 & 0.021 & 73716 & -0.0411 & -0.0024 & -7.021 \\
\hline 0.7750 & 141.596 & 241.900 & 280.295 & -5.3 & 30.3 & -0.1218 & -0.0475 & 0.1940 & -0.831 & 0.021 & 76034 & -0.0407 & -0.0024 & -7.045 \\
\hline 0.8096 & 142.921 & 251.124 & 288.946 & -4.6 & 29.6 & -0.1137 & -0.0410 & 0.1857 & -0.763 & 0.020 & 78381 & -0.0401 & -0.0023 & -7.004 \\
\hline 0.8442 & 144.231 & 260.417 & 297.690 & -4.0 & 29.0 & -0.1055 & -0.0354 & 0.1781 & -0.697 & 0.020 & 80753 & -0.0391 & -0.0023 & -6.904 \\
\hline 0.9481 & 148.195 & 288.571 & 324.399 & -2.2 & 27.2 & -0.0811 & -0.0218 & 0.1586 & -0.510 & 0.019 & 87998 & -0.0347 & -0.0021 & -6.205 \\
\hline 0.9827 & 149.647 & 297.975 & 333.441 & -1.7 & 26.7 & -0.0722 & -0.0180 & 0.1530 & -0.447 & 0.019 & 90451 & -0.0323 & -0.0019 & -5.761 \\
\hline
\end{tabular}

\begin{tabular}{|c|c|c|c|}
\hline RPM & $\begin{array}{c}\text { Total Torque } \\
\text { [ft-lbf] }\end{array}$ & $\begin{array}{c}\text { Total Thrust } \\
\text { [ft-lbf] }\end{array}$ & $\begin{array}{c}\text { Total Power } \\
\text { [watts] }\end{array}$ \\
\hline 21000 & -0.0368 & -0.6915 & -109.75 \\
\hline
\end{tabular}


Table 31. Rotor-2 Blade Element Rotor Model Sectional Results at Peak Power @ Sea Level, 110 mph and 21,000 RPM

\begin{tabular}{|c|c|c|c|c|c|c|c|c|c|c|c|c|c|c|}
\hline r_R & V0 [ft/s] & V2 [ft/s] & V1 [ft/s] & alpha $\left[{ }^{\circ}\right]$ & phi $\left[{ }^{\circ}\right]$ & $\mathbf{a}$ & b & solidity & $\mathrm{CL}$ & CD & $\mathrm{Re}$ & dT [lbf] & $\mathrm{dQ}$ [ft-lbf] & dP [Watts] \\
\hline 0.3250 & 139.469 & 120.704 & 184.448 & -9.8 & 49.1 & -0.1356 & -0.2466 & 0.4627 & -1.146 & 0.035 & 50034 & -0.0188 & -0.0009 & -2.685 \\
\hline 0.3596 & 140.388 & 128.782 & 190.509 & -9.3 & 47.5 & -0.1299 & -0.2020 & 0.4182 & -1.113 & 0.032 & 51678 & -0.0201 & -0.0010 & -2.998 \\
\hline 0.3942 & 141.020 & 137.293 & 196.815 & -8.9 & 45.8 & -0.1259 & -0.1689 & 0.3815 & -1.081 & 0.029 & 53389 & -0.0214 & -0.0011 & -3.315 \\
\hline 0.4288 & 141.391 & 146.176 & 203.369 & -8.4 & 44.0 & -0.1236 & -0.1441 & 0.3507 & -1.056 & 0.026 & 55167 & -0.0229 & -0.0012 & -3.650 \\
\hline 0.4635 & 141.597 & 155.413 & 210.244 & -8.0 & 42.3 & -0.1223 & -0.1251 & 0.3245 & -1.031 & 0.024 & 57032 & -0.0245 & -0.0013 & -3.990 \\
\hline 0.4981 & 141.689 & 164.693 & 217.255 & -7.6 & 40.7 & -0.1218 & -0.1095 & 0.3019 & -1.011 & 0.023 & 58933 & -0.0263 & -0.0015 & -4.340 \\
\hline 0.5327 & 141.677 & 174.122 & 224.479 & -7.3 & 39.1 & -0.1219 & -0.0970 & 0.2823 & -0.992 & 0.022 & 60893 & -0.0281 & -0.0016 & -4.702 \\
\hline 0.5673 & 141.577 & 183.678 & 231.909 & -7.0 & 37.6 & -0.1225 & -0.0867 & 0.2651 & -0.975 & 0.022 & 62909 & -0.0301 & -0.0017 & -5.075 \\
\hline 0.6019 & 141.388 & 193.349 & 239.530 & -6.8 & 36.2 & -0.1237 & -0.0782 & 0.2498 & -0.961 & 0.022 & 64976 & -0.0322 & -0.0018 & -5.463 \\
\hline 0.6365 & 141.136 & 203.295 & 247.484 & -6.6 & 34.8 & -0.1255 & -0.0716 & 0.2363 & -0.948 & 0.022 & 67134 & -0.0345 & -0.0020 & -5.870 \\
\hline 0.6712 & 140.737 & 213.187 & 255.452 & -6.6 & 33.4 & -0.1280 & -0.0658 & 0.2241 & -0.941 & 0.021 & 69295 & -0.0371 & -0.0021 & -6.309 \\
\hline 0.7058 & 140.208 & 223.159 & 263.549 & -6.5 & 32.1 & -0.1313 & -0.0611 & 0.2131 & -0.938 & 0.021 & 71492 & -0.0399 & -0.0023 & -6.781 \\
\hline 0.7404 & 139.550 & 233.214 & 271.778 & -6.5 & 30.9 & -0.1355 & -0.0571 & 0.2031 & -0.938 & 0.021 & 73724 & -0.0430 & -0.0024 & -7.290 \\
\hline 0.7750 & 138.760 & 243.345 & 280.127 & -6.6 & 29.7 & -0.1404 & -0.0538 & 0.1940 & -0.942 & 0.021 & 75988 & -0.0464 & -0.0026 & -7.840 \\
\hline 0.8096 & 137.837 & 253.539 & 288.585 & -6.7 & 28.5 & -0.1462 & -0.0511 & 0.1857 & -0.949 & 0.022 & 78283 & -0.0501 & -0.0028 & -8.431 \\
\hline 0.8442 & 136.785 & 263.786 & 297.142 & -6.8 & 27.4 & -0.1528 & -0.0488 & 0.1781 & -0.959 & 0.022 & 80604 & -0.0542 & -0.0030 & -9.062 \\
\hline 0.8788 & 135.613 & 274.072 & 305.788 & -7.0 & 26.3 & -0.1602 & -0.0468 & 0.1711 & -0.972 & 0.022 & 82949 & -0.0587 & -0.0033 & -9.730 \\
\hline 0.9135 & 134.332 & 284.383 & 314.514 & -7.2 & 25.3 & -0.1683 & -0.0450 & 0.1646 & -0.986 & 0.022 & 85316 & -0.0635 & -0.0035 & -10.427 \\
\hline 0.9481 & 132.774 & 294.614 & 323.151 & -7.4 & 24.3 & -0.1775 & -0.0433 & 0.1586 & -0.999 & 0.023 & 87659 & -0.0685 & -0.0037 & -11.111 \\
\hline 0.9827 & 131.246 & 304.950 & 331.994 & -7.7 & 23.3 & -0.1870 & -0.0419 & 0.1530 & -1.015 & 0.023 & 90058 & -0.0740 & -0.0040 & -11.839 \\
\hline
\end{tabular}

\begin{tabular}{|c|c|c|c|}
\hline RPM & $\begin{array}{c}\text { Total Torque } \\
\text { [ft-lbf] }\end{array}$ & $\begin{array}{c}\text { Total Thrust } \\
\text { [ft-lbf] }\end{array}$ & $\begin{array}{c}\text { Total Power } \\
\text { [watts] }\end{array}$ \\
\hline 21000 & -0.0439 & -0.7944 & -130.91 \\
\hline
\end{tabular}

